University of New Mexico

UNM Digital Repository

Nuclear Engineering ETDs

Engineering ETDs

$1-28-2015$

\title{
Characterization of the Neutron Irradiation System for use in the Low-Dose-Rate Irradiation Facility at Sandia National Laboratories
}

Jr. Manuel Franco

Follow this and additional works at: https://digitalrepository.unm.edu/ne_etds

\section{Recommended Citation}

Franco, Jr. Manuel. "Characterization of the Neutron Irradiation System for use in the Low-Dose-Rate Irradiation Facility at Sandia National Laboratories." (2015). https://digitalrepository.unm.edu/ne_etds/39

This Thesis is brought to you for free and open access by the Engineering ETDs at UNM Digital Repository. It has been accepted for inclusion in Nuclear Engineering ETDs by an authorized administrator of UNM Digital Repository. For more information, please contact disc@unm.edu. 
Manuel Franco Jr.

Candidate

Department of Chemical and Nuclear Engineering

Department

This thesis is approved, and it is acceptable in quality and form for publication:

Approved by the Thesis Committee:

Dr. Gary Cooper , Chairperson

Dr. Maryla A. Wasiolek

Dr. Robert D. Busch 


\title{
CHARACTERIZATION OF THE NEUTRON IRRADIATION SYSTEM FOR USE IN THE LOW-DOSE-RATE IRRADIATION FACILITY AT SANDIA NATIONAL LABORATORIES
}

\author{
by \\ MANUEL FRANCO JR. \\ B.S. NUCLEAR ENGINEERING \\ THE UNIVERSITY OF NEW MEXICO, 2011
}

THESIS

Submitted in Partial Fulfillment of the

Requirements for the Degree of

Master of Science

Nuclear Engineering

The University of New Mexico

Albuquerque, New Mexico

December, 2014 


\section{ACKNOWLEDGEMENTS}

I would like to acknowledge the following individuals because without them this would not be possible. Christina B. Hanson (RSPD) made it known to me that this work needed to be completed, and she guided me to the right people. Truly without her this would have never happened. Dr. Maryla Wasiolek (GIF/Research Advisor) supervised the project, and she provided technical guidance. Dr. Gary Cooper (Graduate advisor) provided guidance, and he agreed to be my graduate advisor. Don Hanson (GIF) moved, configured, and assisted in positioning of the equipment and experiment. Dr. Dann Ward (RP) gave technical advice on the N-Probe Microspec and the neutron Bubble Dosimeter Spectroscopy Set. Albert Bendure (RPSD Manager) and Mike Spoerner (TAV Non-Reactor Nuclear Facilities Manager) gave me permission to work on this project. The radiography group (Kyle Thomspon and Kevin Rolfe) performed the radiography experiment. David Vehar (TAV) provided technical advice on the foil activation. I would like to thank Radiation Protection Sample Diagnostics for allowing me to irradiate their

germanium detector. I would like to thank everyone from Radiation Protection for assisting me. There are many others that I would like to thank for their contribution and assistance in completing this work. Thank you all.

SAND2014-16188T 


\title{
Characterization of the Neutron Irradiation System for Use in the Low-Dose-Rate Irradiation Facility at Sandia National Laboratories
}

by

\author{
Manuel Franco Jr. \\ B.S., Nuclear Engineering, University of New Mexico, 2011 \\ M.S., Nuclear Engineering, University of New Mexico, 2014
}

\begin{abstract}
The objective of this work was to characterize the neutron irradiation system consisting of americium-241 beryllium $\left({ }^{241} \mathrm{AmBe}\right)$ neutron sources placed in a polyethylene shielding for use at Sandia National Laboratories' (SNL) Low Dose Rate Irradiation Facility (LDRIF). With a total activity of $0.3 \mathrm{TBq}(9 \mathrm{Ci})$, the source consisted of three recycled ${ }^{241} \mathrm{AmBe}$ sources of different activities that had been combined into a single source. The source in its polyethylene shielding will be used in neutron irradiation testing of components. The characterization of the source-shielding system was necessary to evaluate the radiation environment for future experiments. Characterization of the source was also necessary because the documentation for the three component sources and their relative alignment within the Special Form Capsule (SFC) was inadequate. The system consisting of the source and shielding was modeled using Monte Carlo N-Particle transport code (MCNP). The model was validated by benchmarking it against measurements using multiple techniques.

To characterize the radiation fields over the full spatial geometry of the irradiation system, it was necessary to use a number of instruments of varying sensitivities. First, the computed photon radiography assisted in determining orientation of the component sources. With the capsule properly oriented inside the shielding, the neutron spectra were measured using a variety of techniques. A N-probe Microspec and a neutron Bubble Dosimeter Spectrometer (BDS) set were used to characterize the neutron spectra/field in several locations. In the third technique, neutron foil activation was used to ascertain the neutron spectra. A high purity germanium (HPGe) detector was used to characterize the photon spectrum.
\end{abstract}


The experimentally measured spectra and the MCNP results compared well. Once the MCNP model was validated to an adequate level of confidence, parametric analyses was performed on the model to optimize for potential experimental configurations and neutron spectra for component irradiation. The final product of this work is a MCNP model validated by measurements, an overall understanding of neutron irradiation system including photon/neutron transport and effective dose rates throughout the system, and possible experimental configurations for future irradiation of components. 


\section{TABLE OF CONTENTS}

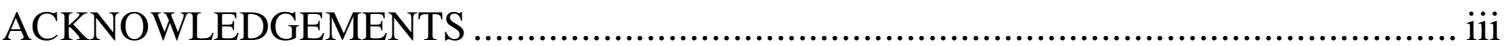

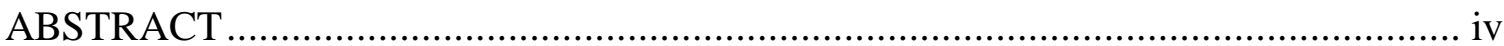

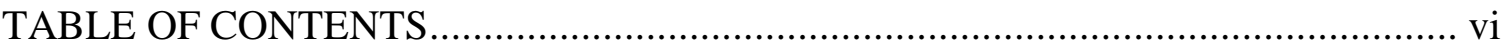

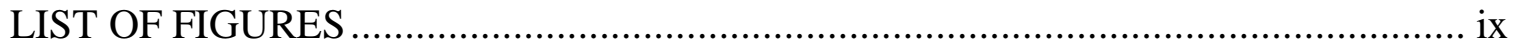

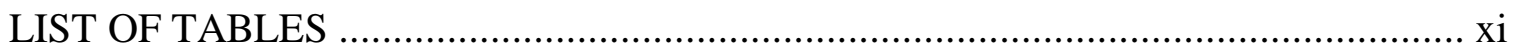

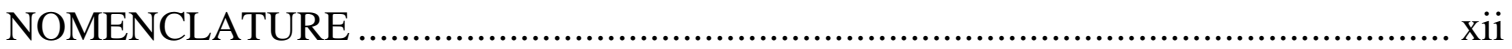

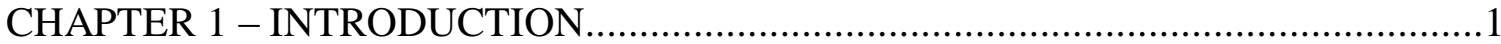

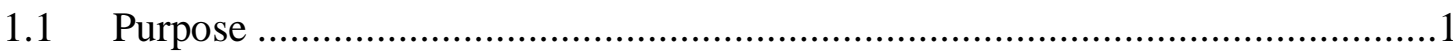

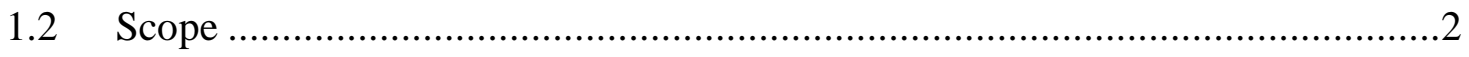

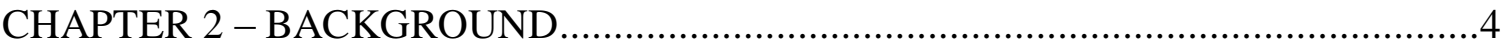

2.1 Description of the System under Evaluation ………......................................

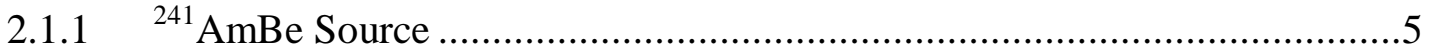

2.1.2 Special Form Capsule ………............................................................

2.1.3 Aluminum Stand .........................................................................

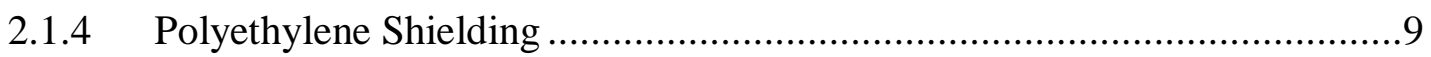

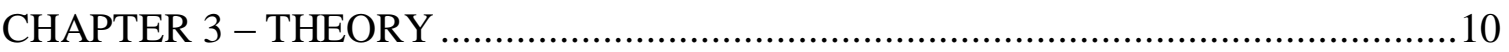

3.1 Neutron/Photon Production in ${ }^{241} \mathrm{AmBe}$ Source ................................................10

3.2 Computed Photon Radiography ………………........................................ 12

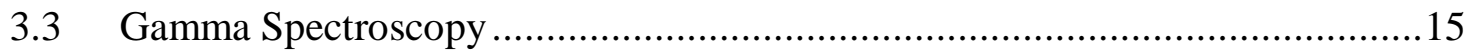

3.3.1 Photon Interactions with HPGe Detector ……………............................15

3.3.2 Neutron Interactions with HPGe Detector...............................................16

3.3.3 Neutron Damage to HPGe Detector.........................................................18

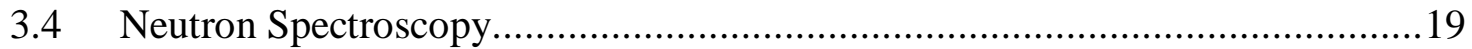

3.4.1 Fast Neutron Detection by Organic Scintillator........................................19

3.4.2 Fast Neutron Detection by Bubble Dosimeter Spectroscopy …….............23

3.4.3 Low Energy Neutron Detection by ${ }^{3} \mathrm{He}$ Gas Proportional Counter .............24

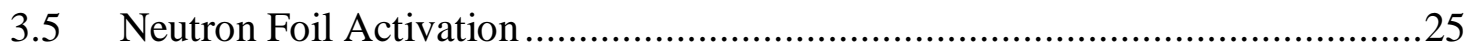

CHAPTER 4 - METHODOLOGY AND EXPERIMENT …………..........................28

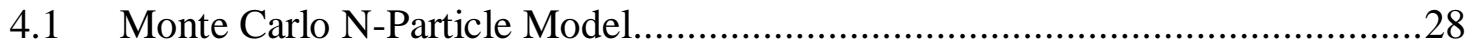

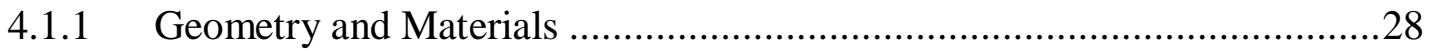




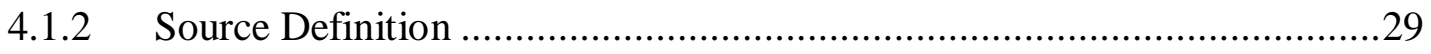

4.1.3 Detector, Mesh, and Surface Tallies ......................................................30

4.2 Instrumentation Used in Model Benchmarking .............................................30

4.2.1 Computed Photon Radiography .............................................................

4.2.2 High Purity Germanium Gamma Spectrometer ..........................................32

4.2.3 N-Probe Microspec Neutron Spectrometer..................................................33

4.2.4 Neutron Bubble Dosimeter Spectrometer...................................................35

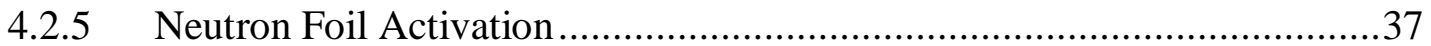

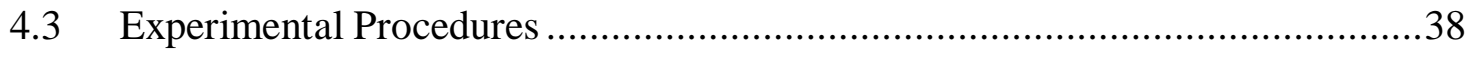

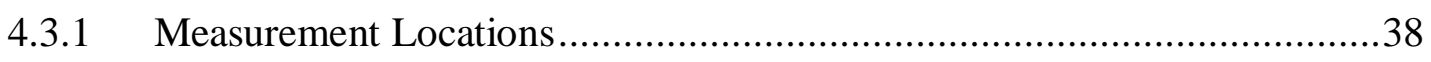

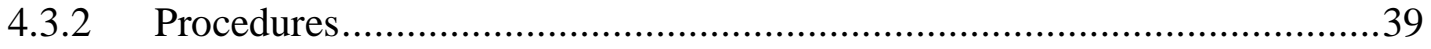

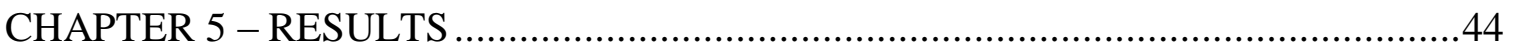

5.1 Computed Photon Radiography ………………….....................................4

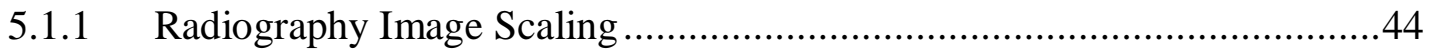

5.1.2 Primary Imaging Plate Comparison .....................................................4

5.1.3 Secondary Imaging Plate Comparison .................................................49

5.1.4 Neutron Activation of Phosphor Imaging Plate ……….............................50

5.2 Monte Carlo N-Particle Neutron Spectral Output..........................................50

5.3 Gamma Spectroscopy by HPGe Detector......................................................53

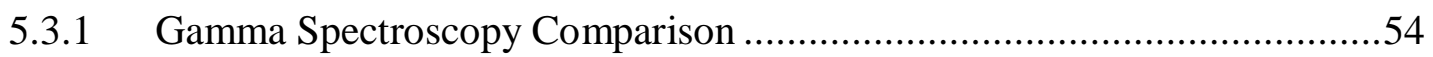

5.3.2 Identified Peaks in Spectrum ............................................................58

5.4 Neutron Spectroscopy Using Various Instruments ..........................................59

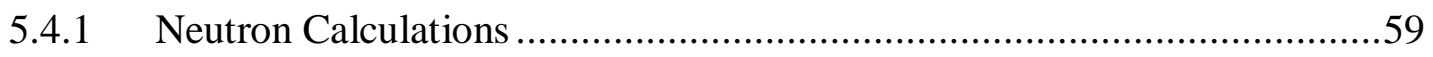

5.4.2 N-Probe Microspec Spectrometer ...........................................................60

5.4.3 Neutron Bubble Dosimeter Spectroscopy Set...........................................62

5.4.4 Neutron Spectra Comparison for Location D ...........................................64

5.5 Neutron Activation Foils Results ………………....................................65

5.6 Summary of Neutron Flux Density Results ....................................................67

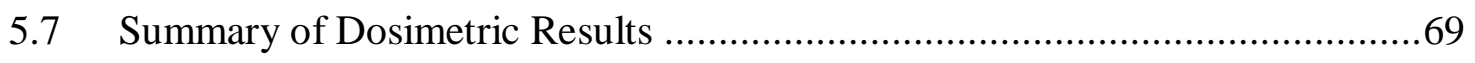

5.8 Neutron and Photon Flux Map in Neutron Irradiation System.........................70

5.8.1 Neutron Flux Density Mapping .............................................................. 
5.8.2 Photon Flux Density Mapping ….................................................... 71

CHAPTER 6 - NEUTRON SPECTRUM PARAMETRIC ANALYSIS ......................74

6.1 Polyethylene Box with Tested Object Inside .........................................74

6.2 Cadmium Box with Tested Object Inside................................................... 77

6.3 Polyethylene Shield between Tested Object and Neutron Source ....................79

6.4 Low Energy Neutron Flux Configuration Using Polyethylene Block ..............83

CHAPTER 7 - ABSORBED DOSE TO VARIOUS MATERIALS ............................87

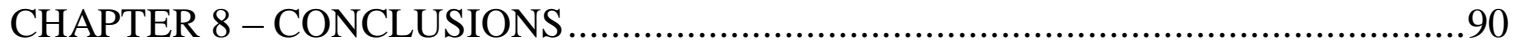

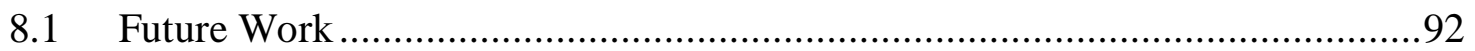

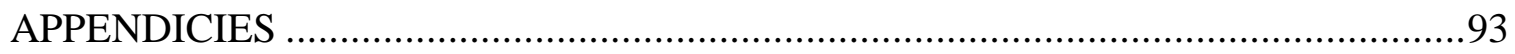

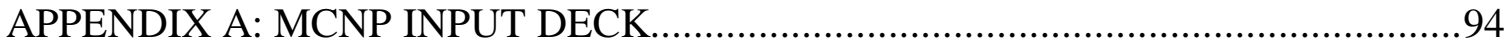

A.1 Neutron MCNP Input Code ............................................................ 94

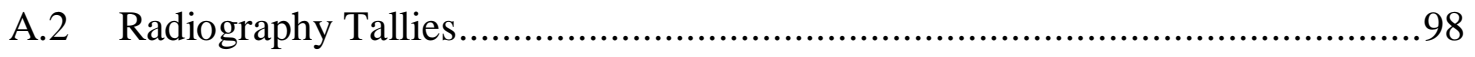

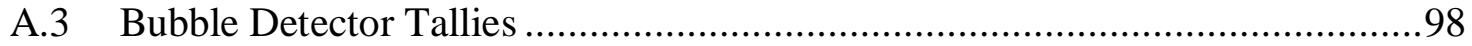

A.4 Microspec Tallies .......................................................................... 101

A.5 High Purity Germanium Detector Tallies .............................................. 104

A.6 Gold Foil Tallies.............................................................................. 105

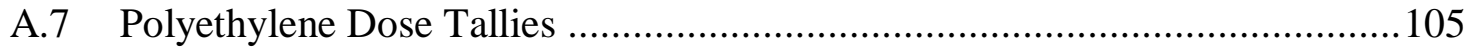

A.8 Silicon Dose Tallies........................................................................ 110

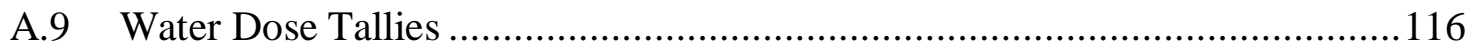

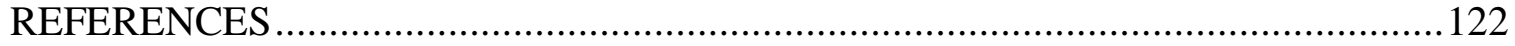




\section{LIST OF FIGURES}

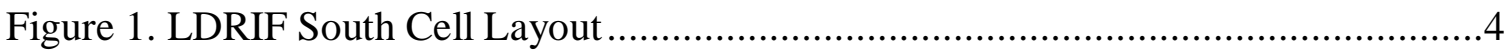

Figure 2. NB570 and NB540 ${ }^{241}$ AmBe Sources Photograph and Schematic ...................6

Figure 3. MRC-AmBe-44 Source Photograph and Schematic ......................................

Figure 4. Special Form Capsule Model II............................................................. 7

Figure 5. Special Form Capsule on Aluminium Stand inside the Shielding ...................8

Figure 6. Polyethylene Chamber for Shielding and Storing the Neutron Source ..............9

Figure 7. ISO-8529:1989, ${ }^{241}$ AmBe Neutron Energy Distribution ............................... 11

Figure 8. Radionuclide ${ }^{241}$ Am Decay Scheme ........................................................ 12

Figure 9. Photon Absorption Range of Various Phosphors.........................................13

Figure 10. Photo-Stimulated Luminescence Complex Theory ......................................14

Figure 11. Stimulation and Emission Spectra of BaFBr:Eu ${ }^{+2}$ Imaging Plate ..................14

Figure 12. ${ }^{60}$ Co Spectrum Obtained with P-type HPGe Detector .................................. 16

Figure 13. Neutron Spectra produced by Fast Neutron Irradiation of Ge(Li) Detector ....17

Figure 14. Electron Energy Light Output as a Function of Proton Energy in NE213 ......20

Figure 15. Pulse Height Plots for Organic Scintillator...........................................21

Figure 16. Measured Pulse Height Spectra for Organic Scintillator ............................22

Figure 17. Neutron Spectral Deconvolution from Microspec....................................22

Figure 18. Portable Computed Radiography Scanner Model CR 50P ..........................31

Figure 19. HPGe Gamma Spectroscopy System...................................................33

Figure 20. N-Probe Microspec Neutron Spectrometer ..........................................34

Figure 21. Bubble Detector Spectroscopy Set and Miscellaneous Equipment .................36

Figure 22. BDS Recompression Shielding and Reader/Bubble Counting Software.........37

Figure 23. Aerial Cross Sectional View of LDGIF South Cell....................................38

Figure 24. Measurement Locations with Door Closed and Open .................................39

Figure 25. Experimental Imaging Plate obtained by Primary Phosphor IP ....................45

Figure 26. MCNP Model of the Cylindrical Imaging Plate......................................46

Figure 27. Horizontal View of the Measured Intensity at Normalization Plane..............46

Figure 28. Horizontal View of the Modeled Intensity at Normalization Plane ...............47

Figure 29. Vertical View of the Measured/Modeled Intensity at Normalization Plane ....48

Figure 30. Location of Each Component Source within the SFC ................................49 
Figure 31. Confirmatory Phosphor Imaging Plate Modeled/Measured Comparison........49

Figure 32. MCNP Neutron Spectra for Various Locations throughout System ..............51

Figure 33. MCNP Neutron Spectra for Locations E and F.....................................52

Figure 34. MCNP Neutron Spectra Relative Change ............................................53

Figure 35. Gamma Spectra Summary Energy Range from $10 \mathrm{keV}$ to $2000 \mathrm{keV} \mathrm{............56}$

Figure 36. Gamma Spectra Summary Energy Range from $2 \mathrm{MeV}$ to $5 \mathrm{MeV}$.................57

Figure 37. Neutron Spectra Obtained by N-Probe Microspec ..................................61

Figure 38. Neutron Spectra Obtained by Bubble Dosimeter Spectroscopy Set...............63

Figure 39. Neutron Spectra Comparison at Location D for BDS and MCNP ................64

Figure 40. Neutron Spectra Comparison at Location D for Microspec and MCNP ........65

Figure 41. Cross Sections for Various Foils as a Function of Energy .........................66

Figure 42. Neutron Flux Density as a Function of Distance from the Source.................68

Figure 43. Neutron Effective Dose Rate as a Function of Distance from the Source .......70

Figure 44. Neutron Transport in Neutron Irradiation System................................... 71

Figure 45. Neutron Induced Photon Transport in Neutron Irradiation System ...............73

Figure 46. Polyethylene Box inside the Polyethylene Shielding ................................74

Figure 47. Poly-Box Configuration at $91 \mathrm{~cm}$ Spectra ........................................ 75

Figure 48. Average Energy as a Function of Polyethylene Box Thickness ...................76

Figure 49. Cadmium-Polyethylene-Source Configuration ..................................... 77

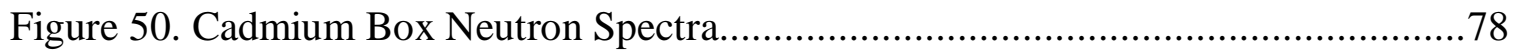

Figure 51. Cadmium Box with Varying Thickness ............................................ 79

Figure 52. Neutron Irradiation System with Polyethylene Shields .............................80

Figure 53. Neutron Spectra for Varying Number of Poly Slabs .................................81

Figure 54. Average Neutron Spectra Energy for Varying Number of Poly Slabs ...........82

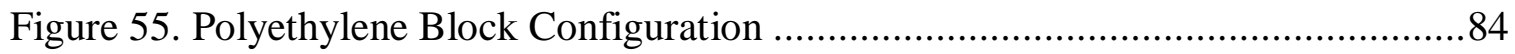

Figure 56. Average Neutron Energy with Varying Polyethylene Block Thickness .........85

Figure 57. Thermal Neutron Spectra with Polyethylene Block .................................85

Figure 58. Neutron Dose Conversion Factors for Material of Interest.........................87

Figure 59. Dose Rates for Various Materials as a Function of Distance ........................88 


\section{LIST OF TABLES}

Table I. Activities and Masses for ${ }^{241} \mathrm{AmBe}$ Component Sources ...................................5

Table II. Dimensions of the Special Form Capsule Model II .....................................8

Table III. Nuclear Properties of ${ }^{241} \mathrm{AmBe}(\alpha, n)$ Source............................................... 11

Table IV. Major Interactions of ${ }^{241}$ AmBe Source Neutrons with HPGe Detector ............18

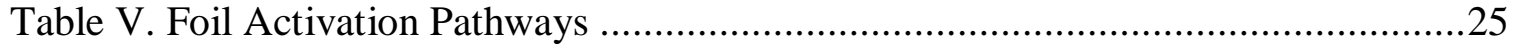

Table VI. Physical and Nuclear Constants for Gold Foils........................................22

Table VII. Measurement Locations and Methods Inside and Outside the Shielding ........39

Table VIII. HPGe Detector Measurement Details ................................................. 41

Table IX. N-Probe Microspec Measurement ...........................................................41

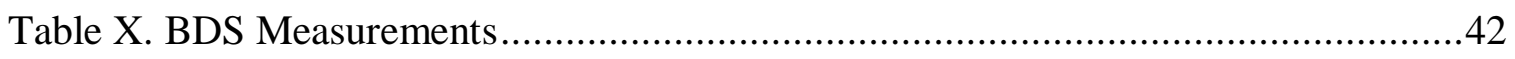

Table XI. Activation Foil Measurement Time and Dates........................................43

Table XII. Gamma Statistics Obtained by HPGe Detector Analyzed by PeakEasy ..........58

Table XIII. Neutron Activation Foil Tabulated Results ..........................................66

Table XIV. Neutron Flux Density at All Measurements Locations ..............................67

Table XV. Neutron Effective Dose Rate at All Measurements Locations .....................69

Table XVI. Ratio of Thermal to Fast Neutrons for Different Box Thicknesses ...............77

Table XVII. Ratio of Thermal to Fast Neutrons for Different Cadmium Thicknesses .....79

Table XVIII. Ratio of Thermal to Fast Neutrons at $91 \mathrm{~cm}$ verses the Number of Slabs...83

Table XIX. Ratio of Thermal to Fast Neutrons for Varying Block Width ......................86

Table XX. Tabulated Dose Rate for Various Material as a Function of Distance ............88 


\section{NOMENCLATURE}

\begin{tabular}{|c|c|}
\hline${ }^{241} \mathrm{AmBe}$ & Americium-241 Beryllium \\
\hline $\mathrm{AmO}_{2}$ & Americium Oxide \\
\hline BDS & Bubble Dosimeter Spectrometer \\
\hline BTI & Bubble Technology Industries \\
\hline DCFs & Dose Conversion Factors \\
\hline DEP & Double Escape Peak \\
\hline GIF & Gamma Irradiation Facility \\
\hline HPGe & High Purity Germanium \\
\hline ICRP & International Commission on Radiological Protection \\
\hline IPs & Imaging Plate(s) \\
\hline ISO & International Organization for Standardization \\
\hline LANL & Los Alamos National Laboratory \\
\hline LDRIF & Low Dose Rate Irradiation Facility \\
\hline MCA & Multi-Channel Analyzer \\
\hline $\operatorname{MCNP}(5)$ & Monte Carlo N-Particle (Version 5) \\
\hline MeVee & MeV Electron Equivalent \\
\hline NIST & National Institute of Standards and Technology \\
\hline ORNL & Oak Ridge National Laboratory \\
\hline OSRP & Off-Site Source Recovery Project \\
\hline PSLC & Photo-Stimulated Luminescence Complex \\
\hline $\mathbf{R P}$ & Radiation Protection \\
\hline RPSD & Radiation Protection Sample Diagnostics \\
\hline SEP & Single Escape Peak \\
\hline SFC & Special Form Capsule \\
\hline SNL & Sandia National Laboratories \\
\hline
\end{tabular}




\section{CHAPTER 1 - INTRODUCTION}

The Gamma Irradiation Facility (GIF), along with its annex, the Low Dose Rate Irradiation Facility (LDRIF) at Sandia National Laboratories (SNL), provides environments for high- to low-dose-rate irradiation for components and materials using

${ }^{60} \mathrm{Co}$ and ${ }^{137} \mathrm{Cs}$ sources. These capabilities are being expanded to include low-dose-rate neutron and mixed neutron-gamma irradiation capabilities. The facility has acquired three "recycled" americium-241 beryllium $\left({ }^{241} \mathrm{AmBe}\right)$ sources, with a total activity of $0.3 \mathrm{TBq}$ (9 Ci). These sources were placed inside a Special Form Capsule (SFC), which was positioned inside a polyethylene shield at the LDRIF. The neutron irradiation system consisting of the ${ }^{241} \mathrm{AmBe}$ neutron sources and the polyethylene shielding will provide low-dose-rate neutron and mixed neutron-gamma fields for irradiation of materials, components, and equipment, which complements high- to low-dose-rate gamma irradiation capabilities provided by the GIF and the LDRIF.

Diverse methods were required to understand, characterize, and model the newly added neutron source in its polyethylene shielding. First, the orientation of the three sources within the SFC was determined. Then, the predicted neutron and photon spectra were obtained by modeling the ${ }^{241} \mathrm{AmBe}$ sources inside the polyethylene shielding. Finally, the model was validated with data from benchmark experiments. A variety of instruments that were sensitive to different intensities and energies were required to measure the neutron and photon spectra throughout the experimental configuration. Multiple independent measurements were obtained with different instruments, and they also served to verify the accuracy of the measurements.

The project also included parametric studies of different source shielding arrangements for the purpose of neutron spectrum modification. From the neutron and photon spectra, it was also possible to determine absorbed dose rates to various materials and effective dose rates to personnel for comparison with the Radiation Protection (RP) instrument readings.

\subsection{Purpose}

The purpose of this work was to characterize the neutron source and the environment around the polyethylene shielding. This would assist the facility personnel 
to determine neutron and gamma absorbed dose rates in the materials and components that may be used in future irradiation experiments. Considerations were included of a configurable setup that would allow for variation of average spectral energies and intensities to accommodate future experimental needs of the facility customers.

\subsection{Scope}

The scope of work included MCNP modeling of the irradiation system, MCNP model validation by measurements using different experimental techniques, parametric studies, and measurements towards potential neutron spectra modifications, and the use of the validated model to evaluate the absorbed dose rates in various materials as well as effective dose rates for comparison with the response of radiation protection instrumentation in neutron fields. The MCNP model was constructed to predict the neutron field for all measurement locations and to understand the radiation transport in the modeled system. The modeled system consists of the ${ }^{241} \mathrm{AmBe}$ sources, the source support stand, the polyethylene shielding, as well as the space around the shielding. The model predictions were compared with the results of measurements at selected points, and thus validating the model with experimental data. The following experimental techniques were used to set up the model and, subsequently, to validate it.

Computed photon radiography was used to understand the distribution of radioactive material within the SFC to appropriately represent the source in the MCNP model. This technique is useful for determining orientation and intensity for bulk radioactive material without the need of destroying or violating the integrity of an object that contains the radioactive material ${ }^{(1)}$. A high-purity germanium (HPGe) detector was used to determine the gamma spectrum of the source. It was also used to determine background gamma spectrum prior to bringing the source into the facility. The instrument chosen for this purpose was a coaxial germanium $\mathrm{N}$-type detector manufactured by Canberra Industries, which is relatively resistant to neutron damage on the crystal $^{(2)}$. The neutron spectroscopy was accomplished using two instruments: the N-probe Microspec Spectrometer and the Bubble Dosimeter Spectrometer (BDS) Set. These two instruments were used to measure neutron spectra over a wide range of neutron energies ${ }^{(3)}$. Foil activation was used as a supplemental method to obtain spectral information about the source ${ }^{(4)}$. 
Once the neutron spectra were determined by using a validated model, a parametric study was conducted using MCNP. This was done to develop potential experimental configurations for future testing of materials and components by exposing them to the source. The neutron spectra were also used to predict absorbed dose rates in various materials and effective dose rates to workers. The latter were compared with readings of instruments routinely used to evaluate neutron dose rates to workers. 


\section{CHAPTER 2 - BACKGROUND}

Chapter two provides a background of the neutron irradiation system under evaluation. This section details the source component design, source component radioactivity, and capsule design. The polyethylene chamber and source location within the chamber are also described. This combination of source and chamber is referred to as the neutron irradiation system.

\subsection{Description of the System under Evaluation}

The system, which is the subject of this work, is located in the Low Dose Rate Irradiation Facility (LDRIF). The LDRIF is a stand-alone concrete bunker, which includes two test cells and a setup/data acquisition lab. The LDRIF provides environments for low-dose-rate, long-duration testing of equipment, materials, and components. The south cell contains lead shielding for gamma irradiation experiments using reconfigurable ${ }^{137} \mathrm{Cs}$ sources and a polyethylene neutron irradiation system. The neutron source and shielding are the new additions to the facility. The model layout of the south cell is represented in Figure 1.

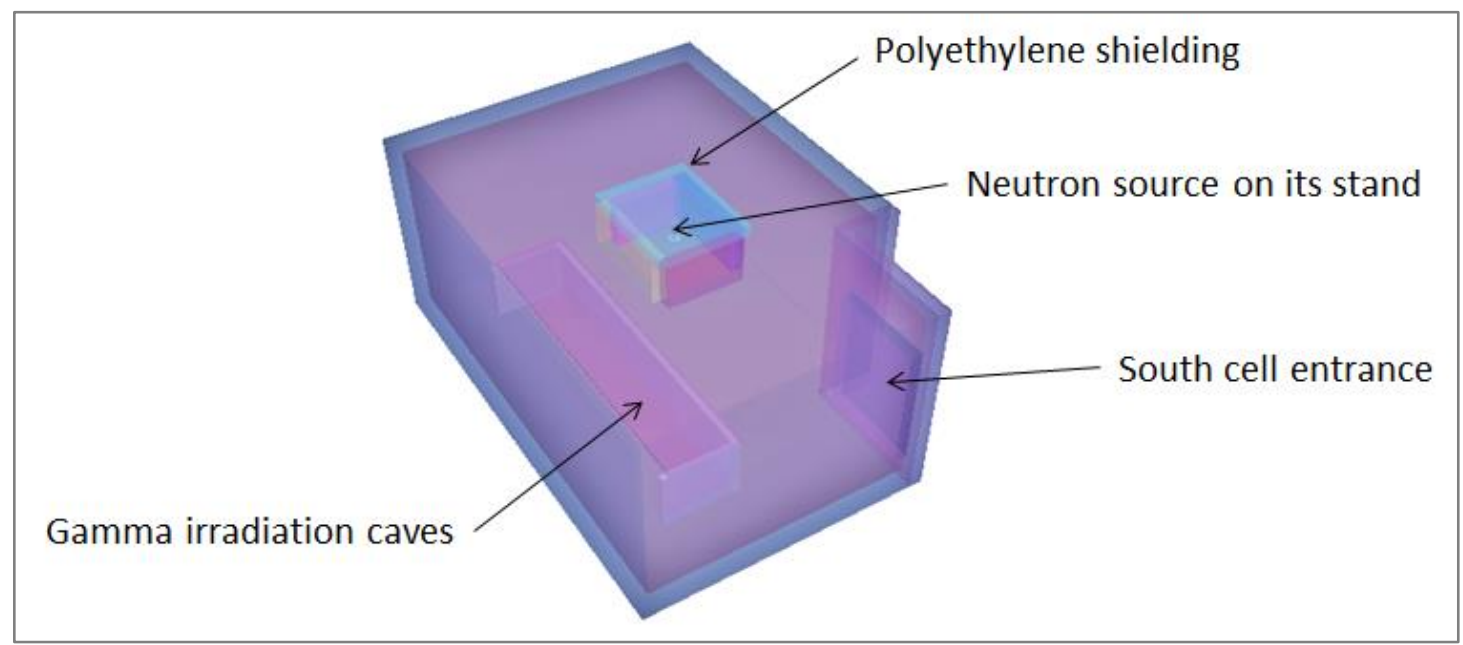

Figure 1. LDRIF South Cell Layout

The system consists of a custom, one-of-a-kind neutron source, an aluminum source stand, polyethylene shielding positioned on a concrete floor, and the environment inside and immediately outside the shielding. The lead caves used for gamma irradiation using ${ }^{137}$ Cs sealed sources contribute low-level gamma background inside the south cell. 


\subsection{1 ${ }^{241} \mathrm{AmBe}$ Source}

The neutron source consists of three well-logging sources, which in 2012 were placed inside the Off-Site Source Recovery Project (OSRP) Special Form Capsule (SFC), and they were destined for disposal through OSRP at Los Alamos National Laboratory (LANL). Prior to shipment, the decision to dispose of the sources was re-evaluated, and the source ownership was transferred to the Gamma Irradiation Facility (GIF) with the intent of using them as a new single source for the low-dose-rate neutron irradiation system. The information about the component sources, based on process knowledge and documentation, is provided in Table I. These values and other information were obtained from the disposal request forms at Sandia National Laboratories (SNL).

Table I. Activities and Masses for ${ }^{241}$ AmBe Component Sources

\begin{tabular}{|c|c|c|c|c|}
\hline Source \# & Serial \# & $\begin{array}{c}\text { Mass of } \\
\mathbf{2 4 1}_{\mathbf{A m}}(\mathbf{g})^{\mathbf{a}}\end{array}$ & $\begin{array}{c}\text { Activity at Birth } \\
(\mathbf{G B q} / \mathbf{C i})\end{array}$ & $\begin{array}{c}\text { Activity on 1/19/14 } \\
(\mathbf{G B q} / \mathbf{C i})\end{array}$ \\
\hline 1 & NB570 & 0.296 & $(38 / 1.02)$ & $(34 / 0.92)$ \\
\hline 2 & NB540 & 0.8 & $(100 / 2.7)$ & $(93 / 2.5)$ \\
\hline 3 & MRC-AmBe-44 & 1.8 & $(230 / 6.2)$ & $(210 / 5.7)$ \\
\hline Total & SFC & 2.9 & $(370 / 9.9)$ & $(340 / 9.1)$ \\
\hline
\end{tabular}

${ }^{\text {a }}$ Values obtained from Disposal Request Form

A specific activity for ${ }^{241} \mathrm{Am}$ of $3.429 \pm 0.005 \mathrm{Ci} / \mathrm{g}{ }^{(5)}$ was used for all calculations in this work. It is noted that each of the component neutron sources were created at different times, and the documentation of each was not always complete. Exact geometric dimensions were not available in the documentation for component sources NB570 and NB540. The dimensions of these two sources were determined by using similar source designs used at the time of manufacture. These two sources were manufactured in the early 1950s. They were modeled in MCNP identically, and the only differences between the two sources are the mass and the weight fractions of the component materials. The NB570 and NB540 sources are shown in Figure 2. The photograph on the left of Figure 2 was taken prior to encapsulating the sources in the OSRP SFC, and the other image (to the right) is a schematic drawn using the dimensions from a similar design. 

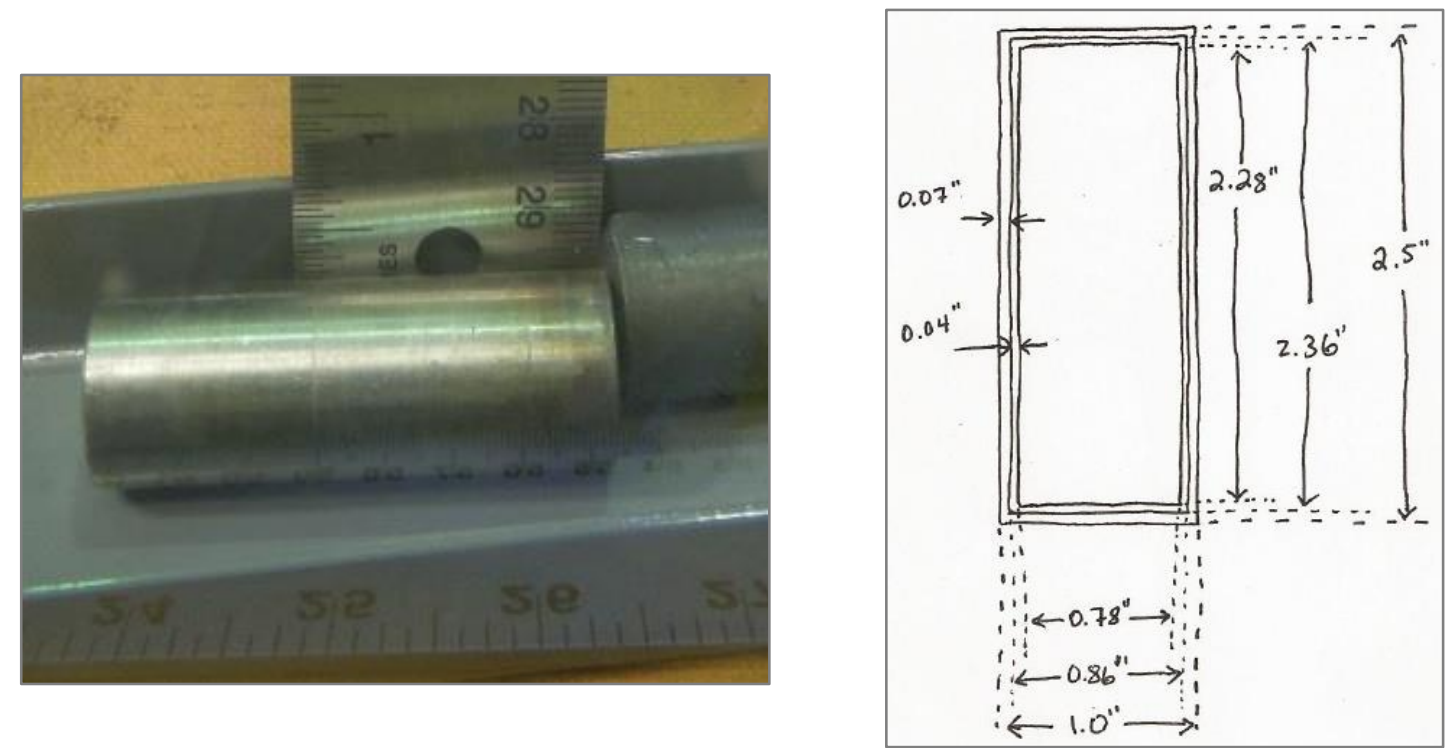

Figure 2. NB570 and NB540 ${ }^{241}$ AmBe Sources Photograph and Schematic

The ratio of americium oxide $\left(\mathrm{AmO}_{2}\right)$ mass to beryllium $(\mathrm{Be})$ mass is not stated in the documentation for sources NB570 and NB540. Therefore an assumption had to be made based on documentation from the 1960s and the weight fraction calculations from Source \# 3 (MRC-AmBe-44). Based on documentation from the 1960s, the neutron source manufacturing industry mixed $\mathrm{Be}$ and $\mathrm{AmO}_{2}$ using ratios from 2:1 to 20:1 by weight ${ }^{(6)}{ }^{(7)}$. For example, ten parts by weight of Be metal was mixed with one part by weight $\mathrm{AmO}_{2}$. In the example, the weight fraction ratio 10:1 was used to avoid self-absorption effects to maximize yield. For sources NB570 and NB540, the ratio of Be to $\mathrm{AmO}_{2}$ was set at $10: 2\left(\mathrm{Be}-\mathrm{to}-\mathrm{AmO}_{2}\right)$ similar to the $\mathrm{MRC}-\mathrm{AmBe}-44$ source. This assumption was made for NB570 and NB540.

The most radioactive source of the three is MRC-AmBe-44. It was manufactured by Monsanto Research Corporation on January 14, 1964, and there is sufficient information about this source to characterize and model it. This source is shown in Figure 3. The photograph on the left of Figure 3 was taken prior to encapsulating the sources in the OSRP SFC, and the other image (to the right) is a schematic drawn of the source. 

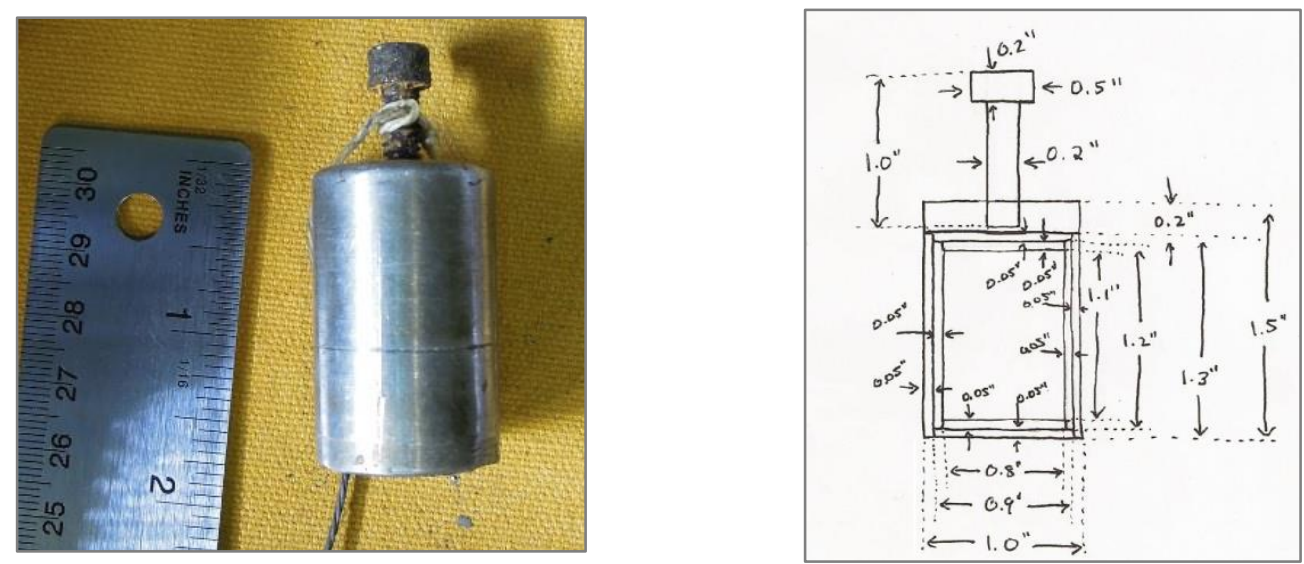

Figure 3. MRC-AmBe-44 Source Photograph and Schematic

\subsubsection{Special Form Capsule}

In the late 1980s, it was recognized that a method was needed to qualify suspect or leaking sources as special form. The SFC was developed and patented by Radiation Service Organization, Inc. in 1989. It was further developed by LANL, so that it could be easily sealed in the field and fabricated in different sizes ${ }^{(8)}$. The SFC is designated as Model II, and it was used in this project to encapsulate the three component neutron sources. SFC Model II is shown in Figure 4.

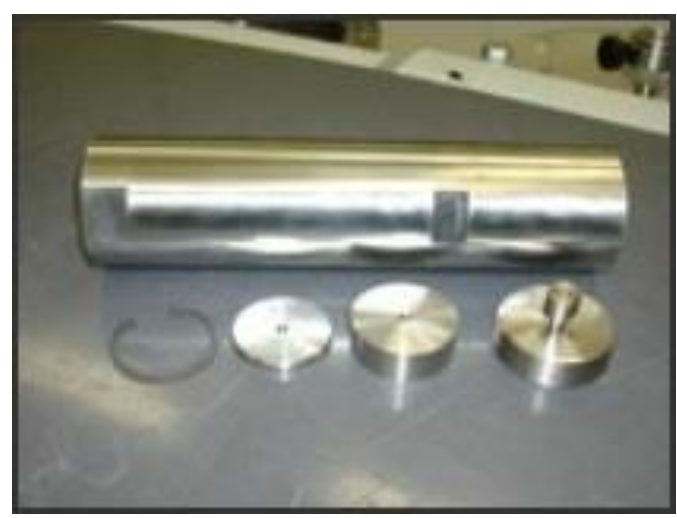

Figure 4. Special Form Capsule Model II $^{(8)}$

The composite neutron source used in this project (RS\# 5838) was produced by combining the three sealed component ${ }^{241} \mathrm{AmBe}$ sources described in the previous section into a Model II OSRP capsule. This produced a single certified special form source. The dimensions of the Model II OSRP capsule are provided in Table II. 
Table II. Dimensions of the Special Form Capsule Model II

\begin{tabular}{|l|l|}
\hline \multicolumn{1}{|c|}{ Parameter } & \multicolumn{1}{c|}{ Value/Description } \\
\hline${ }^{241}$ AmBe source type & Certified special form sealed source \\
\hline Seal total activity & $(0.34 \mathrm{TBq} / 9.1 \mathrm{Ci})$ \\
\hline Capsule type & OSRP special form capsule, Model II. \\
\hline Capsule dimensions ${ }^{(8)}$ & $\begin{array}{l}\text { Outer diameter }=7.6 \mathrm{~cm} \\
\text { Inner diameter }=5.0 \mathrm{~cm} \\
\text { Internal height }=21.6 \mathrm{~cm} \\
\text { Overall length }=29.8 \mathrm{~cm}\end{array}$ \\
\hline
\end{tabular}

When the three component sources were placed inside the SFC in 2012, their location inside the capsule was not well documented. It was only known that all three sources were stacked at the bottom of the SFC, and stainless steel wool was used to keep them from moving around within the SFC. Since the exact information on the component source geometry was not known, it was not possible to accurately model the source in MCNP to characterize the irradiation system.

\subsubsection{Aluminum Stand}

An aluminum stand was fabricated to accommodate the source, so it can be placed at a distance from the concrete floor and the polyethylene roof. The stand also made it easier to reposition the source stand inside the shielding. The stand and the source inside the polyethylene shielding are presented in Figure 5.
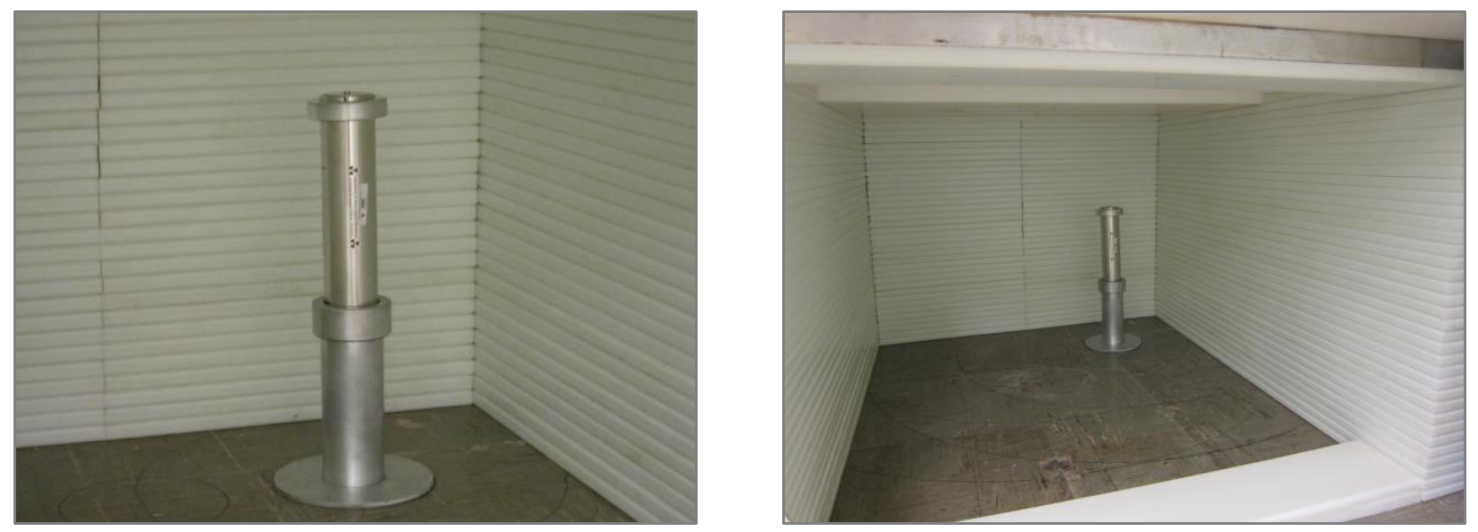

Figure 5. Special Form Capsule on Aluminium Stand inside the Shielding 


\subsubsection{Polyethylene Shielding}

A special polyethylene shield was designed and fabricated to accommodate the neutron source. The interior dimensions of the shielding are $170.7 \mathrm{~cm}$ long, $121.9 \mathrm{~cm}$ wide, and $91.4 \mathrm{~cm}$ high. The wall thickness is $26.9 \mathrm{~cm}$ for the east and the south walls, $24.4 \mathrm{~cm}$ for the north and the west walls, and $20.7 \mathrm{~cm}$ for the roof. The source was placed in the north-west corner (far right hand side as shown in Figure 6), with its vertical axis at $30 \mathrm{~cm}$ from the north and the west walls. Circles were drawn on the floor around the center of the source at $30 \mathrm{~cm}$ increments from $30 \mathrm{~cm}$ to $122 \mathrm{~cm}$ to aid the placement of the instruments used in this project and the future experiments. The polyethylene shielding is shown in Figure 6. The door of the irradiation system faces east, and north is to the right of Figure 6.

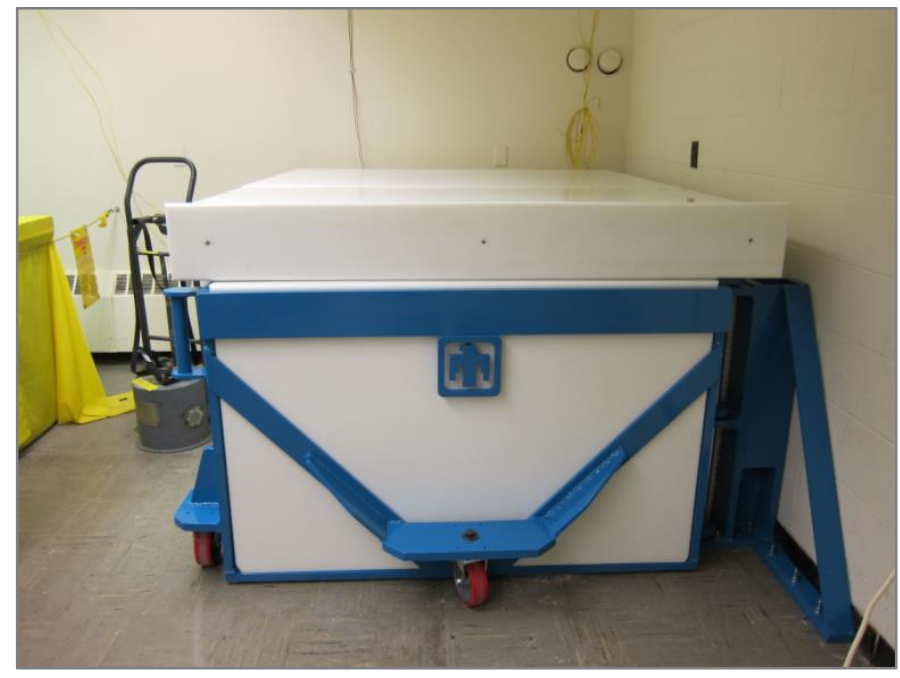

Figure 6. Polyethylene Chamber for Shielding and Storing the Neutron Source

The source on its aluminum stand was placed inside this polyethylene shielding, where it is used and stored when not in use. Some of the polyethylene slabs used to construct the shielding contained trace amounts of boron in them, and most of these were placed on the door. Several ${ }^{137}$ Cs sources share the room with the polyethylene shielding, and they are shielded by several inches of lead. These gamma sources are located to the south (left in Figure 6) of the irradiation system. 


\section{CHAPTER 3 - THEORY}

Chapter three provides information about the mechanisms of how the measurement values were obtained from the instruments. Basic theory about americium-241 beryllium $\left({ }^{241} \mathrm{AmBe}\right)$ sources and instruments utilized in the experiment are discussed. The methods of neutron/photon interactions and detection are detailed as well.

\subsection{Neutron/Photon Production in ${ }^{241}$ AmBe Source}

Americium-241 is an artificially created radionuclide produced in nuclear reactors. ${ }^{241} \mathrm{Am}$ is a decay product of ${ }^{241} \mathrm{Pu}$, and ${ }^{241} \mathrm{Pu}$ has a half-life of 13.2 years. Americium-241 is produced by the following sequence of nuclear reactions ${ }^{(9)}$.

$$
{ }^{239} \mathrm{Pu}+{ }^{1} \mathrm{n} \rightarrow{ }^{240} \mathrm{Pu}+{ }^{1} \mathrm{n} \rightarrow{ }^{241} \mathrm{Pu} \stackrel{\beta^{-}}{\rightarrow}{ }^{241} \mathrm{Am}
$$

A radioactive $(\alpha, n)$ source can be created by mixing natural beryllium with ${ }^{241} \mathrm{Am}$. This type of neutron source is called an "Ambee" source. ${ }^{241} \mathrm{AmBe}$ sources produce neutrons mostly by the ${ }^{9} \mathrm{Be}(\alpha, \mathrm{n})$ reaction, where an alpha particle emitted by ${ }^{241} \mathrm{Am}$ interacts with ${ }^{9} \mathrm{Be}$, producing ${ }^{12} \mathrm{C}$ and a neutron. The neutron emission from an ${ }^{241} \mathrm{AmBe}$ source can be accompanied by de-excitation gamma emission from excited ${ }^{12} \mathrm{C}$ as follows:

$$
{ }^{9} \mathrm{Be}(\alpha, \mathrm{n}){ }^{12} C^{*} \rightarrow{ }^{12} C+\gamma^{\prime} s
$$

Most of the neutron emissions from the above reaction are associated with a cascade of de-excitation gammas whose energies are $4.4 \mathrm{MeV}$ and $7.7 \mathrm{MeV}$ (9) (10) (11). There are other reactions occurring within the ${ }^{241} \mathrm{AmBe}$ source, but they are not significant relative to the alpha-neutron reaction shown above. These reactions will only be mentioned here for informational purposes, and they are as follows ${ }^{(12)}$ :

$$
\begin{gathered}
{ }^{9} \mathrm{Be}\left(\alpha, \alpha^{\prime}\right){ }^{9} \mathrm{~B} e * \rightarrow{ }^{8} \mathrm{Be}+n \\
{ }^{9} \mathrm{Be}\left(\alpha,{ }^{8} \mathrm{Be}\right){ }^{5} \mathrm{He} \rightarrow{ }^{4} \mathrm{He}+n \\
{ }^{9} \mathrm{Be}(\alpha, \mathrm{n}) 3 \alpha \\
{ }^{9} \mathrm{Be}(\mathrm{n}, 2 \mathrm{n}){ }^{8} \mathrm{Be}
\end{gathered}
$$


A brief note about the $(n, 2 n)$ beryllium reaction, this reaction increases the neutron flux density in the system. The flux density increase is dependent on source design and location. The distribution of neutron energies emitted range from approximately $0.01 \mathrm{MeV}$ to $10 \mathrm{MeV}$. Industry standard, ISO-8529:1989, is used as the known neutron energy distribution throughout the document ${ }^{(13)}$. The neutron spectrum source strength of an ${ }^{241} \mathrm{AmBe}$ source is plotted as a function of energy, and it is presented in Figure 7.

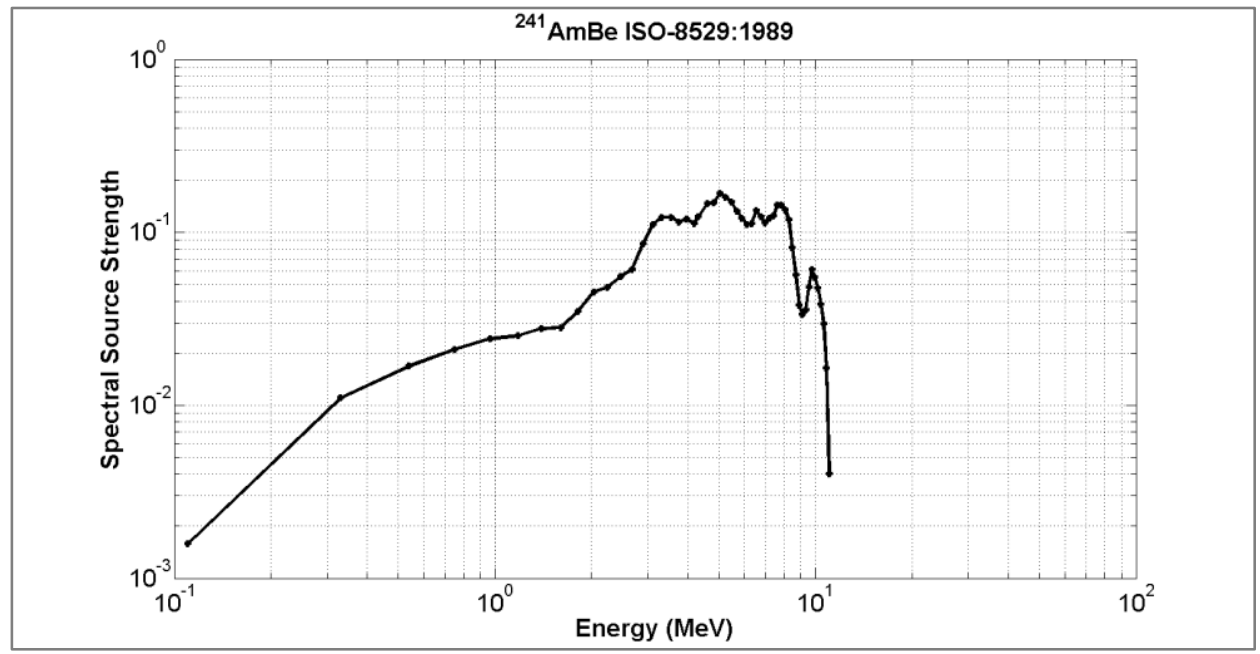

Figure 7. ISO-8529:1989, ${ }^{241}$ AmBe Neutron Energy Distribution ${ }^{(13)}$

The rate of decay of the ${ }^{241} \mathrm{AmBe}$ source is dependent on the decay of ${ }^{241} \mathrm{Am}$. The physical properties for ${ }^{241} \mathrm{AmBe}$ are shown in Table III.

Table III. Nuclear Properties of ${ }^{241} \mathrm{AmBe}(\alpha, n)$ Source ${ }^{(5)(7)(9)(12)}$

\begin{tabular}{|l|c|}
\hline \multicolumn{1}{|c|}{ Property } & Value \\
\hline Half-life of ${ }^{241} \mathrm{Am}$ & $432.6 \pm 0.6 \mathrm{yr}$ \\
\hline Specific activity of ${ }^{241} \mathrm{Am}$ & $1.27 \times 10^{11} \mathrm{~Bq} / \mathrm{g}$ \\
& $(3.429 \pm 0.005 \mathrm{Ci} / \mathrm{g})$ \\
\hline Average neutron energy & $4.16 \mathrm{MeV}$ \\
\hline Max neutron energy & $11 \mathrm{MeV}$ \\
\hline Neutron emission & $\sim 6 \times 10^{7} \mathrm{n} / \mathrm{s} \mathrm{per} \mathrm{TBq}$ \\
& $\left(\sim 2.2 \times 10^{6} \mathrm{n} / \mathrm{s} \mathrm{per} \mathrm{Ci}\right)$ \\
\hline Average alpha energy from ${ }^{241} \mathrm{Am}$ & $5.70 \mathrm{MeV}$ \\
\hline
\end{tabular}

Another significant emission of the ${ }^{241} \mathrm{AmBe}$ source are the gamma rays emitted by decay of ${ }^{241} \mathrm{Am}$. There are many gamma rays emitted by ${ }^{241} \mathrm{Am}$, but the most common gamma ray energy emitted is at $60 \mathrm{keV}$. 
The decay of ${ }^{241} \mathrm{Am}$ is given as follows ${ }^{(5)}$ :

$$
{ }^{241} \mathrm{Am} \rightarrow{ }^{237} \mathrm{~Np}+{ }_{2}^{4} \alpha+\gamma^{\prime} s
$$

The ${ }^{241}$ Am decay scheme is given in Figure 8. This diagram shows the decay for energies less than $230 \mathrm{keV}$, showing $60 \mathrm{keV}$ as the most common emission ${ }^{(9)}$.

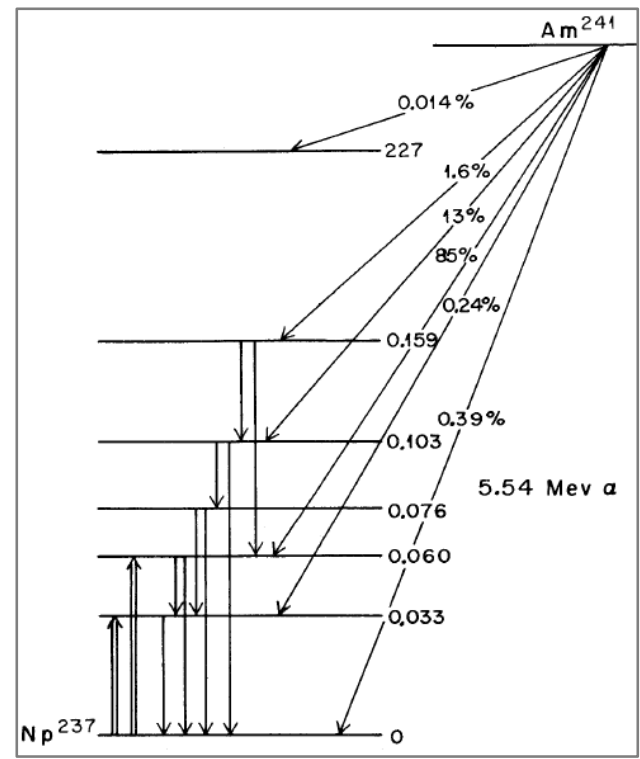

Figure 8. Radionuclide ${ }^{241}$ Am Decay Scheme ${ }^{(9)}$

\subsection{Computed Photon Radiography}

Figure 7 shows that neutrons emitted from an ${ }^{241} \mathrm{AmBe}$ source generate a fast neutron spectrum. These neutrons interact with surrounding material in many ways such as inelastic/elastic scattering and radiative capture. The neutrons may interact with the material inducing gammas rays, and then these gammas rays can interact via the photoelectric effect, Compton scatter, and/or pair production. Gamma- or x- rays are indirectly produced at a broad range of energies depending on the material ${ }^{(14)}$. The intensity of the rays produced by this fast spectrum is dependent on the neutron source strength. The nuclear reaction rates in a neutron field propagating through a material have an inherent gamma- and $\mathrm{x}$ - ray field proportional to it.

In computed photon radiography, imaging plates (IPs) are used to detect low energy gamma- and $\mathrm{x}$ - rays that come directly from the source or are induced by neutrons. In this experiment, the IPs used are composed of $\mathrm{BaFBr}: \mathrm{Eu}^{+2}$. The IPs are doped with trace amounts of impurities, such as $\mathrm{Eu}^{+2}$ (also called activators), and 
ionization via low energy gamma- and $\mathrm{x}$ - rays in the IPs allow for an electron/hole pairs to raise the activator to an excited state ${ }^{(15)}$. Photo-stimulable phosphor IPs can trap low energy gamma- or x-ray energy in the crystal structure of the plate for photons having energies of $10 \mathrm{keV}$ to $140 \mathrm{keV}$ depending on IP material. In Figure 9, three different types of phosphor IPs are displayed showing the photon absorption fraction as a function of incident energy ${ }^{(15)}$.

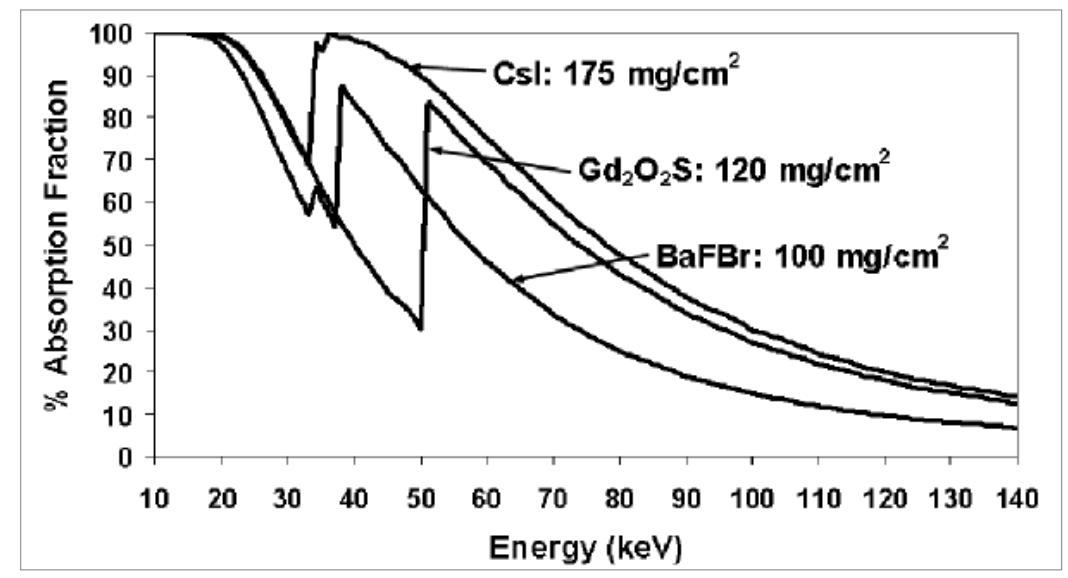

Figure 9. Photon Absorption Range of Various Phosphors ${ }^{(15)}$

If the phosphor IP crystal structure containing the trapped energy is stimulated by low energy light of a specified wavelength, it releases the trapped energy in the form of light. This process is known as photo-stimulated luminescence ${ }^{(16)}$. The low energy gamma- and $\mathrm{x}$ - rays absorbed in the phosphor IPs induce the formation of holes and electrons, and it is best described by the Photo-Stimulated Luminescence Complex (PSLC) theory. This theory states that the PSLC is an F-center in close proximity to an $\mathrm{Eu}^{3+}-\mathrm{Eu}^{2+}$ recombination center. The holes and electrons induced by the low energy gamma- and $\mathrm{x}$ - rays can either activate a PSLC by being captured by an F-Center, or it can form an active PSLC via formation and recombination of exitons ${ }^{(15)}$. The active PSLC's created are proportional to the low energy gamma- and x-ray dose to the phosphor IP.

The dose to the IPs is then related to the intensity of the photons. The PSLC theory is illustrated in Figure 10, where the incident photon approaches the IPs from the bottom. The photon interacts with the energy band of the phosphor IPs, and then a very low energy photon is emitted via stimulation as shown on the left of Figure 10. 


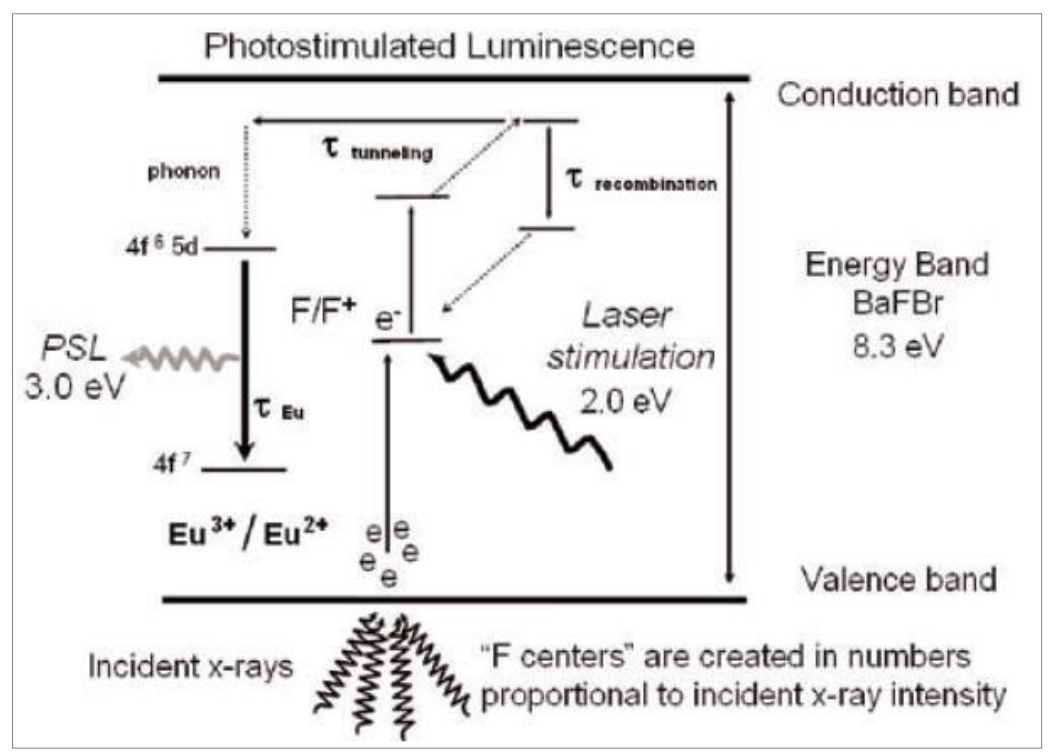

Figure 10. Photo-Stimulated Luminescence Complex Theory ${ }^{(15)}$

The IPs are passed through the computed photon reader. The red laser stimulates the IP causing emission of blue light, and the low energy photons are shown in Figure 10 to the left coming out at $3.0 \mathrm{eV}$. This light is then received by a photomultiplier tube, which converts to a voltage, digitizes, and stores the signal in a digital image matrix. Figure 11 illustrates the stimulation and emission of the IPs for $\mathrm{BaFBr}: \mathrm{Eu}^{+2(15)}$.

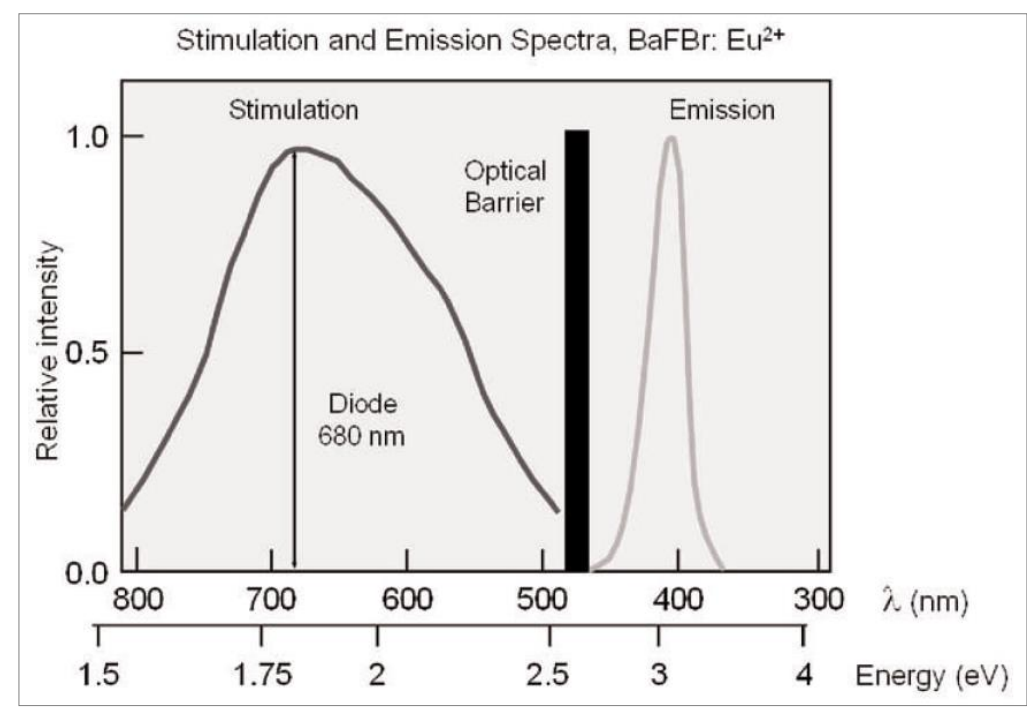

Figure 11. Stimulation and Emission Spectra of BaFBr:Eu ${ }^{+2}$ Imaging Plate $^{(15)}$ 


\subsection{Gamma Spectroscopy}

This section describes basic gamma spectroscopy, neutron interactions in a High Purity Germanium (HPGe) detector relevant to an ${ }^{241} \mathrm{AmBe}$ source, and energy resolution degradation due to neutrons in germanium crystals. A gamma spectrum from a germanium detector exposed to a neutron source is shown, and the neutron limits determined experimentally by fast neutron degradation of geranium detectors is also shown.

\subsubsection{Photon Interactions with HPGe Detector}

The ${ }^{241} \mathrm{AmBe}$ is the source of neutrons and photons. These particles interact with the HPGe detector, i.e., the germanium crystal and the detector components. Photons interact with a material via photoelectric absorption, Compton scatter, and pair production $^{(16)}$.

The photoelectric effect occurs when an incident photon transfers its energy to a photoelectron, which is emitted from one of the atoms electron shells. A Compton scattering interaction occurs when an incident photon collides with an electron. This creates a recoil electron and scattered photon sharing the energy between the two, depending on the scattering angle. Pair production occurs in the electric field near the nucleus of the absorbing material. This interaction results in the creation of an electron-positron pair in exchange for the incident photon. A minimum gamma-ray energy of $1.02 \mathrm{MeV}$ (two times the rest mass of an electron) is required for this to energetically be possible ${ }^{(16)}$.

The detector response to photons reflects interactions with the material of the detector, and the photons are directly related to the energy given to electrons in the process, which is deposited in the detector. The typical features of the gamma spectrum include, but are not limited to the following: backscatter peak, Compton edge, annihilation radiation, single escape peak (SEP), double escape peak (DEP), and summation peaks ${ }^{(16)}$. The ${ }^{60} \mathrm{Co}$ spectrum showing these features are shown in Figure 12. 


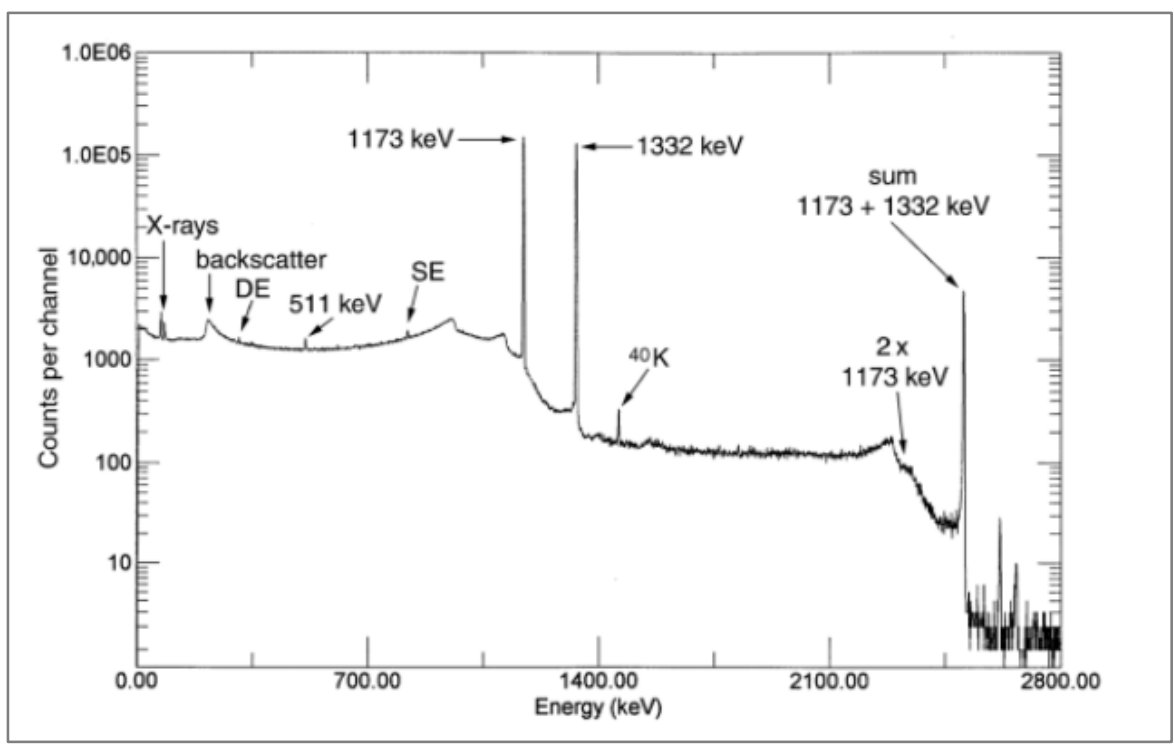

Figure 12. ${ }^{60}$ Co Spectrum Obtained with P-type HPGe Detector ${ }^{(16)}$

Backscatter peak occurs between $0.2 \mathrm{MeV}$ and $0.25 \mathrm{MeV}$, and it is produced by photons that have first interacted via Compton scattering in one or more of the materials surrounding the detector. The photons backscatter into the detector at scattering angle of approximately 180 degrees. Annihilation radiation occurs when a positron generated in the pair production reaction annihilates with an electron and produces two $511 \mathrm{keV}$ photons. A SEP at an energy $511 \mathrm{keV}$ lower than the full energy deposition peak, and it occurs when one of the two $511 \mathrm{keV}$ annihilation gamma rays escape while the second is fully absorbed. A DEP appears at an energy $1.022 \mathrm{MeV}$ lower than the full energy peak, and it occurs when both $511 \mathrm{keV}$ gamma rays escape the detector. Summation peaks in the spectrum occur during coincident detection of two or more gamma-rays. This phenomenon occurs mostly in applications involving a radionuclide that emits multiple cascade gamma rays in its decay ${ }^{(16)}$.

\subsubsection{Neutron Interactions with HPGe Detector}

In the neutron irradiation system, not only do photons interact with the detector, but neutrons interact with it as well. To understand what peaks originate from neutron interactions, Buntin and Kraushaar collected a gamma spectrum exposed to monoenergetic neutrons ranging from 1.2 MeV to $16.3 \mathrm{MeV}$ using a Ge(Li) detector ${ }^{(17)}$. The neutron interactions provide an insight to which peaks originate from neutrons, and these interactions are presented in Figure 13. 


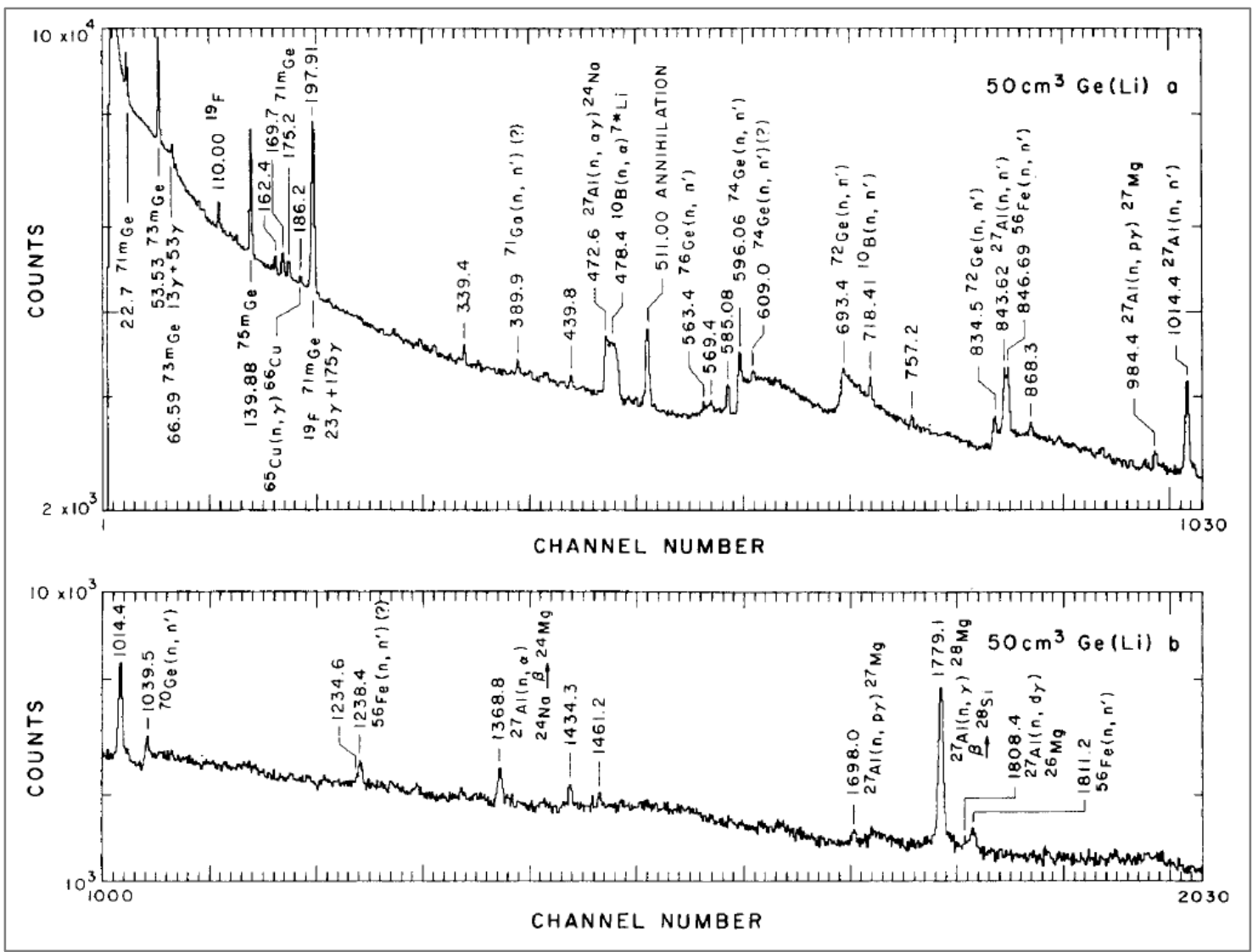

Figure 13. Neutron Spectra produced by Fast Neutron Irradiation of Ge(Li) Detector ${ }^{(17)}$

There should be an expected number of peaks in the spectrum due to neutron interactions with the detector. Similar studies on understanding neutron interactions in HPGe were performed by I. Abt, et al. ${ }^{(18)}$. In their investigation, they looked at interactions in a HPGe detector exposed to neutrons from an ${ }^{241} \mathrm{AmBe}$ source, and they identified significant peaks, which are presented in Table IV. These gamma rays can be used as a guide to identify gamma-ray lines measured at the neutron irradiation system ${ }^{(18)}$. 
Table IV. Major Interactions of ${ }^{241}$ AmBe Source Neutrons with HPGe Detector ${ }^{(18)}$

\begin{tabular}{|c|c|}
\hline Energy (keV) & Interaction Type \\
\hline 595.7 & ${ }^{74} \mathrm{Ge}\left(n, n^{\prime} \gamma\right)$ \\
\hline 846.6 & ${ }^{56} \mathrm{Fe}\left(n, n^{\prime} \gamma\right)$ \\
\hline 867.8 & ${ }^{73} \mathrm{Ge}\left(n, n^{\prime} \gamma\right)$ \\
\hline 1014.3 & ${ }^{27} \mathrm{Al}\left(n, n^{\prime} \gamma\right)$ \\
\hline 1200.8 & $\mathrm{DEP}$ of 2223 \\
\hline 1711.8 & $\mathrm{SEP}$ of 2223 \\
\hline 2223.2 & ${ }^{1} \mathrm{H}(n, \gamma){ }^{2} \mathrm{H}$ \\
\hline 3427 & $\mathrm{DEP}$ of $4441 \mathrm{keV}$ \\
\hline 3931 & $\mathrm{SEP}$ of $4441 \mathrm{keV}$ \\
\hline 4441 & ${ }^{9} \mathrm{Be}(\alpha, n \gamma){ }^{12} \mathrm{C}$ \\
\hline
\end{tabular}

\subsubsection{Neutron Damage to HPGe Detector}

Although the HPGe detector can indirectly detect neutrons via production of gamma-rays, this is not a recommended procedure because the neutrons cause damage to the germanium crystal. Excessive neutron irradiation to the crystal causes the degradation of energy resolution in HPGe detector. When irradiating the detector, it is important to understand the limits of the crystal being irradiated.

Due to the nature of the crystal design, N-type detectors are more resistant to neutron damage than P-type detectors. According to Knoll ${ }^{(16)}$, "exposure of thick planar germanium detectors to a fast neutron fluence of about $10^{9} \mathrm{n} / \mathrm{cm}^{2}$ is sufficient to risk measureable changes in the detector resolution." Knoll also states that "the detector may become totally unusable after exposure to a fluence of $10^{10} \mathrm{n} / \mathrm{cm}^{2}$." The IAEA reports ${ }^{(2)}$, "the approximate threshold fluences for HPGe coaxial and planar detectors for early stages of energy resolution degradation when bombarded with fast neutrons to be the following:

- $2 \times 10^{8} \mathrm{n} / \mathrm{cm}^{2}$ for P-Type detectors up to $20 \%$ in efficiency

- $1 \times 10^{7} \mathrm{n} / \mathrm{cm}^{2}$ for P-Type detectors up to $70 \%$ in efficiency

- $4 \times 10^{9} \mathrm{n} / \mathrm{cm}^{2}$ for $\mathrm{N}$-Type detectors up to $30 \%$ in efficiency

- $1 \times 10^{9} \mathrm{n} / \mathrm{cm}^{2}$ for $\mathrm{N}$-Type detectors up to $70 \%$ in efficiency

- $1 \times 10^{9} \mathrm{n} / \mathrm{cm}^{2}$ for planar detectors" 
Based on the energy degradation thresholds, it is possible to determine how long a HPGe crystal can be irradiated.

\subsection{Neutron Spectroscopy}

This section describes fast neutron detection via NE213 organic scintillators and Bubble Dosimeter Spectrometers (BDS); BDS utilize superheated vapors. Spectra deconvolution methods for these two detectors will also be discussed. This section also presents the basic physics of low energy neutron spectroscopy using ${ }^{3} \mathrm{He}$ gas proportional counters.

\subsubsection{Fast Neutron Detection by Organic Scintillator}

\section{Neutron Interactions}

The NE213 organic scintillator is a proton recoil detector, and it is composed mostly of hydrogen and carbon. The source emits neutrons, and they interact with the elements of the NE213. The neutrons collide by elastic and inelastic scattering, and they create charged particles in the NE213. Most of the energy from the charged particles is dissipated nonradiatively in the form of lattice vibrations or heat, and a small amount of energy is converted into fluorescent energy ${ }^{(16)}$.

The light yield of organics is dependent on the type of particle interacting with it. A special nomenclature is used to describe the absolute light yield from charged particles, and it is used to quantify the light yield on an absolute basis. That unit is called "MeV electron equivalent" (MeVee). A $1 \mathrm{MeV}$ electron generates $1 \mathrm{MeVee}$ of light in the scintillator. For a given energy, a heavy charged particle, such as a proton, will generate less light that an electron of the same energy ${ }^{(16)}$. The light output response of NE213 for electrons and protons as a function of their energy is shown in Figure 14. Since the light output is proportional to the proton's energy, this relationship is useful for discriminating between different incident neutron energies. 


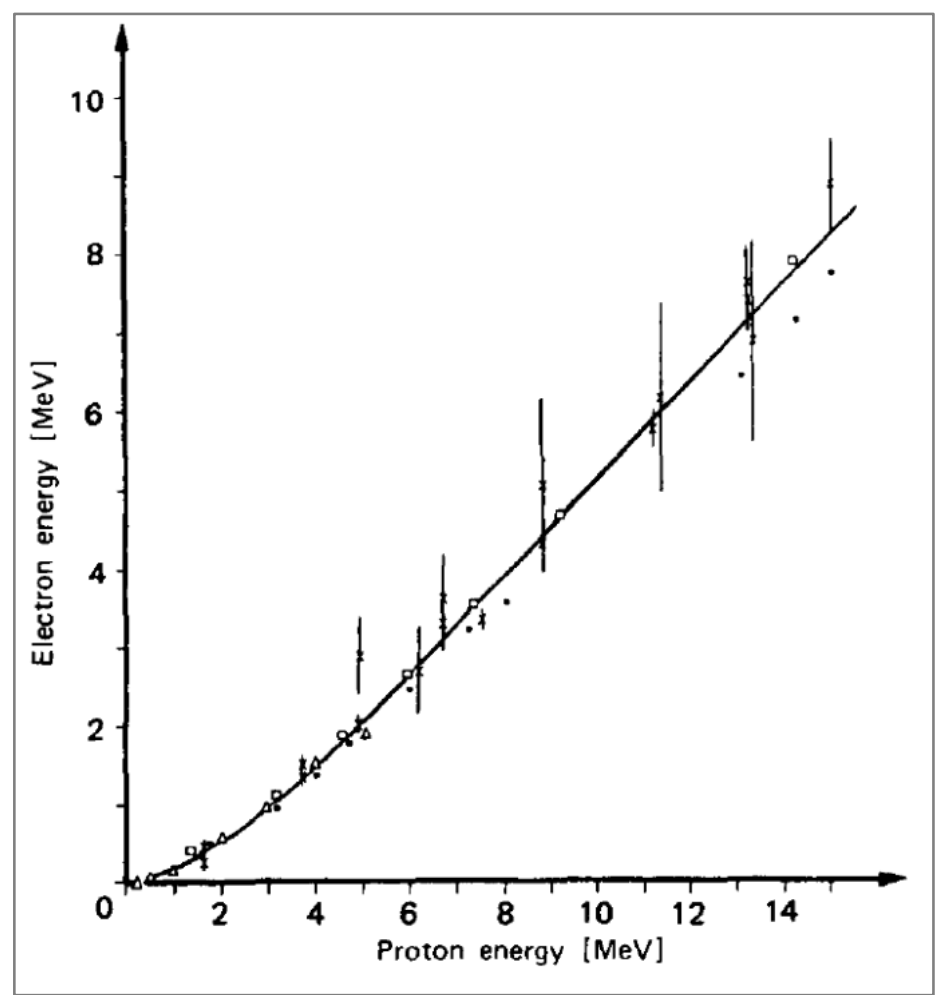

Figure 14. Electron Energy Light Output as a Function of Proton Energy in NE213 ${ }^{(16)}$

The organic scintillator response to heavy charged particles, such as protons, is always less than that for electrons for equivalent energies. The relationship is linear for energies below $125 \mathrm{keV}$, and it then becomes nonlinear at higher energies ${ }^{(16)}$. The resultant detector pulse from Figure 14 is the product of light output from molecules excited by the passage of protons as collected by a photomultiplier tube. Figure 15 is obtained from Radiation Detection and Measurement by Knoll, and it best illustrates organic scintillator detector pulse response. In Figure $15^{(16)}$, "part (a) shows a plot of pulse height $(\mathrm{H})$ verses particle energy $(\mathrm{E})$ for a typical organic scintillator. This nonlinear response leads to a distortion of the rectangular proton recoil spectrum of part (c) into the spectrum shown in part (d)." Using the spectrum from part (d), a spectral deconvolution using an iterative code can now be performed on the spectrum to obtain neutron flux density or fluence values from the proton recoil detector. 


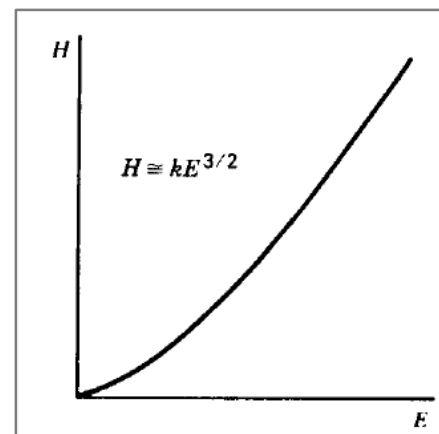

(a)

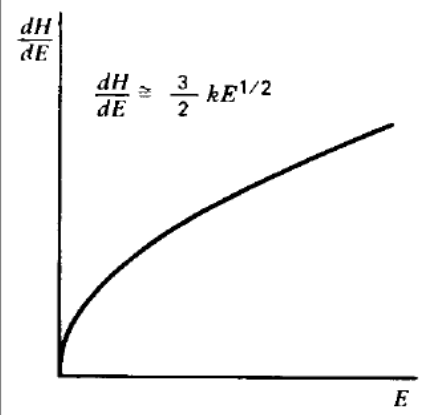

(b)

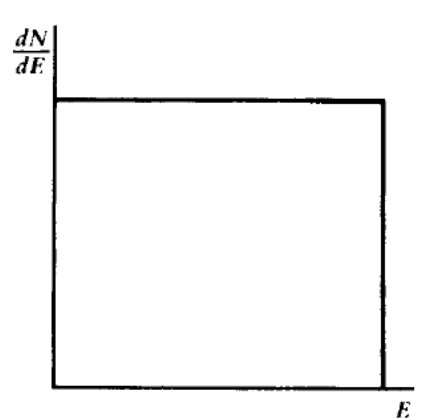

(c)

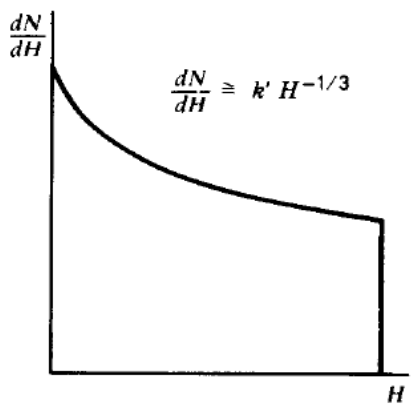

(d)

Figure 15. Pulse Height Plots for Organic Scintillator ${ }^{(16)}$

\section{NE213 Detector Response}

Liquid scintillators are preferred because of their pulse shape discrimination capability to suppress gamma-ray response. Organic liquid scintillators are used for the detection of fast neutrons mainly because of their high detection efficiency, good timing resolution, and excellent $n-\gamma$ pulse shaped discrimination properties ${ }^{(16)}$. The size of the scintillator is also important. A larger crystal may absorb more energy, but there is a loss of resolution. The energy spectrum of proton recoils detectors will closely approximate the rectangular distribution. One would like to keep the scintillator small so that multiple scattering of neutron becomes less likely, and the response is not as complex for the deconvolution process. The pulse distribution suffers from edge effects, multiple scatter from hydrogen, scattering from carbon, detector resolution, and competing reactions at high neutron energies ${ }^{(16)}$. There are many other effects that influence the response of the NE213, but the final spectral product before deconvolution is shown in Figure 16. This figure gives an example for the overall detector response function for a $2.54 \mathrm{~cm}$ by $2.54 \mathrm{~cm}$ cylindrical stilbene crystal for an incident neutron energy of $2.6 \mathrm{MeV}$ as measured by Borman et al ${ }^{(19)}$. 


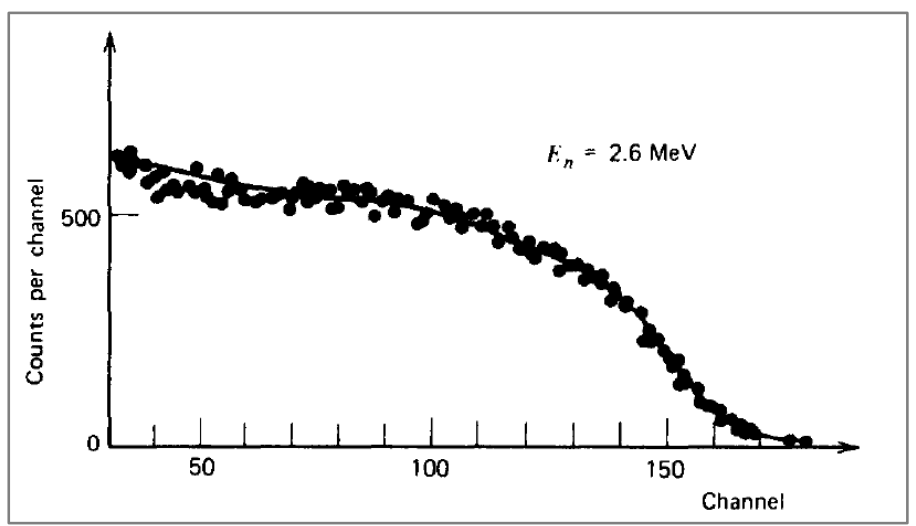

Figure 16. Measured Pulse Height Spectra for Organic Scintillator ${ }^{(19)}$

\section{NE213 Spectrum Deconvolution Methods}

Once the pulse height spectral information is obtained from an organic scintillator, a special code is required to obtain the neutron fluence, and it is also required to understand how the response of the NE213 relates to the neutron flux density. Details for the unfolding algorithm utilized are not provided by the manufacturer for the N-probe Microspec. A literature search reveals that the N-probe probably uses FERDOR ${ }^{(20)}$, a well-established code developed by Oak Ridge National Laboratory (ORNL), or some variation thereof. There are many other codes that could be used to deconvolve, such as FORIST, RADAK, and FLYSPEC which use various methods to deconvolve the spectrum ${ }^{(21)}$. Figure 17 , shows the deconvolution of a ${ }^{3} \mathrm{H}(\mathrm{d}, \mathrm{n}){ }^{4} \mathrm{He}$ producing a $14 \mathrm{MeV}$ neutron beam measured by the N-Probe Microspec.

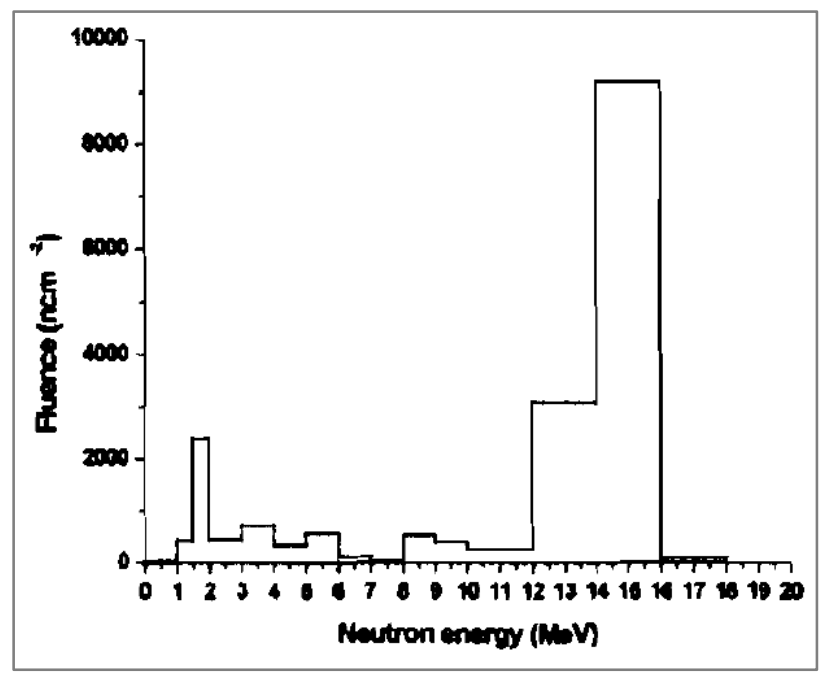

Figure 17. Neutron Spectral Deconvolution from Microspec ${ }^{(22)}$ 


\subsubsection{Fast Neutron Detection by Bubble Dosimeter Spectroscopy}

\section{Neutron-Bubble Interaction}

The Bubble Dosimeter Spectrometer (BDS) set contains 36 tubes with tiny superheated liquid droplets that are dispersed throughout a firm, transparent, elastic polyacrylamide gel. The BDS are received from the manufacturer with a layer of low boiling point liquid above the polymer, which exerts pressure on the elastic polymer. This is done to maintain the detectors in a radiation insensitive state. When the plastic tubes are open and the liquid has dissipated, the BDS is sensitized to neutrons. A typical droplet prior to vaporization is about $25 \mu \mathrm{m}$ in diameter ${ }^{(23)}$.

When the neutrons interact with the detector gel, the neutrons produce secondary charged particles. The charged particles interact with superheated liquid droplets in their vicinity causing them to vaporize. The energy from the charged particles produce heat in the droplets, and the visible bubbles are formed in the gel. The bubbles are trapped at the location of the formation, and they are suspended in the elastic polymer. With the bubbles visible and immobilized, this allows for them to be counted ${ }^{(23)}$.

The sensitivity of the BDS can be adjusted by changing the density or number of droplets per unit volume in the detector. The material composition of the BDS can also be adjusted to obtain different neutron energy thresholds. Also chlorine and nitrogen contribute a thermal neutron sensitivity due to $(n, p)$ reactions in the BDS ${ }^{(23)}$.

\section{Bubble Theory and Response}

The mechanism of the formation can be best explained using Seitz's thermal spike model. According to Seitz model, the neutron interacts with the polymer and transfers its energy to a recoil nucleus. Elastic scatter is the primary mechanism for the interaction of the incident neutron with the nucleus of an atom. The charged nucleus deposits its energy by interaction with electrons and other nuclei via ionization and excitation. The ionization and excitation along the path of the charged particle produces local heating. This results in the formation of relatively small vapor bubbles ${ }^{(24)}$. Once a bubble of radius ' $\mathrm{r}$ ' is formed, it will remain in a stable state as long as the pressure within the bubble remains equal to the pressure exerted on the bubble from without ${ }^{(24)}$. 
This is described as the effective surface pressure:

$$
P_{e s}=\frac{2 \gamma(T)}{r}
$$

Once the vapor bubble expands, it reaches its critical radius defined as:

$$
r_{c}=\frac{2 \gamma(T)}{\Delta P}
$$

$\gamma(\mathrm{T})$ is the temperature dependent surface tension of the liquid. The pressure difference across the bubble surface is given as:

$$
\Delta P=P_{v}(T)-P_{o}
$$

$\mathrm{P}_{\mathrm{O}}$ is vapor pressure outside of the bubble, and $\mathrm{P}_{\mathrm{v}}(\mathrm{T})$ is the vapor pressure within the bubble at temperature ' $\mathrm{T}$ '. Equation 2 indicates that if a bubble grows to a size where its radius is as large as or exceeds $r_{c}$ that bubble becomes thermodynamically unstable. At this point, it will continue to grow by consuming or boiling the entire super-heated liquid droplet $^{(24) \text {. }}$

\section{BDS Neutron Spectrum Deconvolution}

Since there are not many energy bins available for the BDS, the neutron spectral deconvolution is relatively simple to perform, and it is performed by spectral stripping. In spectral stripping, the spectrum is unpeeled by starting with the largest energy bin. The corresponding response function for the BDS is multiplied by a variable factor, and then subtracted from the coded spectrum. The next lower energy is then chosen, and the subtraction process is repeated ${ }^{(16)}$. The deconvoluted spectrum looks similar to the spectrum shown in Figure 17, except it will have fewer energy bins.

\subsubsection{Low Energy Neutron Detection by ${ }^{3} \mathrm{He}$ Gas Proportional Counter}

\section{Neutron Interactions}

The second method of detection in the N-Probe Microspec is the ${ }^{3} \mathrm{He}$ gas proportional counter. The Microspec measures neutron energies less than about $1.5 \mathrm{MeV}$ using the following reaction:

$$
{ }^{3} \mathrm{He}(n, p){ }^{3} \mathrm{H}
$$

The cross section for this reaction follows the well-known $1 / \mathrm{v}$ dependence with the thermal neutron cross section at 5330 barns. The Q-value of this reaction is 
$0.764 \mathrm{MeV}$. Conservation of energy and momentum dictates the proton will be given an energy of $0.573 \mathrm{MeV}$ and the ${ }^{3} \mathrm{He}$ an energy of $0.191 \mathrm{MeV}^{(16)}$. A literature search reveals that several authors have successfully unfolded the incident neutron spectrum from ${ }^{3} \mathrm{He}{ }^{(25)}$. The calculations of ${ }^{3} \mathrm{He}$ detector response functions are complex, and the calculations can lead to large uncertainties, which can distort the unfolded spectrum. Also, low energy neutrons create pile-up which obscures details in the fast neutron spectrum ${ }^{(26)}$. Bubble Technology Industries (BTI) resolved these problems assigning three energy bins in the unfolded spectrum: thermal to $10 \mathrm{keV}, 10 \mathrm{keV}$ to $500 \mathrm{keV}$, and $500 \mathrm{keV}$ to $1 \mathrm{MeV}$. The highest energy group overlaps with the lowest NE213 group. Information about how the unfolding algorithm determines the neutron fluence at the cross-over bin is not known. BTI also used a "special" boron shield placed around the ${ }^{3} \mathrm{He}$ detector, so the over-response to low energy neutrons in the lower energy bin is decreased. According to BTI ${ }^{(25)}$, "these techniques have been carefully designed to optimize the detectors energy response by the inclusion of partial and full penetrations through the shield."

\subsection{Neutron Foil Activation}

Many materials (often in the form of foils) can be activated by neutrons by a variety of neutron reactions, some of which may have energy thresholds. By exposing enough different foils having a suitable range of reaction thresholds to a neutron source and measuring the resulting activities, the spectrum of the neutron source can be unfolded and the flux density determined. Table $\mathrm{V}$ shows the reactions of interest for all the foils used in the experiment. Since gold was the only foil to actually yield useful data, it will be the only one discussed in detail here.

Table V. Foil Activation Pathways (27) (28)

\begin{tabular}{|c|c|c|c|}
\hline Reaction of Interest & $\begin{array}{c}\text { Half-Life } \\
\text { (days) }\end{array}$ & $\begin{array}{c}\text { Effective Threshold } \\
\text { Energy (MeV) }\end{array}$ & $\begin{array}{c}\text { Energy of Particle } \\
\text { Emitted (MeV) }\end{array}$ \\
\hline${ }^{32} \mathrm{~S}(n, p){ }^{32} \mathrm{P}$ & 14.28 & 2.9 & 0.0017 (beta) \\
\hline${ }^{58} \mathrm{Ni}(n, p){ }^{58} \mathrm{Co}$ & 70.88 & 1.3 & 0.81 (gamma) \\
\hline${ }^{197} \mathrm{Au}(n, \gamma){ }^{198} \mathrm{Au}$ & 2.7 & Thermal & 0.41 (gamma) \\
\hline
\end{tabular}

The determination of thermal neutron flux density by gold and cadmium covered gold was obtained using the following methodology. This method is accepted in industry, 
and it was discovered as a viable method dating as early as the 1960s in an unclassified document ${ }^{(4)}$. In general, there can be many correction factors that can be applied to the gold foil methodology to improve accuracy of the measurement, and it is left up to the experimenter to make that determination. The specific methodology used to determine the gold foil results in this work is as follows. Assuming a Maxwellian distribution at temperature $\mathrm{T}$ and given the cross-section of natural gold, the group averaged cross-section is given by ${ }^{(29)}$ :

$$
\sigma_{\bar{v}}\left(T_{n}\right)=\sigma_{o} \frac{\sqrt{\pi}}{2} \sqrt{\frac{T_{o}}{T}}
$$

$\mathrm{T}_{\mathrm{o}}=293.61 \mathrm{~K}$

The number of target nuclei is defined by $\mathrm{N}_{\mathrm{T}}$ as:

$$
\mathrm{N}_{\mathrm{T}}=\frac{\mathrm{mw} \mathrm{N}}{\mathrm{A}}
$$

$\mathrm{m}$ - Mass of sample $(\mathrm{g})$

$\mathrm{W}$ - Abundance of target isotope (\%)

A - Mass number of target isotope (amu)

$\mathrm{N}_{\mathrm{a}}$-Avogadro's number $6.022 \times 10^{23}(\mathrm{amu} / \mathrm{g})$

The macroscopic absorption cross-section is defined as:

$$
\Sigma_{\overline{\mathrm{v}}}\left(\mathrm{T}_{\mathrm{n}}\right)=\sigma_{\overline{\mathrm{v}}}\left(\mathrm{T}_{\mathrm{n}}\right) * \mathrm{~N}_{\mathrm{T}}
$$

The cadmium correction factor is used to correct for absorption of neutrons in the cadmium covered gold foil. The equation for this factor is given as:

$$
\mathrm{F}_{\mathrm{Cd}}=\left(1-\frac{\mathrm{A}_{\mathrm{cd}}}{\mathrm{A}_{\mathrm{bare}}}\right)
$$

The following equation corrects for build-up in the gold foil during irradiation:

$$
\mathrm{CF}_{\text {Bup }}=\left(1-\mathrm{e}^{-\lambda \mathrm{t}_{\text {irr }}}\right)
$$

$\lambda$ - Decay constant of ${ }^{198} A u$

The following equation corrects for decay between the removal of the foil from field and the start of the count time:

$$
C F_{\text {decay }}=\left(e^{-\lambda t_{\text {decay }}}\right)
$$


The following equation corrects for decay during the count time:

$$
C F_{\text {sample }}=\frac{\left(1-e^{-\lambda t_{\text {sample }}}\right)}{\lambda t_{\text {sample }}}
$$

The activity induced in the foil by thermal neutron capture is given as:

$$
A_{t h}=\left(A_{\text {bare }}-F_{c d} A_{c d}\right)
$$

The self-shielding correction factor of the gold foils was determined by modeling the gold foil in MCNP. The ratio of the perturbed neutron flux to the unperturbed neutron flux was determined by modeling and it was found to be 0.85 . The following equation was used:

$$
G_{t h}=\frac{\bar{\varphi}_{t h}}{\varphi_{t h}^{o}}
$$

$\bar{\varphi}_{t h}-$ Average Perturbed Thermal Neutron Flux

$\varphi_{t h}^{o}$ - Unperturbed Thermal Neutron Flux

The thermal neutron flux density equation can be obtained using the following equation $^{(4)}(28)$ :

$$
\varphi_{t h}(E<0.5 \mathrm{eV})=\frac{A_{t h}}{\sum_{\bar{v}}\left(T_{n}\right) G_{t h} \mathrm{CF}_{\mathrm{Bup}} C F_{\text {decay }} C F_{\text {sample }}}
$$

Equation 13 only quantifies neutrons for energies less than $0.5 \mathrm{eV}$, the cadmium cutoff from the cadmium cross-section. For convenience, Table VI provides the physical and nuclear constants for gold foils.

Table VI. Physical and Nuclear Constants for Gold Foils

\begin{tabular}{|c|c|c|c|}
\hline$\#$ & Property & Symbol & Value \\
\hline 1 & Density & $\rho$ & $19.32 \mathrm{~g} / \mathrm{cc}$ \\
\hline 2 & Isotopic abundance of ${ }_{79}^{197} \mathrm{Au}$ & & $100 \%$ \\
\hline 3 & Average atomic weight & $\mathrm{A}$ & $196.967 \mathrm{amu}$ \\
\hline 4 & Half-life of ${ }_{79}^{198} \mathrm{Au}$ & $T_{1 / 2}$ & 2.6952 days \\
\hline 5 & Decay constant & $\lambda$ & $0.25721 /$ days \\
\hline 6 & Gamma ray of interest & & $412 \mathrm{keV}$ \\
\hline 7 & $\begin{array}{c}\text { Absorption microscopic } \\
\text { cross-section }\end{array}$ & $\sigma_{a}$ & $98.8 \mathrm{~b}$ (thermal) \\
\hline
\end{tabular}




\section{CHAPTER 4 - METHODOLOGY AND EXPERIMENT}

The objective of this work is to develop the ability to predict the neutron flux density, neutron spectrum, and associated gamma-ray spectrum as a function of location in the neutron irradiation system for any desired shielding or scattering configuration. The methodology used to accomplish this goal will be to model the neutron irradiation system using Monte Carlo N-Particle Code (MCNP), Version 5; to verify the source configuration using computed photon radiography; and to measure the neutron flux density and spectrum at a variety of locations using a variety of instruments and techniques including the N-probe Microspec neutron spectrometer, the Bubble Dosimeter Spectrometer, foil activation; and to measure the gamma-ray spectrum with a High Purity Germanium (HPGe) detector. This chapter will describe how each of these techniques and instruments will help achieve the objective of this work.

\subsection{Monte Carlo N-Particle Model}

The model of the neutron irradiation system was constructed using the MCNP. MCNP can be used for neutron, photon, electron, or coupled neutron/photon/electron transport. It can perform calculations for many applications including, but not limited to, radiation protection, radiation shielding, radiography, nuclear criticality safety, reactor design, etc. MCNP was used to determine the radiation transport throughout the neutron irradiation system, and it was used to verify component orientation inside the Special Form Capsule (SFC). Once validated, the MCNP code can be used to quickly estimate the neutron flux density and spectrum at any point in the system. By use of a validated model, one avoids the necessity of experimentally measuring these locations, which would be labor intensive and require many man-hours to complete. The MCNP model was also used for the parametric analysis whose goal was to find experimental configurations inside the shielding that result in specific average spectral energies and intensities. Details of the construction of the MCNP model follow.

\subsubsection{Geometry and Materials}

The geometry of the neutron irradiation system is relatively simple to model in MCNP. Figure 1 (Chapter 2) was generated using MCNPX Visual Editor (Vised) from the MCNP model of the Low Dose Rate Irradiation Facility (LDRIF) room. The entire 
room was included in the model to determine the neutron radiation field not only inside the neutron shielding but also inside the room. This was done to better simulate the overall environment and to have the capability to evaluate neutron activation of items outside the shielding, if necessary.

The polyethylene shielding was modeled as five slabs. The door material was modeled as borated high density polyethylene, and the remainder of the chamber was modeled high density polyethylene. An iterative method was used to align the MCNP model with the physical representation of the neutron source setup based on the radiography images, which are discussed in Section 4.2.1. The radiography gave guidance on the location of the strongest source, but it did not provide enough information about the other two sources. An assumption was made that that the strongest of the three sources and one of the other sources are at the bottom of the SFC. The remaining source was modeled as stacked on top of these two sources. The metal mount of the shielding door was not modeled in the MCNP model. Transformation cards were used to allow the flexibility to represent the shielding with the door open, closed, or partially open $\left(45^{\circ}\right.$ and $\left.60^{\circ}\right)$. The material compositions for the MCNP model were taken from Pacific Northwest National Laboratory document titled, "Compendium of Material Composition Data for Radiation Transport Modeling." (30) This reference is a tool useful for determining composition of material in MCNP. The alternative source of material compositions was the National Institute of Standards and Technology (NIST) website ${ }^{(31)}$.

\subsubsection{Source Definition}

For each americium-241 beryllium $\left({ }^{241} \mathrm{AmBe}\right)$ component source, the MCNP model activities were taken from the last column of Table I. This information was used to simulate the probability of neutron emission from each source. The neutron energy distribution of the ${ }^{241} \mathrm{AmBe}$ was modeled using the ISO 8529-1989 spectrum (Figure 7). The source definition was formulated for each component source, and each source was modeled as cylinder. Representing each of the component sources separately in the MCNP model (rather than modeling the SFC as the radioactive source) allows the radiation transport within the SFC to be modeled more accurately. Then using MCNP, it is possible to determine the emission rate of the SFC if needed, with the understanding that the source material is not homogenous inside the SFC. From the MCNP model, it 
was possible to obtain the net neutron multiplication from $(n, 2 n)$ reactions in the ${ }^{241} \mathrm{AmBe}$ sources, and it was determined to be 1.021 indicating a $2 \%$ increase in the neutron population.

\subsubsection{Detector, Mesh, and Surface Tallies}

The total emission rate for all composite sources within the SFC is $2.0 \times 10^{7} \mathrm{n} / \mathrm{s}$. This value was used as a multiplier for all the tallies in the MCNP model of the neutron irradiation system. An activity-to-emission rate conversion factor of $2.2 \times 10^{6} \mathrm{n} / \mathrm{s} / \mathrm{Ci}{ }^{(7)}$ (32) was used to determine the emission rate for each component source. All neutron flux density tallies, in particular F4 tallies, were modeled for a sphere with $1 \mathrm{~cm}$ radius to simulate the flux density at point near the measurement locations. A F5 tally was used to determine the self-shielding correction factor of gold foils (Equation 12) for the neutron foil activation technique described in Section 3.5. It was also used to determine the neutron flux density incident on the foil, and this is the flux density found in Table XIII. For the dose tallies, the DF and DE cards were used to assign the dose conversion factors (DCFs) to the output. For the biological dose rates (effective dose rates), ICRP-74 H*(10) neutron and photon DCF coefficients were used ${ }^{(33)}$. The energy binning used to represent the distribution of flux density throughout the calculations followed the energy binning from ICRP-74. The effective and absorbed dose rates were also determined using the DF and DE cards. The FMESH card allows the user to define a mesh tally superimposed over the problem geometry. The FMESH card was used to determine the neutron and photon flux density throughout the polyethylene shielding up to $30 \mathrm{~cm}$ from the door and the side walls. Tally cards FIR and FIC were used for the radiography, and they are further discussed in the radiography results section.

\subsection{Instrumentation Used in Model Benchmarking}

The instrumentation used in the experiment is presented in this section. Brief description, design, and limitations are provided for each instrument used for the characterization. All hardware and software used are also listed, and purpose of use for the instrument is also stated. 


\subsubsection{Computed Photon Radiography}

To appropriately represent the source in the MCNP model, computed photon radiography was used to understand the distribution of radioactive material within the SFC. The Portable Computed Radiography Scanner, model CR 50P from GE Inspection Technologies with special flexible phosphor imaging plates (IPs) was used to provide rapid images for radiography analysis. The flexible phosphor IPs allow for any needed geometry of analysis, such as wrapping around a cylindrical source. The IPs ability to instantaneously erase the image and to reuse them was beneficial to the characterization of the source. The Rhythm software provided rapid data analysis by quickly contrasting and adjusting images to bring out important features of the radiograph. Combination of these features made computed radiography a tool useful for the characterization of the source, specifically the source components.

Two IPs were used in the measurements. The primary IP had dimensions of $19.7 \mathrm{~cm} \times 26.7 \mathrm{~cm}$ with a plate thickness of $605 \mu \mathrm{m}$. This IP was used for most of the measurements by wrapping it around the source. A secondary IP made of similar material and of the same thicknesses was also used. Its dimensions were $40.7 \mathrm{~cm} \times 35.0 \mathrm{~cm}$. The secondary IP was placed next to the source as confirmatory measurement to verify the image of the primary IP. The photon radiography system used is shown in Figure 18 with one of the IP loaded on the scanner.

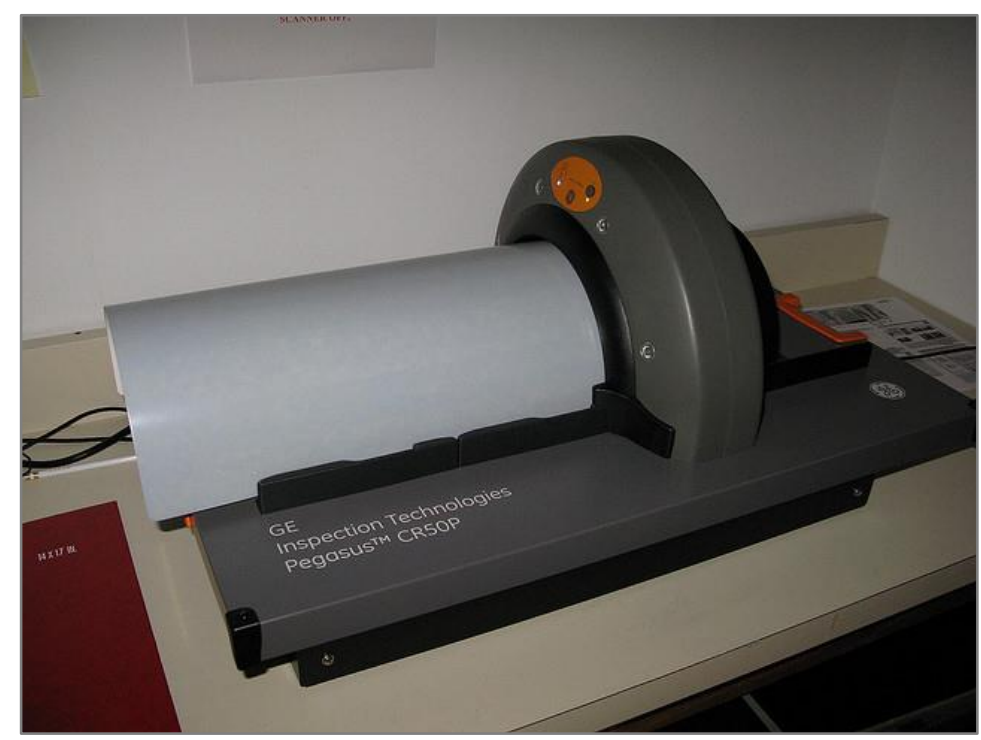

Figure 18. Portable Computed Radiography Scanner Model CR 50P ${ }^{(34)}$ 
The following radiography equipment was used to determine the source orientation:

- GE Inspection Technologies, Pegasus ${ }^{\mathrm{TM}}$ CR50P computed radiography imaging plate scanner

- Laptop with GE Rhythm ${ }^{\circledR}$ Acquire, version 4.0.30.0 and GE Rhythm ${ }^{\circledR}$ Review, Version 2.2 software

- Kodax Industrex Flex GP S-170 phosphor IPs

\subsubsection{High Purity Germanium Gamma Spectrometer}

A HPGe detector was used to determine the background gamma radiation spectrum from the neighboring gamma shielding, which is co-located with the neutron irradiation system. The gamma spectrum of the neutron source was also obtained by the HPGe detector. The instrument chosen for this purpose was Canberra Industries coaxial germanium N-type detector, which is relatively resistant to neutron damage on the crystal.

In general, N-type detectors are more resistant to neutron damage than P-type germanium detectors, therefore, this detector allowed for longer irradiation time at a given location, resulting in reduced uncertainties. The gamma-ray spectroscopy system consisted of the detector and the Canberra InSpector 2000 Multichannel Analyzer (MCA). With an InSpector 2000, the digital MCA allows for dead time correction up to $50 \%$ with accuracy up to $5 \%$ at that system dead time ${ }^{(35)}$. Also this HPGe detector was chosen over sodium iodide $(\mathrm{NaI})$ or any other gamma instrument due to the higher resolution. HPGe detectors have a 20 to 30 times better resolution than NaI detectors ${ }^{(36)}$. The MCA provides a broad-window range of photon visibility, up to 64 thousand channels, and it also allows adjustment of gamma-ray energy window to a relatively high energy. The gamma-ray spectroscopy system used in this project is shown in Figure 19. 


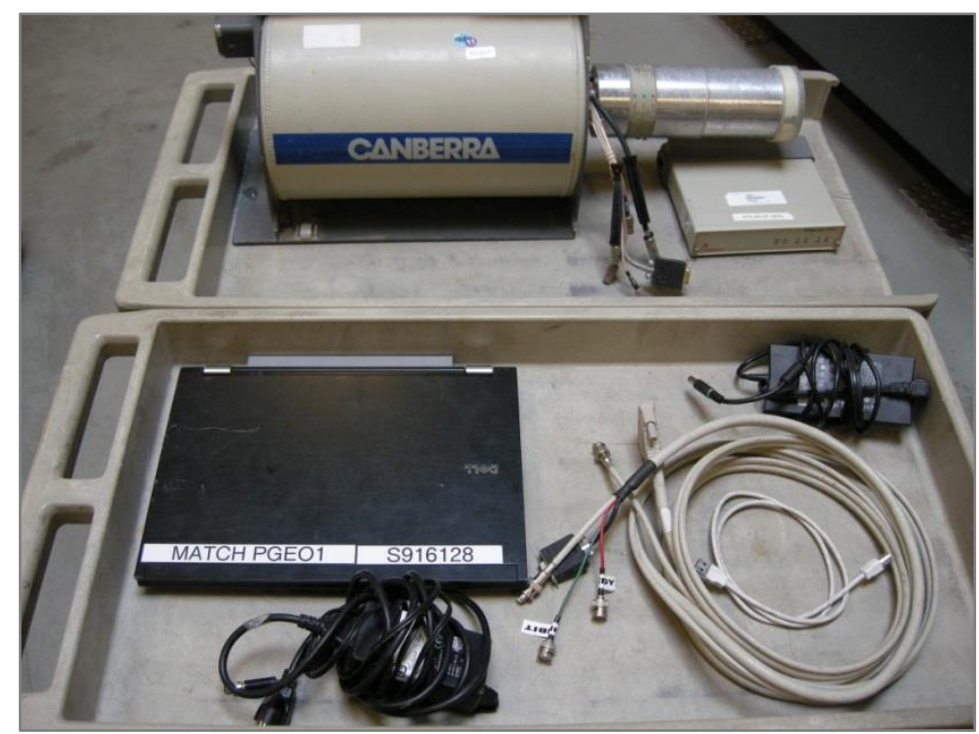

Figure 19. HPGe Gamma Spectroscopy System

The following Canberra equipment was used to determine the background and neutron source photon spectra:

- HPGe N-type detector with $50 \%$ efficiency crystal

○ Crystal Dimensions $64 \mathrm{~mm} \times 39 \mathrm{~mm}$ (diameter $\times$ length)

- InSpector 2000 Digital Signal Processing

- Composite Detector Cables

○ Preamp power (9-pin D), Energy, HV Inhibit, BNCs, High Voltage (SHV)

- Computer Cables

- RS-232, USB, MCS Cable

- $\quad$ Laptop with spectroscopy software Genie 2000 Version 3.2.1

\subsubsection{N-Probe Microspec Neutron Spectrometer}

The N-probe Microspec neutron spectrometer was used to determine neutron spectra of the source at distances of $122 \mathrm{~cm}$ and greater from the source. The N-Probe Microspec can only be exposed to up to $200 \mu \mathrm{Sv} / \mathrm{hr}(20 \mathrm{mrem} / \mathrm{hr}$ ) without suffering too much dead time; for greater dose rates the accuracy of the measurement would decrease ${ }^{(37)}$. This instrument was manufactured by Bubble Technology Industries (BTI). The N-Probe Microspec uses a combination of two neutron detectors: a liquid scintillator, NE213 consisting mostly of hydrogen and carbon, and a ${ }^{3} \mathrm{He}$ spherical gas counter 
encased within a ${ }^{10} \mathrm{~B}$ shield. These two separate detectors cover a neutron energy range from $10^{-8} \mathrm{MeV}$ to $20 \mathrm{MeV}$. The $\mathrm{N}$-Probe contains a $5 \mathrm{~cm} \times 5 \mathrm{~cm} \mathrm{NE} 213$ type liquid scintillator, which measures energies from $800 \mathrm{keV}$ to $20 \mathrm{MeV}$. The special ${ }^{3} \mathrm{He}$ gas proportional counter encased within a ${ }^{10} \mathrm{~B}$ shield measures energies from thermal up to $800 \mathrm{keV}$. Sophisticated pulse-shape discrimination rejects unwanted photons up to a gamma-ray to neutron rejection ratio of approximately 1000:1 ${ }^{(37)}$.

The software for neutron spectral deconvolution is proprietary. The NE213 output is binned into 13 energy groups, and the ${ }^{3} \mathrm{He}$ is binned into four energy groups. Thus, the Microspec has a total of 17 energy bins ${ }^{(25)}$. The instrument manual states the dose rate sensitivity range is from $<1$ to $200 \mu \mathrm{Sv} / \mathrm{hr}(<0.1$ to $20 \mathrm{mrem} / \mathrm{hr}$ ). The $\mathrm{N}$-Probe software has the ability to determine the kerma, dose equivalent NCRP-38 ${ }^{(38)}$, and ambient dose equivalent, $H^{*}(10)$ ICRP-74 ${ }^{(33)}$. The dose rate feature of the Microspec is useful for relating the measured dose rate to the MCNP results and to other instrument readings. The Microspec has proven to be an instrument useful for the characterization of the source, and it is shown in Figure 20. The N-probe Microspec is in the top left of the figure.

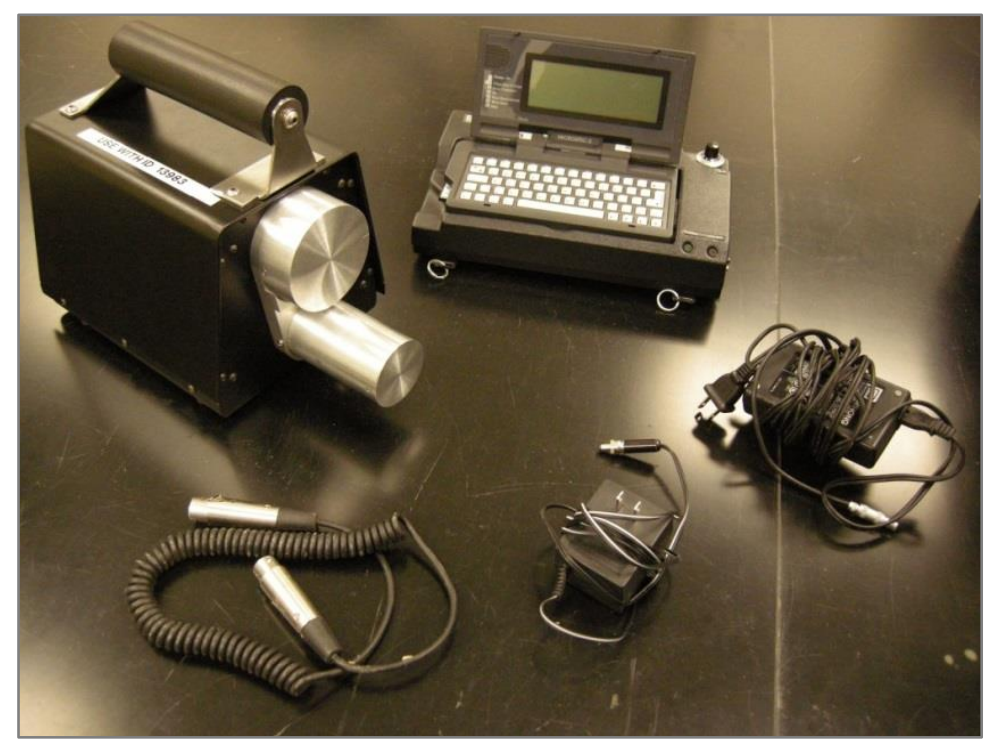

Figure 20. N-Probe Microspec Neutron Spectrometer

The following is a list of equipment used to determine the neutron spectrum using the N-Probe Microspec: 
- Analyzer

- Mircrospec -2

- Palmtop computer with Nview Software

- Flash card

- N-probe

- High voltage module

- Organic liquid scintillator with photomultiplier tube and ${ }^{3} \mathrm{He}$ gas counter with boron shield and preamplifier

- Pulse shape discrimination electronics

○ Signal multiplex electronics

- Signal Cable

- Retractile cable with a XLR connector for the analyzer

- A Bendix connector for the probe

- Charger for

- Analyzer module batteries

- The N-Probe batteries

\subsubsection{Neutron Bubble Dosimeter Spectrometer}

The Bubble Dosimeter Spectrometer (BDS) set was used to determine neutron spectra at various locations within the polyethylene shielding out to a distance of $122 \mathrm{~cm}$ from the source. Thus, the BDS measurements complemented those obtained with N-probe Microspec, which could not be used in close proximity to the source due to its sensitivity limitations, and included one overlapping point at $122 \mathrm{~cm}$.

The BDS was also manufactured by BTI. BDS contain gels with superheated vapors, which are engineered to be sensitive to different neutron energies. The BDS tubes of various sensitivities can be used as one spectrometer set. There are six detectors of each of six different energy thresholds for a total of 36 tubes in the set. The different energy thresholds provided are 10, 100, 600, 1000, 2500, and $10000 \mathrm{keV}$. The sensitivities of these tubes are between 0.1 bubbles $/ \mu \mathrm{Sv}$ and 0.2 bubbles $/ \mu \mathrm{Sv}$ ( 1 bubbles/mrem to 2 bubbles/mrem) ${ }^{(39)}$. 
During irradiation the BDS must be kept at a temperature of $20 \pm 0.5^{\circ} \mathrm{C}$, otherwise the measurements are biased due to temperature sensitivities. Once the tubes are irradiated, the bubbles must be counted to determine the neutron spectrum. Following the count, the bubbles inside the BDS are removed using the bubble recompression chambers (to zero the detector set). During storage, the tubes must be kept at $6^{\circ} \mathrm{C}$, and their reuse is limited to three months according to the manufacturer. The algorithm used by this instrument is Excel spreadsheet-based, and it is provided by BTI, which applies spectral stripping to deconvolve the spectrum ${ }^{(39)}$. The total count of each the bin is determined, and it is iteratively subtracted as the calculation progresses to the lower energy bins. The BDS set to be used in this project is shown in Figure 21 (image to the left). The bubble recompression chambers and cooler are presented in Figure 21 as well (image to the right). The other equipment used in conjunction with the BDS set is shown in Figure 22.
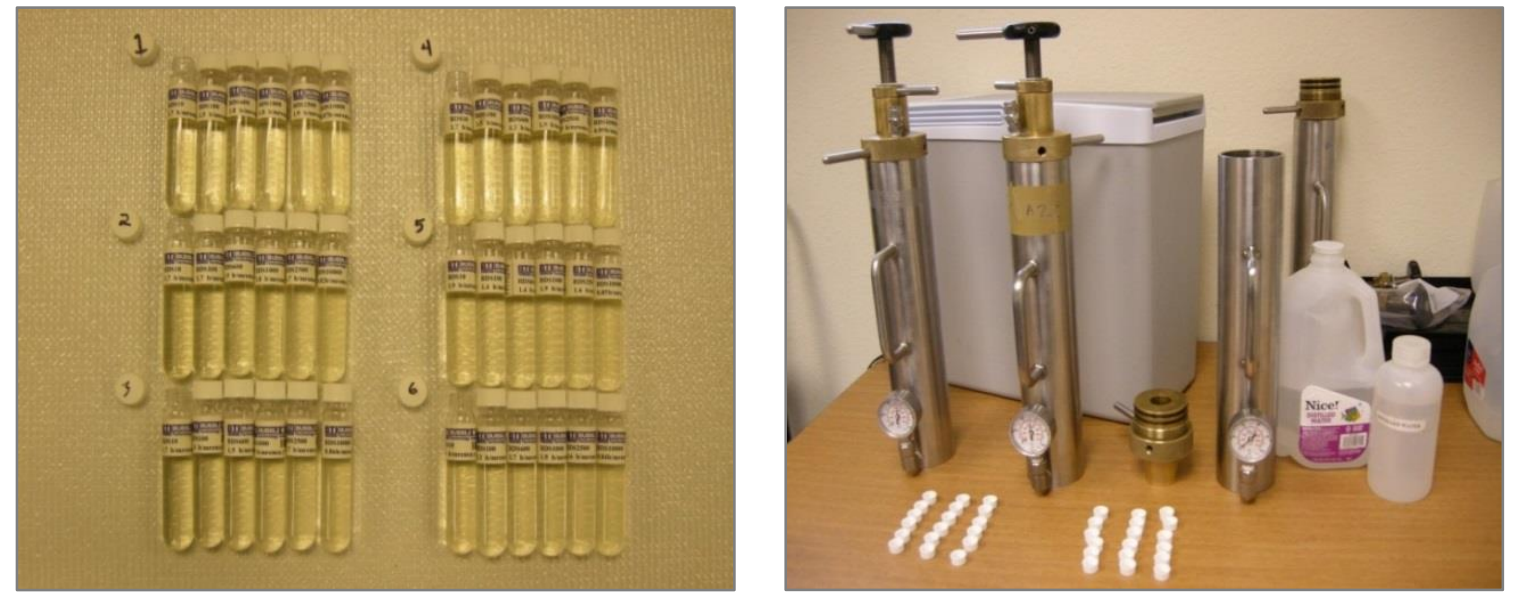

Figure 21. Bubble Detector Spectroscopy Set and Miscellaneous Equipment 

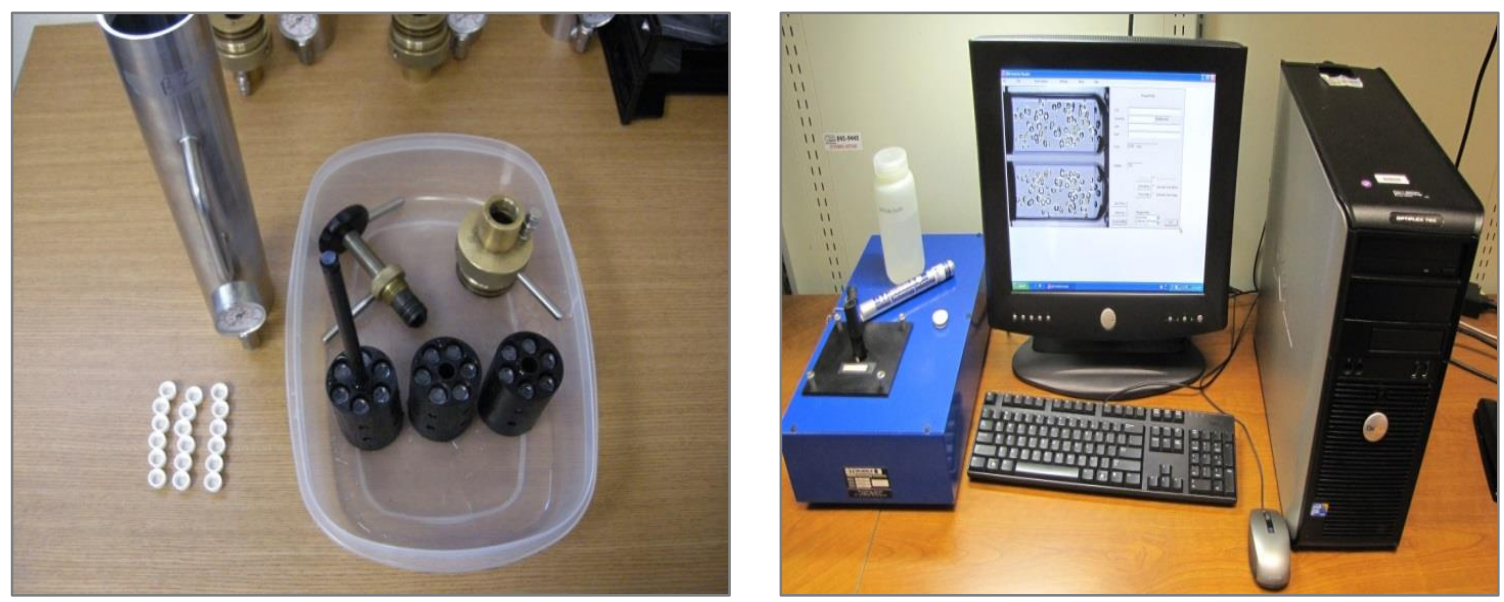

Figure 22. BDS Recompression Shielding and Reader/Bubble Counting Software

The following equipment was used to determine the neutron spectrum. All the equipment is from Bubble Technology Industries.

- $\mathrm{BDS}^{\mathrm{TM}}$ Bubble Detector Spectrometer Set

- $\quad$ RC-18 Recompression Chambers

- BDR-III Automatic Bubble Reader

- Bubble Detector Bubble Counter Software

- Unfolding Bubble Detector Software

- Distilled ionized water

- Cooler capable of providing the $20^{\circ} \mathrm{C}$ environment

\section{$\underline{4.2 .5}$ Neutron Foil Activation}

Foil activation was used as a supplemental method to obtain spectral information about the neutron source. Three different foils were initially selected: nickel, sulfur, and gold. An additional gold foil with a cadmium layer was also used to filter the thermal neutrons. These foils were selected to give a coarse evaluation of the neutron energy spectrum from thermal energies to several $\mathrm{MeV}$. All of the foils were $0.025 \mathrm{~cm}$ thick, and they all have a radius of $0.75 \mathrm{~cm}$. Predictions of expected induced activities suggest that the neutron flux density may not be sufficiently strong to activate the foils to measureable levels. 


\subsection{Experimental Procedures}

This section describes measurement locations and instrument usage at specified locations. The dates and times the experiments were performed are provided. Details on how the measurements were taken and any anomalies during the measurements are also described.

\subsubsection{Measurement Locations}

This section describes the experimental setup and measurement locations to be used in the benchmarking of the MCNP model. Figure 23 presents a cross-sectional view of the south cell at the LDRIF, showing the location of the polyethylene shielding with the neutron source and the gamma shielding. The experimental locations inside and outside the shielding (with shielding door closed and open) are identified in Figure 24. These locations indicate where the N-Probe Microspec, BDS set, and activation foils were placed to obtain measurements for benchmarking the MCNP model. It was not possible to place all instruments at all locations. Rather, they were placed as their sensitivity limits permitted. For instance, the HPGe detector could only be used outside the shielding with the door open due to dead time limitations and the desire to minimize potential neutron damage to the detector. For each lettered location, Table VII describes the distance from the source and the detection methods used at each respective location.

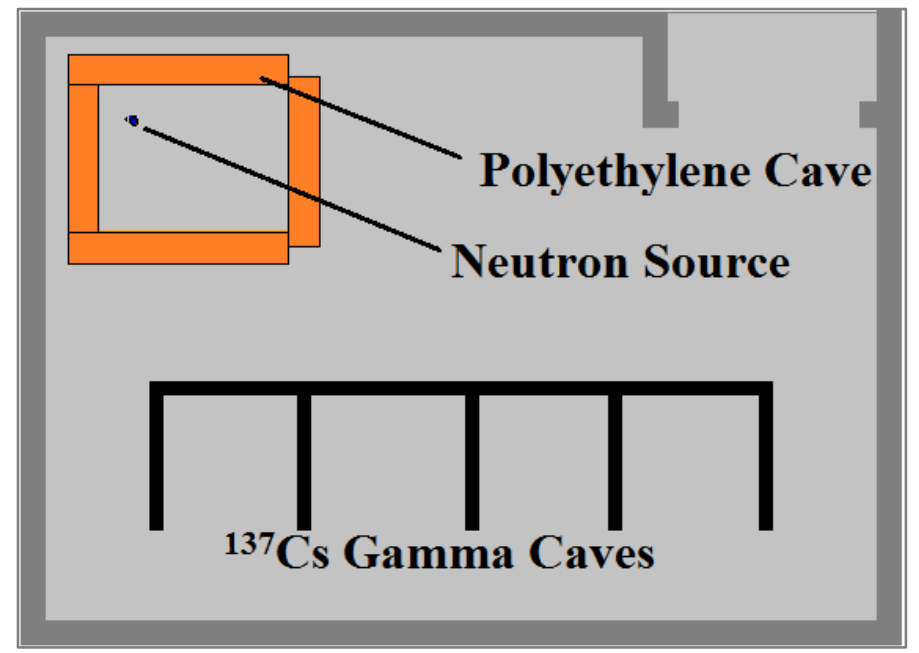

Figure 23. Aerial Cross Sectional View of LDGIF South Cell 

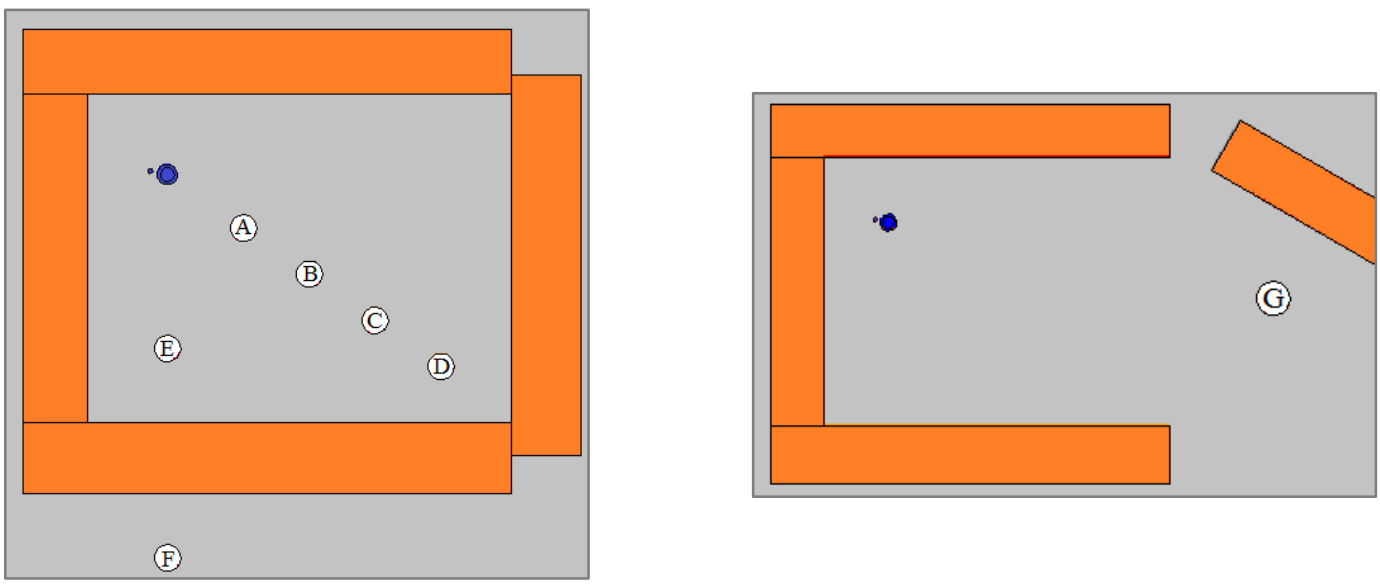

Figure 24. Measurement Locations with Door Closed and Open

Table VII. Measurement Locations and Methods Inside and Outside the Shielding

\begin{tabular}{|c|c|c|}
\hline Location & $\begin{array}{c}\text { Distance from } \\
\text { Source }(\mathbf{c m})\end{array}$ & Detection Method \\
\hline A (inside) & 30 & Activation Foils/ Bubble Detectors \\
\hline B (inside) & 61 & Bubble Detectors \\
\hline C (inside) & 91 & Bubble Detectors \\
\hline D (inside) & 122 & Bubble Detectors/ Microspec \\
\hline E (inside) & 61 & Bubble Detectors \\
\hline F (outside) & 145 & Microspec \\
\hline G (outside) & 183 & Microspec/ HPGe Detector \\
\hline
\end{tabular}

\subsubsection{Procedures}

\section{Radiography}

A total of six separate exposures were taken on the IPs for the radiography on $11 / 21 / 2013$. The primary IP was wrapped around the source. The first exposure was 60 seconds in duration, and it produced an image with intensity levels just above background noise. Subsequent exposures were taken for about 10 minutes, which produced useful results. During the last three exposures, a larger flat IP was placed behind the primary IP. It was centered on the source hotspot which was identified in the previous exposures. This second plate confirmed that the image of the hotspot on the primary IP was not an anomaly. The last image produced the best results, and it was used to mark the hot range on the source capsule. 
In the last trial, the primary IP was positioned so that the bottom edge would be aligned with the bottom of the source capsule. The images were exposed for 11 minutes. Lead numbers were taped around the source to identify direction on the primary IP. The images were used to obtain an understanding of the directionality and positioning of the ${ }^{241} \mathrm{AmBe}$ source components inside the SFC. The images assisted in an iterative process of adjusting the source within the MCNP model to best simulate the actual source geometry.

\section{Gamma Spectroscopy}

The HPGe detector was placed outside the shielding at location $\mathrm{G}(1.83 \mathrm{~m}$ from the source) facing the hot spot. Before the HPGe detector was used, preliminary measurements were taken using Portable Survey Neutron REM Meter Model E-600/NRD and the Microspec to determine the dose rate and the neutron flux density. This was done to ensure that the HPGe detector placement was such as to minimize crystal degradation from the fast neutrons. At location G, the REM Meter measured $125 \mu \mathrm{Sv} / \mathrm{hr}$ (12.5 mrem/hr), which was less than the upper threshold limit of the Microspec. The Microspec data showed the neutron flux density at location $G$ to be $120 \mathrm{n} / \mathrm{cm}^{2} / \mathrm{s}$. This intensity was adequate for the gamma measurement. The gamma spectroscopy count was taken for a total of 225.6 seconds, or 126.42 live-time seconds. The initial count time duration was 300 seconds, live-time seconds, but fear of over exposure to the germanium lead to an early termination of the measurement. Dead time for this measurement was at about $41 \%$. For the dead time correction, Canberra states ${ }^{(35)}$ "the accuracy of reference peak area is $5 \%$ (3\% typical) at up to $50 \%$ system dead time with a setting of $5.6 \mu$ s rise time and $0.8 \mu$ s flat top."

The total fluence on the germanium crystal for fast neutrons (energy greater than $10 \mathrm{keV}$ ) was $2.71 \times 10^{4} \mathrm{n} / \mathrm{cm}^{2}$ based on the Microspec measurement. This is much less than the fluence threshold before energy resolution degradation occurs ${ }^{(2)}$, which is $\sim 1.0 \times 10^{9} \mathrm{n} / \mathrm{cm}^{2}$. The summary of the HPGe detector measurement details is presented in Table VIII. 
Table VIII. HPGe Detector Measurement Details

\begin{tabular}{|c|c|c|c|c|}
\hline $\begin{array}{c}\text { Measurement } \\
\text { Number }\end{array}$ & Date & Duration of Exposure & Distance & Location \\
\hline 1 & $12 / 11 / 13$ & $\begin{array}{c}126.42 \mathrm{~s} \text { (live time) } \\
225.62 \mathrm{~s} \text { (real time) }\end{array}$ & $183 \mathrm{~cm}$ & $\mathrm{G}$ (door open) \\
\hline
\end{tabular}

\section{Microspec Neutron Spectroscopy}

The N-Probe Microspec was placed in two different locations with the door closed and one location with the door open. The locations with the door closed are D and $\mathrm{F}, 122 \mathrm{~cm}$ and $144 \mathrm{~cm}$ from the source, respectively. Location D was the farthest point from the source in the shielding, centerline to the hotspot. It was decided to make location $\mathrm{D}$ the pivotal point for the neutron measurements. The measurement at location $\mathrm{F}$ was made to determine how the neutrons propagated through the polyethylene wall. The third location was outside of the shielding with the door open at point G, $182 \mathrm{~cm}$ from the source, between the door and the opening of the irradiation system. A summary of the N-Probe Microspec measurement details is presented in Table IX. The measurement number five at location $\mathrm{F}$ was the longest in duration because it was outside of the irradiation system behind a polyethylene wall, and additional time was needed for good statistics.

Table IX. N-Probe Microspec Measurement

\begin{tabular}{|c|c|c|c|c|}
\hline $\begin{array}{c}\text { Measurement } \\
\text { Number }\end{array}$ & Date & Duration (s) & Distance (cm) & Location \\
\hline 1 & $12 / 11 / 13$ & 152 & 122 & D (door closed) \\
\hline 2 & $12 / 11 / 13$ & 148 & 122 & D (door open) \\
\hline 3 & $12 / 11 / 13$ & 292 & 183 & G (door open) \\
\hline 4 & $5 / 2 / 14$ & 301 & 122 & D (door closed) \\
\hline 5 & $5 / 2 / 14$ & 3,828 & 145 & F (door closed) \\
\hline 6 & $5 / 2 / 14$ & 301 & 122 & D (door closed) \\
\hline
\end{tabular}

\section{Bubble Detector Spectroscopy}

Because the BDS are not as sensitive as the Microspec, they were placed closer to the source. The BDS were placed every $30 \mathrm{~cm}$ (locations A through E) from $30 \mathrm{~cm}$ to $122 \mathrm{~cm}$ from the source. During irradiations, the BDS were kept inside the cooler at a constant temperature of $20^{\circ} \mathrm{C}$. The bubble detectors had to be irradiated long enough to 
generate more than 75 bubbles but not more than 200 bubbles in each of the tubes for all energy ranges. This was necessary to obtain good statistics for the deconvolution software. The numbers of bubbles were determined using the bubble reader and counting software. After the number of the bubbles was determined, the tubes had to immediately be recompressed to avoid the expansion of the bubbles and potential ripping of the gel. The BDS were recompressed using the recompression chamber. The BDS were recompressed using pressures up to $4.14 \mathrm{MPa}$ (600 psi) for at least 45 minutes. If all of the bubbles did not recompress, longer times were used. This was done weekly, regardless of the BDS use, as recommended by BTI. The details of the BDS measurements are provided in Table X. Measurement number five at location E was performed "on the side" meaning directly south of the source, rather than southeast.

Table X. BDS Measurements

\begin{tabular}{|c|c|c|c|c|}
\hline $\begin{array}{c}\text { Measurement } \\
\text { Number }\end{array}$ & Date & Irradiation Time & $\begin{array}{c}\text { Distance from } \\
\text { Source }(\mathbf{c m})\end{array}$ & Location \\
\hline 1 & $1 / 29 / 14$ & $20 \pm 0.25 \mathrm{~min}$ & 30 & $\mathrm{~A}$ \\
\hline 2 & $1 / 29 / 14$ & $2.667 \mathrm{hr} \pm 30 \mathrm{~s}$ & 122 & $\mathrm{D}$ \\
\hline 3 & $2 / 5 / 14$ & $3.5 \mathrm{hr}$ & 122 & $\mathrm{D}$ \\
\hline 4 & $2 / 19 / 14$ & $50 \pm 1 \mathrm{~min}$ & 61 & $\mathrm{~B}$ \\
\hline 5 & $2 / 26 / 14$ & $1 \mathrm{hr} \pm 30 \mathrm{~s}$ & 61 (on side) & $\mathrm{E}$ \\
\hline 6 & $2 / 26 / 14$ & $2 \mathrm{hr} 5 \mathrm{~min} \pm 30 \mathrm{~s}$ & 91 & $\mathrm{C}$ \\
\hline 7 & $3 / 11 / 14$ & $2 \mathrm{hr}$ and $5 \mathrm{~min} \pm 30 \mathrm{~s}$ & 91 & $\mathrm{C}$ \\
\hline
\end{tabular}

\section{Foil Activation}

Four different foils were placed at position A, which was $30 \mathrm{~cm}$ from the source centerline, to determine if foil activation was a viable method for neutron field characterization. The four foils consisted of a gold foil, a cadmium-covered gold foil, a nickel foil, and sulfur pellet. After one week of irradiation, they were pulled out, and they were counted via gamma spectroscopy and gross alpha/beta. The times and dates of actions performed on the foil measurements are presented in Table XI. 
Table XI. Activation Foil Measurement Time and Dates

\begin{tabular}{|l|c|}
\hline Event & Dates and Times \\
\hline Irradiation start time & $1 / 15 / 2014,15: 00$ \\
\hline Irradiation end time & $1 / 22 / 2014,13: 00$ \\
\hline Gold foil count start time & $1 / 23 / 2014,15: 32$ \\
\hline Gold foil count end time & $1 / 24 / 2014,5: 26$ \\
\hline Cadmium-covered gold foil count start time & $1 / 23 / 2014,16: 11$ \\
\hline Cadmium-covered gold foil count end time & $1 / 24 / 2014,6: 04$ \\
\hline
\end{tabular}




\section{CHAPTER 5 - RESULTS}

Chapter five presents the modeling and experimental results, which were obtained using multiple measurement techniques. Throughout the chapter the measurements are compared with the corresponding quantities obtained from the Monte Carlo N-Particle (MCNP) model of the neutron irradiation system (the combined source and polyethylene shielding) for model validation.

\subsection{Computed Photon Radiography}

Computed photon radiography was used to determine the location of the component sources inside the Special Form Capsule (SFC) and the directionality of the source. This technique relies on photons producing an image on the image plates (IPs). The photon radiation emitted from the source was used as a surrogate of the neutron radiation, which was assumed to have the same spatial distribution.

\subsubsection{Radiography Image Scaling}

MATLAB was used to perform image processing on the radiography data from the tally results from MCNP and on the experimental images obtained from computed photon radiography. The intensity of the radiographs was normalized to highest intensity value (100\%). The plane containing the highest intensity point is referred to hereafter as the normalization plane. The length and width of the images were scaled to the actual physical dimensions of the IPs. All the images were scaled accordingly, so that proper comparison could be done.

\subsubsection{Primary Imaging Plate Comparison}

It was expected that the radiography would give sufficient resolution to determine the orientation of each component source inside the SFC. Some of the resolution was lost due to the photon attenuation in the stainless steel, but the intensity was sufficient to produce adequate images. Computed photon radiography is a technique used for photon imaging, and the magnitude of the neutron interaction with the IPs, if any, is not known. However, it can be assumed that the strongest neutron emission would be in the same region as the strongest photon emission. For the primary IP, the bottom of the IP was aligned with the bottom of the capsule. Lead numbers were taped around the capsule 
about $2.5 \mathrm{~cm}$ apart from each other as indicators, and then the IP was wrapped around the capsule. The lead numbers were used to mark the orientation of the IP relative to the source to determine the source directionality. Figure 25 shows the image from the primary IP. The lead numbers are also visible in the image.

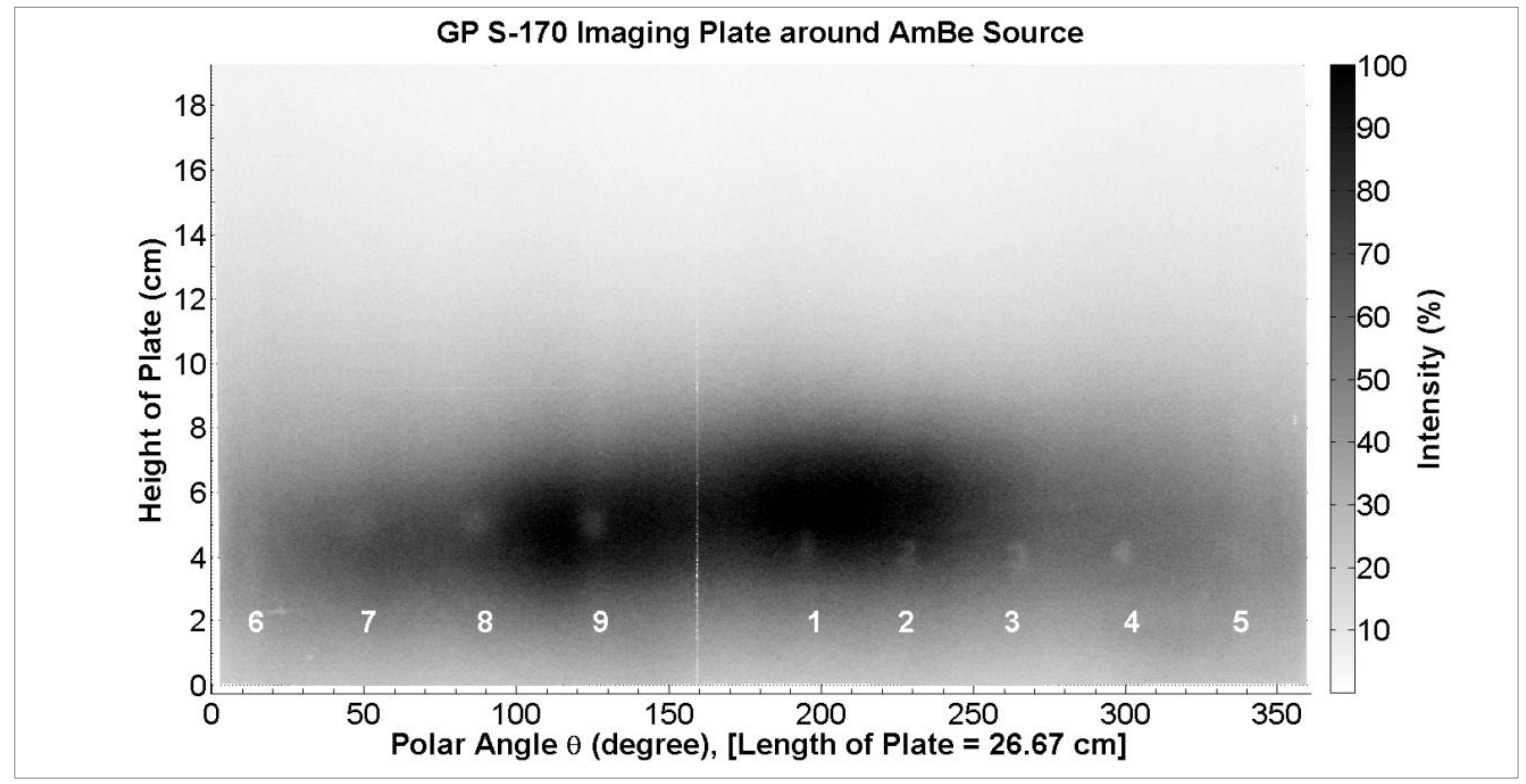

Figure 25. Experimental Imaging Plate obtained by Primary Phosphor IP

A white vertical line can be identified at about 160 degrees. This is the edge of the IP. Lead numbers from one to four are barely visible, and the remaining lead numbers are smeared. Therefore, the numbers were marked below the smeared numbers. The darkest regions in Figure 25 are between the numbers one and two, and the numbers eight and nine. These two regions of the highest intensity indicate which part of the source has the highest photon (and neutron) emissions. This range is between 90 degrees and 250 degrees, or between numbers eight and three respectively. This corresponds to about 160 degrees. The height of the hot spot is approximately $5.5 \mathrm{~cm}$ from the base of the IP and the source.

An MCNP radiography model was generated using the FIC (Flux Image on Cylinder) tally. A cylindrical radiography image was simulated to align the experiment with the model. In the model, the image was wrapped around the SFC at the bottom, similar to how the experiment was performed. The component sources in the model were moved around inside the SFC, in an iterative manner, to obtain the best match with the 
experimental radiography image until the model matched the experiment. The modeled radiography image is shown in Figure 26.

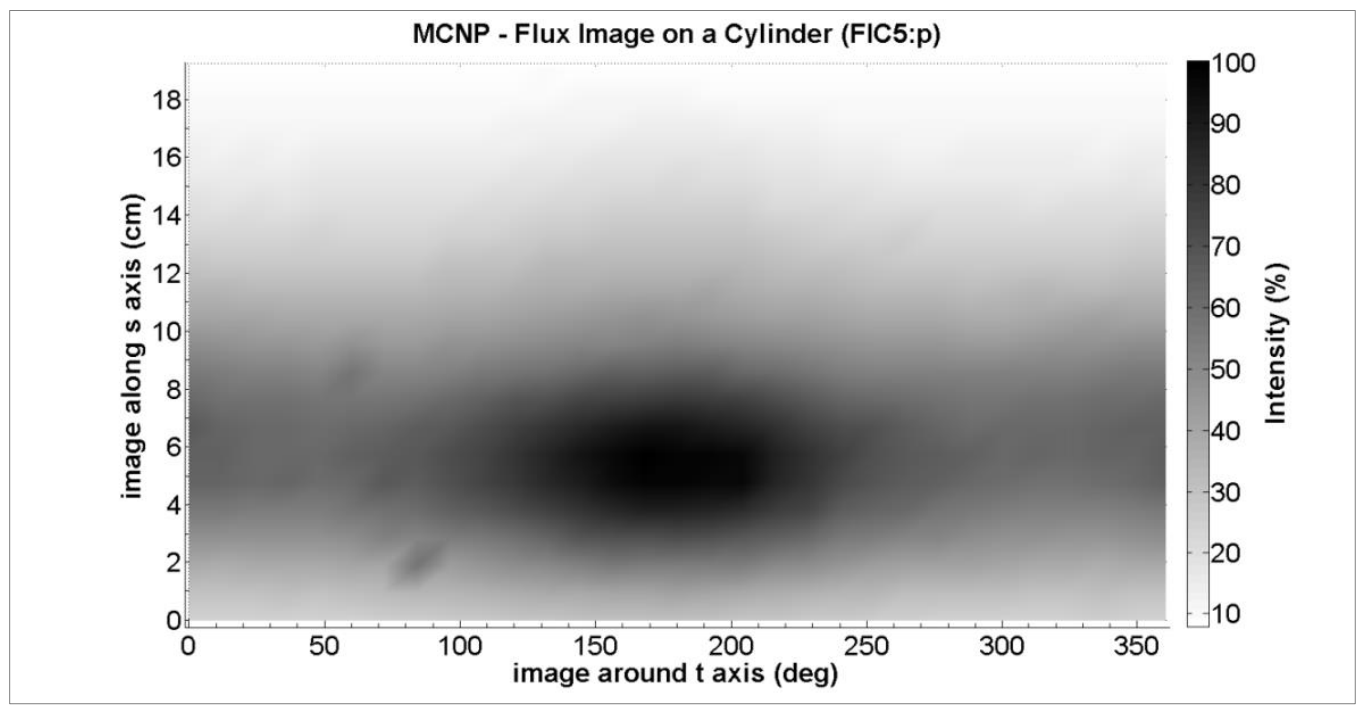

Figure 26. MCNP Model of the Cylindrical Imaging Plate

In the MCNP radiography model, a hot spot range can be seen between 110 degrees and 230 degrees. This is approximately 120 degrees. The height of the hot spot is approximately $5.5 \mathrm{~cm}$ from the bottom of the modeled SFC. The modeled image matches the experimental image well. Further analysis of the images reveals more details about the component sources. Image processing reveals some insight about the orientation, as shown in the horizontal view across the normalization plane in Figure 27.

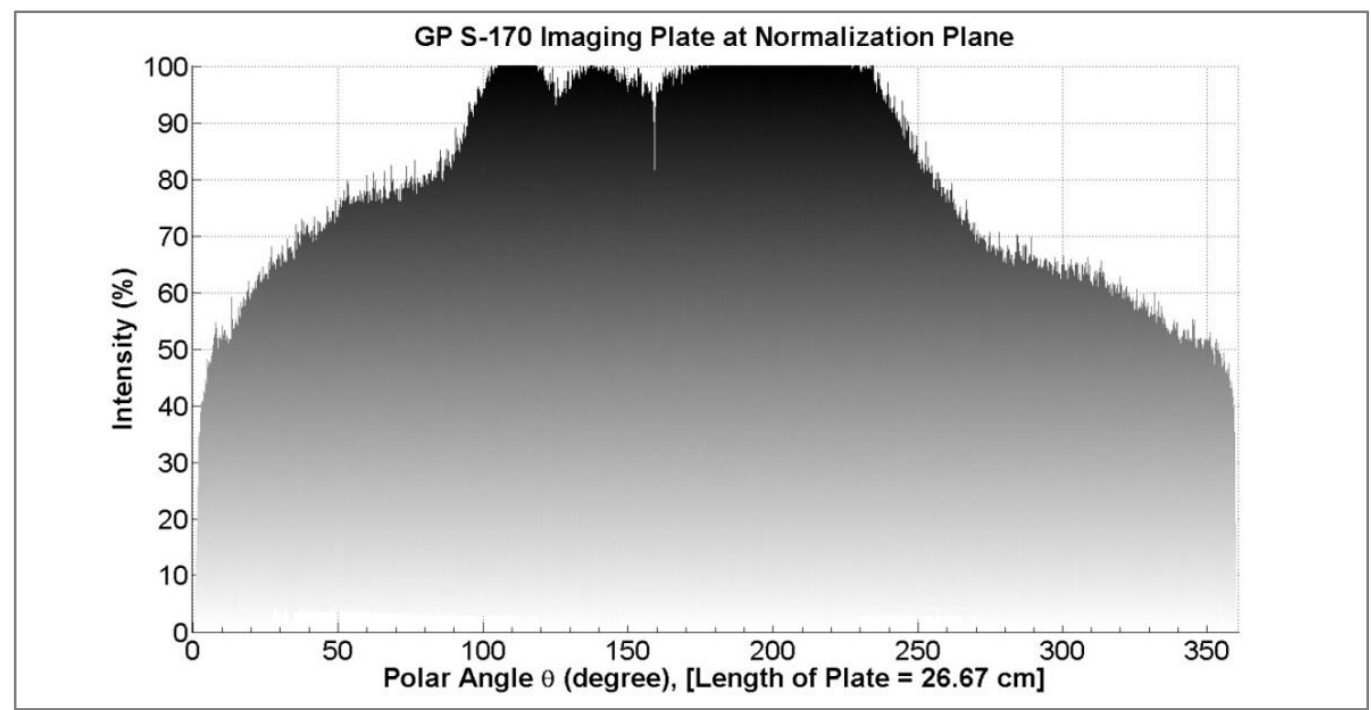

Figure 27. Horizontal View of the Measured Intensity at Normalization Plane 
Figure 27 is the experimental radiography image intensity across the horizontal normalization plane. Again, the IP saturation range can be seen from 90 to 250 degrees, and the discontinuity from the IPs can be seen at 160 degrees. Also, the intensity suppression from one of lead numbers occurs at 125 degrees. It can be concluded from the experimental radiography image that the areas of the highest intensity are not spots, but rather they extend over approximately 180 degree range. From this image, it can be concluded that the strongest source is located at the bottom of the SFC tucked on one side, sharing half of the space in the SFC with one of the other component sources. The radiography image from the model can be analyzed in a similar fashion. Figure 28 shows the horizontal normalization plane of the modeled radiography image.

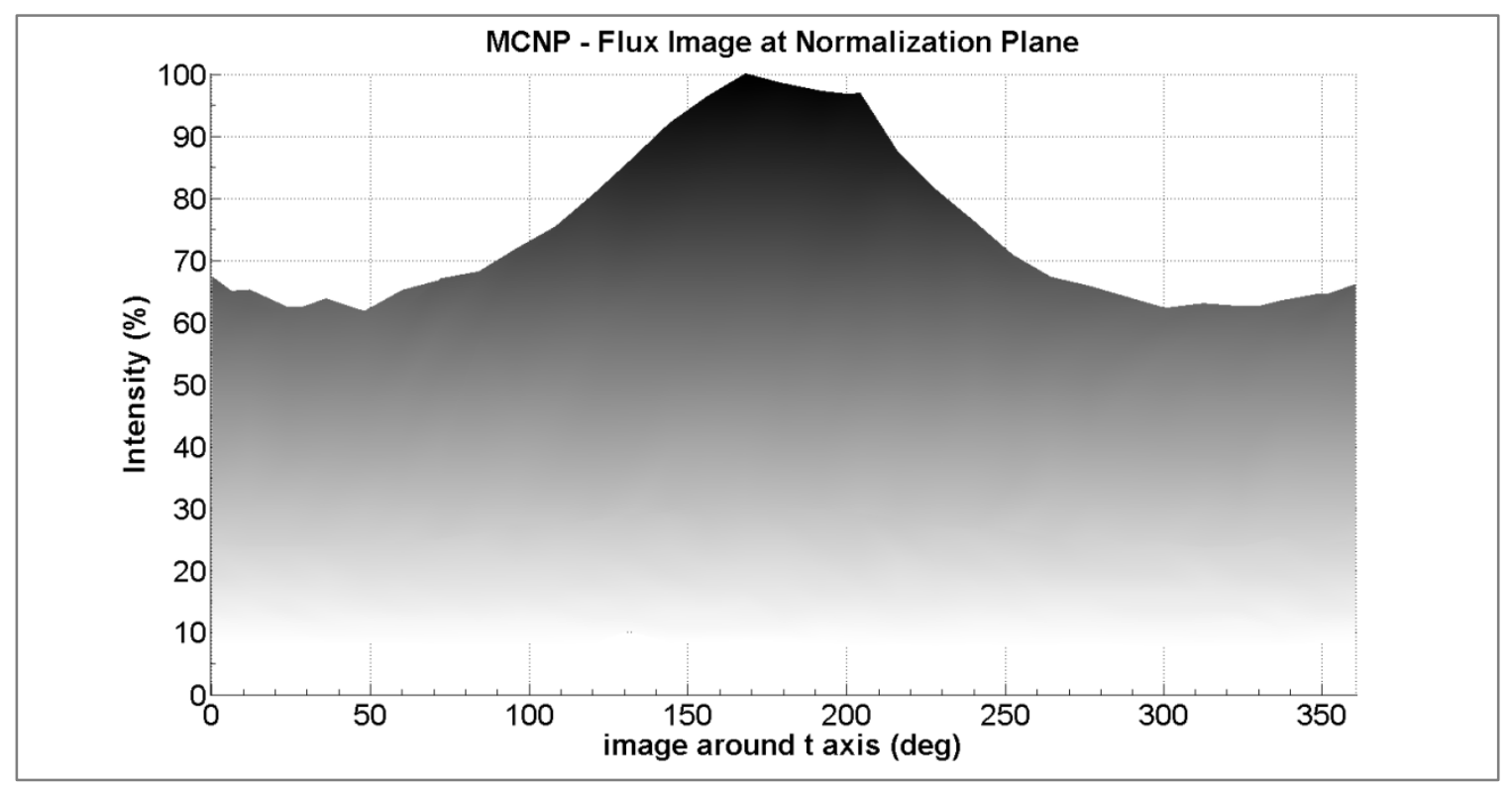

Figure 28. Horizontal View of the Modeled Intensity at Normalization Plane

The distribution of intensity across the normalization plane in MCNP is illustrated in Figure 28. The measured image from the IP shows the saturation of the phosphor, which is absent from the MCNP image. Therefore, the maximum was centered at the midpoint of the hot range from the experimental IP, which is at 160 degrees. Vertical cross sections analysis of the IPs verifies that the strongest source was placed at the bottom of the capsule. The capsule has a layer of stainless steel on the bottom with at a thickness of $4.3 \mathrm{~cm}$, and the vertical hot spot is at $5.5 \mathrm{~cm}$. The vertical cross-sections are shown in Figure 29. 


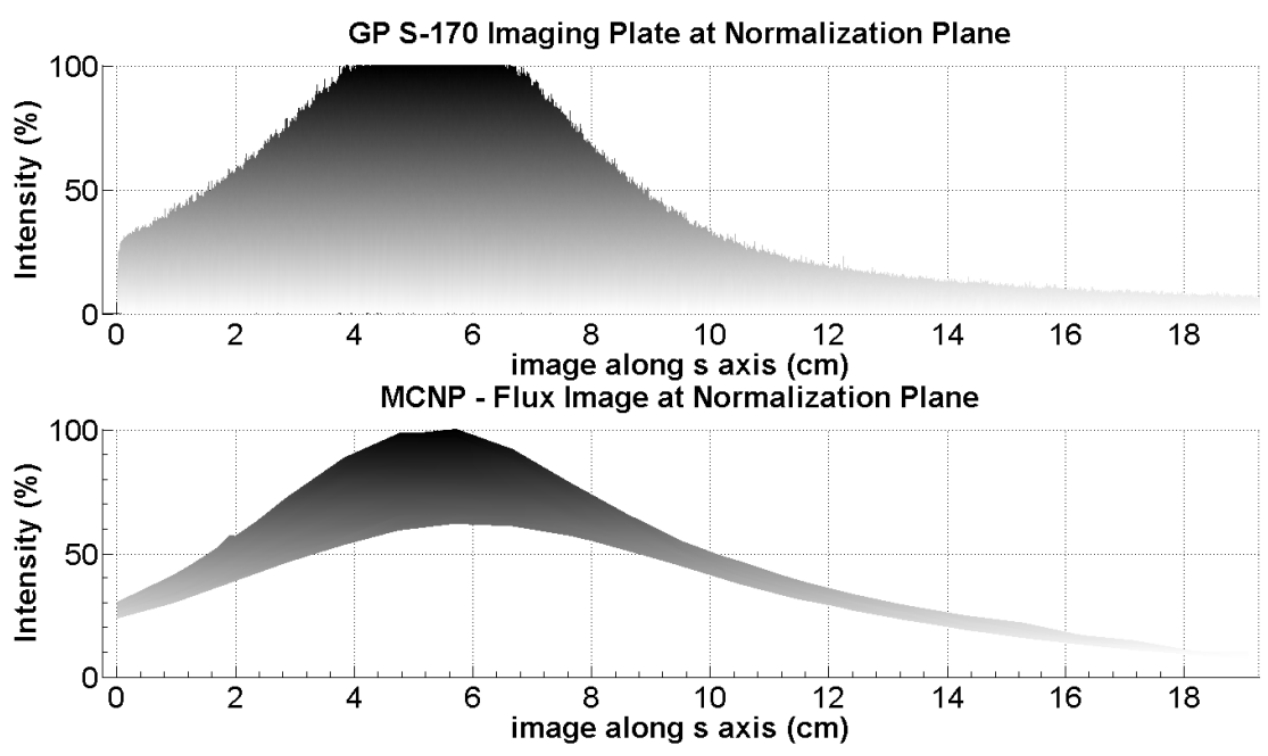

Figure 29. Vertical View of the Measured/Modeled Intensity at Normalization Plane

The images in Figure 25 through Figure 29 confirm the orientation and vertical location of the strongest $0.3 \mathrm{MBq}(6 \mathrm{Ci})$ source within the SFC. The strongest source was placed at the bottom of the SFC tucked on one side, which is clearly visible from the images. One of the lower activity sources was placed next to it, which can be seen in Figure 25. Such configuration explains the higher intensity in half of Figure 25, and the lower intensity in the other half, which was exposed to one of the other weaker component sources. The MCNP model was oriented according to the actual experiment. The "hot spot" was marked on the SFC, and the spot was oriented toward the center of the door for all measurements described in this work.

Figure 30 illustrates where each component americium- 241 beryllium $\left({ }^{241} \mathrm{AmBe}\right)$ source was placed. Neutron source MRC-AmBe-44 and NB540 were modeled at the bottom inside the SFC. NB570, the weakest source of the three, was modeled above the screw of the MRC-AmBe-44. This was the optimal configuration for best match between the modeled radiography and the experimental radiography as shown below. 


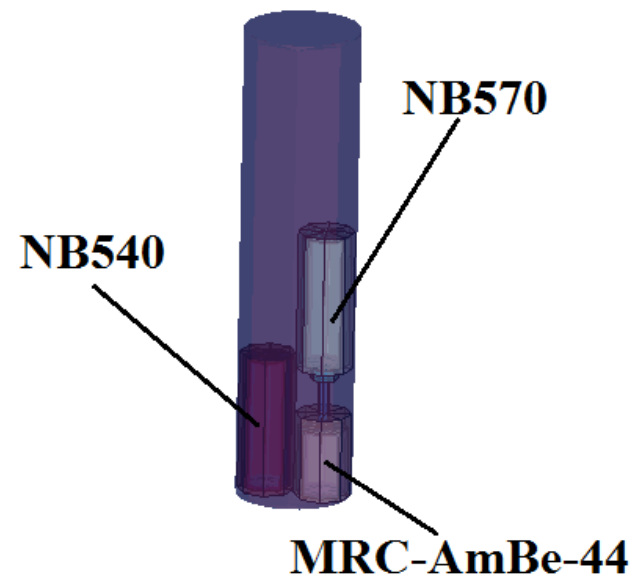

Figure 30. Location of Each Component Source within the SFC

\subsubsection{Secondary Imaging Plate Comparison}

A second IP was placed in front of the hot spot for confirmatory measurement. This image not only confirmed that the primary image was producing correct results, but it also confirmed the height of the strongest source. In addition, it confirmed that there was not any radioactive material inside of the SFC at the top. The MCNP radiography model was obtained using the FIR (Flux Image on Radiograph) tally. The model and the confirmatory IPs results have good agreement. The images from the secondary plate and the corresponding modeled MCNP images are presented in Figure 31. The experimental radiography IP is to the left of the figure, while the MCNP model is to the right.

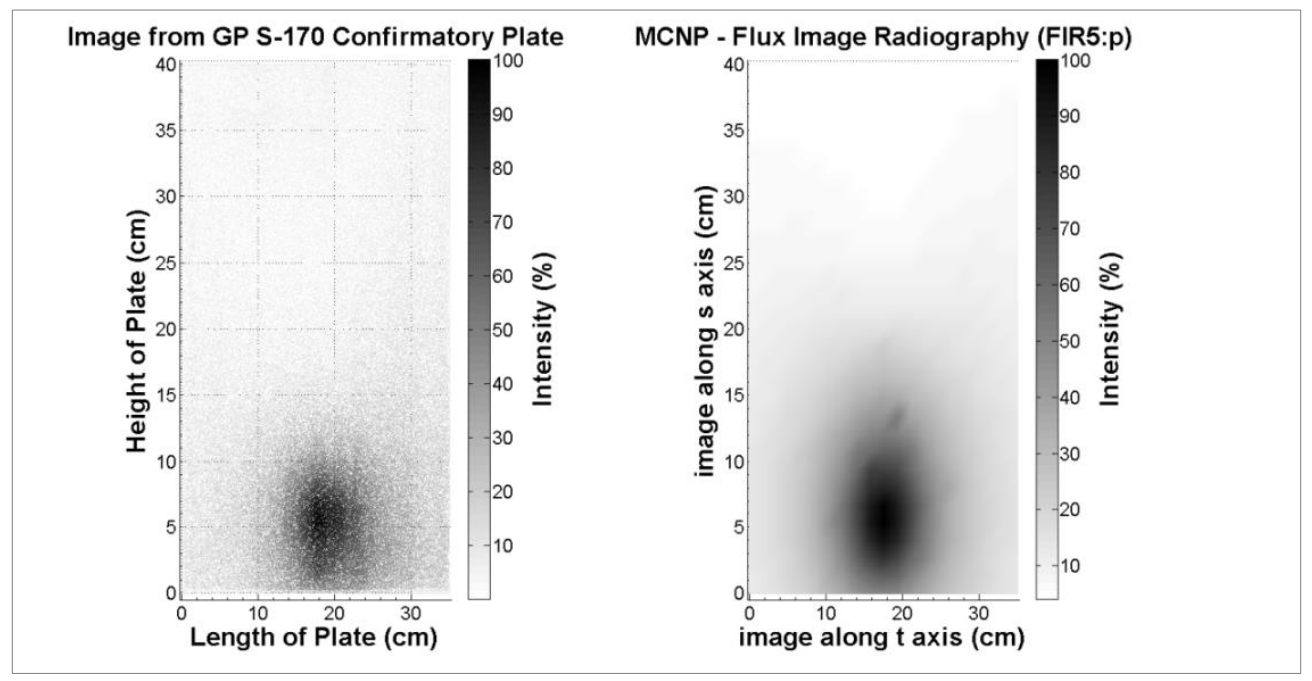

Figure 31. Confirmatory Phosphor Imaging Plate Modeled/Measured Comparison 
The experimental radiography image to the left shows that all of the radioactive material is located at the bottom of the SFC, and it also shows that there is nothing else above it. The MCNP model image to the right, after aligning the cylindrical radiography, produced similar results to the experiment. There was no need to iterate the second model radiography image to converge on the experimental image.

\subsubsection{Neutron Activation of Phosphor Imaging Plate}

Following the irradiation of the primary IP, neutron activation of the phosphor was observed. The radionuclides produced as a result of neutron activation were consistent with the composition of the phosphor. The IP is comprised of a layer of bariumfluorobromioiodide doped with divalent europium (BaFBr/I:Eu2+). Gamma spectroscopy analysis of the plate immediately after the irradiation showed short-lived radionuclides such as ${ }^{128} \mathrm{I}$ (produced from ${ }^{127} \mathrm{I}$ ), ${ }^{139} \mathrm{Ba}$ (produced from ${ }^{128} \mathrm{Ba}$ ), ${ }^{80} \mathrm{Br}$, and

${ }^{82} \mathrm{Br}$. (produced from ${ }^{79} \mathrm{Br}$ and ${ }^{81} \mathrm{Br}$, respectively), which are all produced via $(\mathrm{n}, \gamma)$ capture reactions. All of these radionuclides were short-lived, an all of them decayed after about two weeks.

\subsection{Monte Carlo N-Particle Neutron Spectral Output}

Predictions of the neutron spectra at the experimental locations, A through $\mathrm{G}$, were first obtained by MCNP modeling of the neutron irradiation system. The spectra predicted by the model are represented in Figure 32 and Figure 33 for the locations inside and outside the shielding. The shape of the original neutron spectrum, as provided by ISO 8529, is discernable for all measurement locations. 


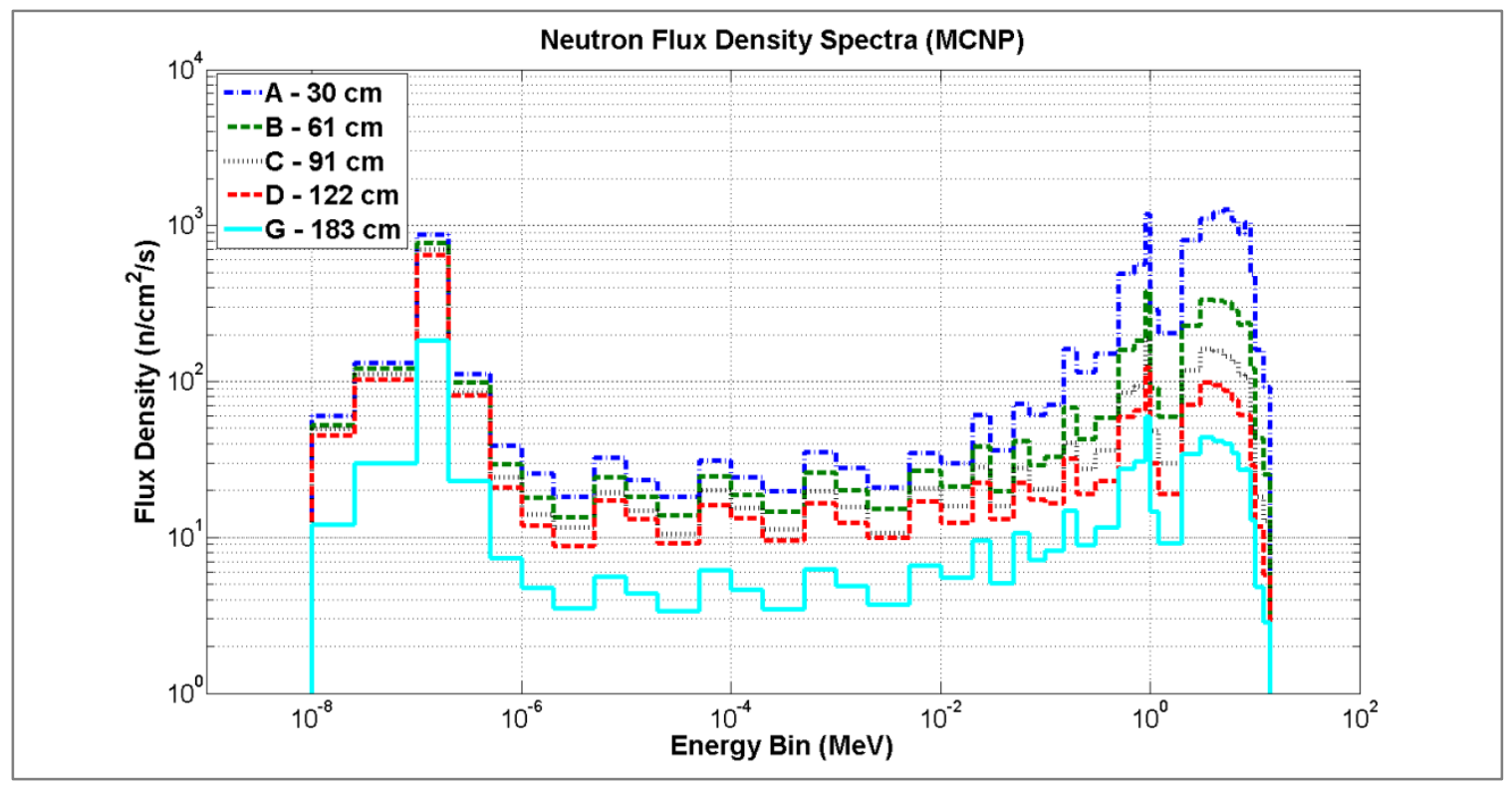

Figure 32. MCNP Neutron Spectra for Various Locations throughout System

Figure 32 shows the neutron spectra for locations A through D, and location G. All spectra include the fast neutrons in the energy range consistent with ISO 8529, from $2 \mathrm{MeV}$ to $10 \mathrm{MeV}$. Also visible is a low energy peak ranging from $10^{-8} \mathrm{MeV}$ to $10^{-6} \mathrm{MeV}$, which results from neutrons scattering from the polyethylene walls and concrete. Also, there is another neutron peak ranging from $0.5 \mathrm{MeV}$ to $1 \mathrm{MeV}$, which is a result of neutron scatter in the SFC. The SFC is mostly composed of iron and nickel, and neutron scattering from them creates that distribution. The neutron distribution caused by iron and nickel can be seen as low as $10^{-2} \mathrm{MeV}$. A small fraction of the fast neutrons have elastically scattered multiple times in the SFC before exiting, and they have lost more energy than neutrons that have scattered once. This is why there is a gradual increase in the flux density from $10^{-2} \mathrm{MeV}$ to $1 \mathrm{MeV}$. These three neutron distributions are dominant throughout the neutron irradiation system.

For locations A through D, as the distance from the source increases, the intensity of the fast neutron component decreases. The intensity of the thermal peak does not vary much throughout the inside of the irradiation system. At location $G$ (outside the shielding with the door open), both the fast neutron and thermal neutron intensities decrease. The thermal peak significantly decreases relative to locations A through D because of the reduced neutron scatter due to the absence of some of the scattering surfaces, so neutrons 
do not have the opportunity moderate because some of the neutrons escape through the door opening.

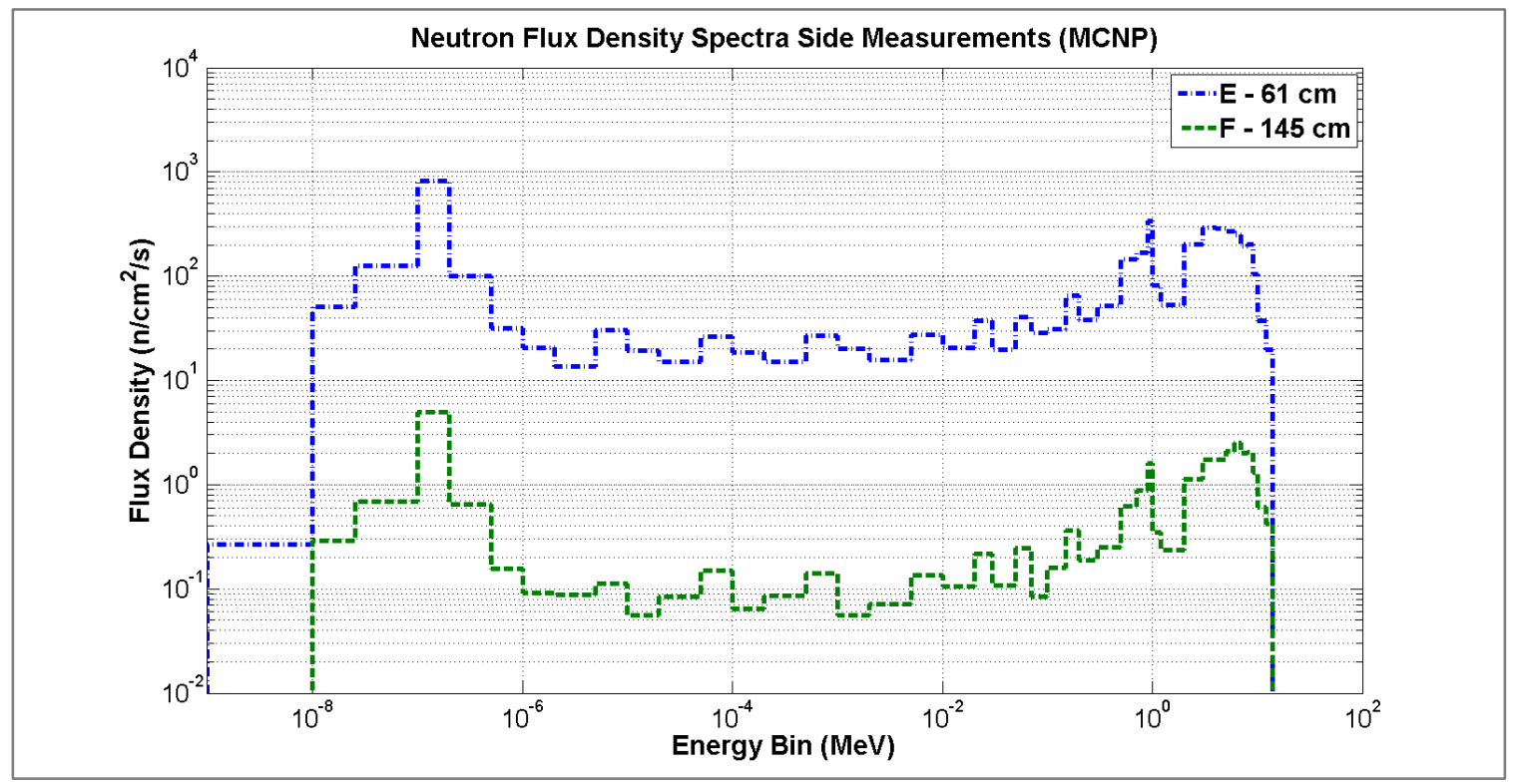

Figure 33. MCNP Neutron Spectra for Locations $E$ and $F$

Neutron spectra for locations $\mathrm{E}$ and $\mathrm{F}$ are shown in Figure 33. Both of these locations are south of the source, and both spectra were modeled with the door closed. The location $\mathrm{E}$ is $61 \mathrm{~cm}$ from the source, directly south. The spectrum at location $\mathrm{E}$ is similar in distribution and intensity to the other measurement at $61 \mathrm{~cm}$, at location $\mathrm{B}$, which is southeast of the source. The measurement location F is outside the shielding, and the neutron flux density at that location decreases substantially as the neutrons are moderated through the wall of the polyethylene shielding.

To better compare reaction rates and to bring out other effects in the neutron irradiation system, the area under the plots was normalized. In Figure 34, the area under the curve is constant for all spectra from A through D and G. The area under the curve has been set to one, and all the spectra are normalized to spectrum A, which is the strongest. Figure 34 shows the relative contributions of different energy neutrons for other locations with respect to location A in the shielding. 


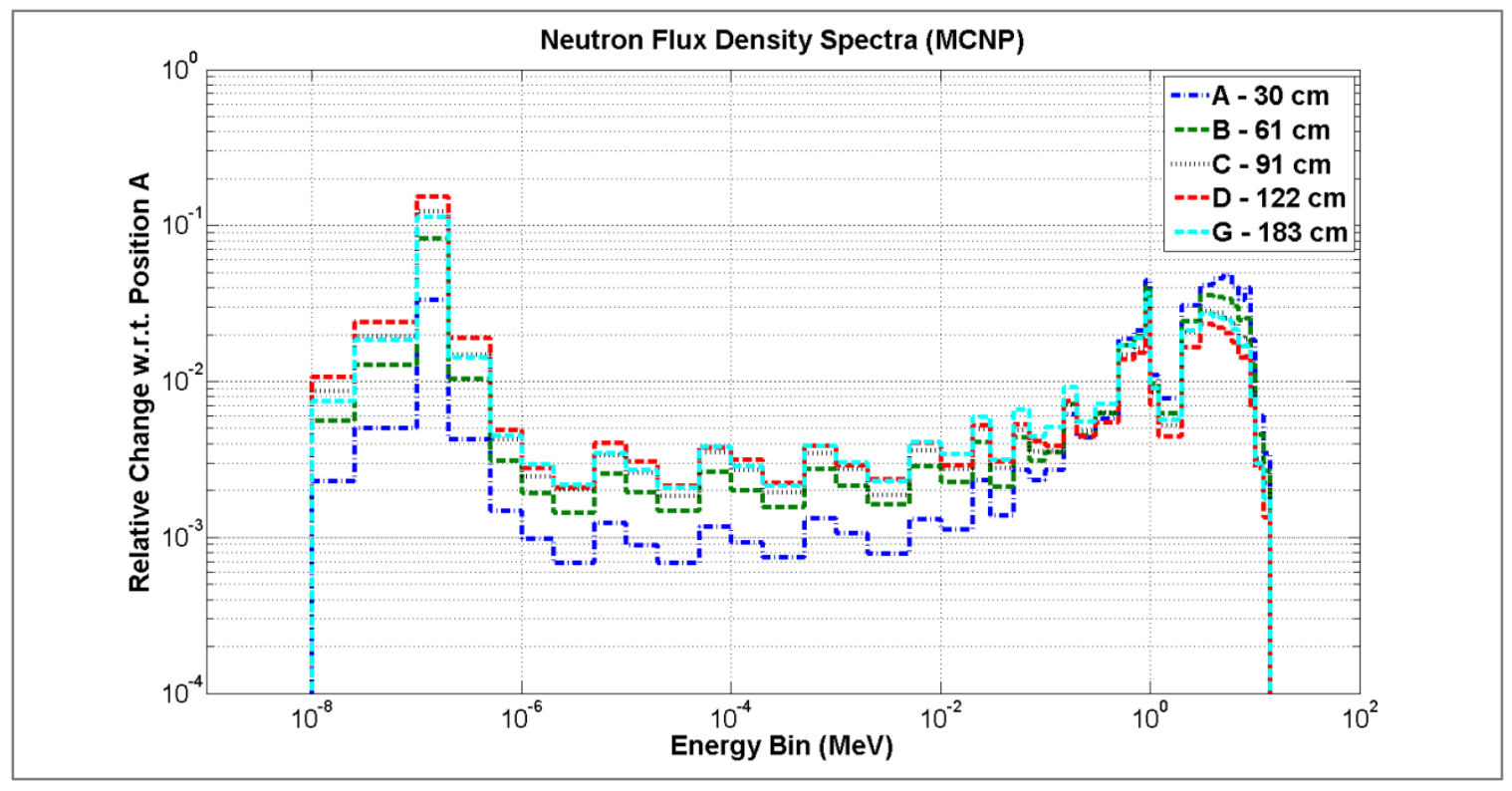

Figure 34. MCNP Neutron Spectra Relative Change

As the distance from the source increases, the ratio of the fast neutrons in the spectrum to thermal neutrons decreases. This trend can be seen in spectra B through $G$. The fast neutrons scatter and moderate from the high energy peak to the thermal peak. In location $\mathrm{G}$, there are more fast neutrons than at location $\mathrm{D}$ because the door is open and the neutrons are not thermalized as efficiently. The open door also allows the neutrons to escape the system rather than thermalize, so leaving the door open reduces the thermal contribution. The thermal peak is reduced by leaving the door open. The MCNP model and detector tallies are provided in APPENDIX A: MCNP INPUT DECK.

\subsection{Gamma Spectroscopy by HPGe Detector}

Gamma spectroscopy was used to characterize the gamma radiation field associated with the neutron irradiation system. The photons contributing to that field may originate from the neutron source, but they may also be produced as a result of neutron interactions with the materials around the source. A background measurement was taken prior to placing the neutron source in the irradiation system to determine the natural background component as well as the contribution from the ${ }^{137} \mathrm{Cs}$ gamma irradiation chambers located in the same room. The MCNP model was also used to determine gamma emissions from the neutron source via elastic and inelastic scattering. 


\subsubsection{Gamma Spectroscopy Comparison}

The gamma radiation background was obtained with the High Purity Germanium (HPGe) detector placed inside of the shielding with the door closed when the source was not present. The gamma background spectrum is shown in Figure 35 and Figure 36, identified by the red line. After the source was moved into place within the shielding, the gamma spectrometry count was taken outside of the irradiation system with the door open, at $1.22 \mathrm{~m}$ from the source. Maintaining the distance from the source was necessary to minimize the degradation of the germanium crystal by the fast neutrons. The gamma spectrum produced by the source is identified in Figure 35 and Figure 36 by the blue line, and it does not correct for background radiation. The gamma spectrum of the source obtained from the MCNP model is identified in the same figures by the black line.

Some of the discernable peaks in the gamma spectrum from the source are due to inelastic and elastic scattering of neutrons from germanium, chromium, and aluminum from the stand or the detector. There is also small contribution from neighboring ${ }^{137} \mathrm{Cs}$ in the spectrum. A $2.2 \mathrm{MeV}$ gamma-ray is of interest in the gamma spectrum because it is not produced directly from the source, and it is emitted from the thermal neutron capture in hydrogen. This reaction occurs in the concrete (the floor) and also in the walls of the polyethylene shielding. The $2.2 \mathrm{MeV}$ gamma-rays cause single and double escape peaks in the detector (SE pk and DE pk in Figure 35).

In the background spectrum, there is a prominent ${ }^{137} \mathrm{Cs}$ peak from nearby sources. There are also terrestrial radiation peaks from ${ }^{40} \mathrm{~K}$ and from radionuclides in the natural decay series. The background spectrum was collected to identify and discriminate the background component of the gamma spectrum from the neutron source gamma spectrum.

The gamma spectrum obtained from the MCNP model only accounts for materials defined in the model, and it does not account for potentially activated components in the detector. Modeling the gamma spectrum in MCNP assists in identifying lines that strictly come from the modeled configuration. For example, the spectrum includes the gamma-rays from neutron scattering with aluminum (from the aluminum stand). Also present are $2.2 \mathrm{MeV}$ photons from the thermal neutron capture reaction in hydrogen. The MCNP model was expanded up to $5 \mathrm{MeV}$ to see if there are any other interactions 
resulting in gamma emissions. As a result, three additional peaks were identified. These three peaks come from the neutron capture in aluminum (the stand), the polyethylene walls, and from the ${ }^{241} \mathrm{AmBe}$ source (de-excitation) gamma following the $(\alpha, \mathrm{n})$ reaction in beryllium. PeakEasy ${ }^{(40)}$ software was utilized to identify the peaks, and it was used to determine where these peaks originated. The gamma spectrum results for the background, the source, and the MCNP model are presented in Table XII. 


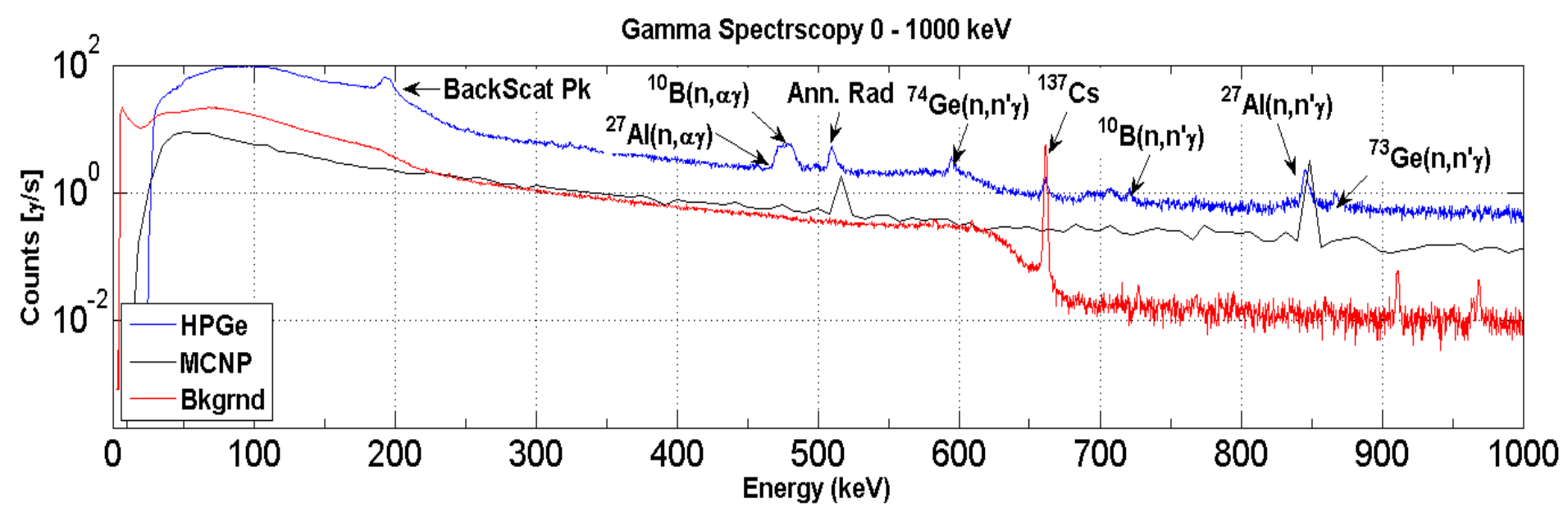

Gamma Spectrscopy 1000 - $2000 \mathrm{keV}$

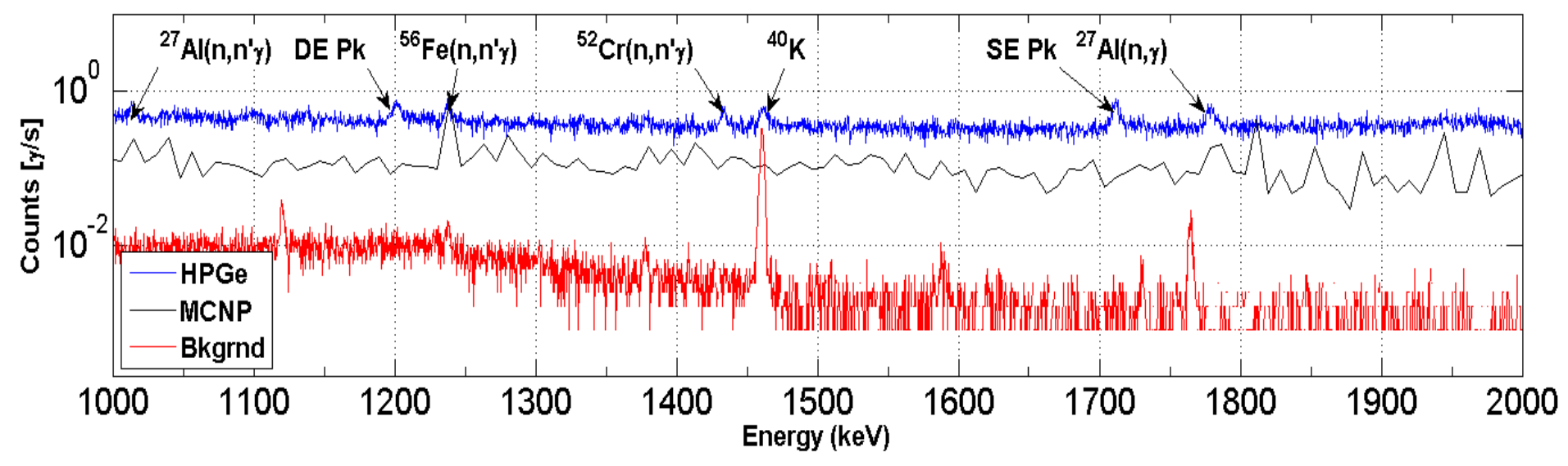

Figure 35. Gamma Spectra Summary Energy Range from $10 \mathrm{keV}$ to $2000 \mathrm{keV}$ 


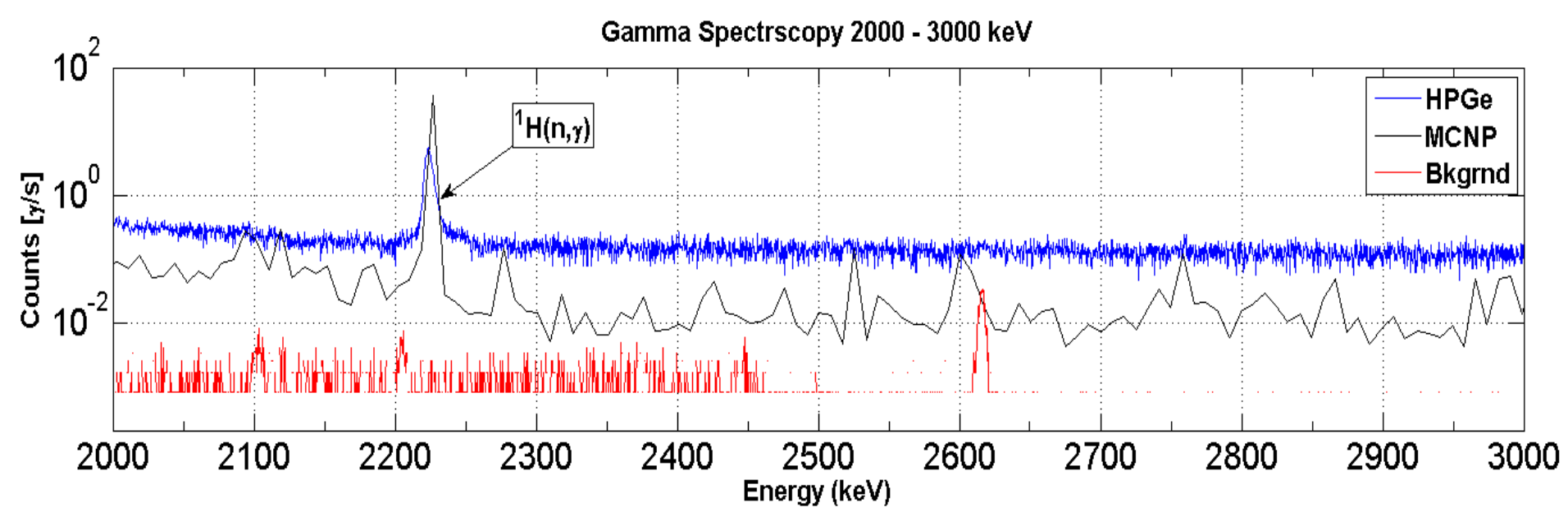

Gamma Spectrscopy $3000-5000 \mathrm{keV}$

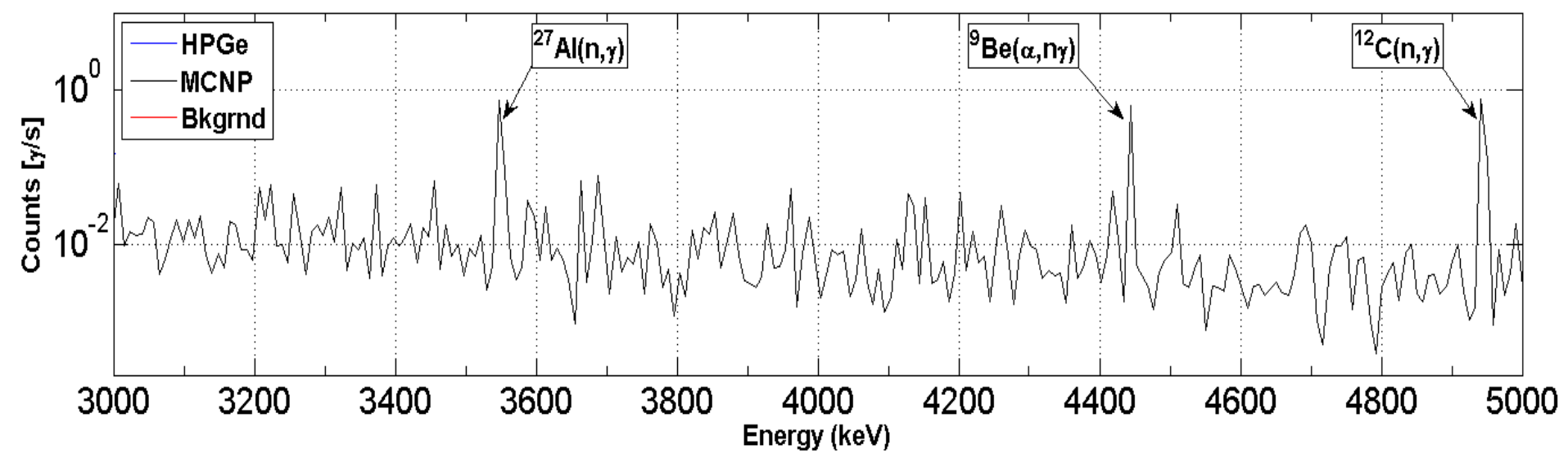

Figure 36. Gamma Spectra Summary Energy Range from $2 \mathrm{MeV}$ to $5 \mathrm{MeV}$ 
5.3.2 Identified Peaks in Spectrum

Table XII. Gamma Statistics Obtained by HPGe Detector Analyzed by PeakEasy



Errors Reported at one sigma (68\% CI) 


\subsection{Neutron Spectroscopy Using Various Instruments}

This section presents the results of neutron spectra measurements, which are then compared with the modeled spectra. The first subsection explains how the plots presented throughout Section 5.4 were generated. The following subsection presents the results obtained by the neutron spectrometers: the N-probe Microspec and the Bubble Dosimeter Spectrometer set. Then, the activation foil results used to determine neutron flux density are presented and discussed. Finally, by summarizing all the neutron measurements, it is possible to validate the MCNP model. It is possible to determine how the neutron population behaves and moves throughout the neutron irradiation system configuration. From a validated MCNP model, the effective dose rates to personnel can be calculated.

\subsubsection{Neutron Calculations}

\section{Neutron Spectra Plotting}

When plotting function $\frac{d \phi(E)}{d E}$ on the ordinate and variable $E$ on the abscissa over a broad range of energies, it is necessary to plot on a logarithmic scale rather than a linear scale to bring out significant effects in the spectrum. When changing the abscissa to logarithmic scale, the ordinate and the abscissa change accordingly $\frac{d \phi(E)}{d(\log (E))}$ and $\log (E)$. This subtends the plot area by the curve between any pair of abscissas $\log \left(\mathrm{E}_{1}\right)$ and $\log \left(\mathrm{E}_{2}\right)$. The logarithmic plot is now proportional to the integral of the distribution between $E_{1}$ and $E_{2}$. Therefore, any group bin is described by it lower boundary $\left(E_{i}\right)$ and its upper boundary $\left(\mathrm{E}_{\mathrm{i}+1}\right)$. There are any number of bins based on instrument design and limitations. The group flux density bin is given as:

$$
\varphi_{g}=\int_{E_{i}}^{E_{i+1}} \varphi_{i}(E) d E
$$

As the energy in the spectra range from thermal to fast energies, the abscissa will be plotted on a logarithmic scale. All neutron spectra ordinates in this report are plotted using the following equation:

$$
\varphi_{g}=\frac{\varphi_{i}}{\log \left(\frac{E_{i+1}}{E_{i}}\right)}
$$




\section{Average Neutron Spectral Energy}

The average neutron spectral energy is calculated by:

$$
\bar{E}=\frac{1}{\varphi_{\text {total }}} \sum_{i=1}^{n}\left(E_{n} \times \varphi(E)_{n}\right)
$$

The average neutron spectral energy is useful in determining the average energy of the neutron population at any given location in the irradiation system.

\section{Ratio of Thermal to Fast Neutrons}

The thermal neutron fraction is defined as:

$$
f r_{t h}=\int_{10^{-8} \mathrm{MeV}}^{10^{-6} \mathrm{MeV}} \varphi(E) d E
$$

The fast neutron fraction is defined as:

$$
f r_{f s}=\int_{10^{-1} \mathrm{MeV}}^{10^{1} \mathrm{MeV}} \varphi(E) d E
$$

The ratio between thermal and fast neutrons is defined as:

$$
R=\frac{f r_{t h}}{f r_{f s}}
$$

The ratio between thermal and fast neutrons is useful for determining how many backscatter neutrons compared with fast neutrons coming from the ${ }^{241} \mathrm{AmBe}$ source are present at any given location. For component irradiation, whether if the average neutron energy decreases or increases, the ratio will inform if there are more thermal neutrons crossing through a point in the chamber; it is useful for parametric analysis of the irradiation system.

\subsubsection{N-Probe Microspec Spectrometer}

Due to its sensitivity limitation, the N-probe Microspec was placed at measurement locations $\mathrm{D}, \mathrm{F}$, and $\mathrm{G}$, which are relatively far from the source $(1.22 \mathrm{~m}$, $1.45 \mathrm{~m}$, and $1.83 \mathrm{~m}$ respectively). The measurement locations are shown in Figure 24, and the neutron spectra obtained at these three locations are shown in Figure 37. The 
energy range is from $10^{-8} \mathrm{MeV}$ to $20 \mathrm{MeV}$, and there are 17 energy bins for the Microspec.

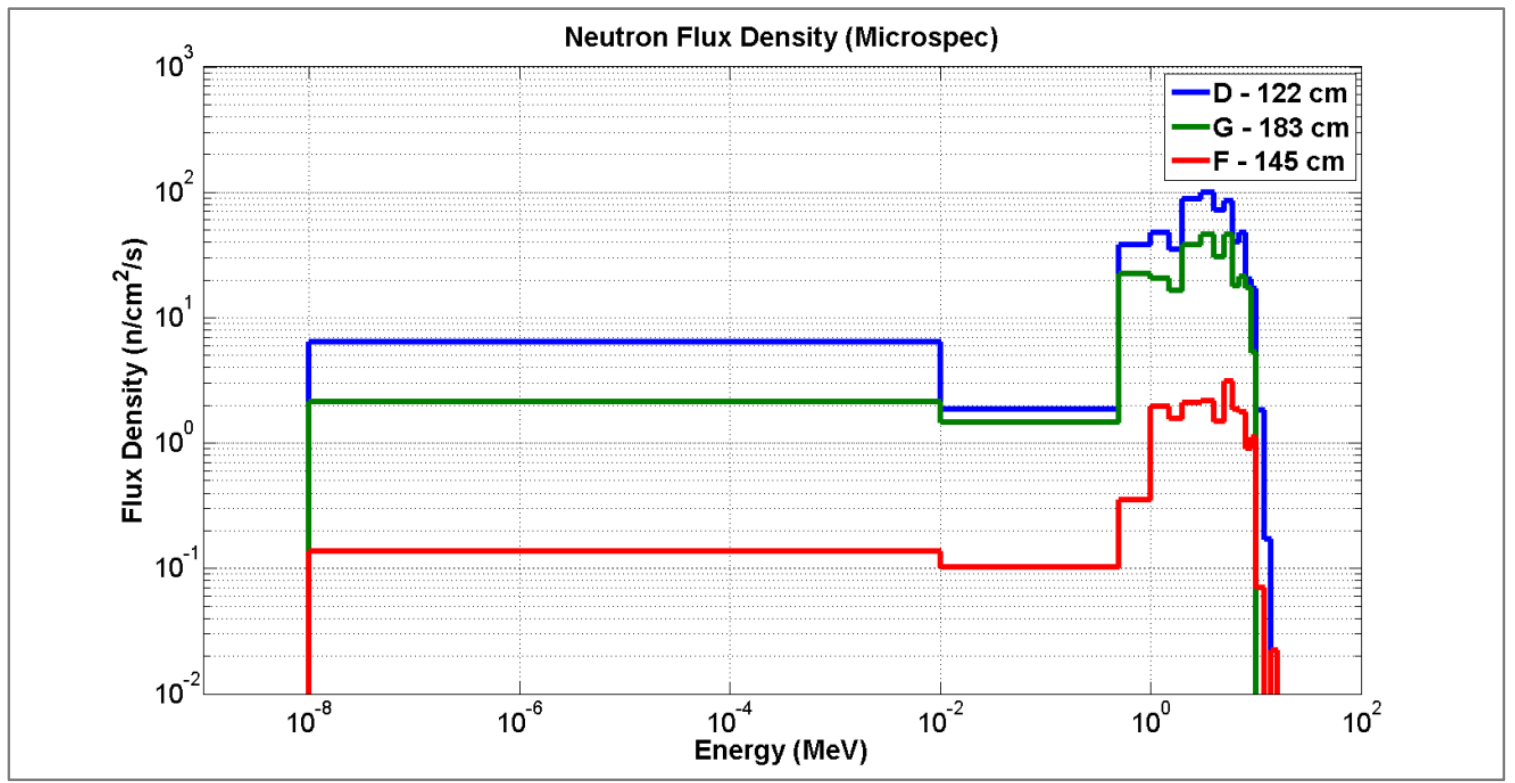

Figure 37. Neutron Spectra Obtained by N-Probe Microspec

In Figure 37, the Microspec measurements display a neutron energy distribution from about $0.5 \mathrm{MeV}$ to $10 \mathrm{MeV}$. This is consistent with the MCNP model. The ${ }^{241} \mathrm{AmBe}$ neutron energy distribution is shown between $2 \mathrm{MeV}$ and $10 \mathrm{MeV}$, and the neutron spectral shift caused by neutron interactions with the iron in the SFC expands the energy distribution down to $0.5 \mathrm{MeV}$ for all locations. Unfortunately, the resolution in the Microspec does not bring out the full peak distribution from the iron, but it does broaden the ${ }^{241} \mathrm{AmBe}$ distribution. This is a key indicator that the neutron scatter off of iron is seen by the Microspec. This broadening causes the average neutron energy emitted from the source to decrease.

At measurement location $\mathrm{D}$, the door is closed in the experimental configuration, and the instrument is $1.22 \mathrm{~m}$ from the source. The overall neutron intensity is the highest for this location for the Microspec because it is the closest to the source from the three locations. It is worth noting the thermal bin $\left(10^{-8} \mathrm{MeV}\right.$ to $\left.10^{-2} \mathrm{MeV}\right)$ for location $\mathrm{D}$ is the highest among the three spectra. This indicates that for location $\mathrm{D}$, there are relatively more neutrons in the thermal bin than for the other two locations. This is due to the contribution of the low energy neutrons from the polyethylene, which acts as a moderating medium. The Microspec deconvolution software places all the thermal and 
low energy neutrons in one bin. Therefore, this bin should only be used as an indicator of neutron moderation. If the ${ }^{241} \mathrm{AmBe}$ sources were suspended in air with no moderator nearby, the low energy bin would decrease rather than increase.

At measurement location $G$, the configuration has the door open, and the instrument was placed at a farther distance from the source than location D $(1.83 \mathrm{~m})$. At location $\mathrm{G}$, there is a decrease in the overall neutron intensity due to increased distance from the source. The ${ }^{241} \mathrm{AmBe}$ energy spectrum does not change significantly with distance at location $\mathrm{G}$, and it is still similar to ISO 8529 at this distance. The thermal bin intensity is lower at location $\mathrm{G}$ with the door open. This decrease in low energy neutrons is because neutrons escape the chamber with the door open instead of being moderated by the door and reflecting back into the chamber.

The measurement at location $\mathrm{F}$ was taken with the door closed, and the instrument was placed outside of the shielding on the side, directly south, and at $1.45 \mathrm{~m}$ from the source. The fast neutron component of the ${ }^{241} \mathrm{AmBe}$ energy distribution is still discernable outside of the polyethylene shielding. The intensity has dropped by several orders of magnitude, and at this point the neutrons have passed through approximately $25.4 \mathrm{~cm}$ of polyethylene.

\subsubsection{Neutron Bubble Dosimeter Spectroscopy Set}

The neutron Bubble Dosimeter Spectroscopy (BDS) set was placed at locations A though D inside the shielding. The locations used for the BDS measurements were closer to the source than the Microspec because of the lower sensitivity of the BDS. The energy bins measured by the BDS are wider, and the BDS do not measure energies lower than $10^{-2} \mathrm{MeV}$. These are also a few limitations of the BDS, which are described below. The spectra obtained with the BDS for all measurement locations are shown in Figure 38. 


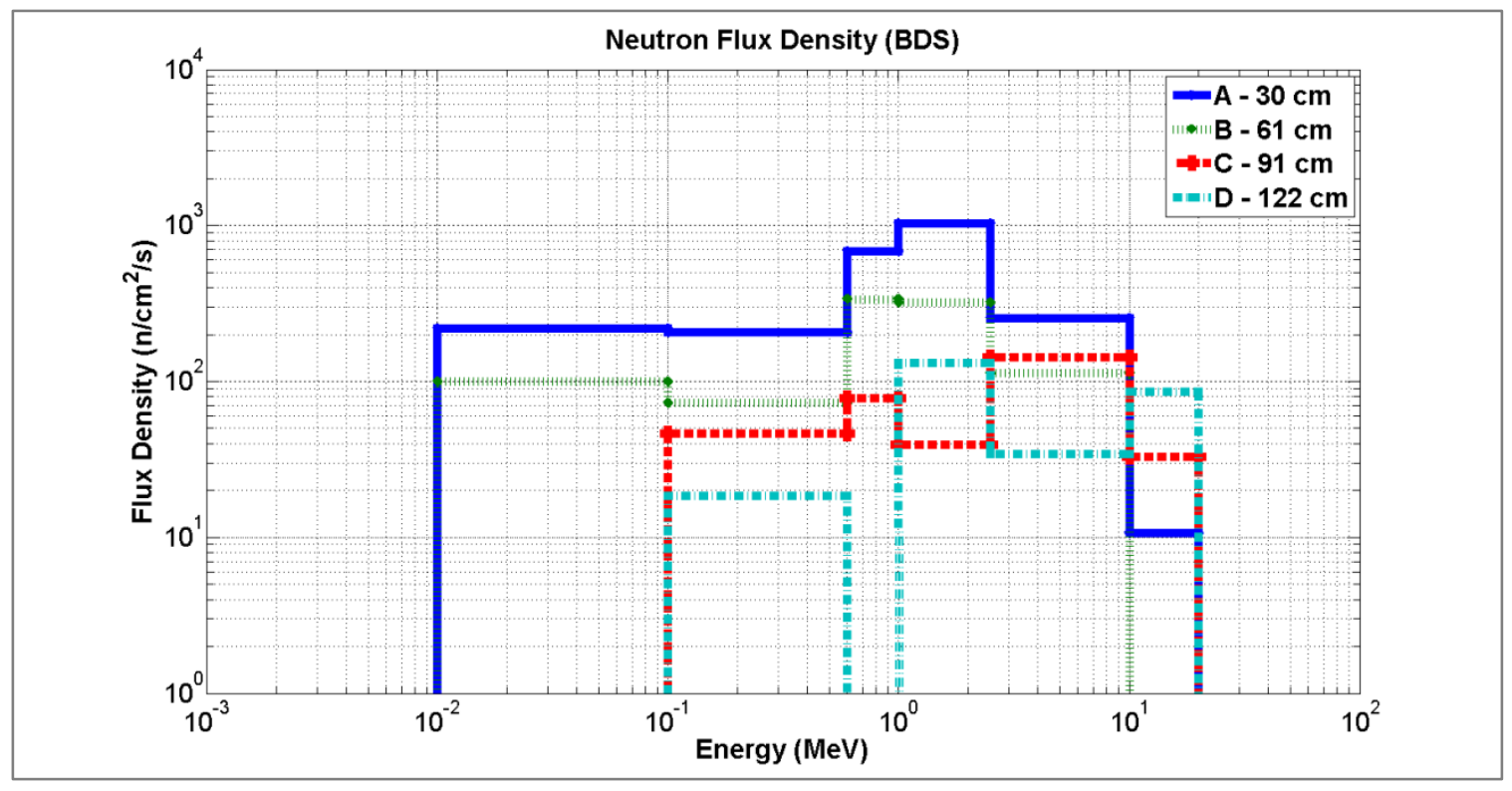

Figure 38. Neutron Spectra Obtained by Bubble Dosimeter Spectroscopy Set

At measurement location A, the BDS was $30 \mathrm{~cm}$ from the source. The spectrum for this location is characterized by a broad distribution of neutron energies up to $10 \mathrm{MeV}$, which is consistent with the reference distribution of an ${ }^{241} \mathrm{AmBe}$ source, as defined in ISO 8529. The BDS at location A also detect the neutrons that have lost a fraction of their energy by the iron. At location B, the detector set was placed $61 \mathrm{~cm}$ from the source. Although the neutron flux density is lower in all energy bins than in location A, the general shape of the spectrum is similar. For the location $\mathrm{C}$, which was $91 \mathrm{~cm}$ from the source, the spectral deconvolution software begins to over-strip at the lower bin because of the low bubble count in the lower energy bins. However, the energy distribution for the higher energies is consistent with the reference spectrum. For measurement location $\mathrm{D}$, at $122 \mathrm{~cm}$ from the source, the spectral deconvolution software eliminates another bin, but the ${ }^{241} \mathrm{AmBe}$ distribution in the high energy range is still consistent with the reference spectrum.

The BDS deconvolution software uses an underdetermined matrix to obtain the flux density. The BDS produce a spectrum that is rather crude, yet the results are still valid. For the locations A through D, the flux density shows a decrease in neutron intensity with increasing distance from the source. 


\subsubsection{Neutron Spectra Comparison for Location D}

The Microspec and the BDS were both used to measure neutron spectra at location D, and a MCNP spectrum was obtained as well. In Figure 39, the BDS and MCNP spectra are plotted together to see how they compare. For the bins available in the BDS, they compared reasonably well with the MCNP model. The BDS lost two bins due to over stripping from the deconvolution algorithm. All of the low energy neutrons in the MCNP model were binned in the lowest bin. If the deconvolution algorithm would have preserved the spectrum for the lower energy bin of the BDS, it would have been lower than the MCNP representation.

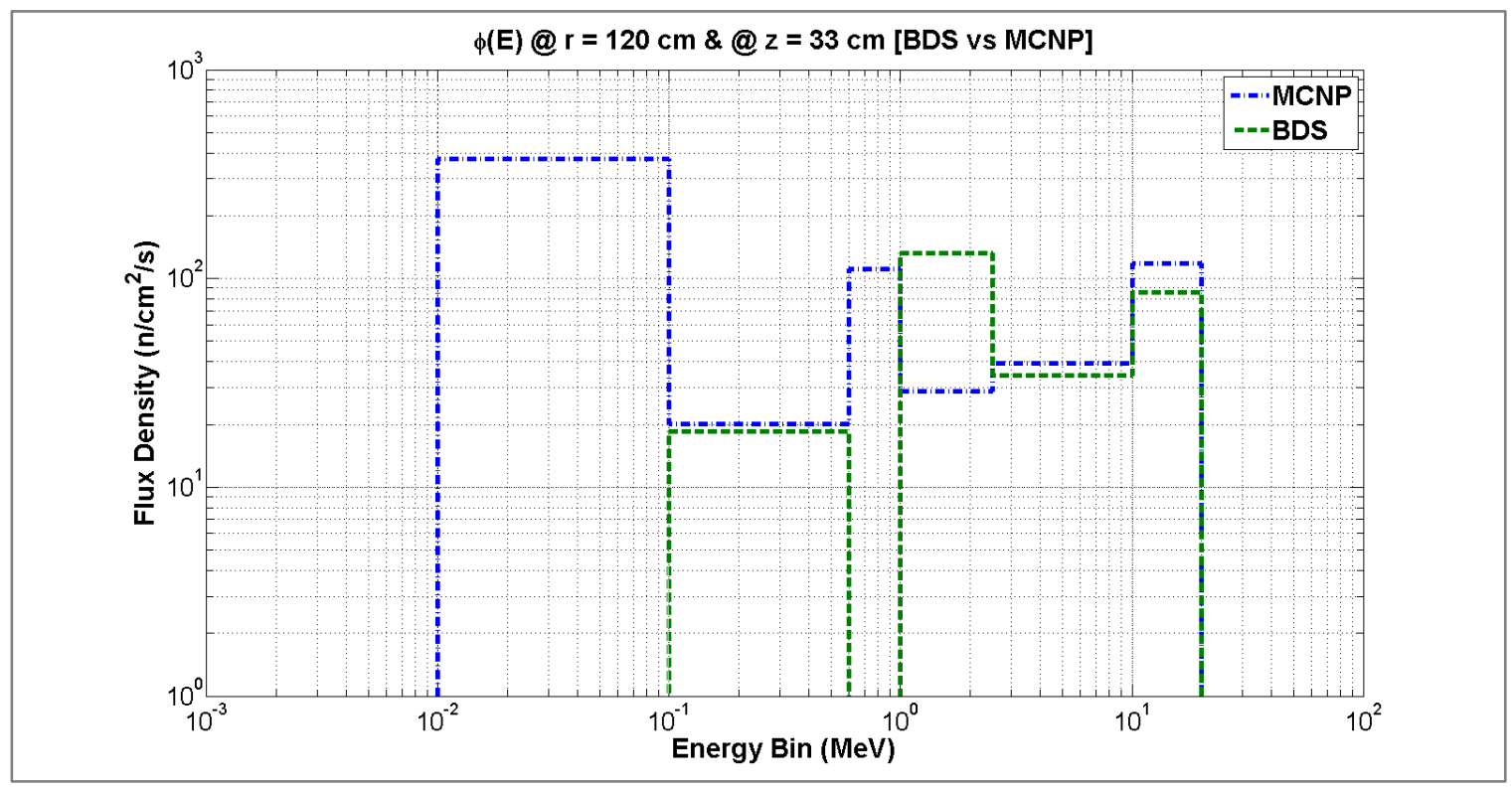

Figure 39. Neutron Spectra Comparison at Location D for BDS and MCNP

The Microspec and the MCNP neutron spectra at location D are shown in Figure 40. The Microspec compares well with the MCNP model for the fast spectrum, but it does not compare well for energies lower than $1 \mathrm{MeV}$. It begins to deviate at about $2 \mathrm{MeV}$. The three lower energy bins belong to the ${ }^{3} \mathrm{He}$ gas proportional counter, and the cross over between the two instruments occur at $1 \mathrm{MeV}$. The Microspec low energy bin compared reasonably well with the MCNP model. 


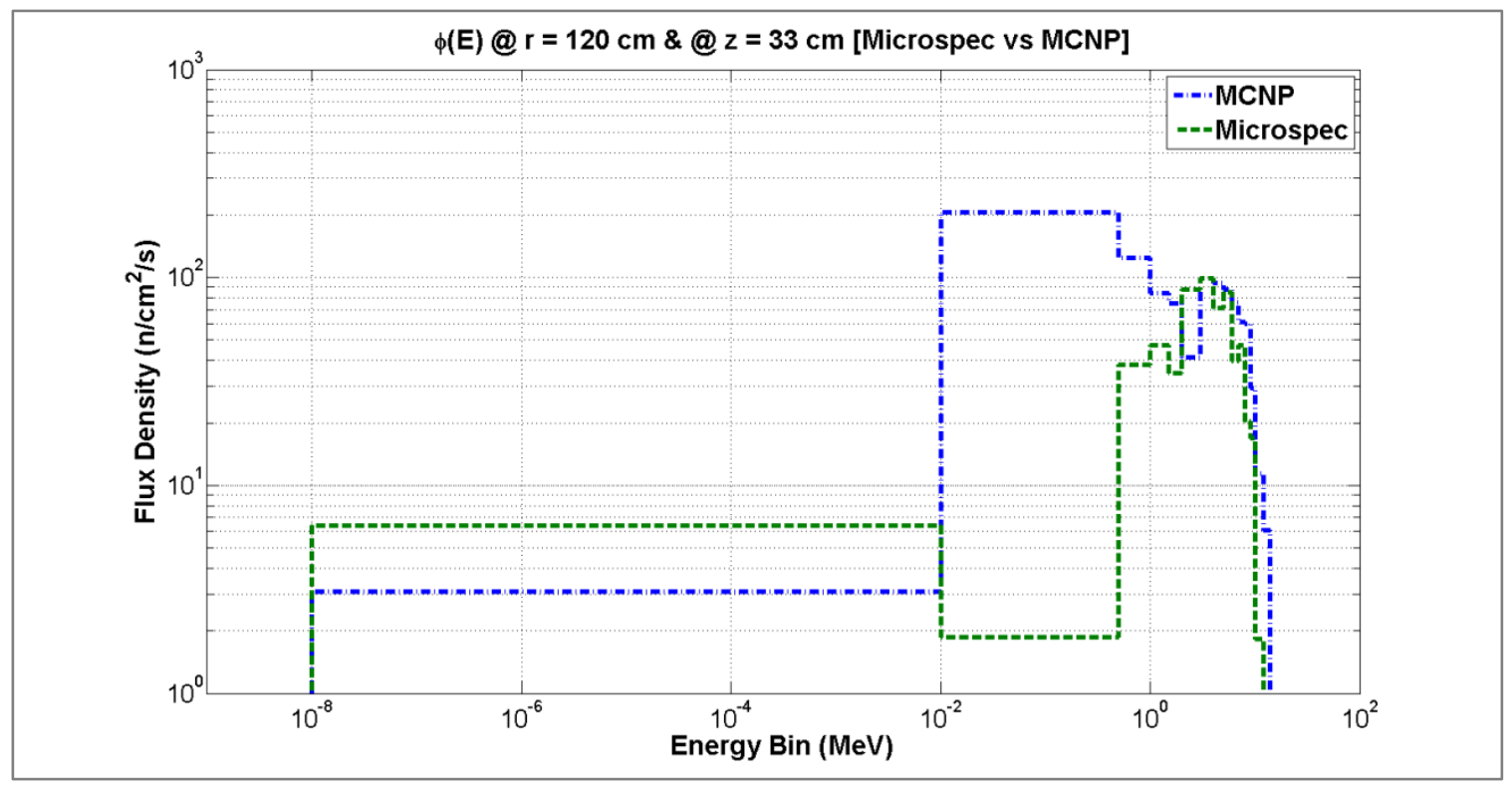

Figure 40. Neutron Spectra Comparison at Location D for Microspec and MCNP

The Microspec uses the ${ }^{3} \mathrm{He}$ gas proportional counter to measure lower energy neutrons which has a very coarse resolution, and the software uses one bin for thermal neutrons. The accuracy of the N-probe spectral data in the lower energy groups was questioned by Williams ${ }^{(25)}$. In his report he compared an ISO reference for an ${ }^{241} \mathrm{AmBe}$ to the N-Probe Microspec. In the example spectrum in his report, the high-energy portion compared fairly, but the lower energy bins disagreed.

Regardless, for practical applications in this experiment, the Microspec low neutron energy bins can serve as indicators of low energy neutrons in the field, which can help with the characterization of the neutron energy distributions. Each analytical method identified the ${ }^{241} \mathrm{AmBe}$ energy distribution from the source, and the methods also indirectly measured the neutron energy shift caused by the iron in the SFC.

\subsection{Neutron Activation Foils Results}

Activation foils were used as one of the methods of neutron spectra characterization, but they were partially successful. There was no detectable activity from the nickel foil or the sulfur pellet. There was some activity from both the cadmium-covered gold foil and the bare gold foil. The neutron flux density obtained from the gold foils is shown in Table XIII. The foils were exposed at location A, centerline with the hot range, for seven days. 
Table XIII. Neutron Activation Foil Tabulated Results

\begin{tabular}{|c|c|c|}
\hline \multirow{2}{*}{ Foil Method } & \multicolumn{2}{|c|}{ Neutron Flux Density $\left(\mathbf{n} / \mathbf{c m}^{\mathbf{2}} / \mathbf{s}\right)$} \\
\cline { 2 - 3 } & Experiment & $\mathbf{M C N P}$ \\
\hline Nickel & $\times$ & $\times$ \\
\hline Sulfur & $\times$ & $\times$ \\
\hline Gold $(\mathbf{E}<\mathbf{0 . 5} \mathbf{~ e V})$ & $(620 \pm 40)$ & $(740 \pm 22)$ \\
\hline
\end{tabular}

*Errors Reported at one sigma

The gold foils were irradiated to about $85 \%$ of the saturation activity. The neutron flux density calculated from the experiment is compared with the results predicted by a MCNP calculation. The MCNP flux density at the foil location is higher, but the method to quantify the experimental flux density from the gold foil exposure could be improved by using a more precise cross-section rather than assuming a Maxwellian distribution. This might bring the experimental value closer to the MCNP value. The samples could also have been placed closer to the source to significantly increase the flux rate to increase the activity of foils. The following figure illustrates the capture cross sections for various foils as a function of energy, obtained from ENDFPLOT.

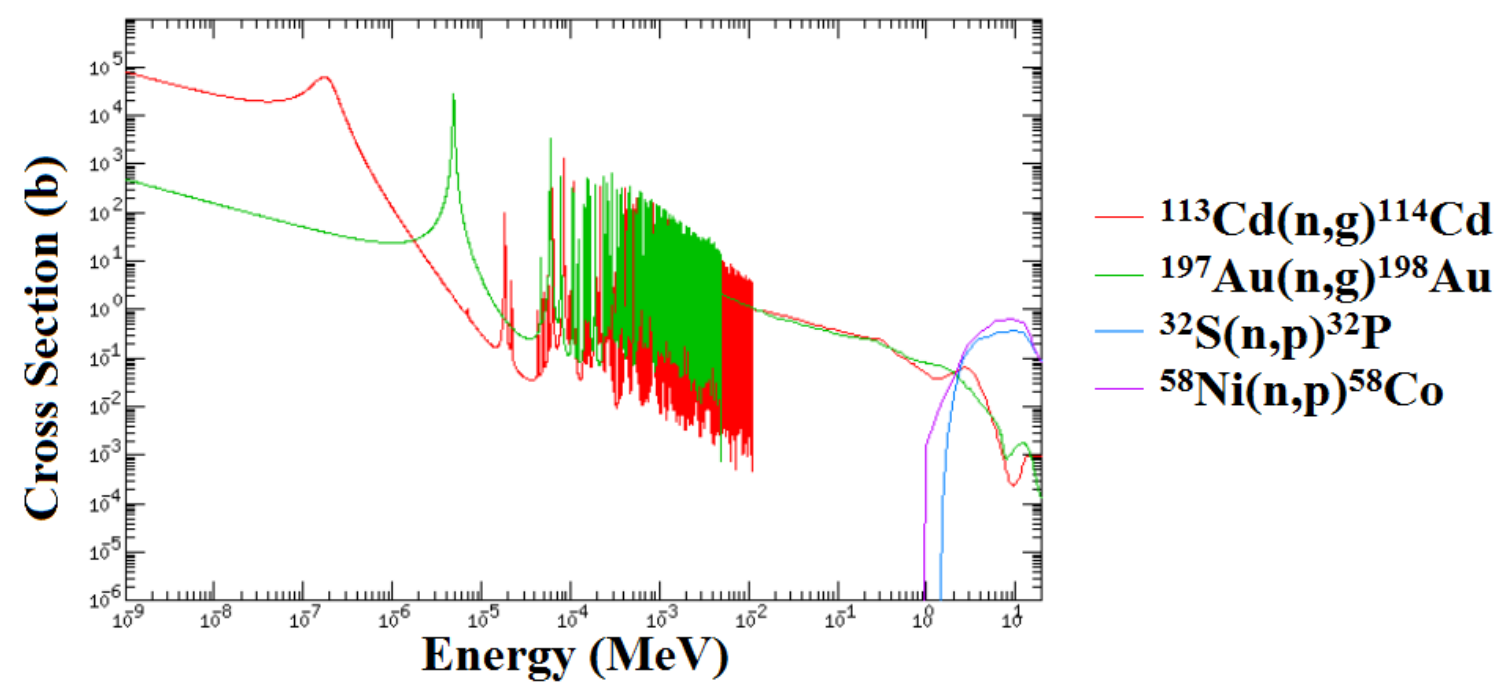

Figure 41. Cross Sections for Various Foils as a Function of Energy ${ }^{(41)}$

The sulfur pellet and the nickel foil did not get activated to detectable levels due to the relatively short irradiation time compared with the half-life (refer to Table V) of the activation products and the relatively low neutron flux density. The 2,200 m/s microscopic absorption cross section for gold is 98.8 barns ${ }^{(29)}$, and the sulfur and nickel capture cross sections for fast energy neutrons reach a maximum value at approximately 
0.5 barns as shown in Figure 41. If the gold foil was the only foil to undergo activation, based on the capture cross sections, the other two foils have significantly less of a chance of absorbing neutrons. Fortunately, enough gold was activated to be detected. Still, the experimental value obtained from the neutron activation of gold foils and the value obtained from MCNP compared relatively well.

\subsection{Summary of Neutron Flux Density Results}

The neutron flux density spectral information from all the neutron instruments and the MCNP model are summarized in Table XIV. The location and distance from the source are provided in the first and second columns. In the third column, the total flux density for the entire spectrum from MCNP is provided. In the fourth column only energies greater than $10 \mathrm{keV}$ from MCNP are given. Displaying column three and four in such matter allows for an understanding of how many neutrons have been slowed down to less than $10 \mathrm{keV}$. In the fifth and sixth columns the total flux density from the Microspec and BDS measurements are provided, respectively, so they can be compared. The average energy of the neutron spectrum at the location is provided in the last column, and it is based on the MCNP model as defined by Equation 16.

Table XIV. Neutron Flux Density at All Measurements Locations

\begin{tabular}{|c|c|c|c|c|c|c|}
\hline \multirow{3}{*}{ Location } & \multirow{3}{*}{$\begin{array}{c}\text { Distance } \\
\text { from } \\
\text { Source } \\
\text { (cm) }\end{array}$} & \multicolumn{4}{|c|}{ Neutron Flux Density $\left(\mathrm{n} / \mathrm{cm}^{2} / \mathrm{s}\right)$} & \multirow{3}{*}{$\begin{array}{r}\text { Average } \\
\text { Energy } \\
(\mathrm{MeV})\end{array}$} \\
\hline & & All Energy & $\mathrm{E}>10 \mathrm{keV}$ & $\mathrm{E}>10 \mathrm{keV}$ & $\mathrm{E}>10 \mathrm{keV}$ & \\
\hline & & MCNP & MCNP & Microspec & BDS & \\
\hline A & 30.5 & 3760 & 2550 & & $2500 \pm 800$ & 2.16 \\
\hline B & 61.0 & 1820 & 779 & & $1000 \pm 300$ & 1.19 \\
\hline $\mathrm{C}$ & 91.4 & 1330 & 408 & & $380 \pm 103$ & 0.78 \\
\hline $\mathrm{D}$ & 121.9 & 1110 & 266 & $260 \pm 50$ & $260 \pm 50$ & 0.55 \\
\hline G & 182.9 & 371 & 122 & $120 \pm 10$ & & 0.75 \\
\hline $\mathrm{F}$ & 144.8 & 10.7 & 4.42 & $6.92 \pm 0.10$ & & 1.48 \\
\hline $\mathrm{E}$ & 61.0 & 1780 & 694 & & $770 \pm 160$ & 1.05 \\
\hline
\end{tabular}

Errors Reported at one sigma

From Table XIV, it is possible to draw many conclusions about the neutron irradiation system. In comparing the MCNP results for all the neutrons and the neutrons with energies greater than $10 \mathrm{keV}$, it is obvious that initially most of the neutrons are fast neutrons. As the distance from the source increases, there are significantly more low 
energy neutrons, even at location $\mathrm{F}$ which is outside the shielding. In comparing all three results from MCNP, Microspec, and BDS for energies greater than $10 \mathrm{keV}$, they all compare well given the uncertainties. The uncertainty in the BDS measurements could be improved by repeating them. The best results are for location D, where all instruments' results align with the model. The average energy inside the shielding with the door closed is the highest closer to the source, and the average energy decreases as a function of distance due to the diminishing contribution from fast neutrons. Outside the shielding, the contribution from the moderated neutrons decreases, which results in the overall increase of the average neutron energy. The neutron flux density is significantly lower for the locations outside the shielding because the shielding attenuates many neutrons.

The flux densities for neutrons with energies greater than $10 \mathrm{keV}$ were plotted for locations A though D (with door closed) and $\mathrm{G}$ (with door open) as a function of distance to demonstrate relationship between these quantities. The flux density does not decrease as fast as a $1 / \mathrm{r}^{2}$ point source, but instead it is closer to a $1 / \mathrm{r}^{1.7}$ relationship. This is shown in Figure 42 for those locations throughout the irradiation system. All the MCNP results shown in the figure are within one standard deviation of the measurement results. The MCNP theoretical flux density and the experimental flux density logarithmic fits are also plotted, and they compare well. For the experimental fit, locations A through D and G only were accounted for in the power function fit.

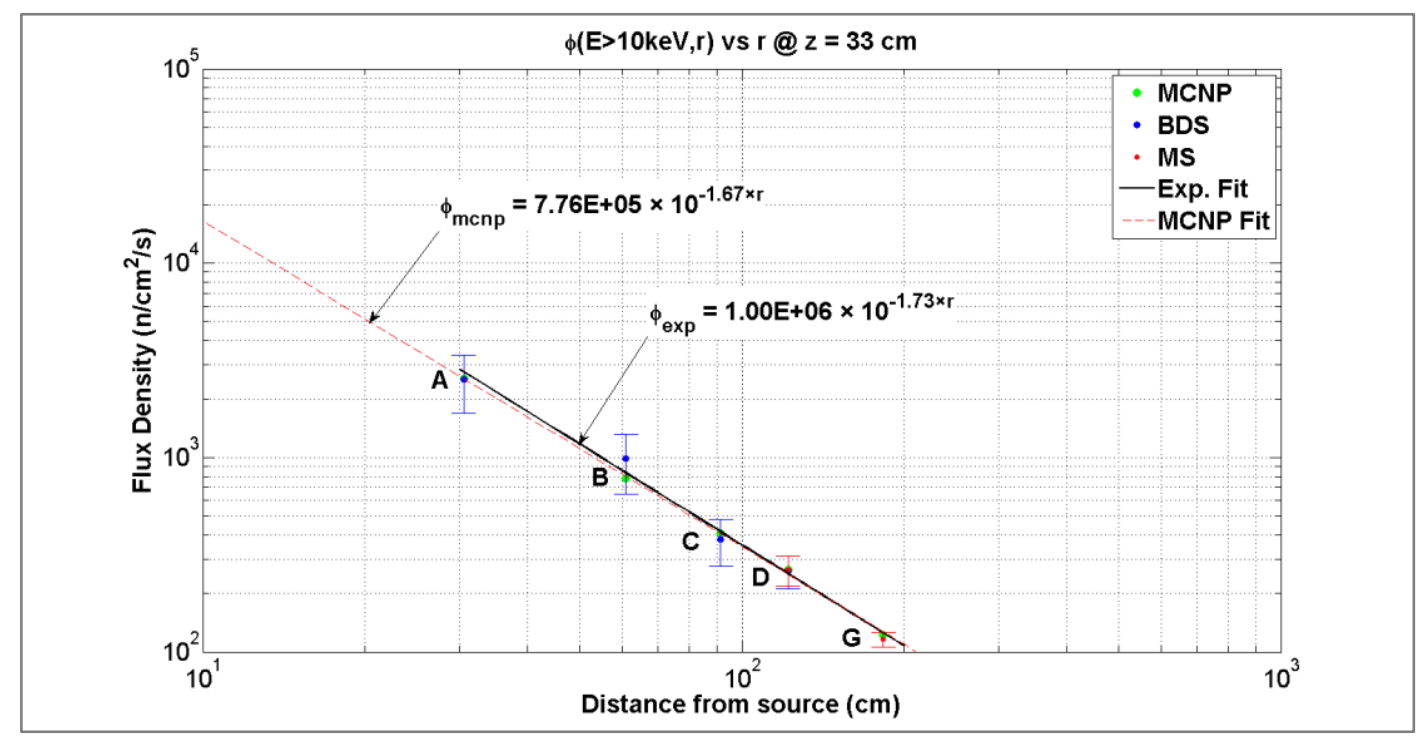

Figure 42. Neutron Flux Density as a Function of Distance from the Source 


\subsection{Summary of Dosimetric Results}

From the neutron spectral information, it is possible to calculate the effective dose to a human body. The values in Table XV were calculated by converting the neutron flux densities to the effective dose rates using the ICRP-74 neutron dose conversion factors. The columns in Table XV are displayed in a similar fashion to Table XIV along with the measurements obtained with the Portable Survey Neutron REM Meter Model E-600/NRD.

Table XV. Neutron Effective Dose Rate at All Measurements Locations

\begin{tabular}{|c|c|c|c|c|c|c|}
\hline \multirow{2}{*}{ Location } & \multirow{2}{*}{$\begin{array}{c}\text { Distance } \\
(\mathbf{c m})\end{array}$} & $\begin{array}{c}\text { All } \\
\text { Energy }\end{array}$ & $\mathbf{E}>\mathbf{1 0 k e V}$ & $\mathbf{E}>\mathbf{1 0 k e V}$ & $\mathbf{E}>\mathbf{1 0 k e V}$ & \\
\cline { 3 - 7 } & & MCNP & MCNP & Microspec & BDS & E-600/NRD \\
\hline A & 30.5 & 337 & 332 & & $290 \pm 60$ & \\
\hline B & 61.0 & 99 & 95 & & $110 \pm 20$ & \\
\hline C & 91.4 & 51 & 47 & & $50 \pm 14$ & \\
\hline D & 121.9 & 33 & 29 & $28 \pm 5$ & $40 \pm 7$ & 22.1 \\
\hline G & 182.9 & 15 & 13 & $13.8 \pm 1.2$ & & 12.5 \\
\hline F & 144.8 & 0.58 & 0.56 & $0.798 \pm$ & & 0.012 \\
\hline E & 61.0 & 88 & 84 & & $110 \pm 20$ & \\
\hline
\end{tabular}

\section{Errors Reported at one sigma}

As expected, the effective dose rates decreases with distance from the source. It can be seen from the MCNP values that the effective dose rate contribution from the neutrons with energies less than $10 \mathrm{keV}$ is negligible compared with those with energies greater than $10 \mathrm{keV}$. Overall, for most locations, the effective dose rates compare well among the instruments within the range of uncertainty. At location $\mathrm{D}$, the bubble detector dose rate deviates from the MCNP model and the Microspec measurements. This is due to the spectral loss of the lower energy bins by over stripping in the neutron spectrum. Similar to Figure 42, the effective dose rates were plotted as a function of distance from the source for each instrument, and both MCNP model values and experimental data show an approximate $1 / \mathrm{r}^{1.7}$ relationship for the effective dose rate. 


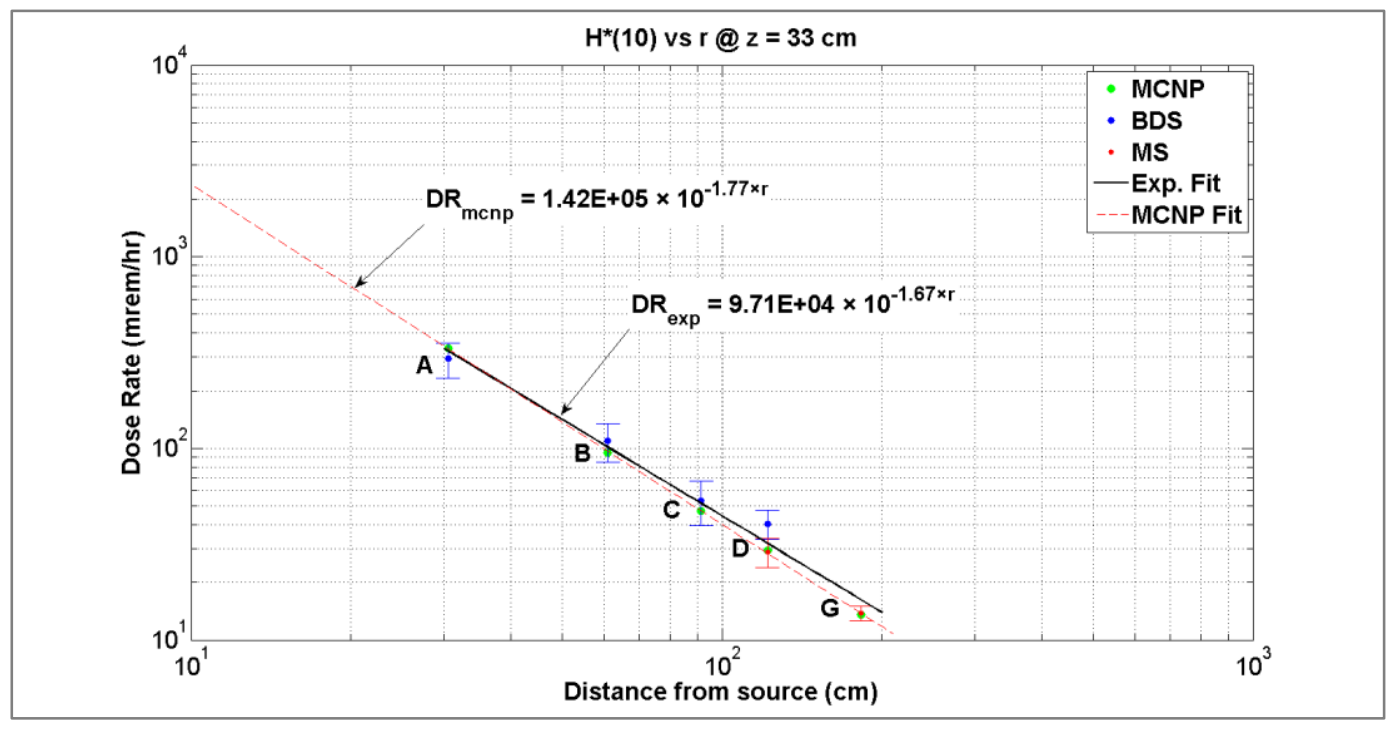

Figure 43. Neutron Effective Dose Rate as a Function of Distance from the Source

\subsection{Neutron and Photon Flux Map in Neutron Irradiation System}

This section presents the three dimensional spatial neutron and photon distribution in a steady state case with the polyethylene shielding door closed. Based on the successful MCNP model validation presented in the previous sections, the model can be utilized to determine other properties of the neutron irradiation system without the need of additional measurements.

\subsubsection{Neutron Flux Density Mapping}

The neutron distribution within the neutron irradiation system was represented visually using the Fmesh feature of the MCNP software. Figure 44 visually demonstrates how the neutrons propagate throughout the shielding, and it shows how strong the field is at any given location. In the figure, the source is located toward the back of the shielding away from the door $30 \mathrm{~cm}$ form the west and the north walls. The spatial domain for the MCNP neutron radiation transport modeling extends from the far right hand side corner of the shielding out to $30 \mathrm{~cm}$ from the shielding's outer wall and door, and up $30 \mathrm{~cm}$ from its top. 

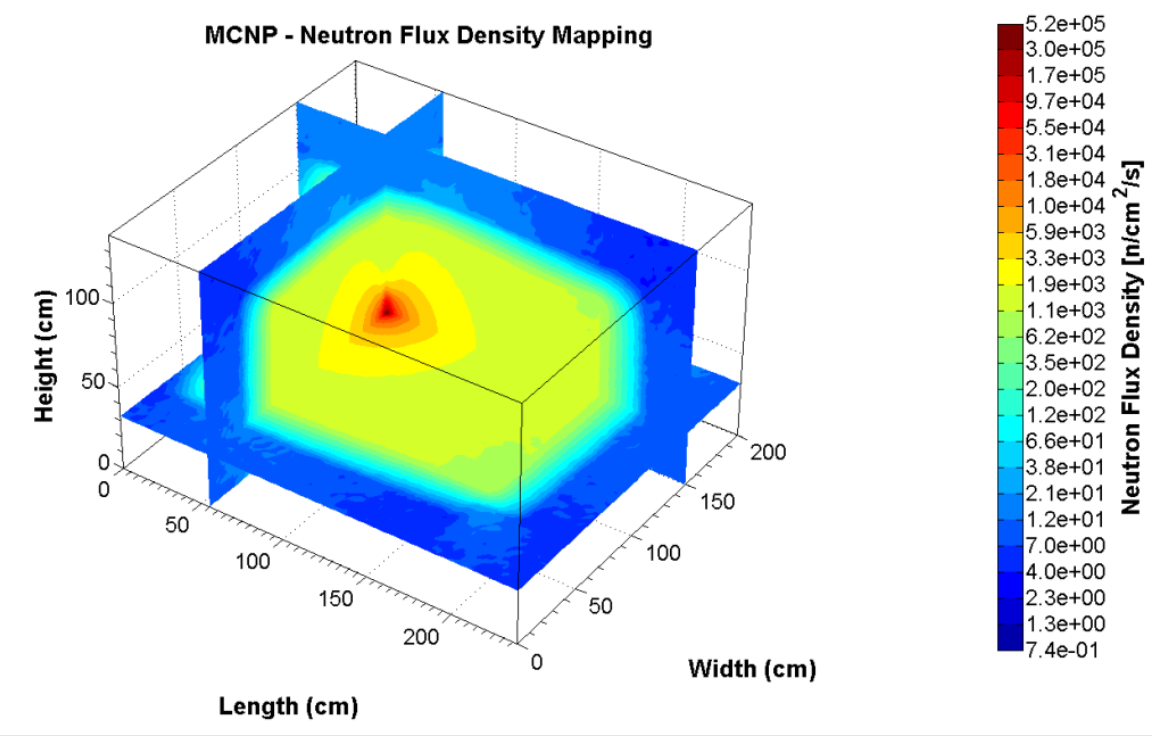

Figure 44. Neutron Transport in Neutron Irradiation System

It can be seen where the wall of the polyethylene shielding begins and ends because this is where the neutron intensity decreases substantially. As expected, the neutron intensity decreases as a function of distance from the source, and it also decreases substantially as it propagates through the polyethylene shielding. There is minor leakage through the cracks of the polyethylene door. The figure shows that the radioactive material in the source behaves similar, but not exactly, to a point source.

\subsubsection{Photon Flux Density Mapping}

Similarly, the photon component can be modeled using MCNP. Figure 45 is set up in a similar fashion to Figure 44. In this figure, the only photons accounted for are photons induced by neutrons. The SFC was modeled using material 304 stainless steel, which contains $69 \%$ iron, $19 \%$ chromium, $9.3 \%$ nickel, $2 \%$ manganese, and $0.7 \%$ other materials by weight. The $2,200 \mathrm{~m} / \mathrm{s}$ absorption cross sections, not including 'other materials,' for each of the elements are 2.55 barns, 3.1 barns, 4.43 barns, and 13.3 barns, respectively. The scatter cross sections are 10.9 barns, 3.8 barns, 17.3 barns, and 2.1 barns $^{(29)}$, respectively (not including 'other material'). This information is provided to make a judgment as to which element is more likely to capture neutrons, and which element is likely to scatter a neutron. 
The 'other materials' are carbon, silicon, phosphorus, and sulfur, and the probability of a gamma emission or neutron scatter from them is highly unlikely since they represent less than $1 \%$ of the material by weight. Most of the 'other materials' do not generate a significant amount of photons, relatively speaking. There are many nuclear reactions and processes occurring in the SFC that contribute to the large production of photons, and only the top two most abundant materials in the SFC will be discussed.

The SFC is composed mostly of iron, and iron is a likely candidate for producing a significant number photons. In the gamma spectrum from Table XII, there are two possible inelastic scattering peaks identified by the HPGe detector. Inelastic scattering of iron, ${ }^{56} \mathrm{Fe}(\mathrm{n}, \mathrm{n} \gamma)$, was detected at $1.24 \mathrm{MeV}$ and possibly at $0.84 \mathrm{MeV}$. It is difficult to quantify whether all or some of the peaks originated in the SFC or in the HPGe detector encapsulation. Although ${ }^{56} \mathrm{Fe}$ is a stable nuclide, neutron capture by ${ }^{56} \mathrm{Fe}$ also emits prompt gamma rays. There are two possible nuclides from natural iron that may capture neutrons, and they are ${ }^{54} \mathrm{Fe}$ and ${ }^{58} \mathrm{Fe} .{ }^{58} \mathrm{Fe}$ cannot be a large contributor to gamma emission because it is less than $0.3 \%$ abundant in natural iron. As for ${ }^{54} \mathrm{Fe}$, although it may be $5.8 \%$ abundant, the neutron capture produces ${ }^{55} \mathrm{Fe}$ which does not emit gammas.

The second most abundant element in the SFC is the chromium, and it generates photons in the SFC. The HPGe detector detected a peak at $1.4 \mathrm{MeV}$ which was identified as inelastic scatter of chromium, ${ }^{52} \mathrm{Cr}\left(\mathrm{n}, \mathrm{n}^{\prime} \gamma\right)$. In regards to neutron capture, there are two possible stable nuclides, and they are ${ }^{50} \mathrm{Cr}$ and ${ }^{54} \mathrm{Cr}$. The natural isotopic abundance of each is $4.3 \%$ and $2.4 \%$, respectfully. Once the chromium stable nuclides absorb neutrons, they create ${ }^{51} \mathrm{Cr}$ and ${ }^{55} \mathrm{Cr}$ which emit gammas. These are a few examples illustrating how photons are generated in the SFC. 

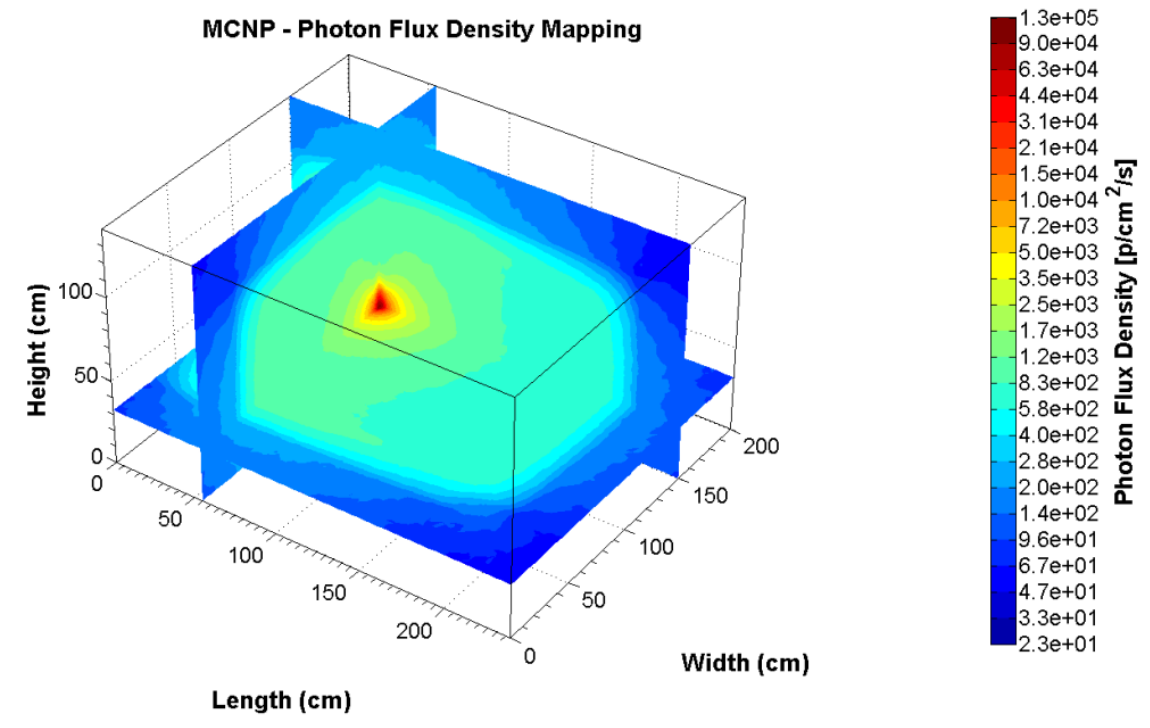

Figure 45. Neutron Induced Photon Transport in Neutron Irradiation System

There is no contribution from the ${ }^{241} \mathrm{Am}$, the neighboring ${ }^{137} \mathrm{Cs}$ sources, or any natural gamma emitter in the MCNP model and the MCNP image. In the case of ${ }^{241} \mathrm{Am}$, most of the low energy photons have been attenuated, but closer look at the gamma spectrum in Table XII results reveals a peak at $0.72 \mathrm{MeV}$. This is a relatively dominant peak in ${ }^{241} \mathrm{Am}$ when the gamma emission is sufficiently strong enough to be detected. This gamma energy may be from the ${ }^{241} \mathrm{Am}$, but it is difficult to determine. It could be coming from inelastic scattering in the borated polyethylene. Further modeling is required to make this determination, and it will be left for future work. In the photon flux density image, it is possible to see the increase of the gamma intensity along the polyethylene wall which is due to the radiative thermal neutron capture in hydrogen inducing the emission of $2.2 \mathrm{MeV}$ gamma-rays.

In summary, the photon flux density image shows significant self-absorption in the SFC. This is one reason why the low energy gamma rays of ${ }^{241} \mathrm{Am}$ were not detected by the HPGe detector. Once the neutrons are emitted from the composite neutron sources, they interact within the SFC. The neutrons elastically scatter, inelastically scatter, and undergo radiative capture generating gamma- and $\mathrm{x}$ - rays and changed particles around the SFC. As expected, the photon flux density decreases as a function of distance. Most of the photons produced in the system originate from neutron interactions in the ${ }^{241} \mathrm{AmBe}$ sources and SFC. 


\section{CHAPTER 6 - NEUTRON SPECTRUM PARAMETRIC ANALYSIS}

Chapter six describes parametric analysis of the neutron irradiation system for various configurations. In the parametric analysis, the validated MCNP model is used to study practical, experimental setups for irradiation of materials and components. The model is also used to examine how simple geometric changes in the setup can be used to modify the energies of neutrons incident on materials. Four configurations were investigated to determine how the neutron spectra change inside the polyethylene chamber. The four configurations are the following: a polyethylene box with a tested object inside, a cadmium box with the tested object inside, polyethylene shields between the source and the tested object, and thick polyethylene block near the wall between source and the tested object. All MCNP tallies were measured at $91 \mathrm{~cm}$ from the source.

\subsection{Polyethylene Box with Tested Object Inside}

In this parametric analysis, a polyethylene box, with a test object to be studied inside, was added to the MCNP model of the neutron irradiation system at $91 \mathrm{~cm}$ from the neutron source. The configuration is shown in Figure 46. The thickness of the box was varied from $2.5 \mathrm{~cm}$ to $25.4 \mathrm{~cm}$. The neutron source was placed in the far right hand corner, and the polyethylene box with tested object was centered at $91 \mathrm{~cm}$ from the source with the door closed. The purpose of this analysis was to determine how the spectra and the average spectral energy change inside the polyethylene box as a function of its thickness.

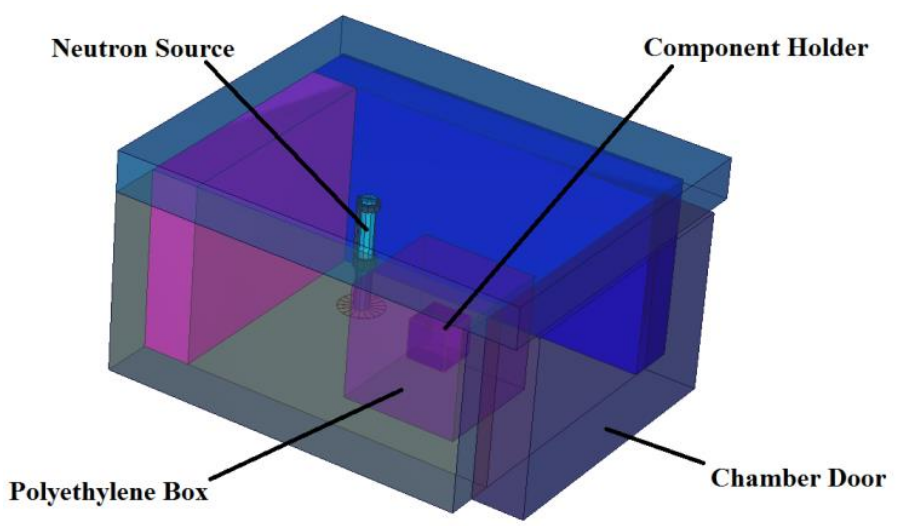

Figure 46. Polyethylene Box inside the Polyethylene Shielding 
Figure 47, shows the changes and effects of the poly-box configuration for the neutron spectra at $91 \mathrm{~cm}$ from the source. From the parametric analysis, it was found that as the polyethylene box thickness increases, the intensity of the fast neutrons decreases, as expected. A strong thermal peak remains inside the poly-box. For a poly-box thickness less than about $5 \mathrm{~cm}$, the thermal neutron peak is not significantly impacted. However, for poly-box thickness greater than about $5 \mathrm{~cm}$, the thermal peak decreases proportionally with the fast neutrons. This is an indicator that the low energy neutrons in the spectra are dependent on the fast neutrons in the system.

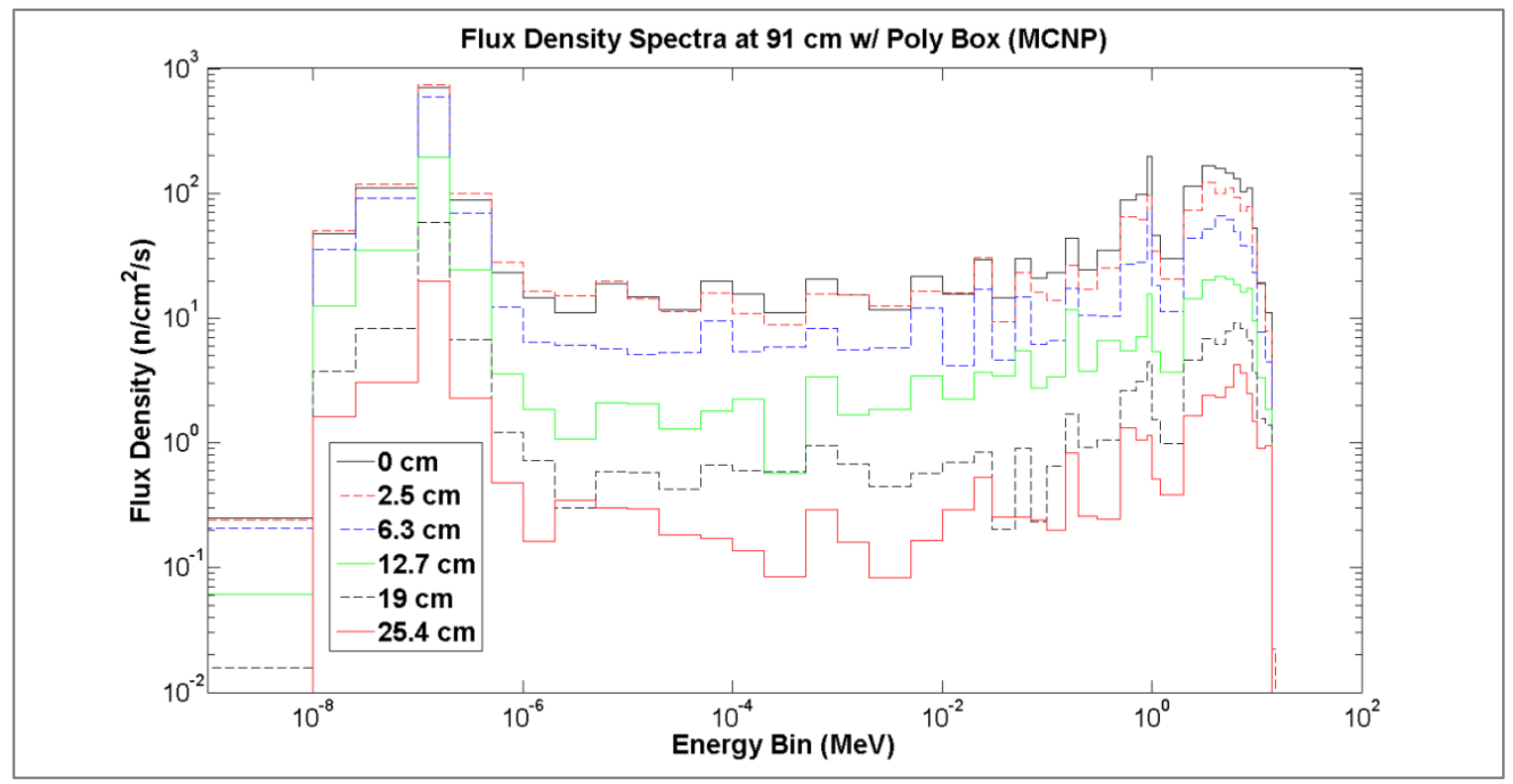

Figure 47. Poly-Box Configuration at $91 \mathrm{~cm}$ Spectra

The average neutron energy for various poly-box thicknesses brings out an interesting relationship. There is an optimal minimum energy at a thickness of about $6 \mathrm{~cm}$ of polyethylene (see Figure 48). If the polyethylene box is any thicker, the spectrum becomes faster due to the loss of low energy neutrons, as they begin to be absorbed in the polyethylene. The average energy as a function of polyethylene box thickness is shown in Figure 48, and the minimum average energy obtainable in this configuration is about $6 \mathrm{~cm}$ of polyethylene thickness at an average energy of $0.45 \mathrm{MeV}$. 


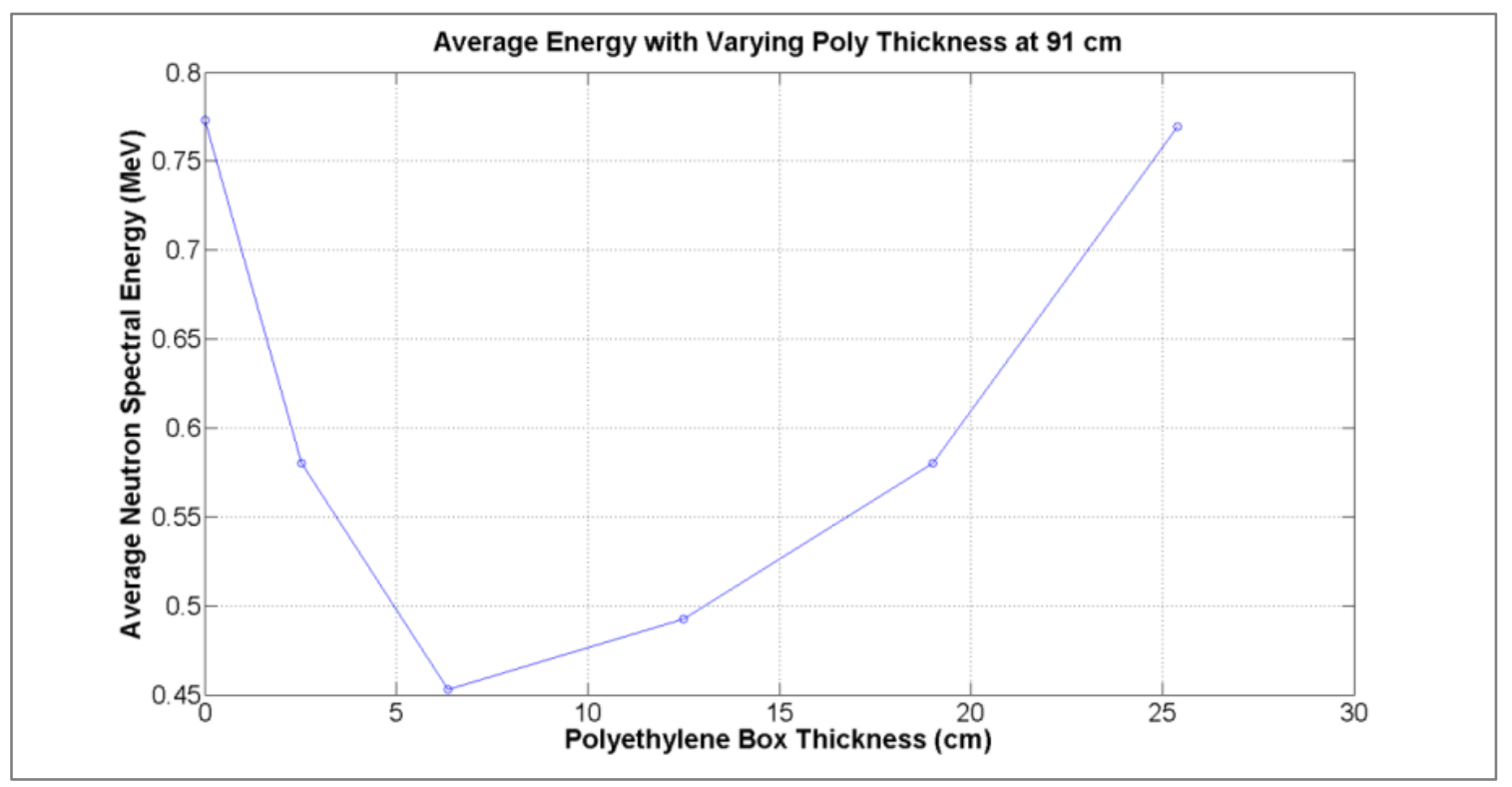

Figure 48. Average Energy as a Function of Polyethylene Box Thickness

From this parametric analysis, it is concluded that to decrease the average energy inside the box using this method, only a few centimeters of polyethylene are recommended. Even though the average spectral energy decreases, the overall neutron intensity is not significantly impacted compared to the original spectrum. The ratio of thermal to fast neutrons as defined in Section 5.4.1 was calculated for this parametric analysis. Without a box, the ratio is 2.22 , and as the thickness of the box increases the ratio oscillates around 4.5 as shown in Table XVI.

Even though the total flux density decreases with increasing thickness, the relative contribution between thermal and fast neutrons does not increase nor decrease. The ratio of thermal to fast neutrons is given in Table XVI. In this table thermal neutrons are defined as neutrons with energies between $10^{-8} \mathrm{MeV}$ and $10^{-6} \mathrm{MeV}$, and the fast neutrons as having energies between $10^{-1} \mathrm{MeV}$ and $10^{1} \mathrm{MeV}$. Thus, even though the average neutron energy is lowest at a box thickness of $6.35 \mathrm{~cm}$, there are actually somewhat more fast neutrons than thermal ones at $6.35 \mathrm{~cm}$ than for a box thicknesses of $2.54 \mathrm{~cm}$ and $12.5 \mathrm{~cm}$. 
Table XVI. Ratio of Thermal to Fast Neutrons for Different Box Thicknesses

\begin{tabular}{|c|c|}
\hline Thickness $(\mathbf{c m})$ & R \\
\hline 0.0 & 2.22 \\
\hline 2.54 & 4.76 \\
\hline 6.35 & 3.86 \\
\hline 12.5 & 5.04 \\
\hline 19.0 & 3.50 \\
\hline 25.4 & 4.13 \\
\hline
\end{tabular}

\subsection{Cadmium Box with Tested Object Inside}

In this parametric analysis, a cadmium box with a tested object was added to the MCNP model of the neutron irradiation system at $91 \mathrm{~cm}$ from the neutron source. The configuration is shown in Figure 49. The thickness of the box was varied from $0.1 \mathrm{~cm}$ to $1 \mathrm{~cm}$. The neutron source was placed in the far right hand corner, and the cadmium box with tested object was centered at $91 \mathrm{~cm}$ from the source with the door closed. The purpose of this analysis was to determine how the spectra and the average spectral energy change inside the cadmium box a function of its thickness.

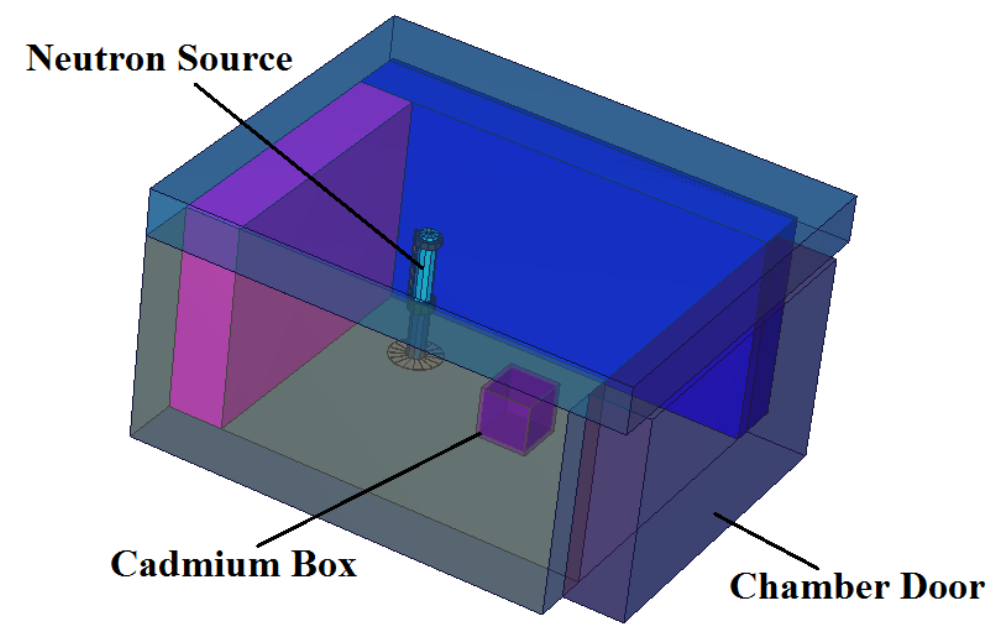

Figure 49. Cadmium-Polyethylene-Source Configuration

From the parametric analysis, it was observed that a very thin layer of cadmium will completely eliminate the thermal peak from the neutron spectrum as shown in Figure 50. It is also shown that the fast neutron spectra are not significantly affected by the cadmium. 


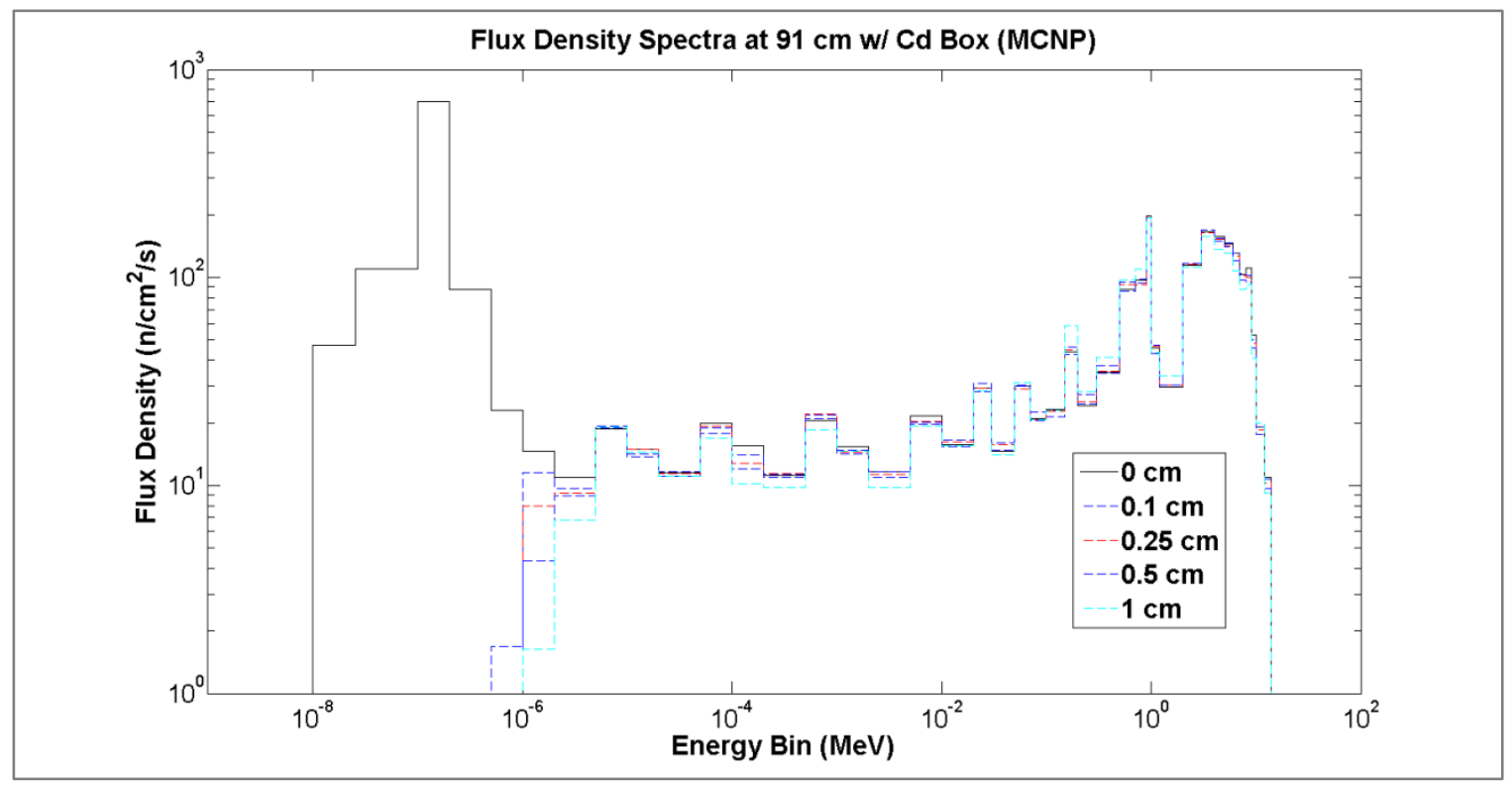

Figure 50. Cadmium Box Neutron Spectra

Using a cadmium box is a simple and practical method of exposing objects to a faster spectrum while inside the polyethylene shielding. The neutron spectrum inside the polyethylene shielding has a significant low-energy component, which results from the fast neutrons interacting with the wall and then scattering back into the irradiation shielding. The cadmium box effectively eliminates this component. In the analysis, the average neutron spectral energy increases from just under $0.8 \mathrm{MeV}$ to almost $2 \mathrm{MeV}$ with just $0.1 \mathrm{~cm}$ of cadmium. For the cadmium thicknesses greater than $0.1 \mathrm{~cm}$, the fast spectra begin to gradually lose neutrons due to the resonances and attenuation in the cadmium. The average energy for the neutron spectra is shown in Figure 51. As before, the ratio of thermal flux density to fast flux density as a function of cadmium wall thickness is given in Table XVII. 


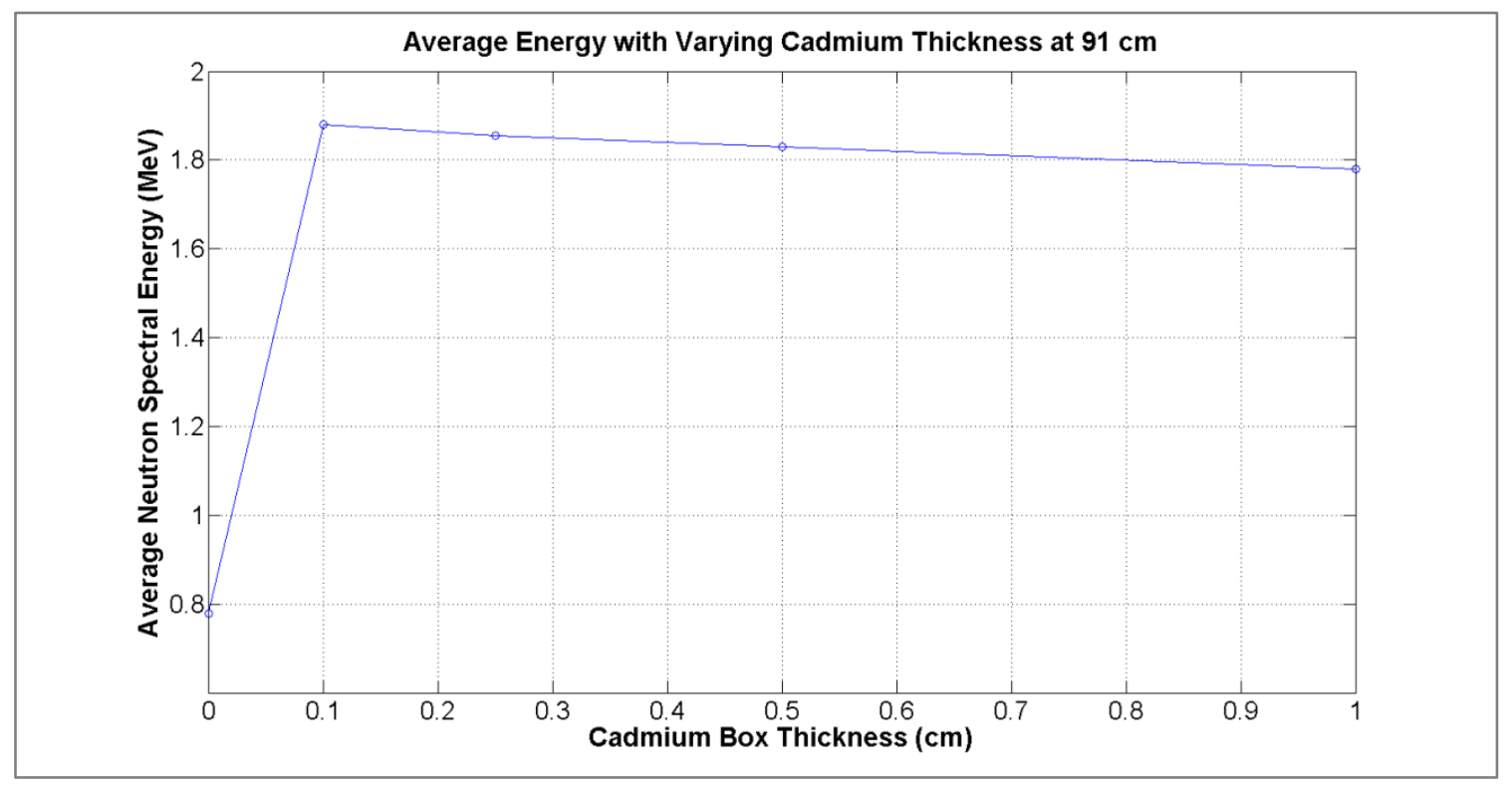

Figure 51. Cadmium Box with Varying Thickness

The ratio between thermal to fast neutrons decreases substantially with the cadmium box as shown in Table XVII. With $1 \mathrm{~mm}$ of cadmium, the ratio decreases by a couple of order of magnitudes, and it does not change by much thereafter. This explains the large gain in the neutron average energy.

Table XVII. Ratio of Thermal to Fast Neutrons for Different Cadmium Thicknesses

\begin{tabular}{|c|c|}
\hline Thickness (cm) & R \\
\hline 0.0 & 2.216 \\
\hline 0.1 & 0.021 \\
\hline 0.2 & 0.031 \\
\hline 0.5 & 0.040 \\
\hline 1.0 & 0.051 \\
\hline
\end{tabular}

It is concluded that a cadmium box of a very small thickness will significantly increase the average neutron energy, provided the cadmium box is thin enough to not absorb fast neutrons.

\subsection{Polyethylene Shield between Tested Object and Neutron Source}

In this parametric analysis, several polyethylene slabs $2.54 \mathrm{~cm}$ thick were added to the MCNP model of the neutron irradiation system. The results were evaluated at $91 \mathrm{~cm}$ from the neutron source. The number of slabs was varied from zero to ten slabs. Another thing to note is that $2.54 \mathrm{~cm}$ of spacing were added between each slab. The purpose of this setup was to decrease the average neutron spectral energy by eliminating 
the fast component from the source and preserving the low-energy component from the wall incident on the irradiated objects. In Figure 52, showing the setup, the neutron source is placed in the far right hand corner of the chamber, and the polyethylene slabs are placed between the source and the $91 \mathrm{~cm}$ detector tally, and the chamber door is closed.

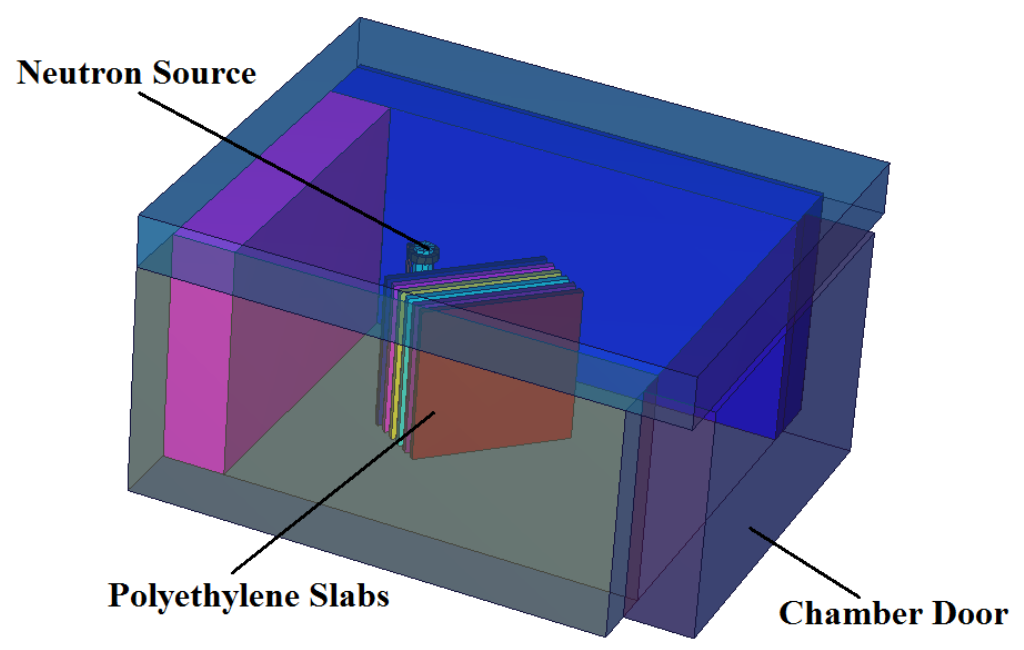

Figure 52. Neutron Irradiation System with Polyethylene Shields

The spectral analysis for this setup was plotted on Figure 53. The analysis showed that as the number of slabs increased, the intensity of the fast neutron contribution from the source decreased. The low-energy peak was affected to a much lesser degree, indicating that the response from the chamber was influenced less than the fast neutron portion of the spectrum by placing the slabs in the chamber. The effect of the first four slabs on the neutron spectrum is greater than that cause by adding more slabs. 


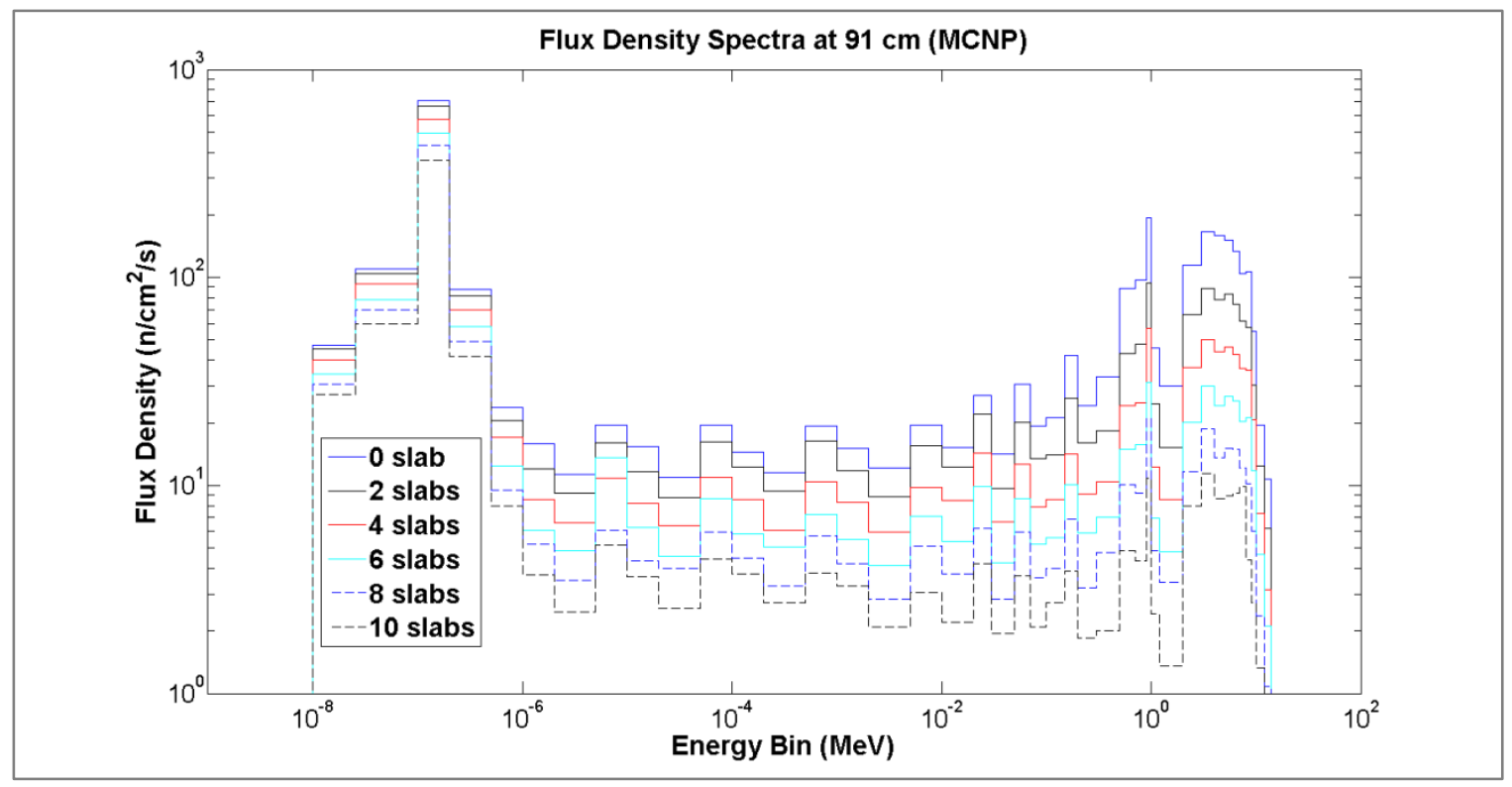

Figure 53. Neutron Spectra for Varying Number of Poly Slabs

As expected, placing a shield between the source and the tested objects decreases the average neutron energy. In Figure 53, it is noted that the slabs have the most effect for the first five slabs. Similar effects can be observed for the average neutron energy. The first five slabs are the most efficient in reducing the average neutron energy. In Figure 54, the average spectral energy is plotted as a function of number of slabs $2.54 \mathrm{~cm}$ thick at $91 \mathrm{~cm}$ and $122 \mathrm{~cm}$ from the source. At $91 \mathrm{~cm}$ with the first five slabs, the energy decreases from $0.79 \mathrm{MeV}$ to $0.31 \mathrm{MeV}$, about $0.48 \mathrm{MeV}$ difference. Adding another five slabs decrease the average energy from $0.3 \mathrm{MeV}$ to $0.15 \mathrm{MeV}$, for about $0.15 \mathrm{MeV}$ difference. Looking at this trend another way, the first five slabs decrease the average energy by $60 \%$, while the second five slabs only decrease the average energy by $50 \%$. 


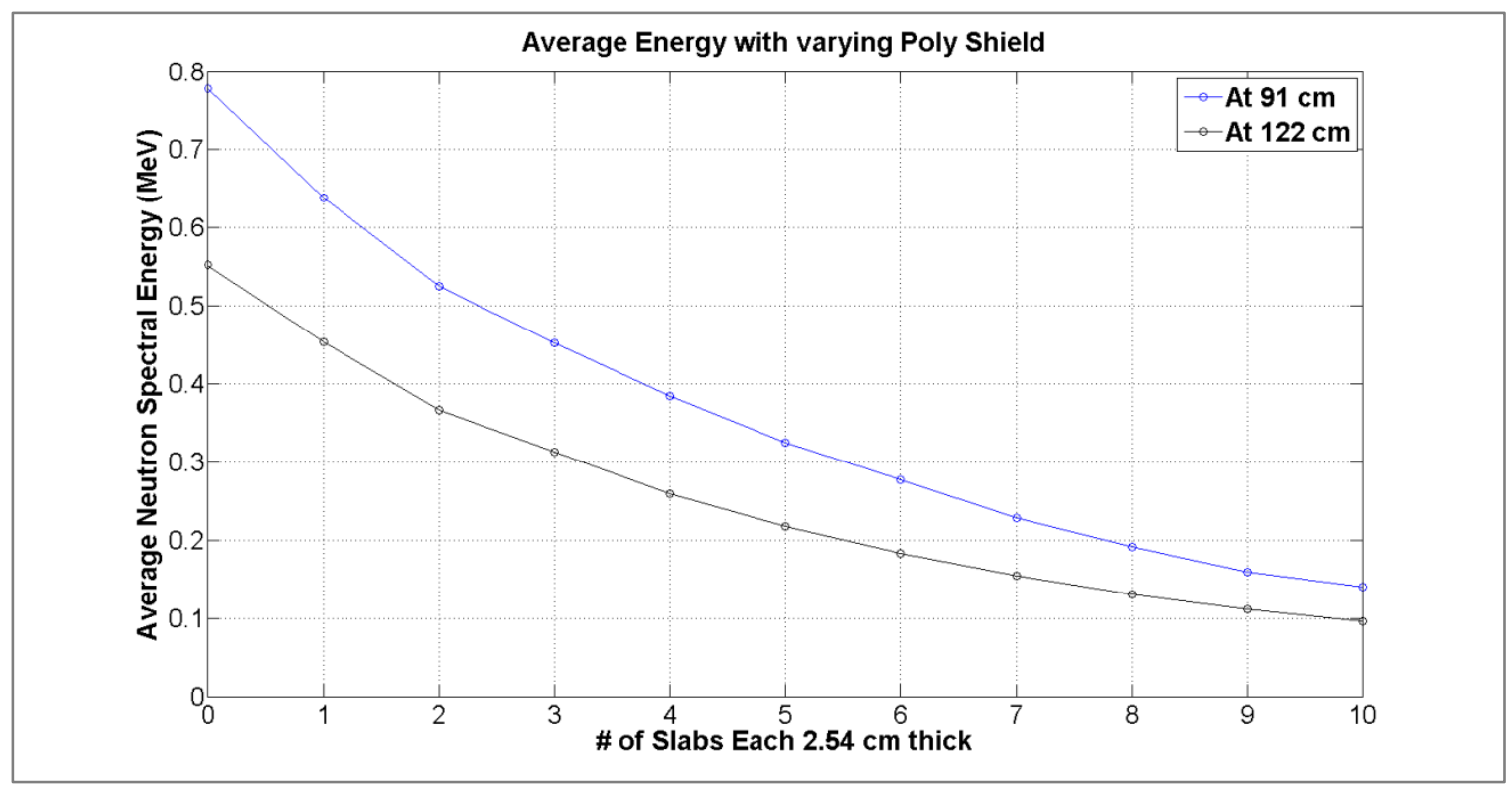

Figure 54. Average Neutron Spectra Energy for Varying Number of Poly Slabs

In Figure 54, the neutron tally was taken not only at $91 \mathrm{~cm}$, but also at $122 \mathrm{~cm}$ to demonstrate that placing the tested object farther away from the neutron source will also decrease the average energy at the object's location. It is concluded that this method will decrease the average neutron energy incident on the tested objects. The ratio between thermal and fast was determined at $91 \mathrm{~cm}$ for varying slabs. The ratio increases as the number of slabs increase. Table XVIII shows the ratio of thermal to fast neutron flux densities as a function of the number of slabs. This table shows that the ratio of thermal neutron flux density to fast neutron flux density varies at approximately the same rate with the number of slabs as does the average neutron energy. 
Table XVIII. Ratio of Thermal to Fast Neutrons at $91 \mathrm{~cm}$ verses the Number of Slabs

\begin{tabular}{|c|c|c|}
\hline \# of Slabs & Thickness $(\mathbf{c m})$ & $\mathbf{R}$ \\
\hline 0 & 0 & 2.24 \\
\hline 1 & 2.54 & 2.92 \\
\hline 2 & 5.08 & 3.87 \\
\hline 3 & 7.62 & 4.84 \\
\hline 4 & 10.16 & 5.90 \\
\hline 5 & 12.7 & 7.21 \\
\hline 6 & 15.24 & 8.45 \\
\hline 7 & 17.78 & 10.29 \\
\hline 8 & 20.32 & 12.06 \\
\hline 9 & 22.86 & 14.49 \\
\hline 10 & 25.4 & 17.97 \\
\hline
\end{tabular}

\subsection{Low Energy Neutron Flux Configuration Using Polyethylene Block}

In this parametric analysis, a block of polyethylene was added to the MCNP model. It was placed up against the north polyethylene wall. The tally was calculated at $91 \mathrm{~cm}$ away from the neutron source, and the thickness of the polyethylene block was varied. The thickness of poly-block was varied from $12.7 \mathrm{~cm}$ to $63.5 \mathrm{~cm}$. The purpose of this analysis was to evaluate if placing a poly-block in the chamber will decrease the average neutron spectral energy by reducing the fast component from the source and preserving the low-energy component from the wall at the object's location. This arrangement is a variation of the poly-shield setup presented in Section 6.3, but location of the poly-block inside the chamber is the key in reducing the average neutron energy spectrum. The arrangement is shown in Figure 55. The neutron source is placed in the far right hand corner, and the polyethylene block is placed on the northern wall between the source and the $91 \mathrm{~cm}$ detector tally; the chamber door is closed. A small gap was left between the poly-block and the top of the shielding, so that more neutrons coming from the chamber walls can arrive at the location of the tested object. 


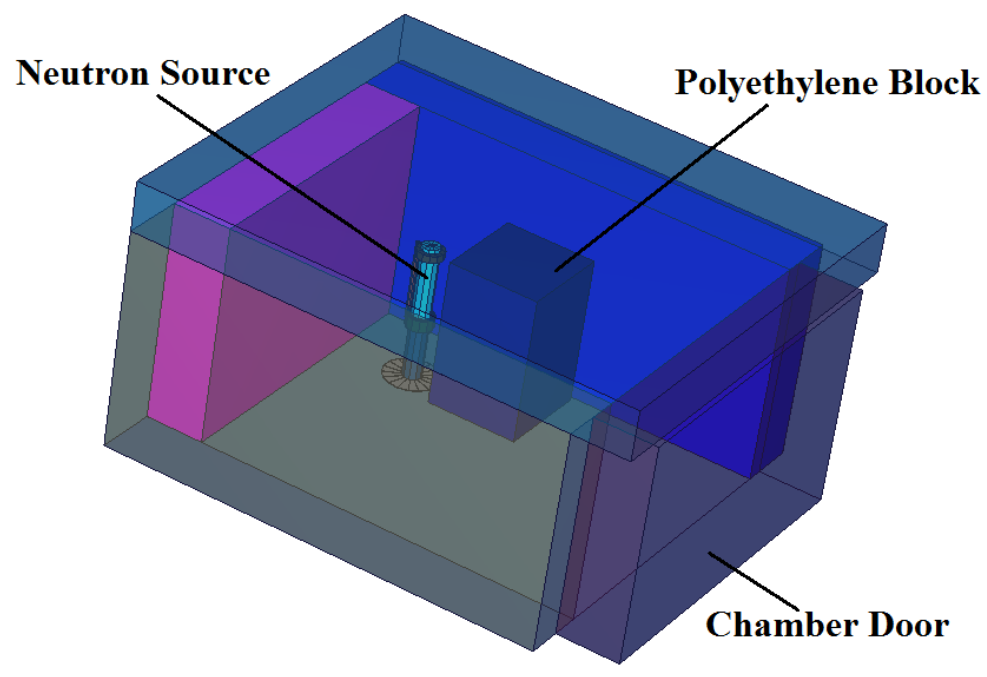

Figure 55. Polyethylene Block Configuration

Figure 56 shows a plot of the average neutron spectral energy as a function of polyethylene block thickness. It can be seen that placing the polyethylene block in this configuration significantly decreased the average neutron spectral energy incident on a tested object at $91 \mathrm{~cm}$ from the neutron source. This is an effective method for reducing the fast neutron component of the spectrum. The energy at that location with no block present is $0.79 \mathrm{MeV}$, and with $30 \mathrm{~cm}$ of polyethylene block thickness, the average energy is $0.12 \mathrm{MeV}$, about $0.67 \mathrm{MeV}$ difference. If another $30 \mathrm{~cm}$ of polyethylene are added, totaling $60 \mathrm{~cm}$, this further decreases the average energy from $0.12 \mathrm{MeV}$ to $0.06 \mathrm{MeV}$, about $0.06 \mathrm{MeV}$ difference (a decrease of another factor of two). Although the first $30 \mathrm{~cm}$ is the most effective in reducing the average neutron energy, this configuration makes it possible to bring the average neutron energy at the location of the tested object to as low as $60 \mathrm{keV}$. 


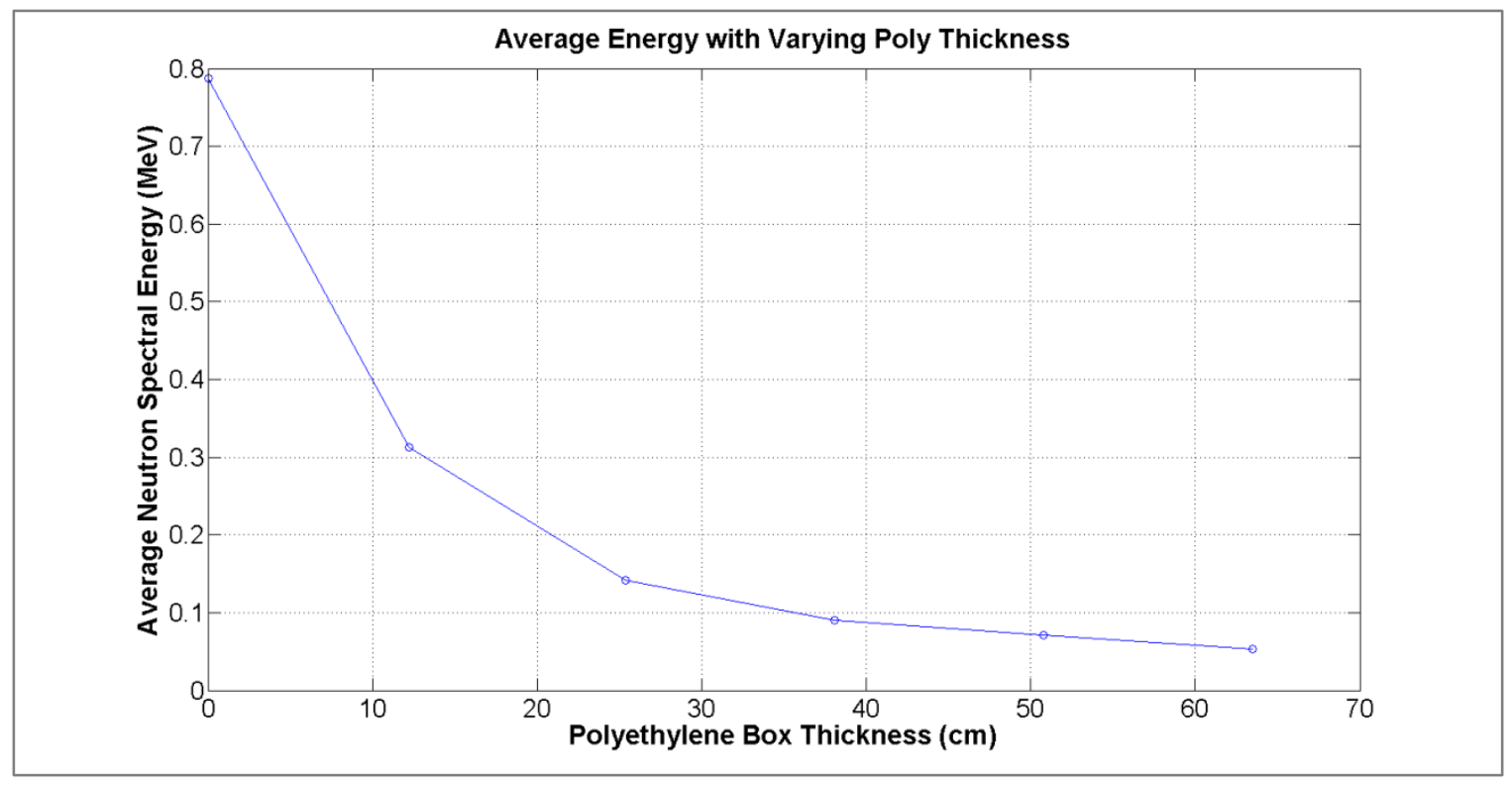

Figure 56. Average Neutron Energy with Varying Polyethylene Block Thickness

Investigation of the neutron spectra reveals that the fast component is almost completely removed while the thermal peak coming from the polyethylene shielding still remains in the spectrum. This effect is shown in Figure 57. The largest decrease in the fast region occurs with the first $30 \mathrm{~cm}$ of polyethylene thickness at $91 \mathrm{~cm}$ from the source. Table XIX gives the ratio of thermal flux to fast flux as a function of block thickness.

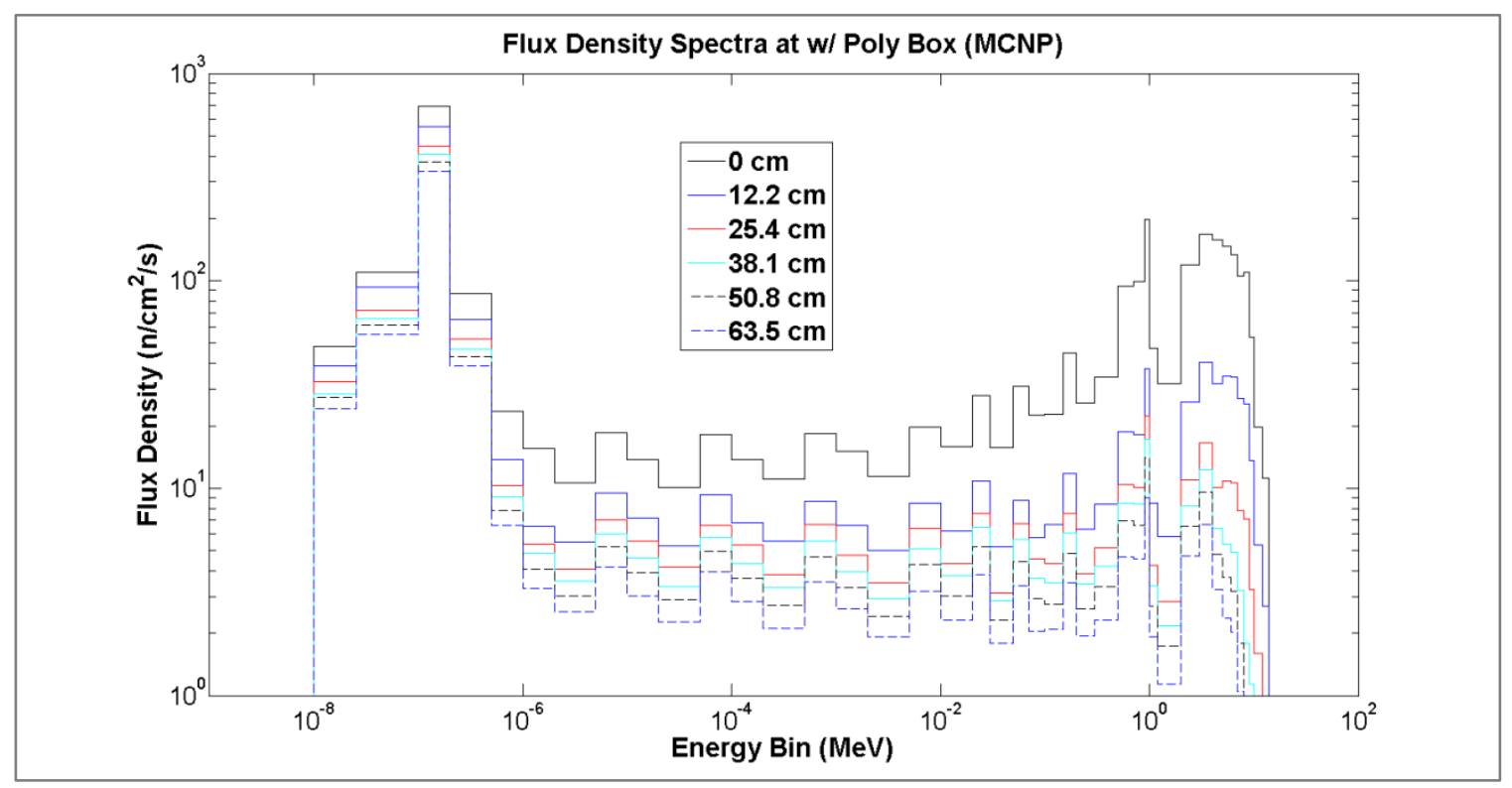

Figure 57. Thermal Neutron Spectra with Polyethylene Block 
It is concluded from the parametric analysis that to maximize low-energy neutron fluence at the tested object, the object has to have maximum view of the wall but be shielded from the source. The reason the poly-shield configuration from Section 6.3 was not as effective in reducing the average energy is because the visibility of the wall to the component was reduced. This is an interesting effect, and should be noted. If multiple experiments are placed inside the chamber, and if the objects are relatively large and contain low $\mathrm{Z}$ material, they may affect the average neutron energy at the neighboring irradiated objects.

\section{Table XIX. Ratio of Thermal to Fast Neutrons for Varying Block Width}

\begin{tabular}{|c|c|}
\hline Thickness (cm) & R \\
\hline 0.0 & 2.15 \\
\hline 12.2 & 9.63 \\
\hline 25.4 & 21.79 \\
\hline 38.1 & 30.39 \\
\hline 50.8 & 39.26 \\
\hline 63.5 & 56.84 \\
\hline
\end{tabular}

The ratio of thermal to fast neutrons was calculated for this configuration in Table XIX. There is a significant contribution of thermal neutrons relative to fast neutrons for this location. For a thickness of $63.5 \mathrm{~cm}$, there are 57 times more thermal neutrons than fast neutron. The polyethylene slabs and the box can be compared for a thickness of $25.4 \mathrm{~cm}$. At this thickness, the ratio for the slabs is 18 , and the ratio for the box is 22 . This confirms that the polyethylene block is still a superior configuration for obtaining the most number of low energy neutrons using simple manipulations with polyethylene within the irradiation system. 


\section{CHAPTER 7 - ABSORBED DOSE TO VARIOUS MATERIALS}

Chapter seven provides the calculated absorbed dose rates to various materials for future irradiation of those components using the neutron irradiation system. There are many types of materials that could be irradiated. At request of the Gamma Irradiation Facility (GIF) personnel, the absorbed dose rate to water, polyethylene, and silicon at various locations in the neutron irradiation system was calculated. The absorbed dose rates were calculated using neutron dose conversion factors (DCFs) and the neutron flux density results from the validated MCNP model. The conversion factors were obtained from "Kerma Factors of Elements and Compounds for Neutron Energies below $30 \mathrm{MeV}$ " by R. S. Caswell et al. This is a good reference for other materials for future irradiations ${ }^{(42)}$.

Figure 58 shows the neutron DCFs that were used in dose calculations as a function of energy for their respective materials. The figure also demonstrates that the energy absorbed in a material per unit flux density depends on the neutron energy, and it is generally greater at higher energies. It also demonstrates that hydrogenous materials (water and polyethylene) absorb neutron energy better than silicon, which is dependent on the cross-sections and nuclear properties.

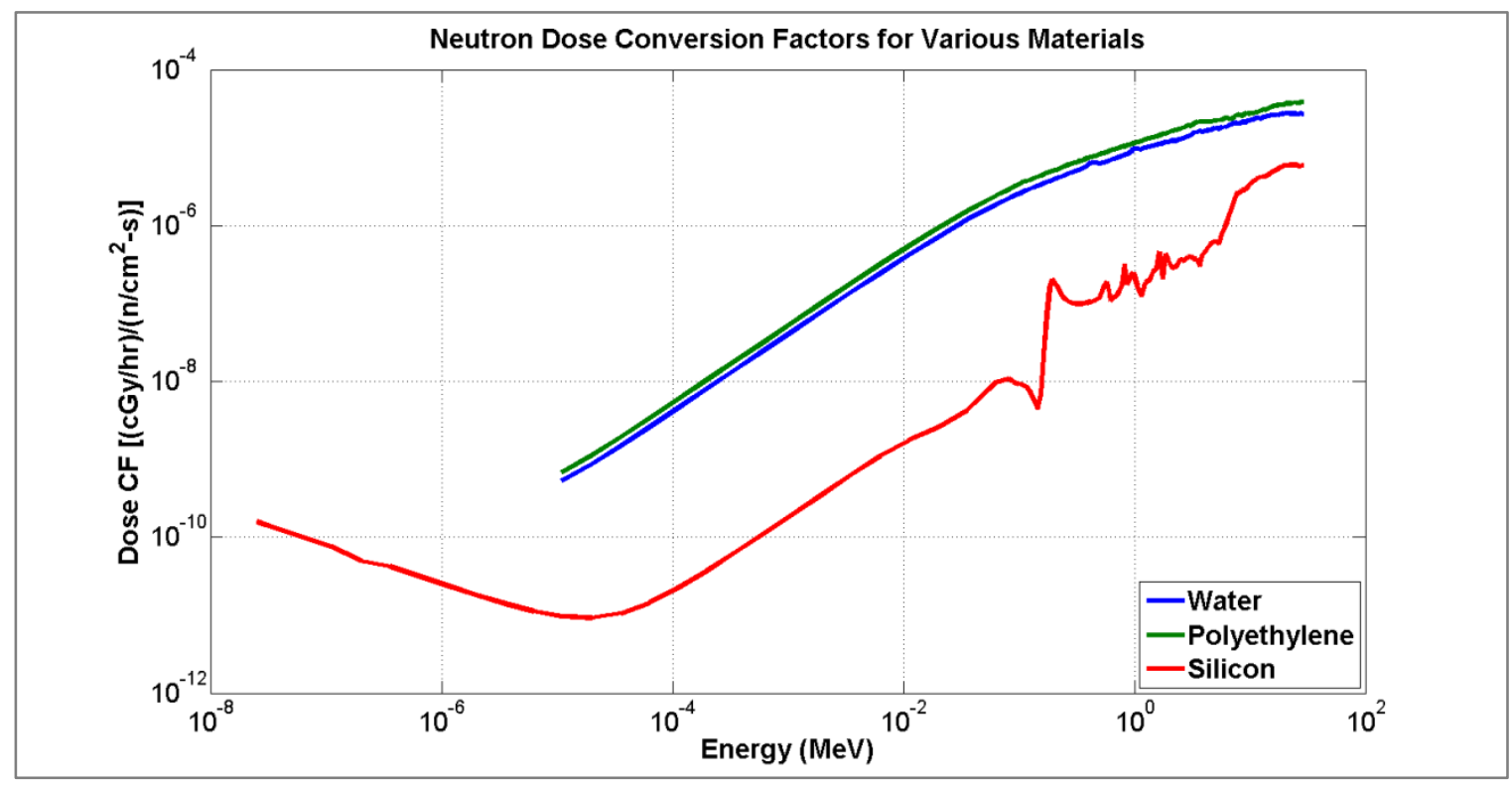

Figure 58. Neutron Dose Conversion Factors for Material of Interest ${ }^{(42)}$

As was indicated in Figure 32, although the neutron flux density decreases with distance from the source, the general shapes of the neutron spectra are similar. The 
absorbed dose rates to a material depend on the DCFs and the shape of the spectrum. This effect is shown in Figure 59. The water and polyethylene absorb more dose per unit incident neutron energy than does the silicon. For the neutron irradiation system, the neutron spectral shape does not change significantly as it propagates through the shielding; the decrease in absorbed dose verses distance shown in Figure 59 is due largely to the decrease in the fast neutron flux with distance.

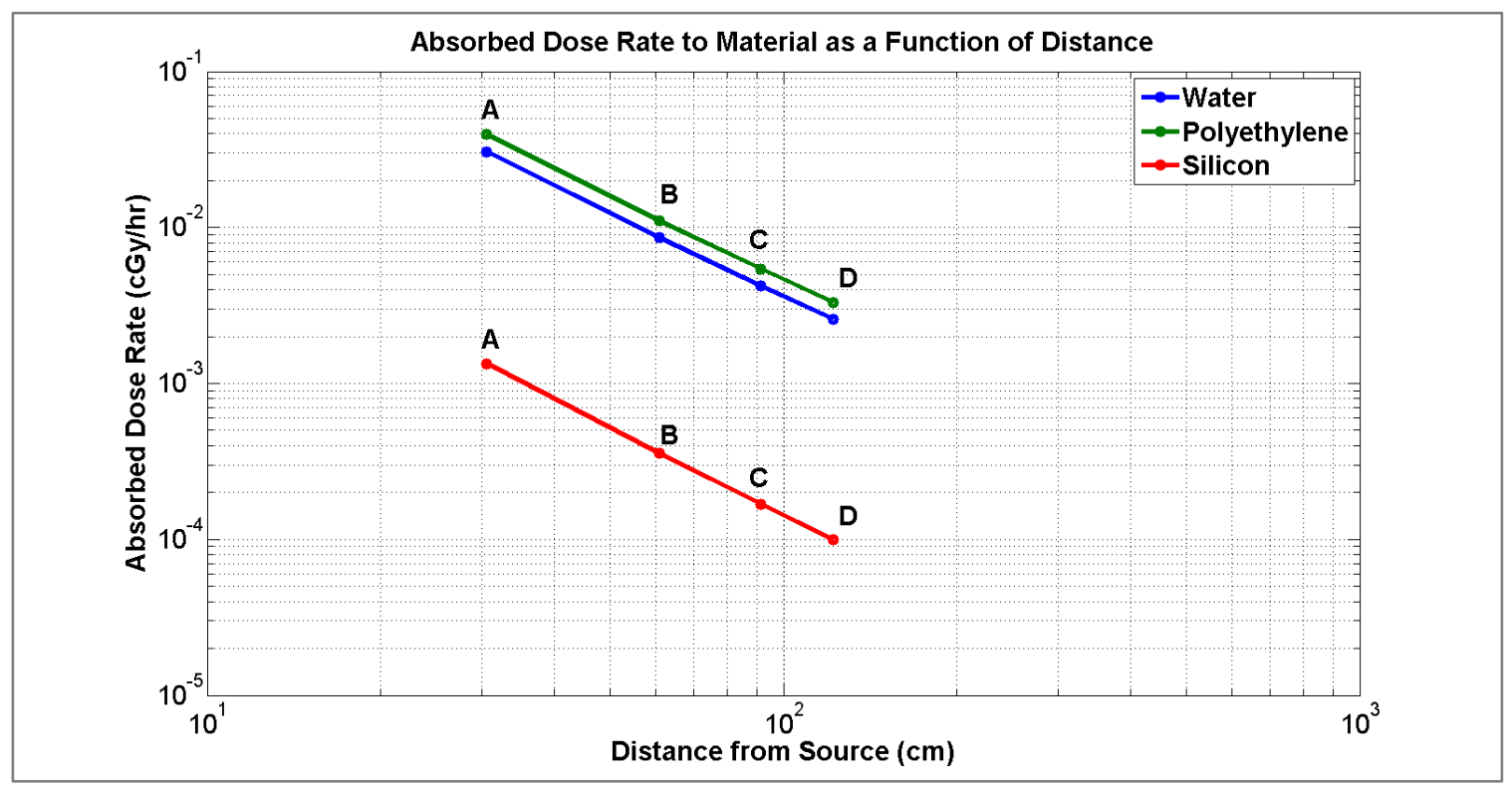

Figure 59. Dose Rates for Various Materials as a Function of Distance

As a compliment to Figure 59, Table XX provides the tabulated values and locations to serve as a guide for absorbed dose rates for water, polyethylene, and silicon. The absorbed dose rate to the material decreases as a function of distance, this effect is similar to the effective dose rate. This indicates again that the fast neutrons contribute most to the absorbed dose for these materials.

Table XX. Tabulated Dose Rate for Various Material as a Function of Distance

\begin{tabular}{|c|c|c|c|c|}
\hline & & \multicolumn{3}{|c|}{ Absorbed Dose (cGy/hr) } \\
\hline Location & Distance (cm) & Water & Polyethylene & Silicon \\
\hline A (inside) & 30 & $3.06 \mathrm{E}-02$ & $3.95 \mathrm{E}-02$ & $1.34 \mathrm{E}-03$ \\
\hline B (inside) & 61 & $8.58 \mathrm{E}-03$ & $1.10 \mathrm{E}-02$ & $3.56 \mathrm{E}-04$ \\
\hline C (inside) & 91 & $4.21 \mathrm{E}-03$ & $5.42 \mathrm{E}-03$ & $1.68 \mathrm{E}-04$ \\
\hline D (inside) & 122 & $2.58 \mathrm{E}-03$ & $3.31 \mathrm{E}-03$ & $9.95 \mathrm{E}-05$ \\
\hline G (outside) & 145 & $5.16 \mathrm{E}-05$ & $6.88 \mathrm{E}-05$ & $2.76 \mathrm{E}-06$ \\
\hline
\end{tabular}


For any material, the neutron absorbed dose rate depends on the neutron spectrum (shape and intensity) and on the energy-dependent DCFs for that material. For the neutron irradiation system, the dose rate inside the chamber decreases with distance at a slightly slower rate than the inverse square law. The fast neutron contribution, which is responsible for the majority of the absorbed dose, follows the inverse square law more closely. The low energy component is less differentiated inside the chamber due to the neutron response of the chamber. The absorbed dose rates to materials other than those evaluated in this section can be determined from the neutron spectra and the material specific DCFs by following the same method. 


\section{CHAPTER 8 - CONCLUSIONS}

The primary objectives of this project were to:

1. Understand, characterize, and model the neutron irradiation system, i.e., the ${ }^{241} \mathrm{AmBe}$ neutron source in the polyethylene shielding

2. Benchmark the MCNP model with experimental data using multiple techniques

3. Characterize photon and neutron spectra inside and outside the chamber

4. Map out photon and neutron fields throughout the polyethylene chamber

5. Determine effective dose rate for personnel

6. Vary geometric configuration for customized energy distribution

7. Determine generic absorbed dose rates to specified materials.

All these objectives were met.

The following measurement techniques were used to develop and benchmark the MCNP model of the neutron irradiation system:

Computed photon radiography was used to establish orientation and directionality of the source components inside the SFC and assisted in this project with the following tasks:

1. Aligning MCNP model with the actual physical ${ }^{241} \mathrm{AmBe}$ source components in the SFC,

2. Verifying that the location of the radioactive material inside the SFC was at the bottom of the SCF,

3. Identifying the location of the strongest ${ }^{241} \mathrm{AmBe}$ source at the bottom of the SFC next to one of the other sources.

The HPGe detector was successfully used to understand the photon spectrum in the polyethylene configuration. This instrument assisted in this project in the following ways:

1. The HPGe detector was used to measure photon spectra in the range from $10 \mathrm{keV}$ to $3 \mathrm{MeV}$,

2. The HPGe detector showed that the most significant peak was for the $2.2-\mathrm{MeV}$ photons coming from the chamber walls rather than the source,

3. The HPGe detector showed all significant peaks in the spectra from inelastic and elastic neutron interactions,

4. The HPGe detector provided the background photon spectrum in the shielding. 
The N-probe Microspec provided an understanding of the fast/low energy neutron spectra inside and outside of the polyethylene shielding. This instrument assisted in this project in the following ways:

1. Provided 17-bin spectral flux density measurements for locations with dose rates less than $300 \mu \mathrm{Sv} / \mathrm{hr}(30 \mathrm{mrem} / \mathrm{hr})$,

2. Confirmed ${ }^{241} \mathrm{AmBe}$ source energy spectral distribution,

3. Confirmed neutron spectra shift caused by SFC,

4. Served as primary neutron measurement instrument.

The BDS set provided an understanding of the fast neutron spectra inside the polyethylene near the source. The instrument was used in this project in the following ways:

1. Provided spectral measurement for locations less than $1,000 \mathrm{mrem} / \mathrm{hr}$ and as low as $200 \mu \mathrm{Sv} / \mathrm{hr}(20 \mathrm{mrem} / \mathrm{hr})$,

2. Confirmed ${ }^{241} \mathrm{AmBe}$ source spectral energy distribution,

3. Served as secondary, confirmatory neutron measurement.

The activation foils assisted in the characterization of the thermal neutron portion of the spectrum. These foils were used in this project in the following ways:

1. The gold foils measured neutrons with energy less than $0.5 \mathrm{eV}$,

2. The gold foils provided experimental value for the thermal flux at $30 \mathrm{~cm}$ from the source.

The MCNP model was developed and benchmarked against the techniques described above. The model was used in the following ways:

1. The MCNP model allowed for overall understanding of radiation transport throughout the shielding configuration,

2. The MCNP model allowed for parametric studies with the goal of modifying the radiation flux density and neutron energy spectrum,

3. The MCNP model allowed for determination of absorbed dose to materials and effective dose to personnel. 
All of these methods were useful and beneficial in meeting the objectives of this project with adequate accuracy. These techniques, instruments, and methods are reliable given they are properly understood and utilized within their operational limits.

\subsection{Future Work}

There was only one measurement for the gold foil at $30 \mathrm{~cm}$. It would be beneficial to properly characterize the thermal neutron spectra by adding more gold foils in other locations of the irradiation system. According to the MCNP model, the thermal spectra should not vary by much with the door closed, and it should be verified.

Additional measurements with the Microspec are desired in front of the door with the door closed to compliment the measurement that was made with the door open. Only one measurement was taken outside of the irradiation system with the door closed at location $\mathrm{F}$, and the additional measurement at location $\mathrm{G}$ in similar configuration would provide an understanding of the neutron transmission through the borated polyethylene door.

A repeat of the gamma background is also desirable without the source in the LDRIF south cell. When the gamma background was obtained, the measurement was taken inside of the neutron irradiation system with the expectation of having a low enough flux density to use the HPGe detector inside. Unfortunately, that was underestimated, and the gamma measurement of the source occurred outside of the polyethylene chamber with the door open while the background was measured inside. It is uncertain if the backscatter peak in the source measurement is caused by neutron interactions, or if it is caused by the neighboring ${ }^{137} \mathrm{Cs}$ gamma chambers.

The contribution from radionuclide ${ }^{241} \mathrm{Am}$ was not considered in the model, and it was not characterized. This can only be done by creating a model specifically for ${ }^{241} \mathrm{Am}$ by changing the material cross-sections and the source distribution. For the completeness of the overall project, the ${ }^{241}$ Am contribution to the photon flux and dose should be added to the MCNP model results. Once the ${ }^{241} \mathrm{Am}$ is accounted for in the model, it may or may not significantly increase the photon flux density in the irradiation system. 


\section{APPENDICIES}




\section{APPENDIX A: MCNP INPUT DECK}

\section{A.1 Neutron MCNP Input Code}

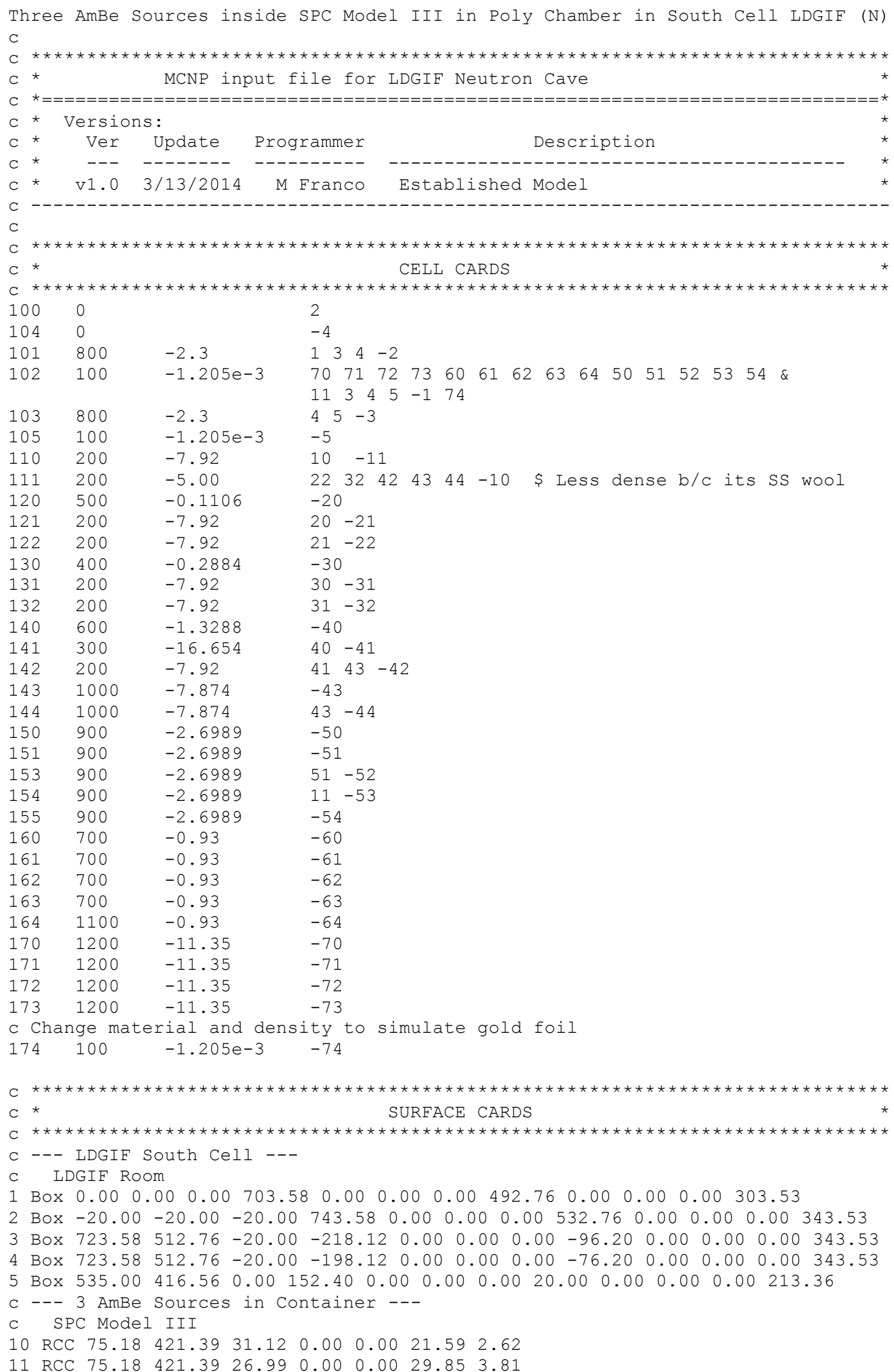




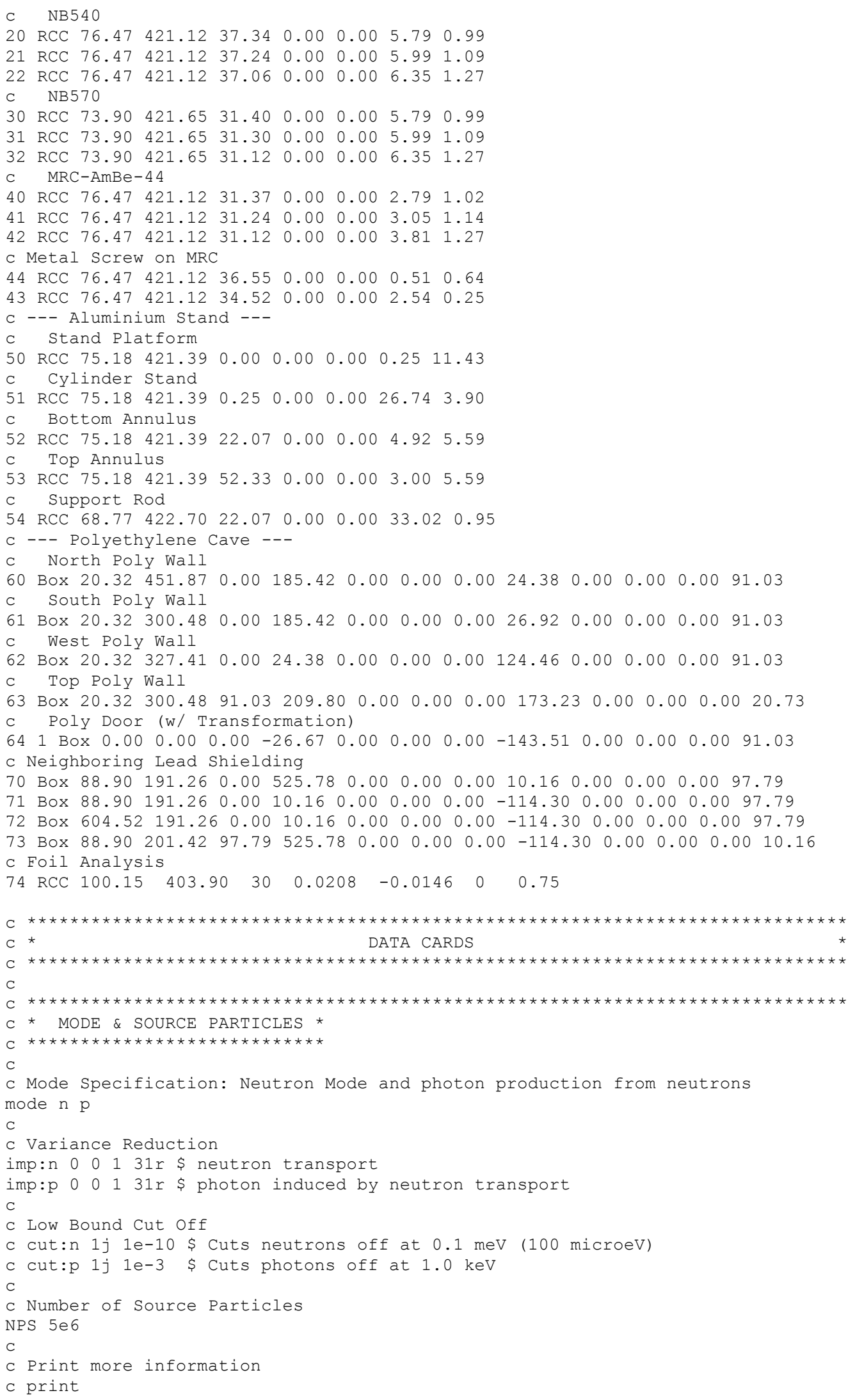




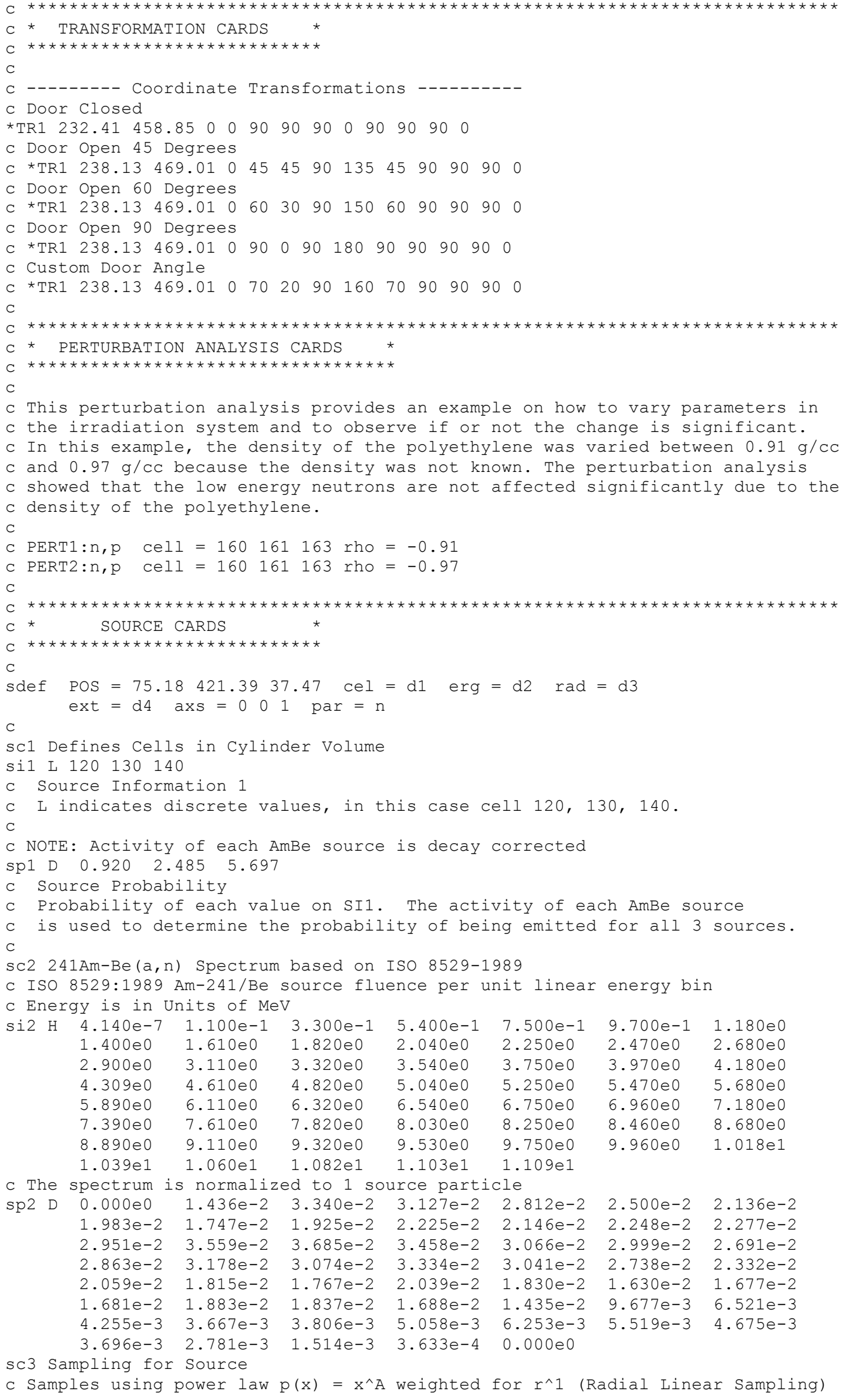




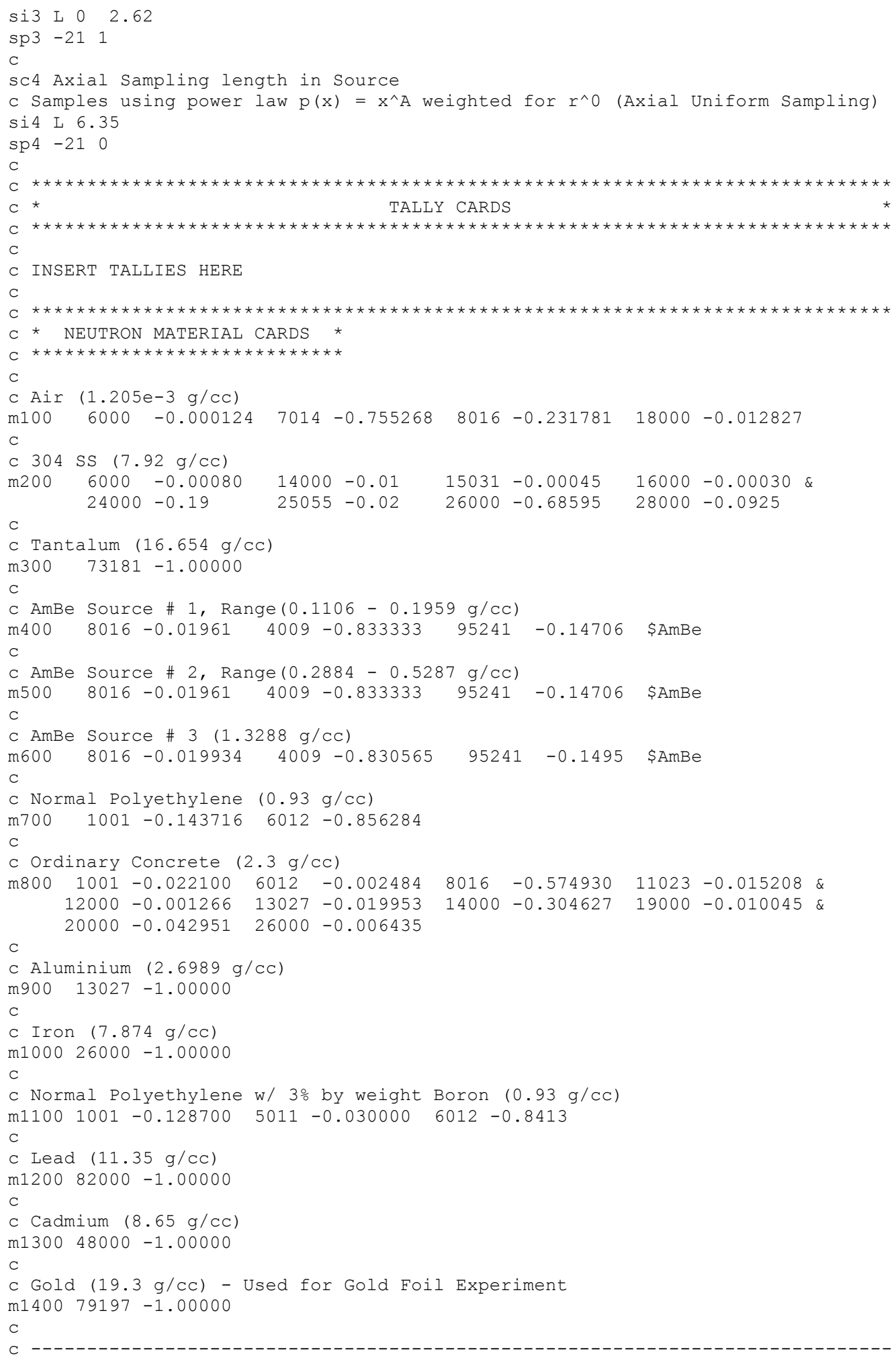




\section{A.2 Radiography Tallies}

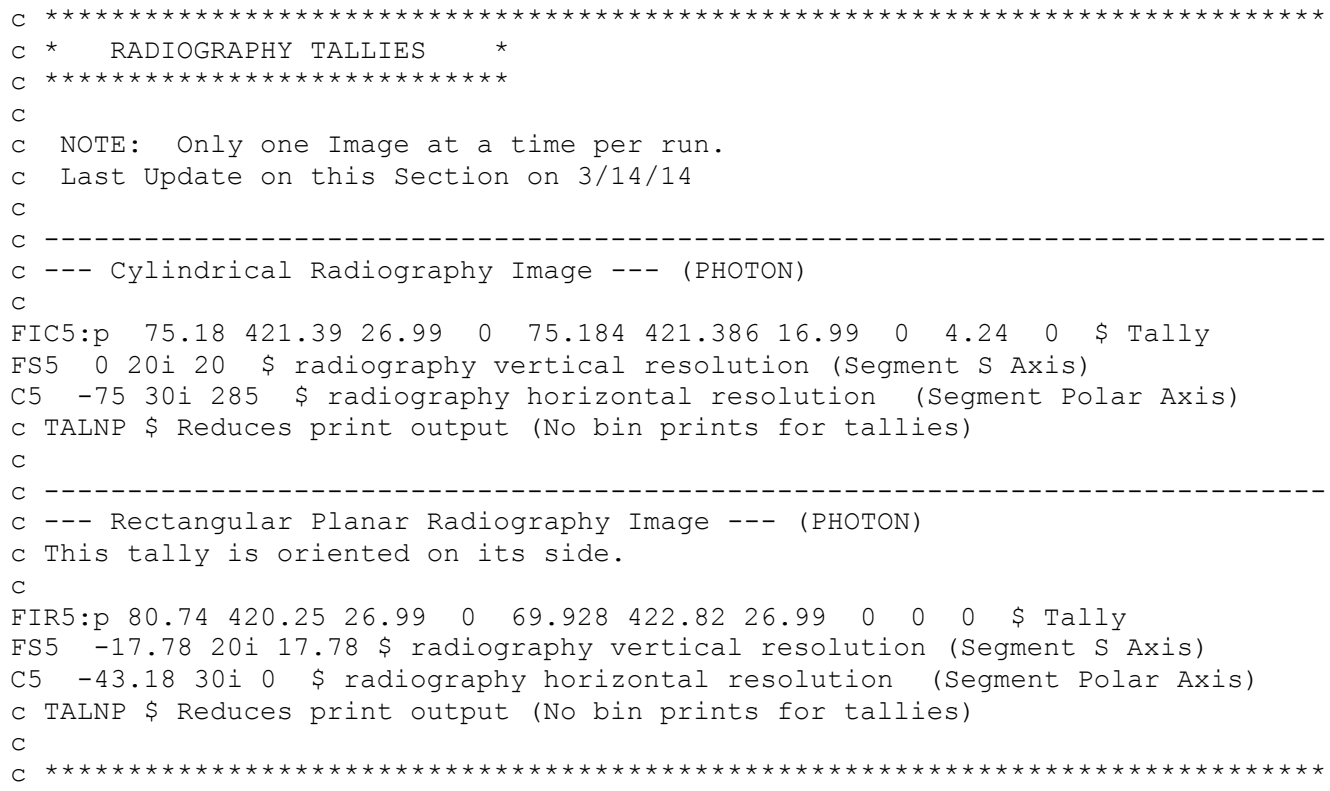

\section{A.3 Bubble Detector Tallies}

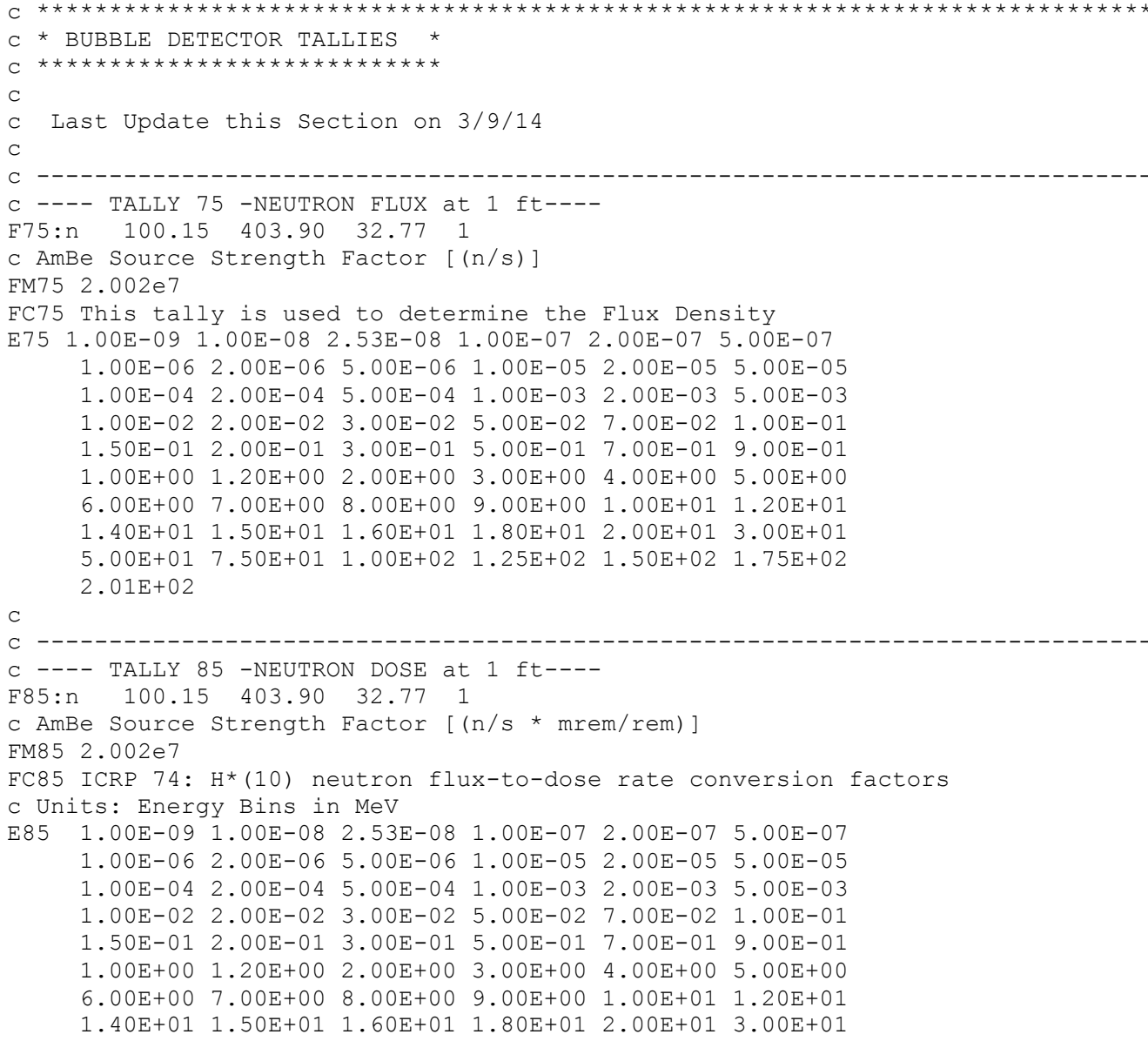




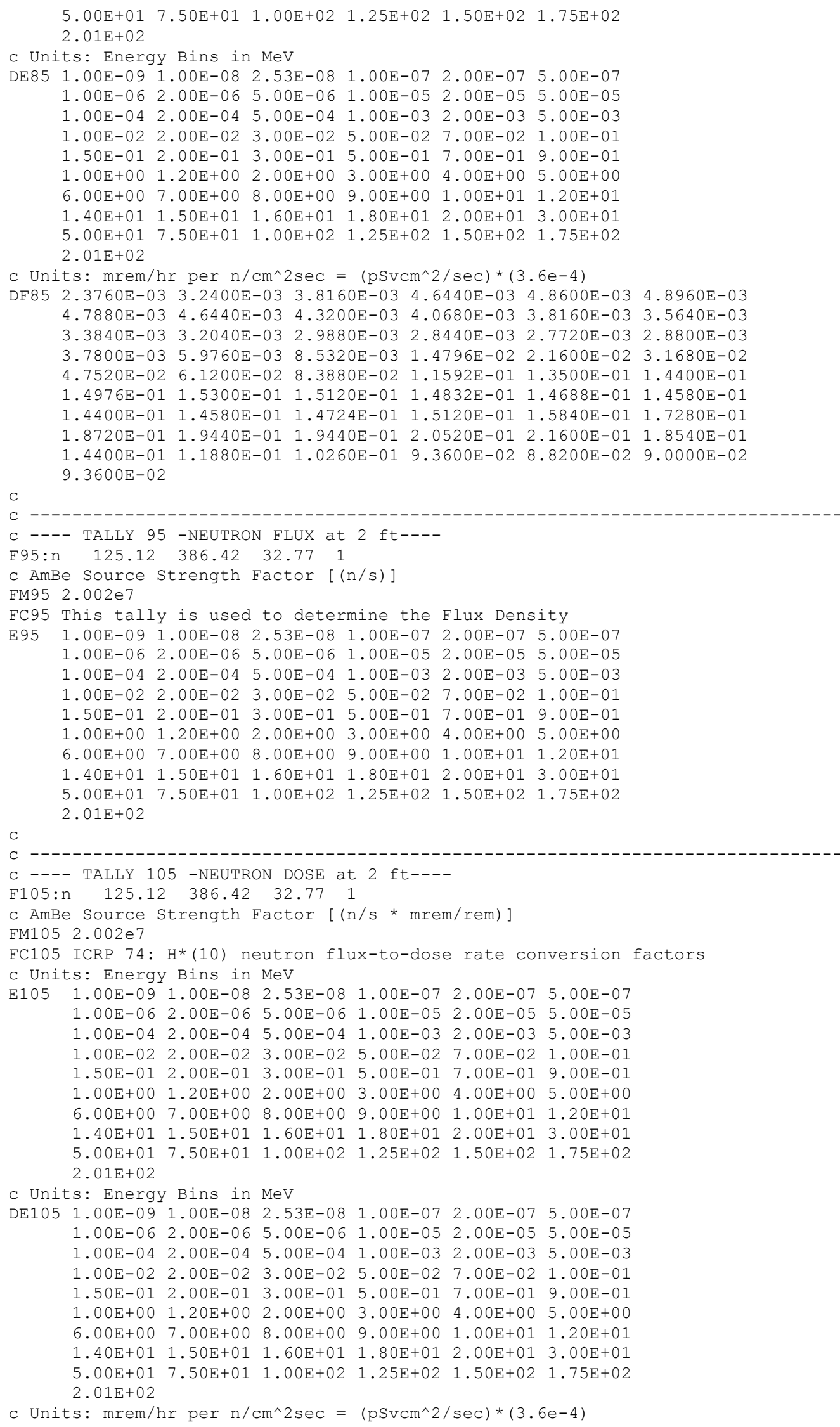

c Units: $\mathrm{mrem} / \mathrm{hr}$ per $\mathrm{n} / \mathrm{cm}^{\wedge} 2 \mathrm{sec}=(\mathrm{pSvcm} \wedge 2 / \mathrm{sec}) *(3.6 \mathrm{e}-4)$ 
DF105 2.3760E-03 3.2400E-03 3.8160E-03 4.6440E-03 $4.8600 \mathrm{E}-03 \quad 4.8960 \mathrm{E}-03$ $\begin{array}{llllll}4.7880 \mathrm{E}-03 & 4.6440 \mathrm{E}-03 & 4.3200 \mathrm{E}-03 & 4.0680 \mathrm{E}-03 & 3.8160 \mathrm{E}-03 & 3.5640 \mathrm{E}-03\end{array}$ $\begin{array}{llllll}3.3840 \mathrm{E}-03 & 3.2040 \mathrm{E}-03 & 2.9880 \mathrm{E}-03 & 2.8440 \mathrm{E}-03 & 2.7720 \mathrm{E}-03 & 2.8800 \mathrm{E}-03\end{array}$ $3.7800 \mathrm{E}-03 \quad 5.9760 \mathrm{E}-03 \quad 8.5320 \mathrm{E}-03 \quad 1.4796 \mathrm{E}-02 \quad 2.1600 \mathrm{E}-02 \quad 3.1680 \mathrm{E}-02$ $\begin{array}{llllll}4.7520 \mathrm{E}-02 & 6.1200 \mathrm{E}-02 & 8.3880 \mathrm{E}-02 & 1.1592 \mathrm{E}-01 & 1.3500 \mathrm{E}-01 & 1.4400 \mathrm{E}-01\end{array}$ $1.4976 \mathrm{E}-01 \quad 1.5300 \mathrm{E}-01 \quad 1.5120 \mathrm{E}-01 \quad 1.4832 \mathrm{E}-01 \quad 1.4688 \mathrm{E}-01 \quad 1.4580 \mathrm{E}-01$ $1.4400 \mathrm{E}-01 \quad 1.4580 \mathrm{E}-01 \quad 1.4724 \mathrm{E}-01 \quad 1.5120 \mathrm{E}-01 \quad 1.5840 \mathrm{E}-01 \quad 1.7280 \mathrm{E}-01$ $\begin{array}{lllllll}1.8720 \mathrm{E}-01 & 1.9440 \mathrm{E}-01 & 1.9440 \mathrm{E}-01 & 2.0520 \mathrm{E}-01 & 2.1600 \mathrm{E}-01 & 1.8540 \mathrm{E}-01\end{array}$ $1.4400 \mathrm{E}-01 \quad 1.1880 \mathrm{E}-01 \quad 1.0260 \mathrm{E}-01 \quad 9.3600 \mathrm{E}-02 \quad 8.8200 \mathrm{E}-02 \quad 9.0000 \mathrm{E}-02$ $9.3600 \mathrm{E}-02$

$\mathrm{C}$

C ---- TALLY 115 -NEUTRON FLUX at $3 \mathrm{ft}----$

F115:n $\quad 150.09 \quad 368.94 \quad 32.77 \quad 1$

C AmBe Source Strength Factor [ $(\mathrm{n} / \mathrm{s})]$

FM115 2.002e7

FC115 This tally is used to determine the Flux Density

E115 1.00E-09 1.00E-08 2.53E-08 1.00E-07 2.00E-07 5.00E-07

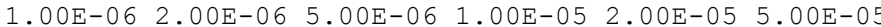
$\begin{array}{llllll}1.00 \mathrm{E}-04 & 2.00 \mathrm{E}-04 & 5.00 \mathrm{E}-04 & 1.00 \mathrm{E}-03 & 2.00 \mathrm{E}-03 & 5.00 \mathrm{E}-03\end{array}$ $1.00 \mathrm{E}-02 \quad 2.00 \mathrm{E}-02 \quad 3.00 \mathrm{E}-02 \quad 5.00 \mathrm{E}-02 \quad 7.00 \mathrm{E}-02 \quad 1.00 \mathrm{E}-01$ $\begin{array}{llllll}1.50 \mathrm{E}-01 & 2.00 \mathrm{E}-01 & 3.00 \mathrm{E}-01 & 5.00 \mathrm{E}-01 & 7.00 \mathrm{E}-01 & 9.00 \mathrm{E}-01\end{array}$

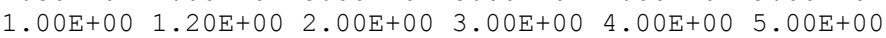
$\begin{array}{llllll}6.00 \mathrm{E}+00 & 7.00 \mathrm{E}+00 & 8.00 \mathrm{E}+00 & 9.00 \mathrm{E}+00 & 1.00 \mathrm{E}+01 & 1.20 \mathrm{E}+01\end{array}$ $\begin{array}{llllll}1.40 \mathrm{E}+01 & 1.50 \mathrm{E}+01 & 1.60 \mathrm{E}+01 & 1.80 \mathrm{E}+01 & 2.00 \mathrm{E}+01 & 3.00 \mathrm{E}+01\end{array}$

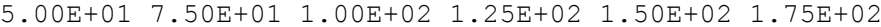
$2.01 \mathrm{E}+02$

C --- TALLY 125 -NEUTRON DOSE at $3 \mathrm{ft----}$

F125:n $\quad 150.09 \quad 368.94 \quad 32.77 \quad 1$

C AmBe Source Strength Factor [ $(\mathrm{n} / \mathrm{s}$ * mrem/rem)]

FM125 2.002e7

FC125 ICRP 74: $H^{*}(10)$ neutron flux-to-dose rate conversion factors

C Units: Energy Bins in MeV

E125 1.00E-09 $1.00 \mathrm{E}-08 \quad 2.53 \mathrm{E}-08 \quad 1.00 \mathrm{E}-07 \quad 2.00 \mathrm{E}-07 \quad 5.00 \mathrm{E}-07$

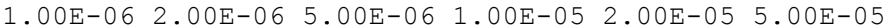
$\begin{array}{llllll}1.00 \mathrm{E}-04 & 2.00 \mathrm{E}-04 & 5.00 \mathrm{E}-04 & 1.00 \mathrm{E}-03 & 2.00 \mathrm{E}-03 & 5.00 \mathrm{E}-03\end{array}$ $1.00 \mathrm{E}-02 \quad 2.00 \mathrm{E}-02 \quad 3.00 \mathrm{E}-02 \quad 5.00 \mathrm{E}-02 \quad 7.00 \mathrm{E}-02 \quad 1.00 \mathrm{E}-01$

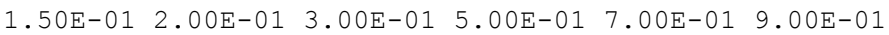

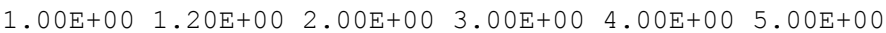
$\begin{array}{llllll}6.00 \mathrm{E}+00 & 7.00 \mathrm{E}+00 & 8.00 \mathrm{E}+00 & 9.00 \mathrm{E}+00 & 1.00 \mathrm{E}+01 & 1.20 \mathrm{E}+01\end{array}$ $\begin{array}{llllll}1.40 \mathrm{E}+01 & 1.50 \mathrm{E}+01 & 1.60 \mathrm{E}+01 & 1.80 \mathrm{E}+01 & 2.00 \mathrm{E}+01 & 3.00 \mathrm{E}+01\end{array}$

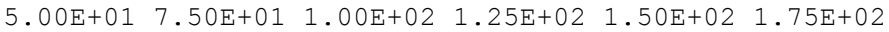
$2.01 \mathrm{E}+02$

C Units: Energy Bins in MeV

DE125 1.00E-09 1.00E-08 2.53E-08 $1.00 \mathrm{E}-07 \quad 2.00 \mathrm{E}-07 \quad 5.00 \mathrm{E}-07$ $1.00 \mathrm{E}-06 \quad 2.00 \mathrm{E}-06 \quad 5.00 \mathrm{E}-06 \quad 1.00 \mathrm{E}-05 \quad 2.00 \mathrm{E}-05 \quad 5.00 \mathrm{E}-05$ $\begin{array}{llllll}1.00 \mathrm{E}-04 & 2.00 \mathrm{E}-04 & 5.00 \mathrm{E}-04 & 1.00 \mathrm{E}-03 & 2.00 \mathrm{E}-03 & 5.00 \mathrm{E}-03\end{array}$

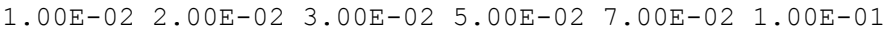
$\begin{array}{llllll}1.50 \mathrm{E}-01 & 2.00 \mathrm{E}-01 & 3.00 \mathrm{E}-01 & 5.00 \mathrm{E}-01 & 7.00 \mathrm{E}-01 & 9.00 \mathrm{E}-01\end{array}$

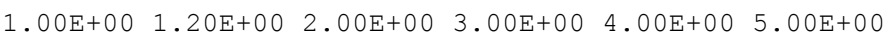
$\begin{array}{llllll}6.00 \mathrm{E}+00 & 7.00 \mathrm{E}+00 & 8.00 \mathrm{E}+00 & 9.00 \mathrm{E}+00 & 1.00 \mathrm{E}+01 & 1.20 \mathrm{E}+01\end{array}$ $\begin{array}{llllll}1.40 \mathrm{E}+01 & 1.50 \mathrm{E}+01 & 1.60 \mathrm{E}+01 & 1.80 \mathrm{E}+01 & 2.00 \mathrm{E}+01 & 3.00 \mathrm{E}+01\end{array}$

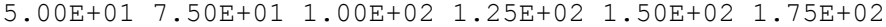
$2.01 \mathrm{E}+02$

C Units: $\mathrm{mrem} / \mathrm{hr}$ per $\mathrm{n} / \mathrm{cm}^{\wedge} 2 \mathrm{sec}=(\mathrm{pSvcm} \wedge 2 / \mathrm{sec}) *(3.6 \mathrm{e}-4)$

DF125 2.3760E-03 3.2400E-03 3.8160E-03 4.6440E-03 $4.8600 \mathrm{E}-03 \quad 4.8960 \mathrm{E}-03$ $\begin{array}{llllll}4.7880 \mathrm{E}-03 & 4.6440 \mathrm{E}-03 & 4.3200 \mathrm{E}-03 & 4.0680 \mathrm{E}-03 & 3.8160 \mathrm{E}-03 & 3.5640 \mathrm{E}-03\end{array}$

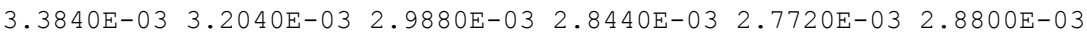
$3.7800 \mathrm{E}-03 \quad 5.9760 \mathrm{E}-03 \quad 8.5320 \mathrm{E}-03 \quad 1.4796 \mathrm{E}-02 \quad 2.1600 \mathrm{E}-02 \quad 3.1680 \mathrm{E}-02$ $4.7520 \mathrm{E}-02 \quad 6.1200 \mathrm{E}-02 \quad 8.3880 \mathrm{E}-02 \quad 1.1592 \mathrm{E}-01 \quad 1.3500 \mathrm{E}-01 \quad 1.4400 \mathrm{E}-01$ $1.4976 \mathrm{E}-011.5300 \mathrm{E}-01 \quad 1.5120 \mathrm{E}-01 \quad 1.4832 \mathrm{E}-01 \quad 1.4688 \mathrm{E}-011.4580 \mathrm{E}-01$ $\begin{array}{lllllll}1.4400 \mathrm{E}-01 & 1.4580 \mathrm{E}-01 & 1.4724 \mathrm{E}-01 & 1.5120 \mathrm{E}-01 & 1.5840 \mathrm{E}-01 & 1.7280 \mathrm{E}-01\end{array}$ $\begin{array}{llllll}1.8720 \mathrm{E}-01 & 1.9440 \mathrm{E}-01 & 1.9440 \mathrm{E}-01 & 2.0520 \mathrm{E}-01 & 2.1600 \mathrm{E}-01 & 1.8540 \mathrm{E}-01\end{array}$ $1.4400 \mathrm{E}-01 \quad 1.1880 \mathrm{E}-01 \quad 1.0260 \mathrm{E}-01 \quad 9.3600 \mathrm{E}-02 \quad 8.8200 \mathrm{E}-02 \quad 9.0000 \mathrm{E}-02$ $9.3600 \mathrm{E}-02$

$\mathrm{C}$

C --- TALLY 135 -NEUTRON FLUX at 2 ft on side----

F135:n $\quad 75.184 \quad 356.61 \quad 32.77 \quad 1$ 


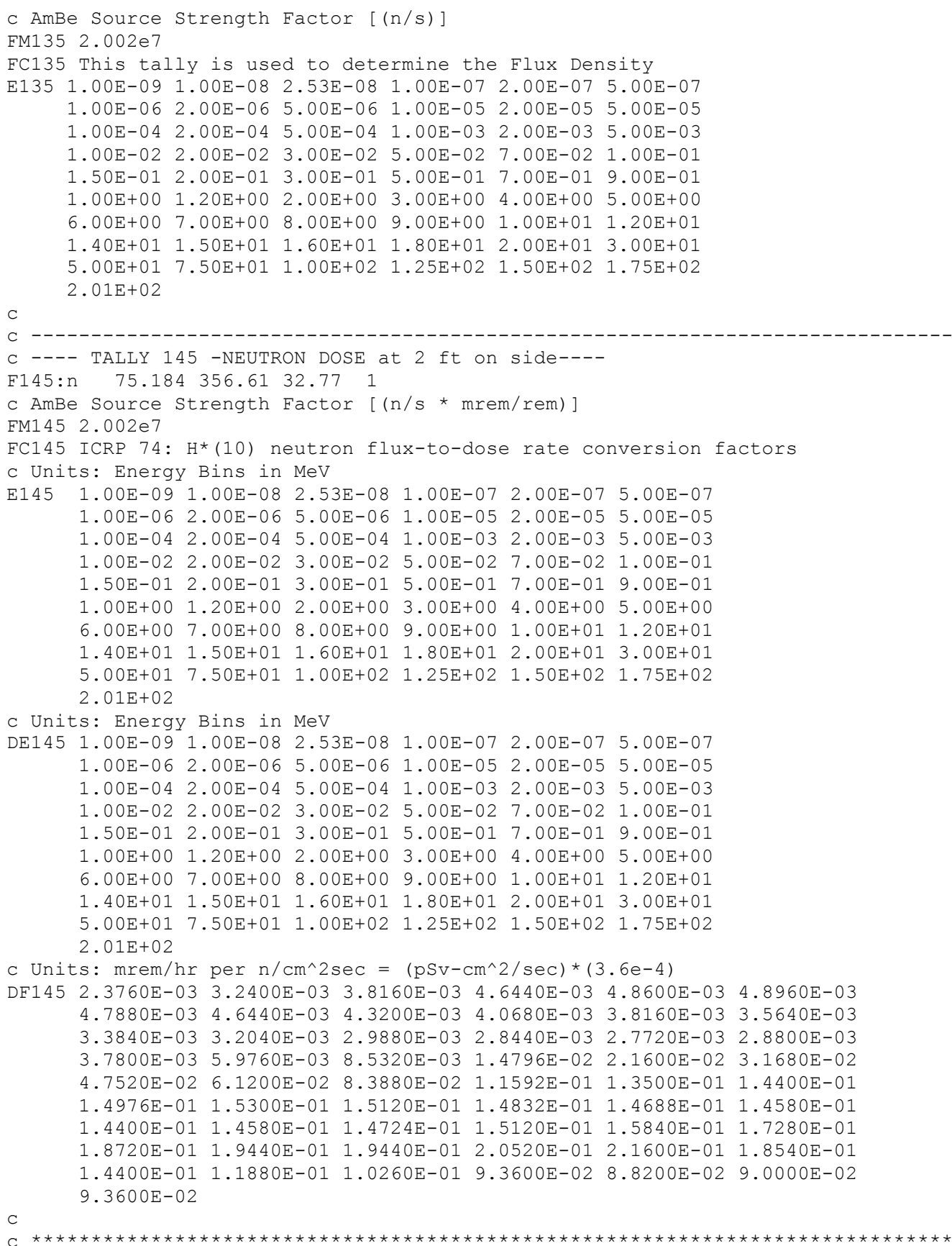

\section{A.4 Microspec Tallies}

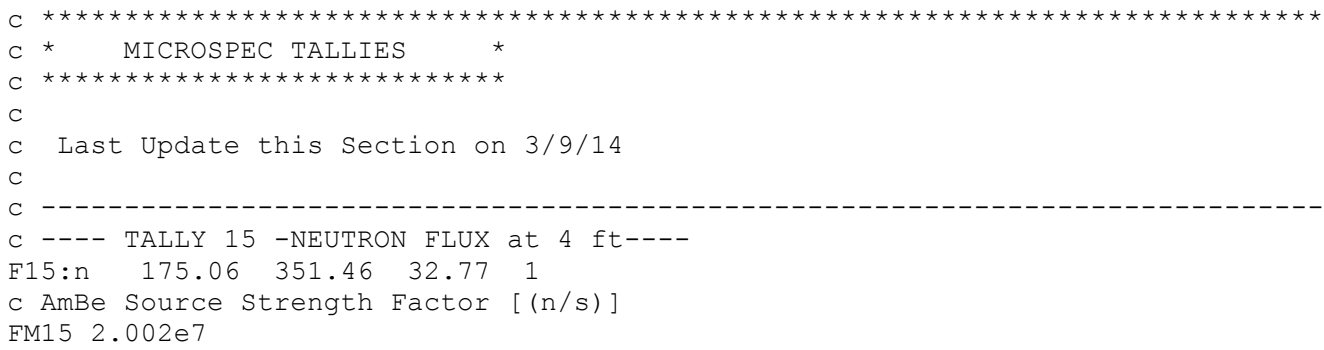


FC15 This tally is used to determine the Flux Density

E15 1.00E-09 1.00E-08 2.53E-08 1.00E-07 2.00E-07 5.00E-07

$1.00 \mathrm{E}-06 \quad 2.00 \mathrm{E}-06 \quad 5.00 \mathrm{E}-06 \quad 1.00 \mathrm{E}-05 \quad 2.00 \mathrm{E}-05 \quad 5.00 \mathrm{E}-05$ $\begin{array}{llllll}1.00 \mathrm{E}-04 & 2.00 \mathrm{E}-04 & 5.00 \mathrm{E}-04 & 1.00 \mathrm{E}-03 & 2.00 \mathrm{E}-03 & 5.00 \mathrm{E}-03\end{array}$ $\begin{array}{llllll}1.00 \mathrm{E}-02 & 2.00 \mathrm{E}-02 & 3.00 \mathrm{E}-02 & 5.00 \mathrm{E}-02 & 7.00 \mathrm{E}-02 & 1.00 \mathrm{E}-01\end{array}$ $\begin{array}{lllllll}1.50 \mathrm{E}-01 & 2.00 \mathrm{E}-01 & 3.00 \mathrm{E}-01 & 5.00 \mathrm{E}-01 & 7.00 \mathrm{E}-01 & 9.00 \mathrm{E}-01\end{array}$ $\begin{array}{llllll}1.00 \mathrm{E}+00 & 1.20 \mathrm{E}+00 & 2.00 \mathrm{E}+00 & 3.00 \mathrm{E}+00 & 4.00 \mathrm{E}+00 & 5.00 \mathrm{E}+00\end{array}$ $\begin{array}{llllll}6.00 \mathrm{E}+00 & 7.00 \mathrm{E}+00 & 8.00 \mathrm{E}+00 & 9.00 \mathrm{E}+00 & 1.00 \mathrm{E}+01 & 1.20 \mathrm{E}+01\end{array}$ $\begin{array}{lllllll}1.40 \mathrm{E}+01 & 1.50 \mathrm{E}+01 & 1.60 \mathrm{E}+01 & 1.80 \mathrm{E}+01 & 2.00 \mathrm{E}+01 & 3.00 \mathrm{E}+01\end{array}$

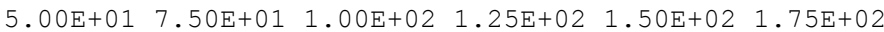
$2.01 \mathrm{E}+02$

C ---- TALLY 25 -NEUTRON DOSE at $4 \mathrm{ft----}$

$\mathrm{F} 25: \mathrm{n} \quad 175.06 \quad 351.46 \quad 32.77 \quad 1$

C AmBe Source Strength Factor [ ( $/ \mathrm{s}$ * mrem/rem)]

FM25 2.002e7

FC25 ICRP 74: $H^{*}(10)$ neutron flux-to-dose rate conversion factors

C Units: Energy Bins in MeV

E25 1.00E-09 1.00E-08 2.53E-08 $1.00 \mathrm{E}-07 \quad 2.00 \mathrm{E}-07 \quad 5.00 \mathrm{E}-07$

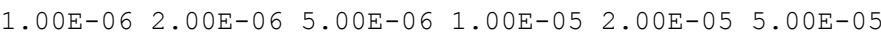

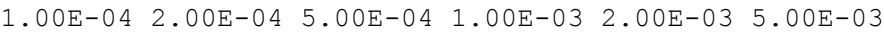

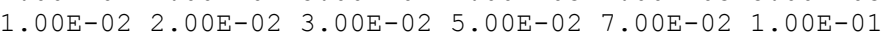

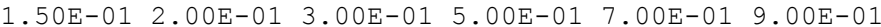

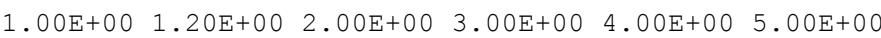

$\begin{array}{llllll}6.00 \mathrm{E}+00 & 7.00 \mathrm{E}+00 & 8.00 \mathrm{E}+00 & 9.00 \mathrm{E}+00 & 1.00 \mathrm{E}+01 & 1.20 \mathrm{E}+01\end{array}$

$\begin{array}{llllll}1.40 \mathrm{E}+01 & 1.50 \mathrm{E}+01 & 1.60 \mathrm{E}+01 & 1.80 \mathrm{E}+01 & 2.00 \mathrm{E}+01 & 3.00 \mathrm{E}+01\end{array}$

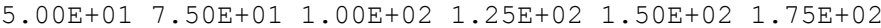

$2.01 \mathrm{E}+02$

C Units: Energy Bins in MeV

DE25 1.00E-09 1.00E-08 2.53E-08 1.00E-07 2.00E-07 5.00E-07

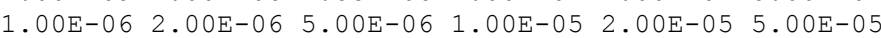

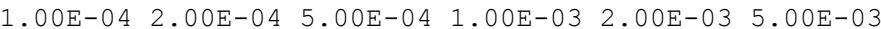

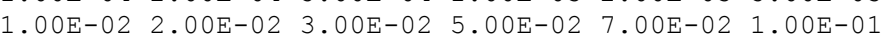
$\begin{array}{llllll}1.50 \mathrm{E}-01 & 2.00 \mathrm{E}-01 & 3.00 \mathrm{E}-01 & 5.00 \mathrm{E}-01 & 7.00 \mathrm{E}-01 & 9.00 \mathrm{E}-01\end{array}$

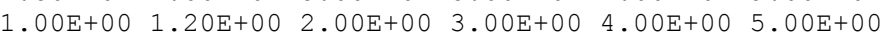
$\begin{array}{llllll}6.00 \mathrm{E}+00 & 7.00 \mathrm{E}+00 & 8.00 \mathrm{E}+00 & 9.00 \mathrm{E}+00 & 1.00 \mathrm{E}+01 & 1.20 \mathrm{E}+01\end{array}$ $\begin{array}{lllllll}1.40 \mathrm{E}+01 & 1.50 \mathrm{E}+01 & 1.60 \mathrm{E}+01 & 1.80 \mathrm{E}+01 & 2.00 \mathrm{E}+01 & 3.00 \mathrm{E}+01\end{array}$

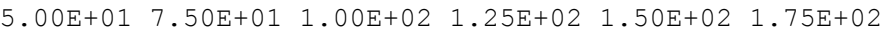
$2.01 \mathrm{E}+02$

C Units: mrem/hr per $\mathrm{n} / \mathrm{cm}^{\wedge} 2 \mathrm{sec}=(\mathrm{pSvcm} \wedge 2 / \mathrm{sec}) *(3.6 \mathrm{e}-4)$

DF25 2.3760E-03 3.2400E-03 3.8160E-03 4.6440E-03 4.8600E-03 4.8960E-03 $\begin{array}{llllll}4.7880 \mathrm{E}-03 & 4.6440 \mathrm{E}-03 & 4.3200 \mathrm{E}-03 & 4.0680 \mathrm{E}-03 & 3.8160 \mathrm{E}-03 & 3.5640 \mathrm{E}-03\end{array}$ $\begin{array}{llllll}3.3840 \mathrm{E}-03 & 3.2040 \mathrm{E}-03 & 2.9880 \mathrm{E}-03 & 2.8440 \mathrm{E}-03 & 2.7720 \mathrm{E}-03 & 2.8800 \mathrm{E}-03\end{array}$

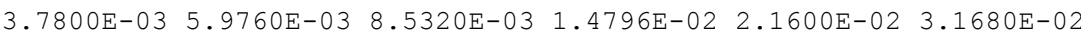
$\begin{array}{llllll}4.7520 \mathrm{E}-02 & 6.1200 \mathrm{E}-02 & 8.3880 \mathrm{E}-02 & 1.1592 \mathrm{E}-01 & 1.3500 \mathrm{E}-01 & 1.4400 \mathrm{E}-01\end{array}$ $\begin{array}{llllll}1.4976 \mathrm{E}-01 & 1.5300 \mathrm{E}-01 & 1.5120 \mathrm{E}-01 & 1.4832 \mathrm{E}-01 & 1.4688 \mathrm{E}-01 & 1.4580 \mathrm{E}-01\end{array}$ $\begin{array}{lllllll}1.4400 \mathrm{E}-01 & 1.4580 \mathrm{E}-01 & 1.4724 \mathrm{E}-01 & 1.5120 \mathrm{E}-01 & 1.5840 \mathrm{E}-01 & 1.7280 \mathrm{E}-01\end{array}$ $\begin{array}{lllllll}1.8720 \mathrm{E}-01 & 1.9440 \mathrm{E}-01 & 1.9440 \mathrm{E}-01 & 2.0520 \mathrm{E}-01 & 2.1600 \mathrm{E}-01 & 1.8540 \mathrm{E}-01\end{array}$ $1.4400 \mathrm{E}-01$ 1.1880E-01 1.0260E-01 9.3600E-02 8.8200E-02 9.0000E-02 $9.3600 \mathrm{E}-02$

C --- TALLY 35 -NEUTRON FLUX at 4.75 ft outside chamber----

F35:n $\quad 75.18 \quad 276.35 \quad 31.12 \quad 1$

C AmBe Source Strength Factor [ $(\mathrm{n} / \mathrm{s})]$

FM35 2.002e7

FC35 This tally is used to determine the Flux Density C Units: Energy Bins in MeV

E35 1.00E-09 1.00E-08 2.53E-08 1.00E-07 2.00E-07 5.00E-07 $1.00 \mathrm{E}-06 \quad 2.00 \mathrm{E}-06 \quad 5.00 \mathrm{E}-06 \quad 1.00 \mathrm{E}-05 \quad 2.00 \mathrm{E}-05 \quad 5.00 \mathrm{E}-05$ $\begin{array}{llllll}1.00 \mathrm{E}-04 & 2.00 \mathrm{E}-04 & 5.00 \mathrm{E}-04 & 1.00 \mathrm{E}-03 & 2.00 \mathrm{E}-03 & 5.00 \mathrm{E}-03\end{array}$

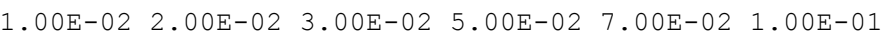
$\begin{array}{llllll}1.50 \mathrm{E}-01 & 2.00 \mathrm{E}-01 & 3.00 \mathrm{E}-01 & 5.00 \mathrm{E}-01 & 7.00 \mathrm{E}-01 & 9.00 \mathrm{E}-01\end{array}$

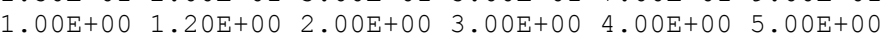
$\begin{array}{llllll}6.00 \mathrm{E}+00 & 7.00 \mathrm{E}+00 & 8.00 \mathrm{E}+00 & 9.00 \mathrm{E}+00 & 1.00 \mathrm{E}+01 & 1.20 \mathrm{E}+01\end{array}$ $\begin{array}{llllll}1.40 \mathrm{E}+01 & 1.50 \mathrm{E}+01 & 1.60 \mathrm{E}+01 & 1.80 \mathrm{E}+01 & 2.00 \mathrm{E}+01 & 3.00 \mathrm{E}+01\end{array}$

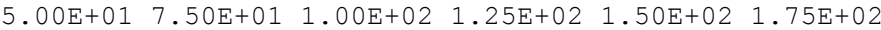
$2.01 \mathrm{E}+02$ 


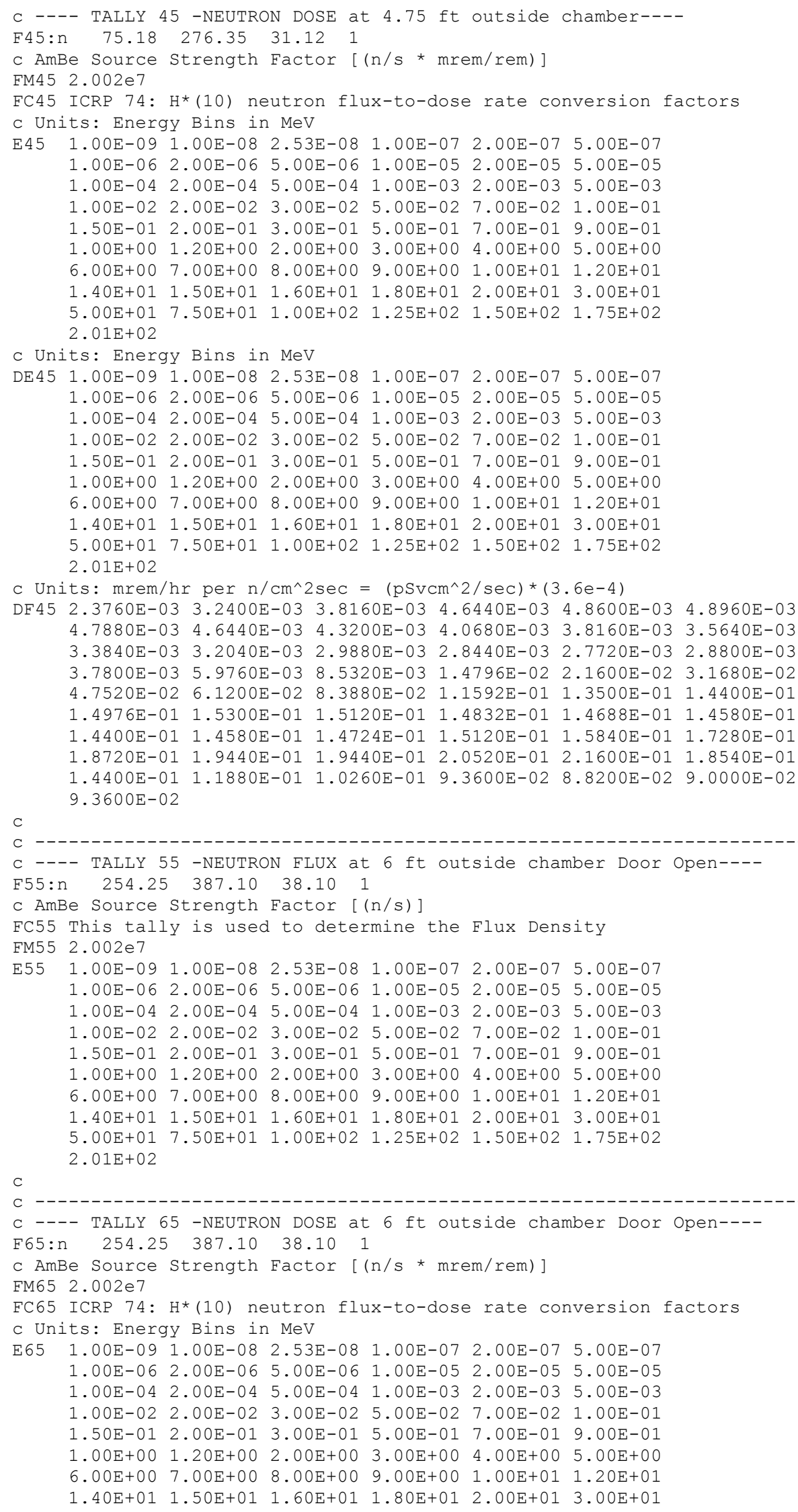




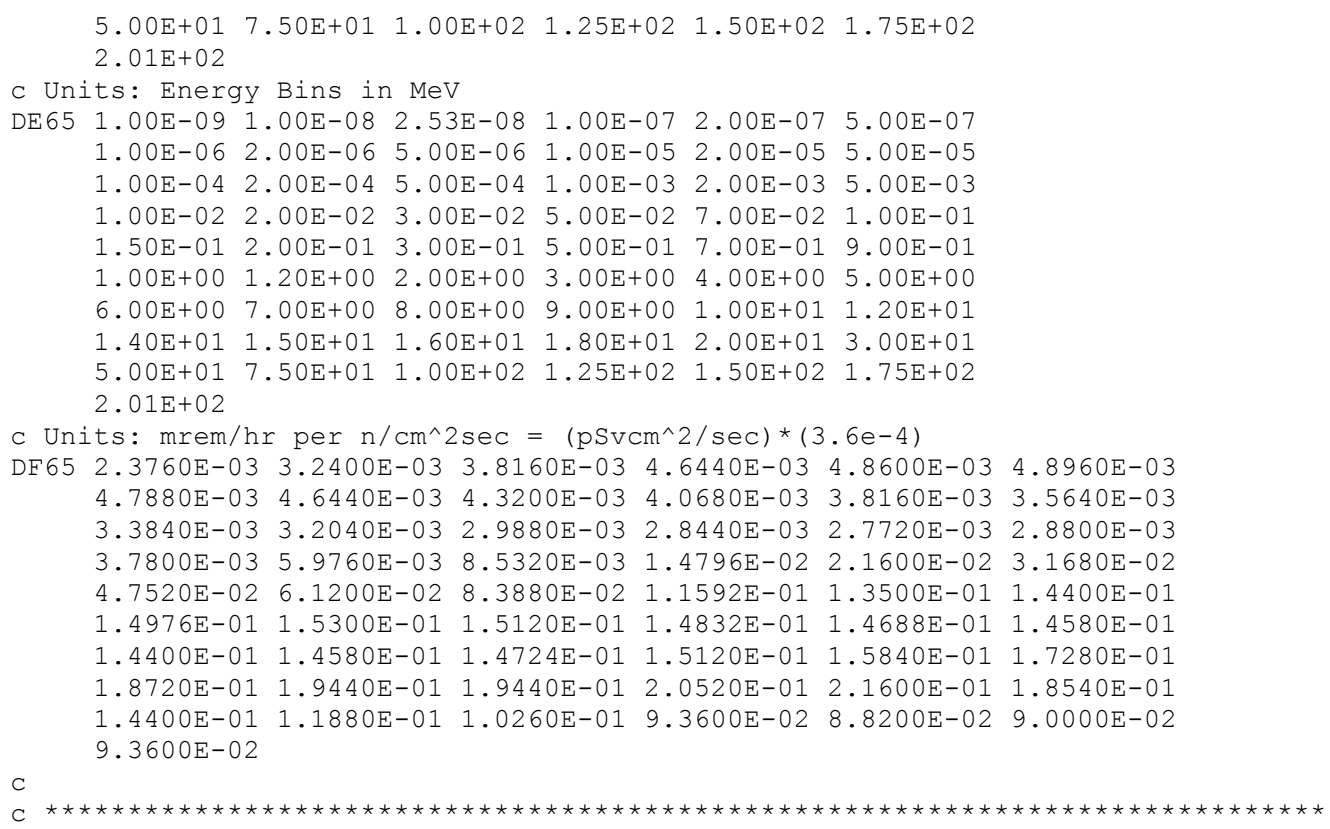

\section{A.5 High Purity Germanium Detector Tallies}

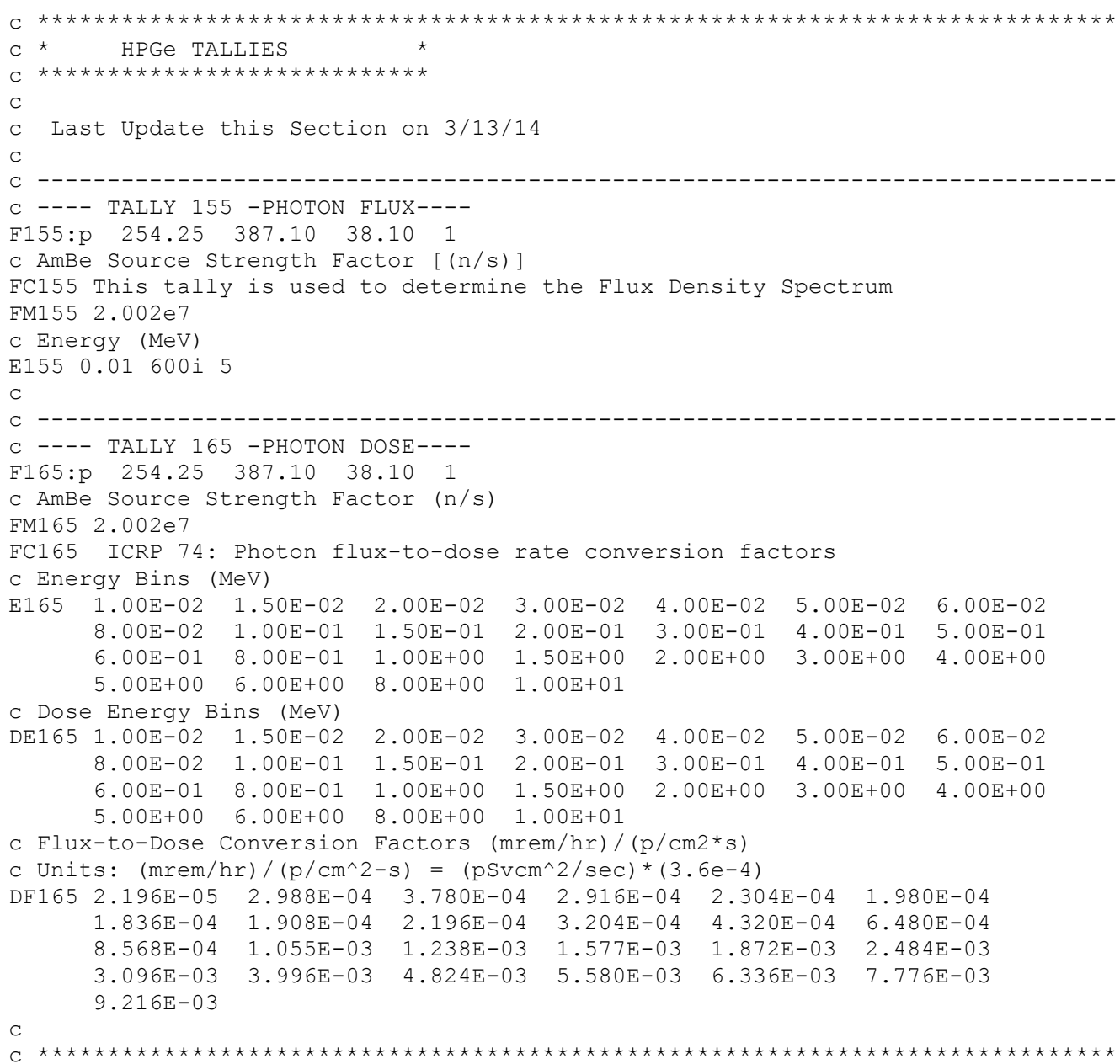




\section{A.6 Gold Foil Tallies}

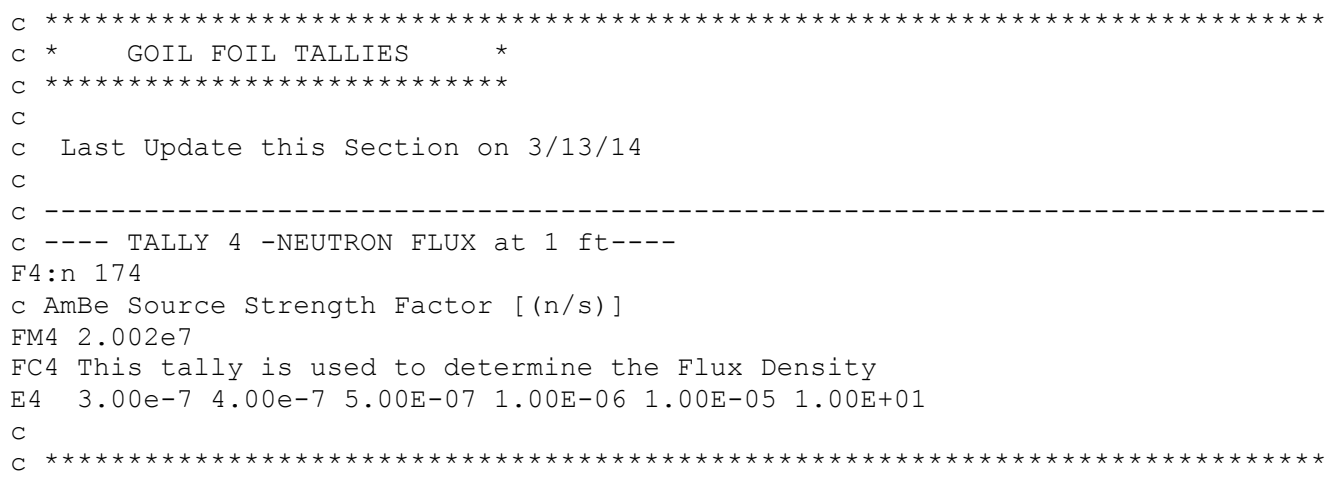

\section{A.7 Polyethylene Dose Tallies}

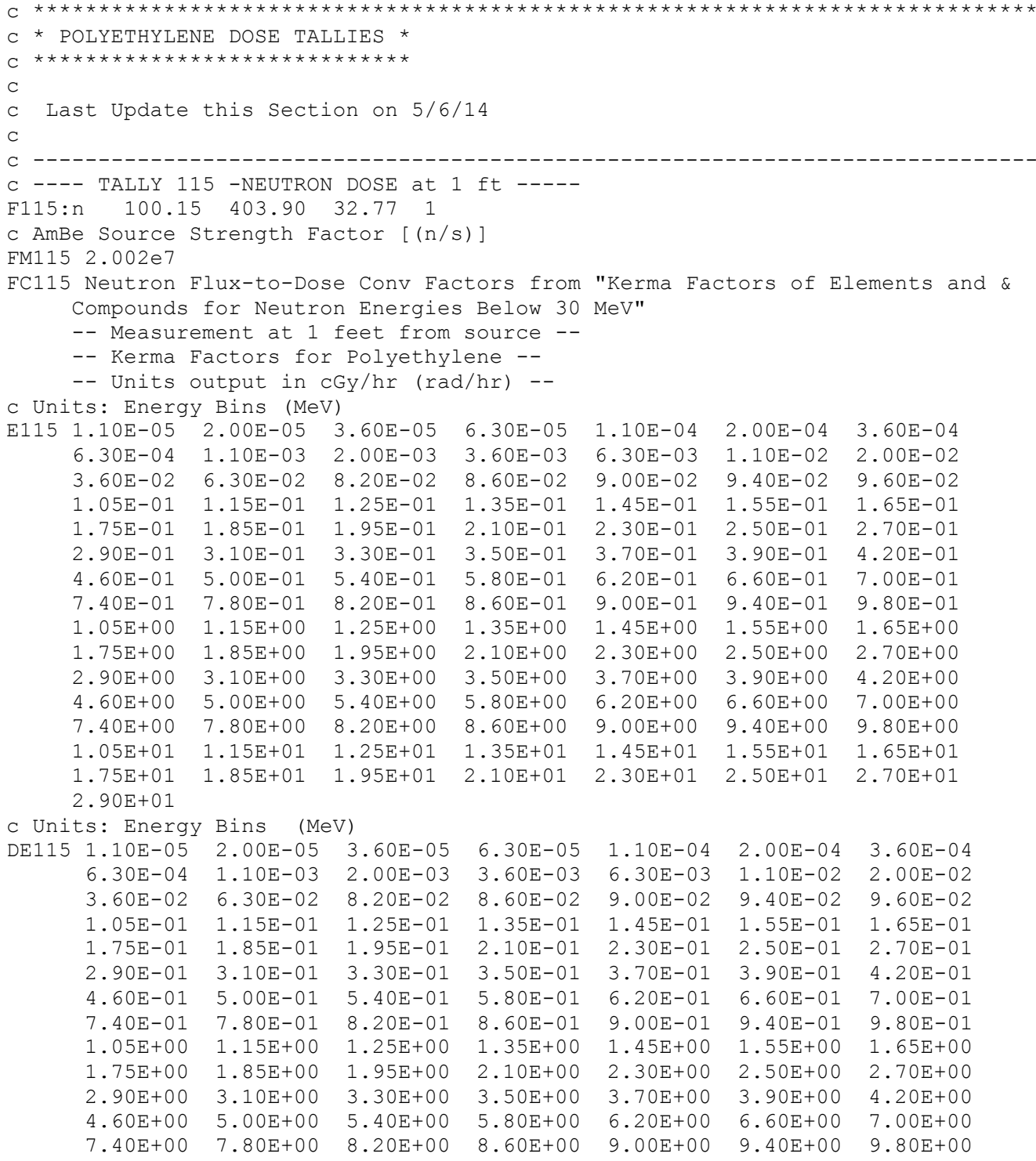




\begin{tabular}{|c|c|c|c|c|c|c|c|}
\hline & $1.05 \mathrm{E}+01$ & $1.15 \mathrm{E}+01$ & $1.25 \mathrm{E}+01$ & $1.35 \mathrm{E}+01$ & $1.45 \mathrm{E}+01$ & $1.55 \mathrm{E}+01$ & $1.65 \mathrm{E}+01$ \\
\hline & $1.75 \mathrm{E}+01$ & $1.85 \mathrm{E}+01$ & $1.95 \mathrm{E}+01$ & $2.10 \mathrm{E}+01$ & $2.30 \mathrm{E}+01$ & $2.50 \mathrm{E}+01$ & $2.70 \mathrm{E}+01$ \\
\hline & $2.90 \mathrm{E}+01$ & & & & & & \\
\hline Uni & ts: $\mathrm{cGy} / \mathrm{hr}$ & $=\operatorname{per} \mathrm{n} / \mathrm{cm}^{\wedge}$ & $2 \mathrm{sec}=(\mathrm{ra}$ & $\mathrm{ad}-\mathrm{cm}^{\wedge} 2 / \mathrm{sec}$ & )$*(3.6 \mathrm{e} 3)$ & & \\
\hline $\mathrm{DF} 115$ & $6.80 \mathrm{E}-10$ & $1.13 \mathrm{E}-09$ & $1.94 \mathrm{E}-09$ & $3.34 \mathrm{E}-09$ & $5.80 \mathrm{E}-09$ & $1.05 \mathrm{E}-08$ & $1.88 \mathrm{E}-08$ \\
\hline & $3.28 \mathrm{E}-08$ & $5.72 \mathrm{E}-08$ & $1.03 \mathrm{E}-07$ & $1.84 \mathrm{E}-07$ & $3.17 \mathrm{E}-07$ & $5.36 \mathrm{E}-07$ & $9.32 \mathrm{E}-07$ \\
\hline & $1.54 \mathrm{E}-06$ & $2.40 \mathrm{E}-06$ & $2.89 \mathrm{E}-06$ & $3.00 \mathrm{E}-06$ & $3.09 \mathrm{E}-06$ & $3.18 \mathrm{E}-06$ & $3.27 \mathrm{E}-06$ \\
\hline & $3.54 \mathrm{E}-06$ & $3.64 \mathrm{E}-06$ & $3.85 \mathrm{E}-06$ & $4.03 E-06$ & $4.21 \mathrm{E}-06$ & $4.39 \mathrm{E}-06$ & $4.54 \mathrm{E}-06$ \\
\hline & $4.72 \mathrm{E}-06$ & $4.86 \mathrm{E}-06$ & $5.00 \mathrm{E}-06$ & $5.22 \mathrm{E}-06$ & $5.47 \mathrm{E}-06$ & $5.76 \mathrm{E}-06$ & $5.98 \mathrm{E}-06$ \\
\hline & $6.23 \mathrm{E}-06$ & $6.44 \mathrm{E}-06$ & $6.66 \mathrm{E}-06$ & $6.84 \mathrm{E}-06$ & $7.06 \mathrm{E}-06$ & $7.24 \mathrm{E}-06$ & $7.52 \mathrm{E}-06$ \\
\hline & $7.85 \mathrm{E}-06$ & $8.17 \mathrm{E}-06$ & $8.50 \mathrm{E}-06$ & $8.82 \mathrm{E}-06$ & $9.11 \mathrm{E}-06$ & $9.36 \mathrm{E}-06$ & $9.65 \mathrm{E}-06$ \\
\hline & $9.90 \mathrm{E}-06$ & $1.02 \mathrm{E}-05$ & $1.04 \mathrm{E}-05$ & $1.07 \mathrm{E}-05$ & $1.09 \mathrm{E}-05$ & $1.11 \mathrm{E}-05$ & $1.13 \mathrm{E}-05$ \\
\hline & $1.17 \mathrm{E}-05$ & $1.22 \mathrm{E}-05$ & $1.27 \mathrm{E}-05$ & $1.31 \mathrm{E}-05$ & $1.36 \mathrm{E}-05$ & $1.40 \mathrm{E}-05$ & $1.44 \mathrm{E}-05$ \\
\hline & $1.48 \mathrm{E}-05$ & $1.51 \mathrm{E}-05$ & $1.55 \mathrm{E}-05$ & $1.62 \mathrm{E}-05$ & $1.67 \mathrm{E}-05$ & $1.74 \mathrm{E}-05$ & $1.81 \mathrm{E}-05$ \\
\hline & $1.93 \mathrm{E}-05$ & $1.91 \mathrm{E}-05$ & $2.05 \mathrm{E}-05$ & $2.13 \mathrm{E}-05$ & $2.16 \mathrm{E}-05$ & $2.16 \mathrm{E}-05$ & $2.16 \mathrm{E}-05$ \\
\hline & $2.16 \mathrm{E}-05$ & $2.20 \mathrm{E}-05$ & $2.25 \mathrm{E}-05$ & $2.29 \mathrm{E}-05$ & $2.40 E-05$ & $2.33 E-05$ & $2.35 \mathrm{E}-05$ \\
\hline & $2.49 \mathrm{E}-05$ & $2.67 \mathrm{E}-05$ & $2.57 \mathrm{E}-05$ & $2.53 \mathrm{E}-05$ & $2.69 \mathrm{E}-05$ & $2.80 \mathrm{E}-05$ & $2.74 \mathrm{E}-05$ \\
\hline & $2.75 E-05$ & $2.84 \mathrm{E}-05$ & $2.97 \mathrm{E}-05$ & $3.05 \mathrm{E}-05$ & $3.17 \mathrm{E}-05$ & $3.34 \mathrm{E}-05$ & $3.45 \mathrm{E}-05$ \\
\hline & $3.48 E-05$ & $3.53 \mathrm{E}-05$ & $3.56 \mathrm{E}-05$ & $3.67 \mathrm{E}-05$ & $3.71 \mathrm{E}-05$ & $3.78 \mathrm{E}-05$ & $3.78 \mathrm{E}-05$ \\
\hline & $3.82 \mathrm{E}-05$ & & & & & & \\
\hline & & & & & & & \\
\hline & & & & & & & \\
\hline - & - TALLY & 25 -NEUTRC & J DOSE at & ft ---- & & & \\
\hline F125: & n $\quad 125.12$ & $2 \quad 386.42$ & $32.77 \quad 1$ & & & & \\
\hline C AmB & e Source & Strength $\mathrm{F}$ & ator & & & & \\
\hline FM125 & $2.002 \mathrm{e} 7$ & & & & & & \\
\hline $\mathrm{FC} 125$ & Neutron & lux-to-Dos & se Conv Fac & tors from & "Kerma $\mathrm{Fa}$ & tors of $\mathrm{El}$ & lements and \\
\hline & & for Neutro & on Energies & Below 30 & MeV" & & \\
\hline & -- Measure & ement at 2 & feet fror & source -- & & & \\
\hline & -- Kerma & actors fo & Polyethyl & Lene -- & & & \\
\hline & -- Units & butput in & Gy/hr (rad & d/hr) -- & & & \\
\hline c Uni & ts: Energs & Bins (MeV & & & & & \\
\hline E125 & $1.10 \mathrm{E}-05$ & $2.00 E-05$ & $3.60 \mathrm{E}-05$ & $6.30 \mathrm{E}-05$ & $1.10 \mathrm{E}-04$ & $2.00 \mathrm{E}-04$ & $3.60 \mathrm{E}-04$ \\
\hline & $6.30 \mathrm{E}-04$ & $1.10 \mathrm{E}-03$ & $2.00 \mathrm{E}-03$ & $3.60 \mathrm{E}-03$ & $6.30 \mathrm{E}-03$ & $1.10 \mathrm{E}-02$ & $2.00 \mathrm{E}-02$ \\
\hline & $3.60 \mathrm{E}-02$ & $6.30 \mathrm{E}-02$ & $8.20 \mathrm{E}-02$ & $8.60 \mathrm{E}-02$ & $9.00 \mathrm{E}-02$ & $9.40 \mathrm{E}-02$ & $9.60 \mathrm{E}-02$ \\
\hline & $1.05 \mathrm{E}-01$ & $1.15 \mathrm{E}-01$ & $1.25 \mathrm{E}-01$ & $1.35 \mathrm{E}-01$ & $1.45 \mathrm{E}-01$ & $1.55 \mathrm{E}-01$ & $1.65 \mathrm{E}-01$ \\
\hline & $1.75 \mathrm{E}-01$ & $1.85 \mathrm{E}-01$ & $1.95 \mathrm{E}-01$ & $2.10 \mathrm{E}-01$ & $2.30 \mathrm{E}-01$ & $2.50 \mathrm{E}-01$ & $2.70 \mathrm{E}-01$ \\
\hline & $2.90 \mathrm{E}-01$ & $3.10 \mathrm{E}-01$ & $3.30 \mathrm{E}-01$ & $3.50 \mathrm{E}-01$ & $3.70 \mathrm{E}-01$ & $3.90 \mathrm{E}-01$ & $4.20 \mathrm{E}-01$ \\
\hline & $4.60 \mathrm{E}-01$ & $5.00 \mathrm{E}-01$ & $5.40 \mathrm{E}-01$ & $5.80 \mathrm{E}-01$ & $6.20 \mathrm{E}-01$ & $6.60 \mathrm{E}-01$ & $7.00 \mathrm{E}-01$ \\
\hline & $7.40 \mathrm{E}-01$ & $7.80 \mathrm{E}-01$ & $8.20 \mathrm{E}-01$ & $8.60 \mathrm{E}-01$ & $9.00 \mathrm{E}-01$ & $9.40 \mathrm{E}-01$ & $9.80 \mathrm{E}-01$ \\
\hline & $1.05 \mathrm{E}+00$ & $1.15 \mathrm{E}+00$ & $1.25 \mathrm{E}+00$ & $1.35 \mathrm{E}+00$ & $1.45 \mathrm{E}+00$ & $1.55 \mathrm{E}+00$ & $1.65 \mathrm{E}+00$ \\
\hline & $1.75 \mathrm{E}+00$ & $1.85 \mathrm{E}+00$ & $1.95 \mathrm{E}+00$ & $2.10 \mathrm{E}+00$ & $2.30 \mathrm{E}+00$ & $2.50 \mathrm{E}+00$ & $2.70 \mathrm{E}+00$ \\
\hline & $2.90 \mathrm{E}+00$ & $3.10 \mathrm{E}+00$ & $3.30 \mathrm{E}+00$ & $3.50 \mathrm{E}+00$ & $3.70 \mathrm{E}+00$ & $3.90 \mathrm{E}+00$ & $4.20 \mathrm{E}+00$ \\
\hline & $4.60 \mathrm{E}+00$ & $5.00 \mathrm{E}+00$ & $5.40 \mathrm{E}+00$ & $5.80 \mathrm{E}+00$ & $6.20 \mathrm{E}+00$ & $6.60 \mathrm{E}+00$ & $7.00 \mathrm{E}+00$ \\
\hline & $7.40 \mathrm{E}+00$ & $7.80 \mathrm{E}+00$ & $8.20 \mathrm{E}+00$ & $8.60 \mathrm{E}+00$ & $9.00 \mathrm{E}+00$ & $9.40 \mathrm{E}+00$ & $9.80 \mathrm{E}+00$ \\
\hline & $1.05 \mathrm{E}+01$ & $1.15 \mathrm{E}+01$ & $1.25 \mathrm{E}+01$ & $1.35 \mathrm{E}+01$ & $1.45 \mathrm{E}+01$ & $1.55 \mathrm{E}+01$ & $1.65 \mathrm{E}+01$ \\
\hline & $1.75 \mathrm{E}+01$ & $1.85 \mathrm{E}+01$ & $1.95 \mathrm{E}+01$ & $2.10 \mathrm{E}+01$ & $2.30 \mathrm{E}+01$ & $2.50 \mathrm{E}+01$ & $2.70 E+01$ \\
\hline & $2.90 \mathrm{E}+01$ & & & & & & \\
\hline i & ts: Energs & y Bins & & & & & \\
\hline $\mathrm{DE} 125$ & $1.10 \mathrm{E}-05$ & $2.00 \mathrm{E}-05$ & $3.60 \mathrm{E}-05$ & $6.30 \mathrm{E}-05$ & $1.10 \mathrm{E}-04$ & $2.00 \mathrm{E}-04$ & $3.60 \mathrm{E}-04$ \\
\hline & $6.30 \mathrm{E}-04$ & $1.10 \mathrm{E}-03$ & $2.00 \mathrm{E}-03$ & $3.60 \mathrm{E}-03$ & $6.30 \mathrm{E}-03$ & $1.10 \mathrm{E}-02$ & $2.00 \mathrm{E}-02$ \\
\hline & $3.60 \mathrm{E}-02$ & $6.30 \mathrm{E}-02$ & $8.20 \mathrm{E}-02$ & $8.60 \mathrm{E}-02$ & $9.00 \mathrm{E}-02$ & $9.40 \mathrm{E}-02$ & $9.60 \mathrm{E}-02$ \\
\hline & $1.05 \mathrm{E}-01$ & $1.15 \mathrm{E}-01$ & $1.25 \mathrm{E}-01$ & $1.35 \mathrm{E}-01$ & $1.45 \mathrm{E}-01$ & $1.55 \mathrm{E}-01$ & $1.65 \mathrm{E}-01$ \\
\hline & $1.75 \mathrm{E}-01$ & $1.85 \mathrm{E}-01$ & $1.95 \mathrm{E}-01$ & $2.10 \mathrm{E}-01$ & $2.30 E-01$ & $2.50 \mathrm{E}-01$ & $2.70 \mathrm{E}-01$ \\
\hline & $2.90 \mathrm{E}-01$ & $3.10 \mathrm{E}-01$ & $3.30 \mathrm{E}-01$ & $3.50 \mathrm{E}-01$ & $3.70 \mathrm{E}-01$ & $3.90 \mathrm{E}-01$ & $4.20 \mathrm{E}-01$ \\
\hline & $4.60 \mathrm{E}-01$ & $5.00 \mathrm{E}-01$ & $5.40 \mathrm{E}-01$ & $5.80 \mathrm{E}-01$ & $6.20 \mathrm{E}-01$ & $6.60 \mathrm{E}-01$ & $7.00 \mathrm{E}-01$ \\
\hline & $7.40 \mathrm{E}-01$ & $7.80 \mathrm{E}-01$ & $8.20 \mathrm{E}-01$ & $8.60 \mathrm{E}-01$ & $9.00 \mathrm{E}-01$ & $9.40 \mathrm{E}-01$ & $9.80 \mathrm{E}-01$ \\
\hline & $1.05 \mathrm{E}+00$ & $1.15 \mathrm{E}+00$ & $1.25 \mathrm{E}+00$ & $1.35 \mathrm{E}+00$ & $1.45 \mathrm{E}+00$ & $1.55 \mathrm{E}+00$ & $1.65 \mathrm{E}+00$ \\
\hline & $1.75 \mathrm{E}+00$ & $1.85 E+00$ & $1.95 \mathrm{E}+00$ & $2.10 \mathrm{E}+00$ & $2.30 \mathrm{E}+00$ & $2.50 \mathrm{E}+00$ & $2.70 \mathrm{E}+00$ \\
\hline & $2.90 \mathrm{E}+00$ & $3.10 \mathrm{E}+00$ & $3.30 \mathrm{E}+00$ & $3.50 \mathrm{E}+00$ & $3.70 \mathrm{E}+00$ & $3.90 \mathrm{E}+00$ & $4.20 \mathrm{E}+00$ \\
\hline & $4.60 \mathrm{E}+00$ & $5.00 \mathrm{E}+00$ & $5.40 \mathrm{E}+00$ & $5.80 \mathrm{E}+00$ & $6.20 \mathrm{E}+00$ & $6.60 \mathrm{E}+00$ & $7.00 \mathrm{E}+00$ \\
\hline & $7.40 \mathrm{E}+00$ & $7.80 \mathrm{E}+00$ & $8.20 \mathrm{E}+00$ & $8.60 \mathrm{E}+00$ & $9.00 \mathrm{E}+00$ & $9.40 \mathrm{E}+00$ & $9.80 \mathrm{E}+00$ \\
\hline & $1.05 \mathrm{E}+01$ & $1.15 \mathrm{E}+01$ & $1.25 \mathrm{E}+01$ & $1.35 \mathrm{E}+01$ & $1.45 \mathrm{E}+01$ & $1.55 \mathrm{E}+01$ & $1.65 \mathrm{E}+01$ \\
\hline & $1.75 \mathrm{E}+01$ & $1.85 \mathrm{E}+01$ & $1.95 \mathrm{E}+01$ & $2.10 \mathrm{E}+01$ & $2.30 \mathrm{E}+01$ & $2.50 \mathrm{E}+01$ & $2.70 \mathrm{E}+01$ \\
\hline & $2.90 \mathrm{E}+01$ & & & & & & \\
\hline & ts: $\mathrm{cGy} / \mathrm{hr}$ & s pe & $2 \mathrm{sec}$ & $d-\mathrm{cm}^{\wedge} 2 / \mathrm{s}$ & $*(3.6 \mathrm{e} 3)$ & & \\
\hline $\mathrm{DF} 125$ & $6.80 \mathrm{E}-10$ & $1.13 E-09$ & $1.94 \mathrm{E}-09$ & $3.34 \mathrm{E}-09$ & $5.80 \mathrm{E}-09$ & $1.05 \mathrm{E}-08$ & $1.88 \mathrm{E}-08$ \\
\hline & $3.28 \mathrm{E}-08$ & $5.72 \mathrm{E}-08$ & $1.03 \mathrm{E}-07$ & $1.84 \mathrm{E}-07$ & $3.17 \mathrm{E}-07$ & $5.36 \mathrm{E}-07$ & $9.32 \mathrm{E}-07$ \\
\hline & $1.54 \mathrm{E}-06$ & $2.40 \mathrm{E}-06$ & $2.89 \mathrm{E}-06$ & $3.00 \mathrm{E}-06$ & $3.09 \mathrm{E}-06$ & $3.18 \mathrm{E}-06$ & $3.27 \mathrm{E}-06$ \\
\hline & $3.54 \mathrm{E}-06$ & $3.64 \mathrm{E}-06$ & $3.85 \mathrm{E}-06$ & $4.03 \mathrm{E}-06$ & $4.21 \mathrm{E}-06$ & $4.39 \mathrm{E}-06$ & $4.54 \mathrm{E}-06$ \\
\hline & $4.72 \mathrm{E}-06$ & $4.86 \mathrm{E}-06$ & $5.00 \mathrm{E}-06$ & $5.22 \mathrm{E}-06$ & $5.47 \mathrm{E}-06$ & $5.76 \mathrm{E}-06$ & $5.98 \mathrm{E}-06$ \\
\hline
\end{tabular}




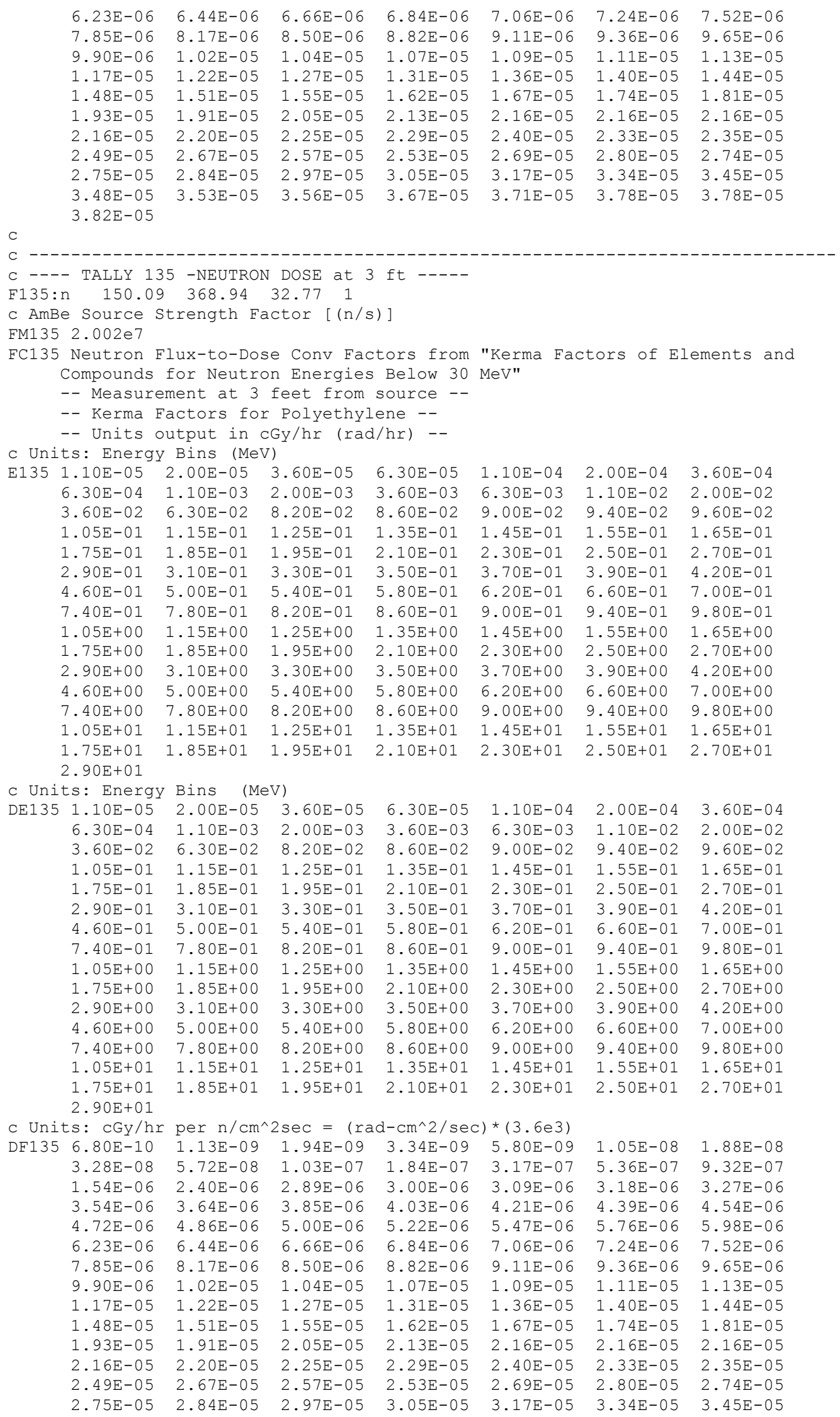




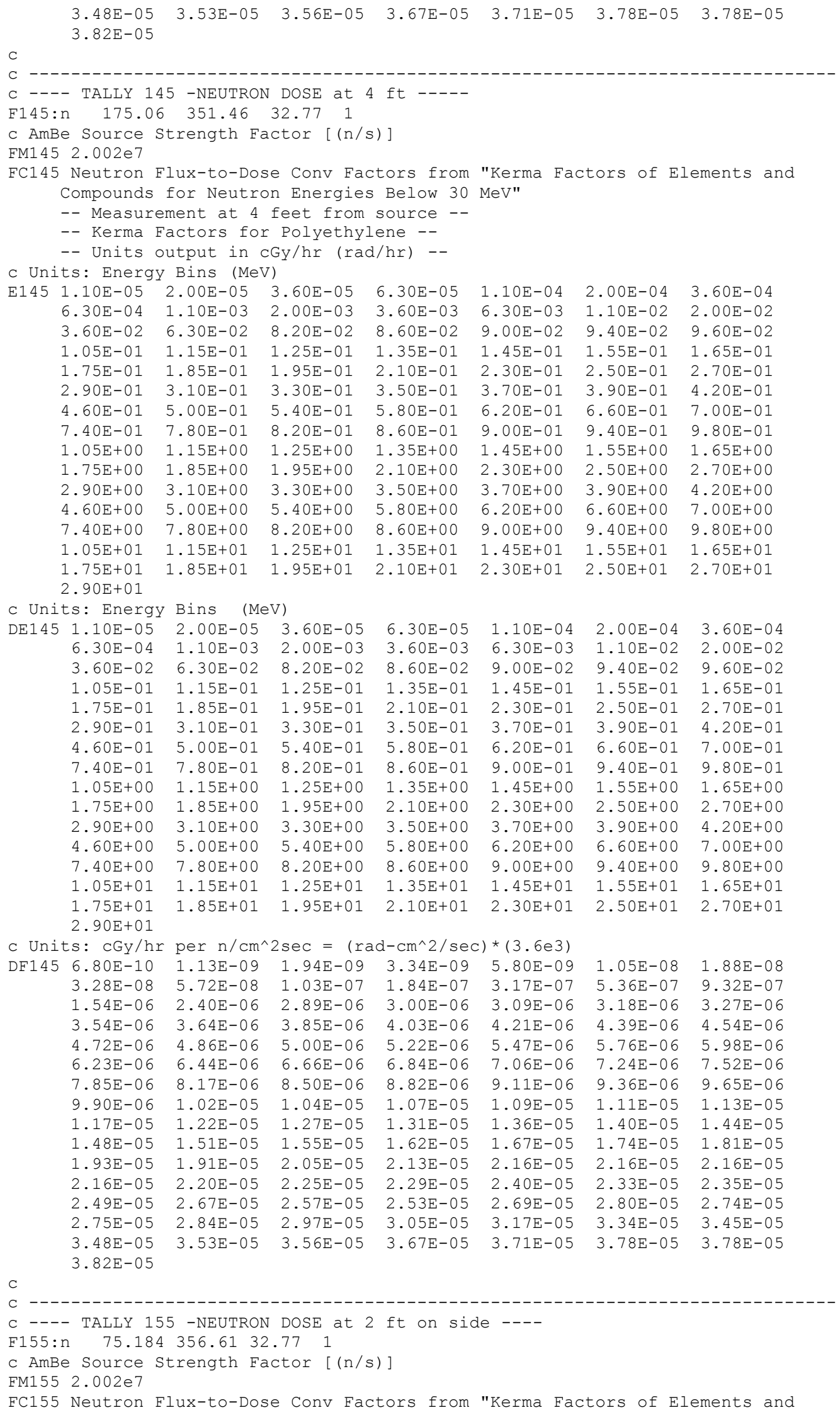




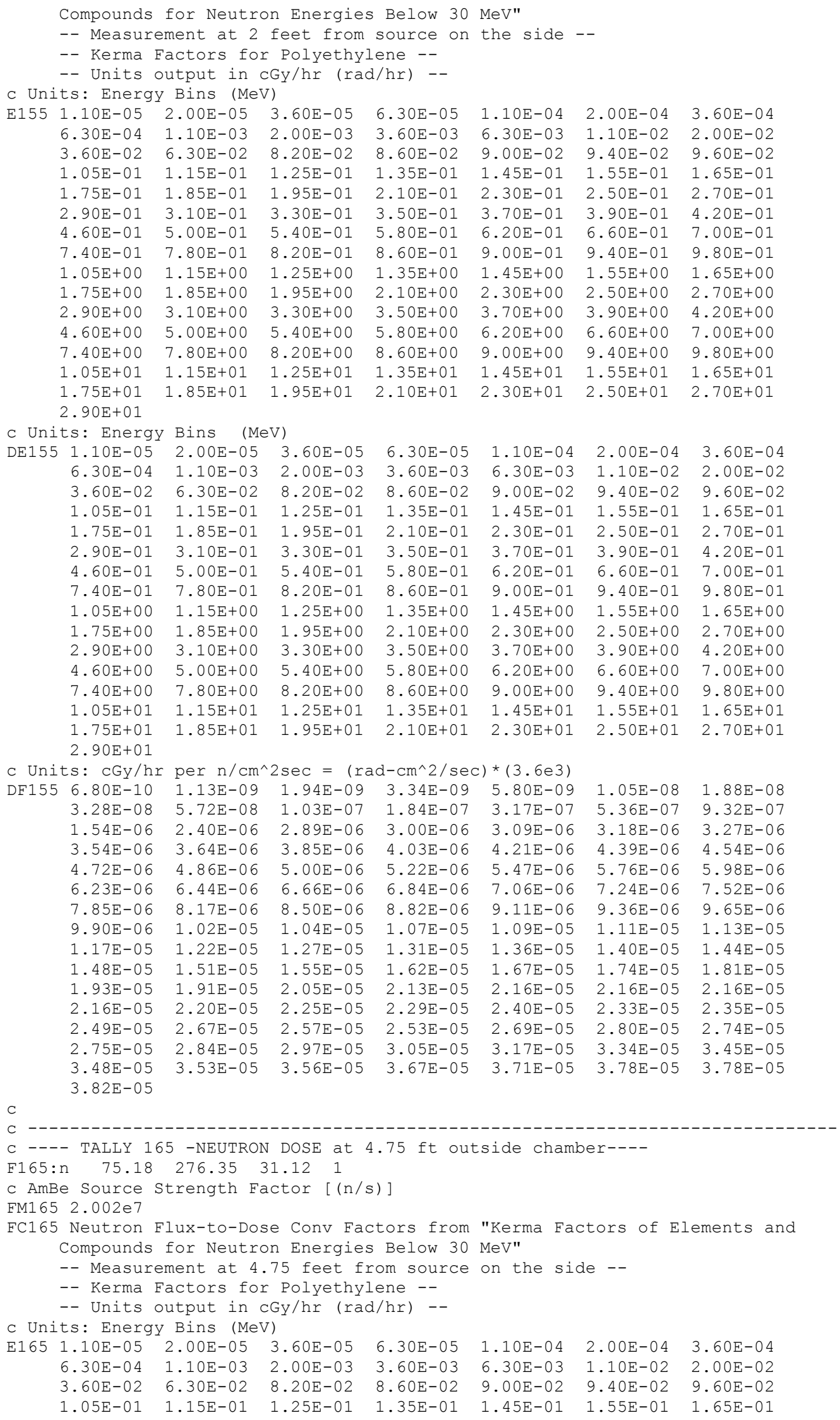




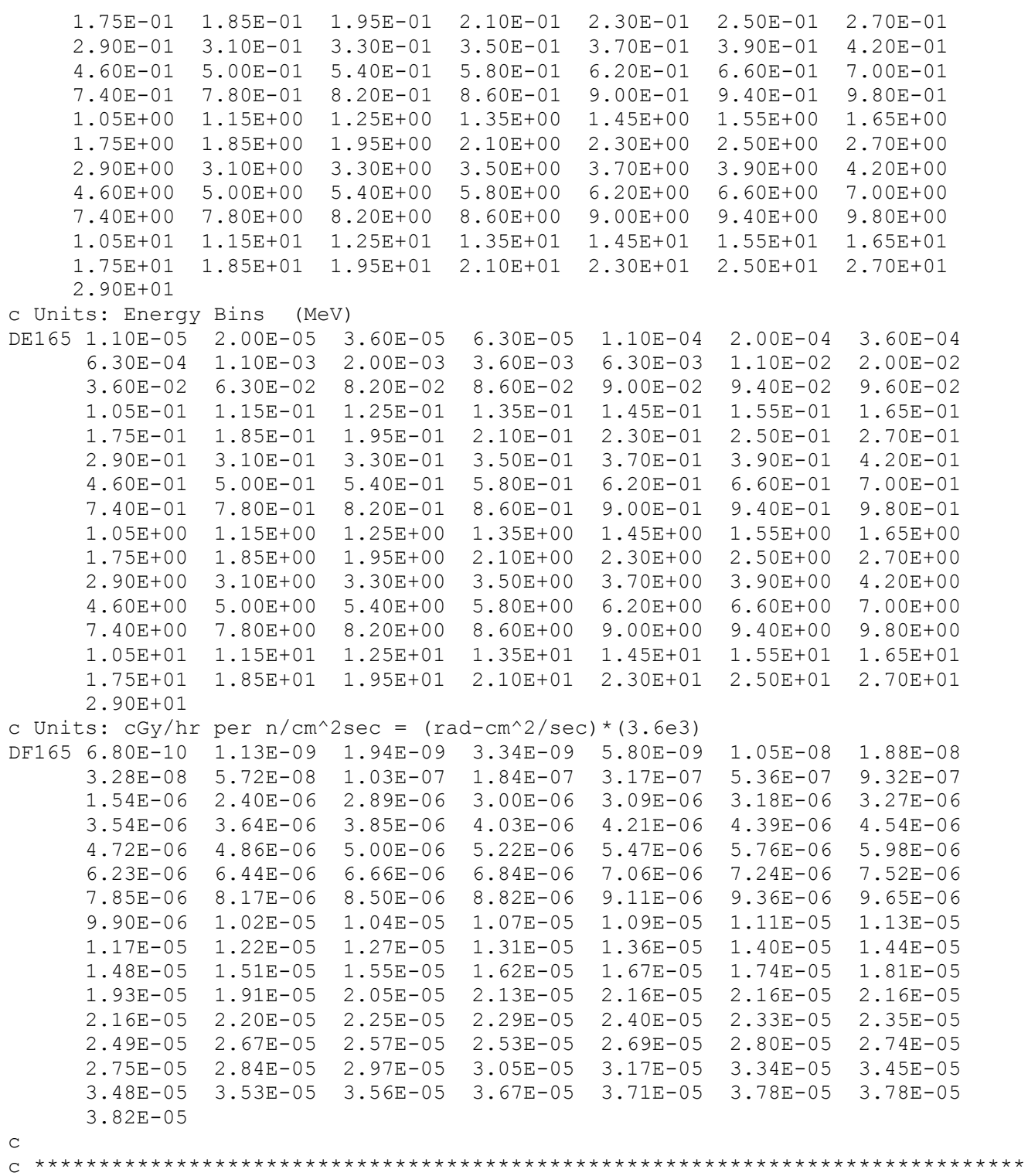

\section{A.8 Silicon Dose Tallies}

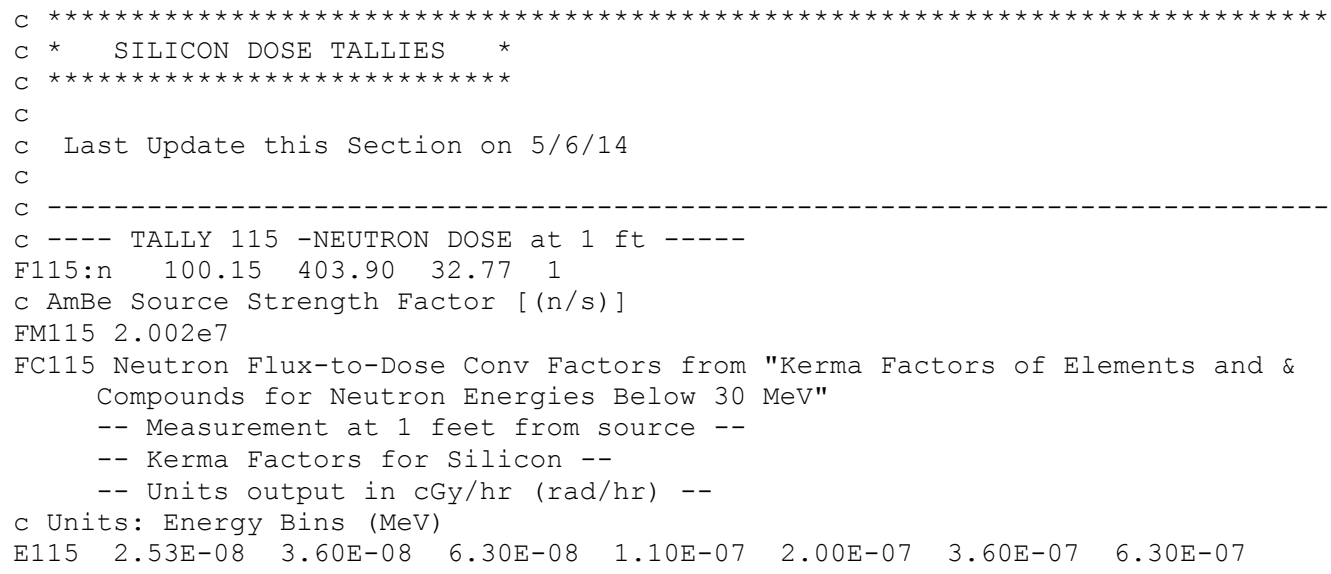




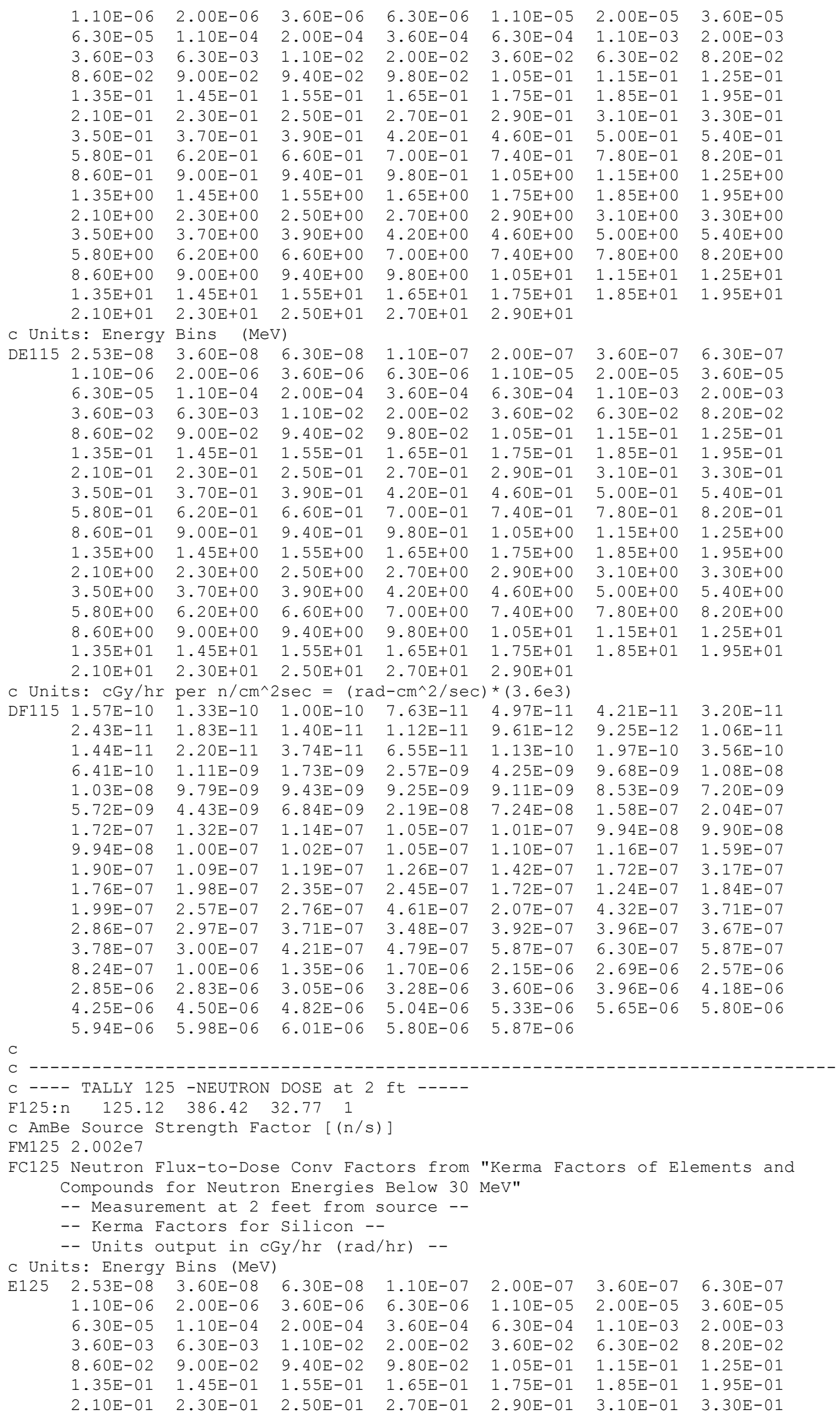




\begin{tabular}{|c|c|c|c|c|c|c|c|}
\hline & $3.50 \mathrm{E}-01$ & $3.70 \mathrm{E}-01$ & $3.90 \mathrm{E}-01$ & $4.20 \mathrm{E}-01$ & $4.60 \mathrm{E}-01$ & $5.00 \mathrm{E}-01$ & $5.40 \mathrm{E}-01$ \\
\hline & $5.80 \mathrm{E}-01$ & $6.20 \mathrm{E}-01$ & $6.60 \mathrm{E}-01$ & $7.00 \mathrm{E}-01$ & $7.40 \mathrm{E}-01$ & $7.80 \mathrm{E}-01$ & $8.20 \mathrm{E}-01$ \\
\hline & $8.60 \mathrm{E}-01$ & $9.00 \mathrm{E}-01$ & $9.40 \mathrm{E}-01$ & $9.80 \mathrm{E}-01$ & $1.05 E+00$ & $1.15 \mathrm{E}+00$ & $1.25 \mathrm{E}+00$ \\
\hline & $1.35 \mathrm{E}+00$ & $1.45 \mathrm{E}+00$ & $1.55 \mathrm{E}+00$ & $1.65 \mathrm{E}+00$ & $1.75 E+00$ & $1.85 \mathrm{E}+00$ & $1.95 \mathrm{E}+00$ \\
\hline & $2.10 \mathrm{E}+00$ & $2.30 \mathrm{E}+00$ & $2.50 \mathrm{E}+00$ & $2.70 \mathrm{E}+00$ & $2.90 \mathrm{E}+00$ & $3.10 \mathrm{E}+00$ & $3.30 \mathrm{E}+00$ \\
\hline & $3.50 \mathrm{E}+00$ & $3.70 \mathrm{E}+00$ & $3.90 \mathrm{E}+00$ & $4.20 \mathrm{E}+00$ & $4.60 E+00$ & $5.00 \mathrm{E}+00$ & $5.40 \mathrm{E}+00$ \\
\hline & $5.80 \mathrm{E}+00$ & $6.20 E+00$ & $6.60 \mathrm{E}+00$ & $7.00 \mathrm{E}+00$ & $7.40 \mathrm{E}+00$ & $7.80 E+00$ & $8.20 \mathrm{E}+00$ \\
\hline & $8.60 \mathrm{E}+00$ & $9.00 \mathrm{E}+00$ & $9.40 \mathrm{E}+00$ & $9.80 \mathrm{E}+00$ & $1.05 E+01$ & $1.15 \mathrm{E}+01$ & $1.25 \mathrm{E}+01$ \\
\hline & $1.35 \mathrm{E}+01$ & $1.45 \mathrm{E}+01$ & $1.55 \mathrm{E}+01$ & $1.65 \mathrm{E}+01$ & $1.75 E+01$ & $1.85 E+01$ & $1.95 \mathrm{E}+01$ \\
\hline & $2.10 \mathrm{E}+01$ & $2.30 E+01$ & $2.50 \mathrm{E}+01$ & $2.70 \mathrm{E}+01$ & $2.90 E+01$ & & \\
\hline Uni & ts: Energy & Bins $\quad(M e$ & & & & & \\
\hline 715 & $2.53 \mathrm{E}-08$ & $3.60 E-08$ & $6.30 \mathrm{E}-08$ & $1.10 \mathrm{E}-07$ & $2.00 E-07$ & $3.60 \mathrm{E}-07$ & $6.30 \mathrm{E}-07$ \\
\hline & $1.10 \mathrm{E}-06$ & $2.00 E-06$ & $3.60 \mathrm{E}-06$ & $6.30 \mathrm{E}-06$ & $1.10 \mathrm{E}-05$ & $2.00 \mathrm{E}-05$ & $3.60 \mathrm{E}-05$ \\
\hline & $6.30 \mathrm{E}-05$ & $1.10 \mathrm{E}-04$ & $2.00 \mathrm{E}-04$ & $3.60 \mathrm{E}-04$ & $6.30 \mathrm{E}-04$ & $1.10 \mathrm{E}-03$ & $2.00 \mathrm{E}-03$ \\
\hline & $3.60 \mathrm{E}-03$ & $6.30 E-03$ & $1.10 \mathrm{E}-02$ & $2.00 \mathrm{E}-02$ & $3.60 \mathrm{E}-02$ & $6.30 \mathrm{E}-02$ & $8.20 \mathrm{E}-02$ \\
\hline & $8.60 \mathrm{E}-02$ & $9.00 \mathrm{E}-02$ & $9.40 \mathrm{E}-02$ & $9.80 \mathrm{E}-02$ & $1.05 E-01$ & $1.15 \mathrm{E}-01$ & $1.25 \mathrm{E}-01$ \\
\hline & $1.35 \mathrm{E}-01$ & $1.45 \mathrm{E}-01$ & $1.55 \mathrm{E}-01$ & $1.65 \mathrm{E}-01$ & $1.75 E-01$ & $1.85 \mathrm{E}-01$ & $1.95 \mathrm{E}-01$ \\
\hline & $2.10 \mathrm{E}-01$ & $2.30 \mathrm{E}-01$ & $2.50 \mathrm{E}-01$ & $2.70 \mathrm{E}-01$ & $2.90 \mathrm{E}-01$ & $3.10 \mathrm{E}-01$ & $3.30 \mathrm{E}-01$ \\
\hline & $3.50 \mathrm{E}-01$ & $3.70 \mathrm{E}-01$ & $3.90 \mathrm{E}-01$ & $4.20 \mathrm{E}-01$ & $4.60 \mathrm{E}-01$ & $5.00 \mathrm{E}-01$ & $5.40 \mathrm{E}-01$ \\
\hline & $5.80 \mathrm{E}-01$ & $6.20 \mathrm{E}-01$ & $6.60 \mathrm{E}-01$ & $7.00 \mathrm{E}-01$ & $7.40 \mathrm{E}-01$ & $7.80 \mathrm{E}-01$ & $8.20 \mathrm{E}-01$ \\
\hline & $8.60 \mathrm{E}-01$ & $9.00 \mathrm{E}-01$ & $9.40 \mathrm{E}-01$ & $9.80 \mathrm{E}-01$ & $1.05 \mathrm{E}+00$ & $1.15 \mathrm{E}+00$ & $1.25 \mathrm{E}+00$ \\
\hline & $1.35 \mathrm{E}+00$ & $1.45 \mathrm{E}+00$ & $1.55 \mathrm{E}+00$ & $1.65 \mathrm{E}+00$ & $1.75 E+00$ & $1.85 \mathrm{E}+00$ & $1.95 \mathrm{E}+00$ \\
\hline & $2.10 \mathrm{E}+00$ & $2.30 E+00$ & $2.50 \mathrm{E}+00$ & $2.70 \mathrm{E}+00$ & $2.90 \mathrm{E}+00$ & $3.10 \mathrm{E}+00$ & $3.30 \mathrm{E}+00$ \\
\hline & $3.50 \mathrm{E}+00$ & $3.70 E+00$ & $3.90 \mathrm{E}+00$ & $4.20 \mathrm{E}+00$ & $4.60 \mathrm{E}+00$ & $5.00 \mathrm{E}+00$ & $5.40 \mathrm{E}+00$ \\
\hline & $5.80 \mathrm{E}+00$ & $6.20 \mathrm{E}+00$ & $6.60 \mathrm{E}+00$ & $7.00 \mathrm{E}+00$ & $7.40 \mathrm{E}+00$ & $7.80 \mathrm{E}+00$ & $8.20 \mathrm{E}+00$ \\
\hline & $8.60 \mathrm{E}+00$ & $9.00 \mathrm{E}+00$ & $9.40 \mathrm{E}+00$ & $9.80 \mathrm{E}+00$ & $1.05 E+01$ & $1.15 \mathrm{E}+01$ & $1.25 \mathrm{E}+01$ \\
\hline & $1.35 \mathrm{E}+01$ & $1.45 \mathrm{E}+01$ & $1.55 \mathrm{E}+01$ & $1.65 \mathrm{E}+01$ & $1.75 E+01$ & $1.85 \mathrm{E}+01$ & $1.95 \mathrm{E}+01$ \\
\hline & $2.10 \mathrm{E}+01$ & $2.30 E+01$ & $2.50 \mathrm{E}+01$ & $2.70 \mathrm{E}+01$ & $2.90 E+01$ & & \\
\hline c Unit & ts: cGy/hr & per $\mathrm{n} / \mathrm{cm}^{\wedge}$ & $2 \mathrm{sec}=(\mathrm{ra}$ & $\mathrm{d}-\mathrm{cm}^{\wedge} 2 / \mathrm{sec}$ & $*(3.6 e 3)$ & & \\
\hline DF125 & $1.57 \mathrm{E}-10$ & $1.33 \mathrm{E}-10$ & $1.00 \mathrm{E}-10$ & $7.63 \mathrm{E}-11$ & $4.97 \mathrm{E}-11$ & $4.21 E-11$ & $3.20 \mathrm{E}-11$ \\
\hline & $2.43 E-11$ & $1.83 E-11$ & $1.40 \mathrm{E}-11$ & $1.12 \mathrm{E}-11$ & $9.61 \mathrm{E}-12$ & $9.25 \mathrm{E}-12$ & $1.06 \mathrm{E}-11$ \\
\hline & 1. $44 \mathrm{E}-11$ & $2.20 \mathrm{E}-11$ & $3.74 \mathrm{E}-11$ & $6.55 \mathrm{E}-11$ & $1.13 \mathrm{E}-10$ & $1.97 \mathrm{E}-10$ & $3.56 \mathrm{E}-10$ \\
\hline & $6.41 \mathrm{E}-10$ & $1.11 E-09$ & $1.73 \mathrm{E}-09$ & $2.57 \mathrm{E}-09$ & $4.25 E-09$ & $9.68 \mathrm{E}-09$ & $1.08 \mathrm{E}-08$ \\
\hline & $1.03 E-08$ & $9.79 E-09$ & $9.43 \mathrm{E}-09$ & $9.25 \mathrm{E}-09$ & $9.11 E-09$ & $8.53 E-09$ & $7.20 \mathrm{E}-09$ \\
\hline & $5.72 \mathrm{E}-09$ & $4.43 E-09$ & $6.84 \mathrm{E}-09$ & $2.19 \mathrm{E}-08$ & $7.24 \mathrm{E}-08$ & $1.58 \mathrm{E}-07$ & $2.04 \mathrm{E}-07$ \\
\hline & $1.72 \mathrm{E}-07$ & $1.32 \mathrm{E}-07$ & $1.14 \mathrm{E}-07$ & $1.05 \mathrm{E}-07$ & $1.01 \mathrm{E}-07$ & $9.94 \mathrm{E}-08$ & $9.90 \mathrm{E}-08$ \\
\hline & $9.94 \mathrm{E}-08$ & $1.00 \mathrm{E}-07$ & $1.02 \mathrm{E}-07$ & $1.05 \mathrm{E}-07$ & $1.10 \mathrm{E}-07$ & $1.16 \mathrm{E}-07$ & $1.59 \mathrm{E}-07$ \\
\hline & $1.90 \mathrm{E}-07$ & $1.09 \mathrm{E}-07$ & $1.19 \mathrm{E}-07$ & $1.26 \mathrm{E}-07$ & $1.42 \mathrm{E}-07$ & $1.72 \mathrm{E}-07$ & $3.17 \mathrm{E}-07$ \\
\hline & $1.76 \mathrm{E}-07$ & $1.98 \mathrm{E}-07$ & $2.35 \mathrm{E}-07$ & $2.45 \mathrm{E}-07$ & $1.72 \mathrm{E}-07$ & $1.24 \mathrm{E}-07$ & $1.84 \mathrm{E}-07$ \\
\hline & $1.99 \mathrm{E}-07$ & $2.57 \mathrm{E}-07$ & $2.76 \mathrm{E}-07$ & $4.61 \mathrm{E}-07$ & $2.07 E-07$ & $4.32 \mathrm{E}-07$ & $3.71 \mathrm{E}-07$ \\
\hline & $2.86 \mathrm{E}-07$ & $2.97 \mathrm{E}-07$ & $3.71 \mathrm{E}-07$ & $3.48 \mathrm{E}-07$ & $3.92 \mathrm{E}-07$ & $3.96 \mathrm{E}-07$ & $3.67 \mathrm{E}-07$ \\
\hline & $3.78 \mathrm{E}-07$ & $3.00 \mathrm{E}-07$ & $4.21 \mathrm{E}-07$ & $4.79 \mathrm{E}-07$ & $5.87 \mathrm{E}-07$ & $6.30 \mathrm{E}-07$ & $5.87 \mathrm{E}-07$ \\
\hline & $8.24 \mathrm{E}-07$ & $1.00 \mathrm{E}-06$ & $1.35 \mathrm{E}-06$ & $1.70 \mathrm{E}-06$ & $2.15 \mathrm{E}-06$ & $2.69 \mathrm{E}-06$ & $2.57 \mathrm{E}-06$ \\
\hline & $2.85 E-06$ & $2.83 E-06$ & $3.05 \mathrm{E}-06$ & $3.28 \mathrm{E}-06$ & $3.60 E-06$ & $3.96 \mathrm{E}-06$ & $4.18 \mathrm{E}-06$ \\
\hline & $4.25 \mathrm{E}-06$ & $4.50 E-06$ & $4.82 \mathrm{E}-06$ & $5.04 \mathrm{E}-06$ & $5.33 E-06$ & $5.65 \mathrm{E}-06$ & $5.80 \mathrm{E}-06$ \\
\hline & $5.94 \mathrm{E}-06$ & $5.98 E-06$ & $6.01 \mathrm{E}-06$ & $5.80 \mathrm{E}-06$ & $5.87 E-06$ & & \\
\hline & & & & & & & \\
\hline & & & & & & & \\
\hline $\begin{array}{c}C---1 \\
\end{array}$ & - TALLY 13 & 5 -NEUTRC & DOSE at & $t-$ & & & \\
\hline $\begin{array}{l}\mathrm{F} 135: \\
\mathrm{C} A \mathrm{AmB}\end{array}$ & n $\quad 150.09$ & 368.94 & 2.77 & & & & \\
\hline $\begin{array}{l}\text { C AmB } \\
\text { FM135 }\end{array}$ & e source s & rength $\mathrm{Fa}$ & tor $[(\mathrm{n} /$ & & & & \\
\hline FM135 & $2.002 e 7$ & & & & & & \\
\hline FC13! & Neutron & $1 u x-t o-D o$ & e Conv $\mathrm{Fa}$ & ors from & "Kerma $\mathrm{E}$ & Cs & ements and \\
\hline & Compounds & for Neutr & n Energie & Below 30 & MeV" & & \\
\hline & -- Measur & nent at 3 & feet & arce -- & & & \\
\hline & -- Kerma & actors for & Silicon & & & & \\
\hline & -- Units & atput in & Gy/hr (rad & /hr) -- & & & \\
\hline & ts: Energy & Bins (MeV & & & & & \\
\hline E135 & $2.53 \mathrm{E}-08$ & $3.60 \mathrm{E}-08$ & $6.30 \mathrm{E}-08$ & $1.10 \mathrm{E}-07$ & $2.00 E-07$ & $3.60 \mathrm{E}-07$ & $6.30 \mathrm{E}-07$ \\
\hline & $1.10 \mathrm{E}-06$ & $2.00 E-06$ & $3.60 \mathrm{E}-06$ & $6.30 \mathrm{E}-06$ & $1.10 \mathrm{E}-05$ & $2.00 \mathrm{E}-05$ & $3.60 \mathrm{E}-05$ \\
\hline & $6.30 \mathrm{E}-05$ & $1.10 \mathrm{E}-04$ & $2.00 \mathrm{E}-04$ & $3.60 \mathrm{E}-04$ & $6.30 \mathrm{E}-04$ & $1.10 \mathrm{E}-03$ & $2.00 \mathrm{E}-03$ \\
\hline & $3.60 \mathrm{E}-03$ & $6.30 \mathrm{E}-03$ & $1.10 \mathrm{E}-02$ & $2.00 \mathrm{E}-02$ & $3.60 \mathrm{E}-02$ & $6.30 \mathrm{E}-02$ & $8.20 \mathrm{E}-02$ \\
\hline & $8.60 \mathrm{E}-02$ & $9.00 \mathrm{E}-02$ & $9.40 \mathrm{E}-02$ & $9.80 \mathrm{E}-02$ & $1.05 E-01$ & $1.15 \mathrm{E}-01$ & $1.25 \mathrm{E}-01$ \\
\hline & $1.35 \mathrm{E}-01$ & $1.45 \mathrm{E}-01$ & $1.55 \mathrm{E}-01$ & $1.65 \mathrm{E}-01$ & $1.75 \mathrm{E}-01$ & $1.85 \mathrm{E}-01$ & $1.95 \mathrm{E}-01$ \\
\hline & $2.10 \mathrm{E}-01$ & $2.30 E-01$ & $2.50 \mathrm{E}-01$ & $2.70 \mathrm{E}-01$ & $2.90 E-01$ & $3.10 \mathrm{E}-01$ & $3.30 \mathrm{E}-01$ \\
\hline & $3.50 \mathrm{E}-01$ & $3.70 \mathrm{E}-01$ & $3.90 \mathrm{E}-01$ & $4.20 \mathrm{E}-01$ & $4.60 \mathrm{E}-01$ & $5.00 \mathrm{E}-01$ & $5.40 \mathrm{E}-01$ \\
\hline & $5.80 \mathrm{E}-01$ & $6.20 \mathrm{E}-01$ & $6.60 \mathrm{E}-01$ & $7.00 \mathrm{E}-01$ & $7.40 \mathrm{E}-01$ & $7.80 \mathrm{E}-01$ & $8.20 \mathrm{E}-01$ \\
\hline & $8.60 \mathrm{E}-01$ & $9.00 \mathrm{E}-01$ & $9.40 \mathrm{E}-01$ & $9.80 \mathrm{E}-01$ & $1.05 E+00$ & $1.15 \mathrm{E}+00$ & $1.25 \mathrm{E}+00$ \\
\hline & $1.35 \mathrm{E}+00$ & $1.45 \mathrm{E}+00$ & $1.55 \mathrm{E}+00$ & $1.65 \mathrm{E}+00$ & $1.75 E+00$ & $1.85 E+00$ & $1.95 \mathrm{E}+00$ \\
\hline & $2.10 \mathrm{E}+00$ & $2.30 \mathrm{E}+00$ & $2.50 \mathrm{E}+00$ & $2.70 \mathrm{E}+00$ & $2.90 E+00$ & $3.10 \mathrm{E}+00$ & $3.30 \mathrm{E}+00$ \\
\hline & $3.50 \mathrm{E}+00$ & $3.70 \mathrm{E}+00$ & $3.90 \mathrm{E}+00$ & $4.20 \mathrm{E}+00$ & $4.60 E+00$ & $5.00 \mathrm{E}+00$ & $5.40 \mathrm{E}+00$ \\
\hline
\end{tabular}




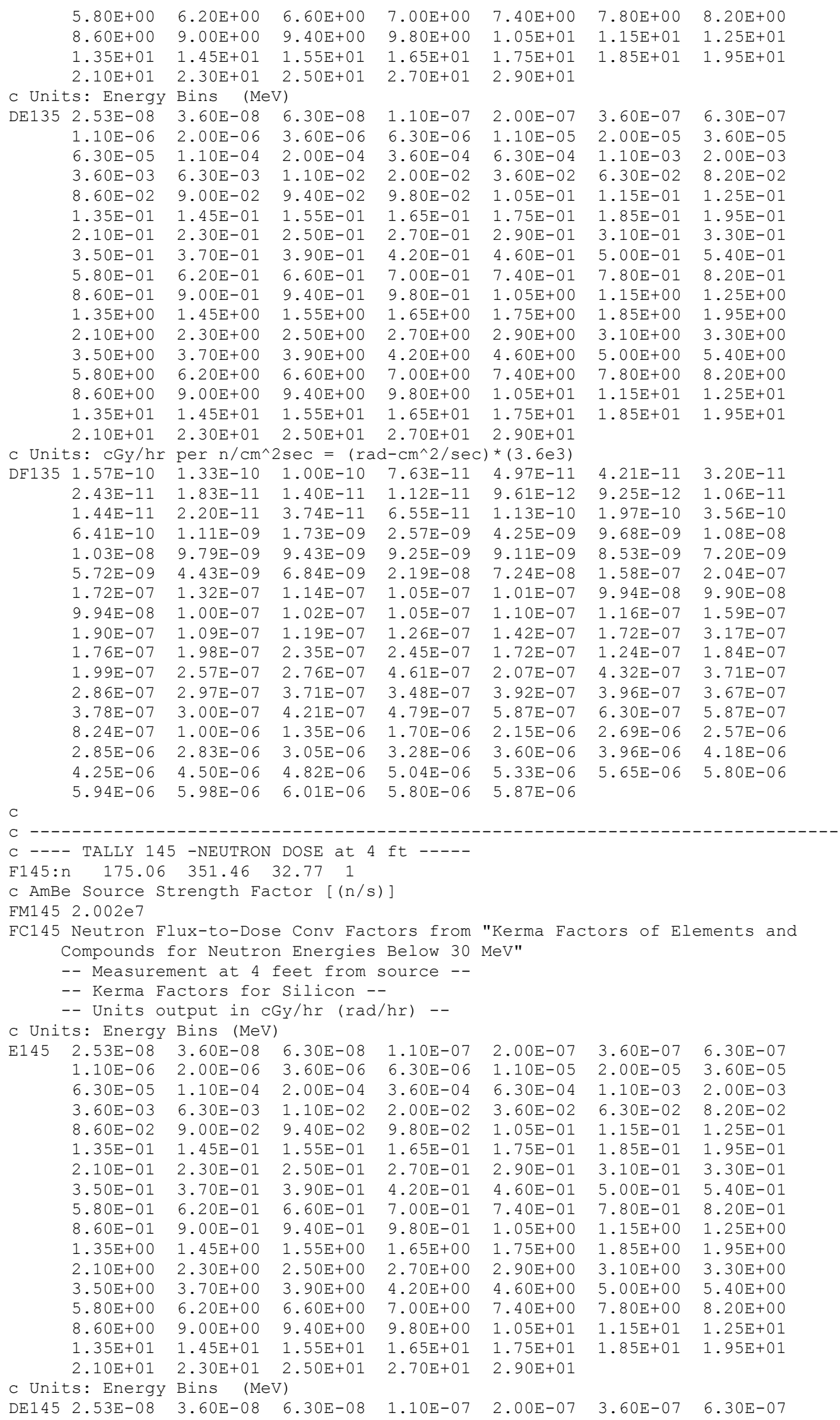




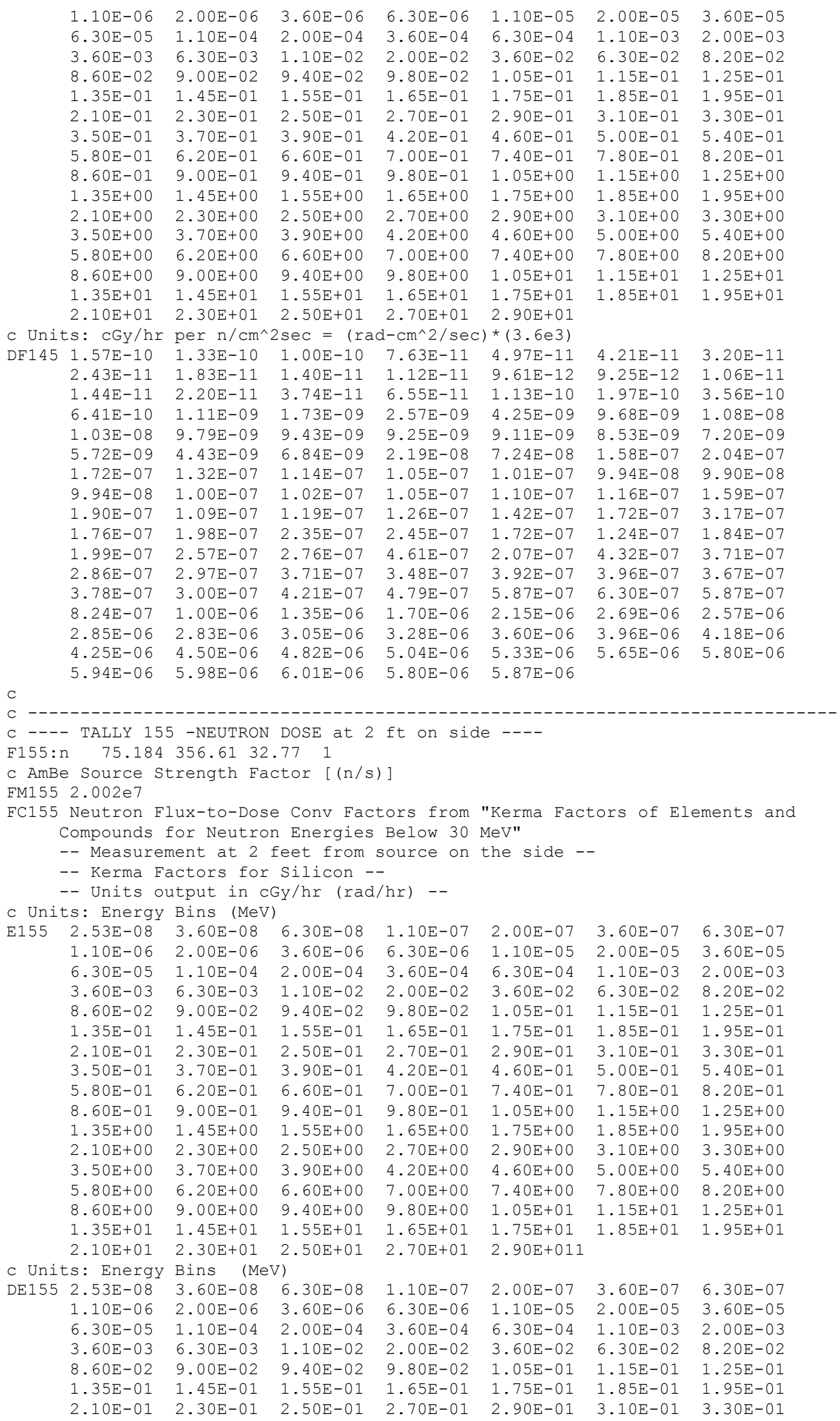




\begin{tabular}{|c|c|c|c|c|c|c|c|}
\hline & $3.50 \mathrm{E}-01$ & $3.70 \mathrm{E}-01$ & $3.90 \mathrm{E}-01$ & $4.20 \mathrm{E}-01$ & $4.60 \mathrm{E}-01$ & $5.00 \mathrm{E}-01$ & $5.40 \mathrm{E}-01$ \\
\hline & $5.80 \mathrm{E}-01$ & $6.20 \mathrm{E}-01$ & $6.60 \mathrm{E}-01$ & $7.00 \mathrm{E}-01$ & $7.40 \mathrm{E}-01$ & $7.80 \mathrm{E}-01$ & $8.20 \mathrm{E}-01$ \\
\hline & $8.60 \mathrm{E}-01$ & $9.00 \mathrm{E}-01$ & $9.40 \mathrm{E}-01$ & $9.80 \mathrm{E}-01$ & $1.05 \mathrm{E}+00$ & $1.15 \mathrm{E}+00$ & $1.25 \mathrm{E}+00$ \\
\hline & $1.35 \mathrm{E}+00$ & $1.45 \mathrm{E}+00$ & $1.55 \mathrm{E}+00$ & $1.65 \mathrm{E}+00$ & $1.75 \mathrm{E}+00$ & $1.85 \mathrm{E}+00$ & $1.95 \mathrm{E}+00$ \\
\hline & $2.10 \mathrm{E}+00$ & $2.30 \mathrm{E}+00$ & $2.50 \mathrm{E}+00$ & $2.70 \mathrm{E}+00$ & $2.90 \mathrm{E}+00$ & $3.10 \mathrm{E}+00$ & $3.30 \mathrm{E}+00$ \\
\hline & $3.50 \mathrm{E}+00$ & $3.70 \mathrm{E}+00$ & $3.90 \mathrm{E}+00$ & $4.20 \mathrm{E}+00$ & $4.60 \mathrm{E}+00$ & $5.00 \mathrm{E}+00$ & $5.40 \mathrm{E}+00$ \\
\hline & $5.80 \mathrm{E}+00$ & $6.20 \mathrm{E}+00$ & $6.60 \mathrm{E}+00$ & $7.00 \mathrm{E}+00$ & $7.40 \mathrm{E}+00$ & $7.80 \mathrm{E}+00$ & $8.20 \mathrm{E}+00$ \\
\hline & $8.60 \mathrm{E}+00$ & $9.00 \mathrm{E}+00$ & $9.40 \mathrm{E}+00$ & $9.80 \mathrm{E}+00$ & $1.05 E+01$ & $1.15 \mathrm{E}+01$ & $1.25 \mathrm{E}+01$ \\
\hline & $1.35 \mathrm{E}+01$ & $1.45 \mathrm{E}+01$ & $1.55 \mathrm{E}+01$ & $1.65 \mathrm{E}+01$ & $1.75 \mathrm{E}+01$ & $1.85 \mathrm{E}+01$ & $1.95 \mathrm{E}+01$ \\
\hline & $2.10 E+01$ & $2.30 \mathrm{E}+01$ & $2.50 \mathrm{E}+01$ & $2.70 \mathrm{E}+01$ & $2.90 \mathrm{E}+01$ & & \\
\hline Uni & ts: $\mathrm{CGy} / \mathrm{hr}$ & per $\mathrm{n} / \mathrm{cm}^{\wedge}$ & $2 \mathrm{sec}=(r a$ & $d-\mathrm{cm}^{\wedge} 2 / \mathrm{sec}$ & )$*(3.6 \mathrm{e} 3)$ & & \\
\hline 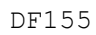 & $1.57 \mathrm{E}-10$ & $1.33 \mathrm{E}-10$ & $1.00 \mathrm{E}-10$ & $7.63 \mathrm{E}-11$ & $4.97 \mathrm{E}-11$ & $4.21 \mathrm{E}-11$ & $3.20 \mathrm{E}-11$ \\
\hline & $2.43 \mathrm{E}-11$ & $1.83 \mathrm{E}-11$ & $1.40 \mathrm{E}-11$ & $1.12 \mathrm{E}-11$ & $9.61 \mathrm{E}-12$ & $9.25 \mathrm{E}-12$ & $1.06 \mathrm{E}-11$ \\
\hline & $1.44 \mathrm{E}-11$ & $2.20 \mathrm{E}-11$ & $3.74 \mathrm{E}-11$ & $6.55 \mathrm{E}-11$ & $1.13 \mathrm{E}-10$ & $1.97 \mathrm{E}-10$ & $3.56 \mathrm{E}-10$ \\
\hline & $6.41 E-10$ & $1.11 \mathrm{E}-09$ & $1.73 \mathrm{E}-09$ & $2.57 \mathrm{E}-09$ & $4.25 \mathrm{E}-09$ & $9.68 \mathrm{E}-09$ & $1.08 \mathrm{E}-08$ \\
\hline & $1.03 E-08$ & $9.79 \mathrm{E}-09$ & $9.43 \mathrm{E}-09$ & $9.25 \mathrm{E}-09$ & $9.11 \mathrm{E}-09$ & $8.53 \mathrm{E}-09$ & $7.20 \mathrm{E}-09$ \\
\hline & $5.72 E-09$ & $4.43 \mathrm{E}-09$ & $6.84 \mathrm{E}-09$ & $2.19 \mathrm{E}-08$ & $7.24 \mathrm{E}-08$ & $1.58 \mathrm{E}-07$ & $2.04 \mathrm{E}-07$ \\
\hline & $1.72 \mathrm{E}-07$ & $1.32 \mathrm{E}-07$ & $1.14 \mathrm{E}-07$ & $1.05 \mathrm{E}-07$ & $1.01 \mathrm{E}-07$ & $9.94 \mathrm{E}-08$ & $9.90 \mathrm{E}-08$ \\
\hline & $9.94 \mathrm{E}-08$ & $1.00 \mathrm{E}-07$ & $1.02 \mathrm{E}-07$ & $1.05 \mathrm{E}-07$ & $1.10 \mathrm{E}-07$ & $1.16 \mathrm{E}-07$ & $1.59 \mathrm{E}-07$ \\
\hline & $1.90 \mathrm{E}-07$ & $1.09 \mathrm{E}-07$ & $1.19 \mathrm{E}-07$ & $1.26 \mathrm{E}-07$ & $1.42 \mathrm{E}-07$ & $1.72 \mathrm{E}-07$ & $3.17 \mathrm{E}-07$ \\
\hline & $1.76 \mathrm{E}-07$ & $1.98 \mathrm{E}-07$ & $2.35 \mathrm{E}-07$ & $2.45 \mathrm{E}-07$ & $1.72 \mathrm{E}-07$ & $1.24 \mathrm{E}-07$ & $1.84 \mathrm{E}-07$ \\
\hline & $1.99 \mathrm{E}-07$ & $2.57 \mathrm{E}-07$ & $2.76 \mathrm{E}-07$ & $4.61 \mathrm{E}-07$ & $2.07 \mathrm{E}-07$ & $4.32 \mathrm{E}-07$ & $3.71 \mathrm{E}-07$ \\
\hline & $2.86 \mathrm{E}-07$ & $2.97 \mathrm{E}-07$ & $3.71 \mathrm{E}-07$ & $3.48 \mathrm{E}-07$ & $3.92 \mathrm{E}-07$ & $3.96 \mathrm{E}-07$ & $3.67 \mathrm{E}-07$ \\
\hline & $3.78 \mathrm{E}-07$ & $3.00 \mathrm{E}-07$ & $4.21 \mathrm{E}-07$ & $4.79 \mathrm{E}-07$ & $5.87 \mathrm{E}-07$ & $6.30 \mathrm{E}-07$ & $5.87 \mathrm{E}-07$ \\
\hline & $8.24 \mathrm{E}-07$ & $1.00 \mathrm{E}-06$ & $1.35 \mathrm{E}-06$ & $1.70 \mathrm{E}-06$ & $2.15 \mathrm{E}-06$ & $2.69 \mathrm{E}-06$ & $2.57 \mathrm{E}-06$ \\
\hline & $2.85 \mathrm{E}-06$ & $2.83 \mathrm{E}-06$ & $3.05 \mathrm{E}-06$ & $3.28 \mathrm{E}-06$ & $3.60 \mathrm{E}-06$ & $3.96 \mathrm{E}-06$ & $4.18 \mathrm{E}-06$ \\
\hline & $4.25 \mathrm{E}-06$ & $4.50 \mathrm{E}-06$ & $4.82 \mathrm{E}-06$ & $5.04 \mathrm{E}-06$ & $5.33 \mathrm{E}-06$ & $5.65 \mathrm{E}-06$ & $5.80 \mathrm{E}-06$ \\
\hline & $5.94 \mathrm{E}-06$ & $5.98 \mathrm{E}-06$ & $6.01 \mathrm{E}-06$ & $5.80 \mathrm{E}-06$ & $5.87 \mathrm{E}-06$ & & \\
\hline & & & & & & & \\
\hline & TAT T Y & & DG & 5 & & & \\
\hline $\begin{array}{l}C-1 . \\
\text { F165:1 }\end{array}$ & $\begin{array}{l}- \text { TALLY } 16 \\
n \\
n\end{array}$ & $\begin{array}{c}5 \text { - NEUTRON } \\
276.353\end{array}$ & $\begin{array}{c}\text { DOSE at } \\
1.12 \text { 1 }\end{array}$ & 5 & $a c h=$ & - & \\
\hline $\mathrm{C} A \mathrm{AmB}$ & e source s & trength $\mathrm{Fa}$ & ctor $[(\mathrm{n})$ & & & & \\
\hline FM165 & $2.002 \mathrm{e} 7$ & & & & & & \\
\hline FC16 & Neutron & lux-to-Dos & e Conv $\mathrm{F}$ & ors from & "Kerma Fac & tors of $\mathrm{El}$ & ements and \\
\hline & Compounds & for Neutro & Energie & Below 30 & MeV" & & \\
\hline & -- Measur & ment at 4 . & 5 feet $f$ & om source & on the $s$ & e -- & \\
\hline & -- Kerma F & actors for & Silicon - & & & & \\
\hline & -- Units o & utput in & Gy/hr (rad & /hr) -- & & & \\
\hline$C$ & ts: Energy & Bins (MeV & & & & & \\
\hline E165 & $2.53 \mathrm{E}-08$ & $3.60 \mathrm{E}-08$ & $6.30 \mathrm{E}-08$ & $1.10 \mathrm{E}-07$ & $2.00 \mathrm{E}-07$ & $3.60 \mathrm{E}-07$ & $6.30 \mathrm{E}-07$ \\
\hline & $1.10 \mathrm{E}-06$ & $2.00 \mathrm{E}-06$ & $3.60 \mathrm{E}-06$ & $6.30 \mathrm{E}-06$ & $1.10 \mathrm{E}-05$ & $2.00 \mathrm{E}-05$ & $3.60 \mathrm{E}-05$ \\
\hline & $6.30 \mathrm{E}-05$ & $1.10 \mathrm{E}-04$ & $2.00 \mathrm{E}-04$ & $3.60 \mathrm{E}-04$ & $6.30 \mathrm{E}-04$ & $1.10 \mathrm{E}-03$ & $2.00 \mathrm{E}-03$ \\
\hline & $3.60 \mathrm{E}-03$ & $6.30 \mathrm{E}-03$ & $1.10 \mathrm{E}-02$ & $2.00 \mathrm{E}-02$ & $3.60 \mathrm{E}-02$ & $6.30 \mathrm{E}-02$ & $8.20 \mathrm{E}-02$ \\
\hline & $8.60 \mathrm{E}-02$ & $9.00 \mathrm{E}-02$ & $9.40 \mathrm{E}-02$ & $9.80 \mathrm{E}-02$ & $1.05 \mathrm{E}-01$ & $1.15 \mathrm{E}-01$ & $1.25 \mathrm{E}-01$ \\
\hline & $1.35 \mathrm{E}-01$ & $1.45 \mathrm{E}-01$ & $1.55 \mathrm{E}-01$ & $1.65 \mathrm{E}-01$ & $1.75 \mathrm{E}-01$ & $1.85 \mathrm{E}-01$ & $1.95 \mathrm{E}-01$ \\
\hline & $2.10 \mathrm{E}-01$ & $2.30 \mathrm{E}-01$ & $2.50 \mathrm{E}-01$ & $2.70 \mathrm{E}-01$ & $2.90 \mathrm{E}-01$ & $3.10 \mathrm{E}-01$ & $3.30 \mathrm{E}-01$ \\
\hline & $3.50 \mathrm{E}-01$ & $3.70 \mathrm{E}-01$ & $3.90 \mathrm{E}-01$ & $4.20 \mathrm{E}-01$ & $4.60 \mathrm{E}-01$ & $5.00 \mathrm{E}-01$ & $5.40 \mathrm{E}-01$ \\
\hline & $5.80 \mathrm{E}-01$ & $6.20 \mathrm{E}-01$ & $6.60 \mathrm{E}-01$ & $7.00 \mathrm{E}-01$ & $7.40 \mathrm{E}-01$ & $7.80 \mathrm{E}-01$ & $8.20 \mathrm{E}-01$ \\
\hline & $8.60 \mathrm{E}-01$ & $9.00 \mathrm{E}-01$ & $9.40 \mathrm{E}-01$ & $9.80 \mathrm{E}-01$ & $1.05 \mathrm{E}+00$ & $1.15 \mathrm{E}+00$ & $1.25 \mathrm{E}+00$ \\
\hline & $1.35 \mathrm{E}+00$ & $1.45 \mathrm{E}+00$ & $1.55 \mathrm{E}+00$ & $1.65 \mathrm{E}+00$ & $1.75 \mathrm{E}+00$ & $1.85 \mathrm{E}+00$ & $1.95 \mathrm{E}+00$ \\
\hline & $2.10 \mathrm{E}+00$ & $2.30 \mathrm{E}+00$ & $2.50 \mathrm{E}+00$ & $2.70 \mathrm{E}+00$ & $2.90 \mathrm{E}+00$ & $3.10 \mathrm{E}+00$ & $3.30 \mathrm{E}+00$ \\
\hline & $3.50 \mathrm{E}+00$ & $3.70 \mathrm{E}+00$ & $3.90 \mathrm{E}+00$ & $4.20 \mathrm{E}+00$ & $4.60 \mathrm{E}+00$ & $5.00 \mathrm{E}+00$ & $5.40 \mathrm{E}+00$ \\
\hline & $5.80 \mathrm{E}+00$ & $6.20 \mathrm{E}+00$ & $6.60 \mathrm{E}+00$ & $7.00 \mathrm{E}+00$ & $7.40 \mathrm{E}+00$ & $7.80 \mathrm{E}+00$ & $8.20 \mathrm{E}+00$ \\
\hline & $8.60 \mathrm{E}+00$ & $9.00 \mathrm{E}+00$ & $9.40 \mathrm{E}+00$ & $9.80 \mathrm{E}+00$ & $1.05 \mathrm{E}+01$ & $1.15 \mathrm{E}+01$ & $1.25 \mathrm{E}+01$ \\
\hline & $1.35 \mathrm{E}+01$ & $1.45 \mathrm{E}+01$ & $1.55 \mathrm{E}+01$ & $1.65 \mathrm{E}+01$ & $1.75 \mathrm{E}+01$ & $1.85 \mathrm{E}+01$ & $1.95 \mathrm{E}+01$ \\
\hline & $2.10 \mathrm{E}+01$ & $2.30 \mathrm{E}+01$ & $2.50 \mathrm{E}+01$ & $2.70 \mathrm{E}+01$ & $2.90 \mathrm{E}+01$ & & \\
\hline & ts: Energy & Bins & & & & & \\
\hline DE165 & $2.53 \mathrm{E}-08$ & $3.60 \mathrm{E}-08$ & $6.30 \mathrm{E}-08$ & $1.10 \mathrm{E}-07$ & $2.00 \mathrm{E}-07$ & $3.60 \mathrm{E}-07$ & $6.30 \mathrm{E}-07$ \\
\hline & $1.10 \mathrm{E}-06$ & $2.00 \mathrm{E}-06$ & $3.60 \mathrm{E}-06$ & $6.30 \mathrm{E}-06$ & $1.10 \mathrm{E}-05$ & $2.00 \mathrm{E}-05$ & $3.60 \mathrm{E}-05$ \\
\hline & $6.30 \mathrm{E}-05$ & $1.10 \mathrm{E}-04$ & $2.00 \mathrm{E}-04$ & $3.60 \mathrm{E}-04$ & $6.30 \mathrm{E}-04$ & $1.10 \mathrm{E}-03$ & $2.00 \mathrm{E}-03$ \\
\hline & $3.60 \mathrm{E}-03$ & $6.30 \mathrm{E}-03$ & $1.10 \mathrm{E}-02$ & $2.00 \mathrm{E}-02$ & $3.60 \mathrm{E}-02$ & $6.30 \mathrm{E}-02$ & $8.20 \mathrm{E}-02$ \\
\hline & $8.60 \mathrm{E}-02$ & $9.00 \mathrm{E}-02$ & $9.40 \mathrm{E}-02$ & $9.80 \mathrm{E}-02$ & $1.05 \mathrm{E}-01$ & $1.15 \mathrm{E}-01$ & $1.25 \mathrm{E}-01$ \\
\hline & $1.35 \mathrm{E}-01$ & $1.45 \mathrm{E}-01$ & $1.55 \mathrm{E}-01$ & $1.65 \mathrm{E}-01$ & $1.75 \mathrm{E}-01$ & $1.85 \mathrm{E}-01$ & $1.95 \mathrm{E}-01$ \\
\hline & $2.10 \mathrm{E}-01$ & $2.30 \mathrm{E}-01$ & $2.50 \mathrm{E}-01$ & $2.70 \mathrm{E}-01$ & $2.90 \mathrm{E}-01$ & $3.10 \mathrm{E}-01$ & $3.30 \mathrm{E}-01$ \\
\hline & $3.50 \mathrm{E}-01$ & $3.70 \mathrm{E}-01$ & $3.90 \mathrm{E}-01$ & $4.20 \mathrm{E}-01$ & $4.60 \mathrm{E}-01$ & $5.00 \mathrm{E}-01$ & $5.40 \mathrm{E}-01$ \\
\hline & $5.80 \mathrm{E}-01$ & $6.20 \mathrm{E}-01$ & $6.60 \mathrm{E}-01$ & $7.00 \mathrm{E}-01$ & $7.40 \mathrm{E}-01$ & $7.80 \mathrm{E}-01$ & $8.20 \mathrm{E}-01$ \\
\hline & $8.60 \mathrm{E}-01$ & $9.00 \mathrm{E}-01$ & $9.40 \mathrm{E}-01$ & $9.80 \mathrm{E}-01$ & $1.05 \mathrm{E}+00$ & $1.15 \mathrm{E}+00$ & $1.25 \mathrm{E}+00$ \\
\hline & $1.35 \mathrm{E}+00$ & $1.45 \mathrm{E}+00$ & $1.55 \mathrm{E}+00$ & $1.65 \mathrm{E}+00$ & $1.75 \mathrm{E}+00$ & $1.85 \mathrm{E}+00$ & $1.95 \mathrm{E}+00$ \\
\hline & $2.10 \mathrm{E}+00$ & $2.30 \mathrm{E}+00$ & $2.50 \mathrm{E}+00$ & $2.70 \mathrm{E}+00$ & $2.90 \mathrm{E}+00$ & $3.10 \mathrm{E}+00$ & $3.30 \mathrm{E}+00$ \\
\hline & $3.50 \mathrm{E}+00$ & $3.70 \mathrm{E}+00$ & $3.90 \mathrm{E}+00$ & $4.20 \mathrm{E}+00$ & $4.60 \mathrm{E}+00$ & $5.00 \mathrm{E}+00$ & $5.40 \mathrm{E}+00$ \\
\hline
\end{tabular}




\begin{tabular}{|c|c|c|c|c|c|c|c|}
\hline \multirow{4}{*}{\multicolumn{2}{|c|}{$\begin{array}{r}5.80 \mathrm{E}+00 \\
8.60 \mathrm{E}+00 \\
1.35 \mathrm{E}+01 \\
2.10 \mathrm{E}+01\end{array}$}} & $6.20 \mathrm{E}+00$ & $6.60 \mathrm{E}+00$ & $7.00 \mathrm{E}+00$ & $7.40 \mathrm{E}+00$ & $7.80 \mathrm{E}+00$ & $8.20 \mathrm{E}+00$ \\
\hline & & $9.00 \mathrm{E}+00$ & $9.40 \mathrm{E}+00$ & $9.80 \mathrm{E}+00$ & $1.05 \mathrm{E}+01$ & $1.15 \mathrm{E}+01$ & $1.25 \mathrm{E}+01$ \\
\hline & & $1.45 \mathrm{E}+01$ & $1.55 \mathrm{E}+01$ & $1.65 \mathrm{E}+01$ & $1.75 \mathrm{E}+01$ & $1.85 \mathrm{E}+01$ & $1.95 \mathrm{E}+01$ \\
\hline & & $2.30 \mathrm{E}+01$ & $2.50 \mathrm{E}+01$ & $2.70 \mathrm{E}+01$ & $2.90 \mathrm{E}+01$ & & \\
\hline \multicolumn{8}{|c|}{ c Units: cGy/hr per $\mathrm{n} / \mathrm{cm}^{\wedge} 2 \mathrm{sec}=\left(\mathrm{rad}-\mathrm{cm}^{\wedge} 2 / \mathrm{sec}\right) *(3.6 \mathrm{e} 3)$} \\
\hline \multirow[t]{17}{*}{ DF165 } & $1.57 \mathrm{E}-10$ & $1.33 E-10$ & $1.00 \mathrm{E}-10$ & $7.63 \mathrm{E}-11$ & $4.97 \mathrm{E}-11$ & $4.21 \mathrm{E}-11$ & $3.20 \mathrm{E}-11$ \\
\hline & $2.43 E-11$ & $1.83 \mathrm{E}-11$ & $1.40 \mathrm{E}-11$ & $1.12 \mathrm{E}-11$ & $9.61 \mathrm{E}-12$ & $9.25 \mathrm{E}-12$ & $1.06 \mathrm{E}-11$ \\
\hline & $1.44 \mathrm{E}-11$ & $2.20 \mathrm{E}-11$ & $3.74 \mathrm{E}-11$ & $6.55 \mathrm{E}-11$ & $1.13 \mathrm{E}-10$ & $1.97 \mathrm{E}-10$ & $3.56 \mathrm{E}-10$ \\
\hline & $6.41 \mathrm{E}-10$ & $1.11 \mathrm{E}-09$ & $1.73 E-09$ & $2.57 \mathrm{E}-09$ & $4.25 \mathrm{E}-09$ & $9.68 \mathrm{E}-09$ & $1.08 \mathrm{E}-08$ \\
\hline & $1.03 E-08$ & $9.79 \mathrm{E}-09$ & $9.43 E-09$ & $9.25 \mathrm{E}-09$ & $9.11 \mathrm{E}-09$ & $8.53 \mathrm{E}-09$ & $7.20 \mathrm{E}-09$ \\
\hline & $5.72 E-09$ & $4.43 E-09$ & $6.84 \mathrm{E}-09$ & $2.19 \mathrm{E}-08$ & $7.24 \mathrm{E}-08$ & $1.58 \mathrm{E}-07$ & $2.04 \mathrm{E}-07$ \\
\hline & $1.72 \mathrm{E}-07$ & $1.32 \mathrm{E}-07$ & $1.14 \mathrm{E}-07$ & $1.05 \mathrm{E}-07$ & $1.01 \mathrm{E}-07$ & $9.94 \mathrm{E}-08$ & $9.90 \mathrm{E}-08$ \\
\hline & $9.94 \mathrm{E}-08$ & $1.00 \mathrm{E}-07$ & $1.02 \mathrm{E}-07$ & $1.05 \mathrm{E}-07$ & $1.10 \mathrm{E}-07$ & $1.16 \mathrm{E}-07$ & $1.59 \mathrm{E}-07$ \\
\hline & $1.90 \mathrm{E}-07$ & $1.09 \mathrm{E}-07$ & $1.19 \mathrm{E}-07$ & $1.26 \mathrm{E}-07$ & $1.42 \mathrm{E}-07$ & $1.72 \mathrm{E}-07$ & $3.17 \mathrm{E}-07$ \\
\hline & $1.76 \mathrm{E}-07$ & $1.98 \mathrm{E}-07$ & $2.35 \mathrm{E}-07$ & $2.45 \mathrm{E}-07$ & $1.72 \mathrm{E}-07$ & $1.24 \mathrm{E}-07$ & $1.84 \mathrm{E}-07$ \\
\hline & $1.99 \mathrm{E}-07$ & $2.57 \mathrm{E}-07$ & $2.76 \mathrm{E}-07$ & $4.61 \mathrm{E}-07$ & $2.07 \mathrm{E}-07$ & $4.32 \mathrm{E}-07$ & $3.71 \mathrm{E}-07$ \\
\hline & $2.86 \mathrm{E}-07$ & $2.97 \mathrm{E}-07$ & $3.71 E-07$ & $3.48 \mathrm{E}-07$ & $3.92 \mathrm{E}-07$ & $3.96 \mathrm{E}-07$ & $3.67 \mathrm{E}-07$ \\
\hline & $3.78 \mathrm{E}-07$ & $3.00 \mathrm{E}-07$ & $4.21 \mathrm{E}-07$ & $4.79 \mathrm{E}-07$ & $5.87 \mathrm{E}-07$ & $6.30 \mathrm{E}-07$ & $5.87 \mathrm{E}-07$ \\
\hline & $8.24 E-07$ & $1.00 \mathrm{E}-06$ & $1.35 \mathrm{E}-06$ & $1.70 \mathrm{E}-06$ & $2.15 \mathrm{E}-06$ & $2.69 \mathrm{E}-06$ & $2.57 \mathrm{E}-06$ \\
\hline & $2.85 E-06$ & $2.83 E-06$ & $3.05 E-06$ & $3.28 \mathrm{E}-06$ & $3.60 \mathrm{E}-06$ & $3.96 \mathrm{E}-06$ & $4.18 \mathrm{E}-06$ \\
\hline & $4.25 E-06$ & $4.50 \mathrm{E}-06$ & $4.82 \mathrm{E}-06$ & $5.04 \mathrm{E}-06$ & $5.33 \mathrm{E}-06$ & $5.65 \mathrm{E}-06$ & $5.80 \mathrm{E}-06$ \\
\hline & $5.94 \mathrm{E}-06$ & $5.98 \mathrm{E}-06$ & $6.01 E-06$ & $5.80 \mathrm{E}-06$ & $5.87 \mathrm{E}-06$ & & \\
\hline
\end{tabular}

\section{A.9 Water Dose Tallies}

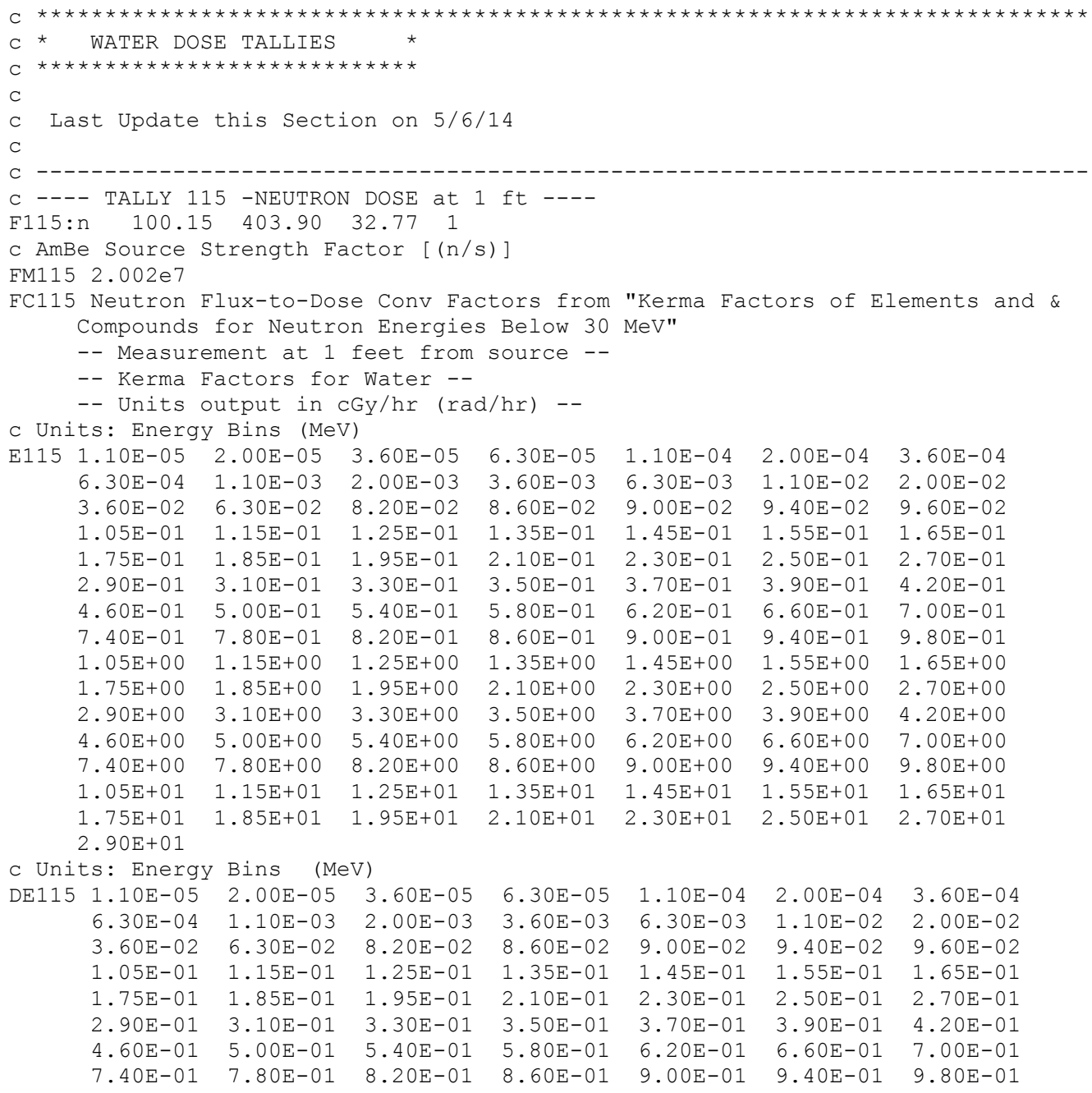




\begin{tabular}{|c|c|c|c|c|c|c|c|}
\hline & $1.05 \mathrm{E}+00$ & $1.15 \mathrm{E}+00$ & $1.25 \mathrm{E}+00$ & $1.35 \mathrm{E}+00$ & $1.45 \mathrm{E}+00$ & 1. $55 \mathrm{E}+00$ & $1.65 \mathrm{E}+00$ \\
\hline & $1.75 \mathrm{E}+00$ & $1.85 \mathrm{E}+00$ & $1.95 \mathrm{E}+00$ & $2.10 \mathrm{E}+00$ & $2.30 \mathrm{E}+00$ & $2.50 \mathrm{E}+00$ & $2.70 \mathrm{E}+00$ \\
\hline & $2.90 \mathrm{E}+00$ & $3.10 \mathrm{E}+00$ & $3.30 \mathrm{E}+00$ & $3.50 \mathrm{E}+00$ & $3.70 \mathrm{E}+00$ & $3.90 \mathrm{E}+00$ & $4.20 \mathrm{E}+00$ \\
\hline & $4.60 \mathrm{E}+00$ & $5.00 \mathrm{E}+00$ & $5.40 \mathrm{E}+00$ & $5.80 \mathrm{E}+00$ & $6.20 \mathrm{E}+00$ & $6.60 \mathrm{E}+00$ & $7.00 \mathrm{E}+00$ \\
\hline & $7.40 \mathrm{E}+00$ & $7.80 \mathrm{E}+00$ & $8.20 \mathrm{E}+00$ & $8.60 \mathrm{E}+00$ & $9.00 \mathrm{E}+00$ & $9.40 \mathrm{E}+00$ & $9.80 \mathrm{E}+00$ \\
\hline & $1.05 \mathrm{E}+01$ & $1.15 \mathrm{E}+01$ & $1.25 \mathrm{E}+01$ & $1.35 \mathrm{E}+01$ & $1.45 \mathrm{E}+01$ & $1.55 \mathrm{E}+01$ & $1.65 \mathrm{E}+01$ \\
\hline & $1.75 E+01$ & $1.85 \mathrm{E}+01$ & $1.95 \mathrm{E}+01$ & $2.10 \mathrm{E}+01$ & $2.30 \mathrm{E}+01$ & $2.50 \mathrm{E}+01$ & $2.70 E+01$ \\
\hline & $2.90 \mathrm{E}+01$ & & & & & & \\
\hline Unit & ts: cGy/hr & per $n / \mathrm{cm}^{\wedge}$ & $2 \mathrm{sec}=(r \mathrm{ra}$ & $d-\mathrm{cm}^{\wedge} 2 / \mathrm{sec}$ & c) $*(3.6 \mathrm{e} 3)$ & & \\
\hline & $5.26 \mathrm{E}-10$ & $8.68 \mathrm{E}-10$ & $1.49 \mathrm{E}-09$ & $2.57 \mathrm{E}-09$ & $4.46 \mathrm{E}-09$ & $8.06 \mathrm{E}-09$ & $1.45 \mathrm{E}-08$ \\
\hline & $2.52 \mathrm{E}-08$ & $4.39 \mathrm{E}-08$ & $7.96 \mathrm{E}-08$ & $1.42 \mathrm{E}-07$ & $2.44 \mathrm{E}-07$ & $4.14 \mathrm{E}-07$ & $7.16 \mathrm{E}-07$ \\
\hline & $1.19 \mathrm{E}-06$ & $1.84 \mathrm{E}-06$ & $2.22 \mathrm{E}-06$ & $2.30 \mathrm{E}-06$ & $2.37 E-06$ & $2.44 \mathrm{E}-06$ & $2.51 \mathrm{E}-06$ \\
\hline & $2.63 \mathrm{E}-06$ & $2.79 \mathrm{E}-06$ & $2.94 \mathrm{E}-06$ & $3.09 \mathrm{E}-06$ & $3.23 \mathrm{E}-06$ & $3.36 \mathrm{E}-06$ & $3.49 \mathrm{E}-06$ \\
\hline & $3.60 \mathrm{E}-06$ & $3.74 \mathrm{E}-06$ & $3.85 \mathrm{E}-06$ & $4.00 \mathrm{E}-06$ & $4.21 \mathrm{E}-06$ & $4.43 E-06$ & $4.61 E-06$ \\
\hline & $4.82 \mathrm{E}-06$ & $5.00 \mathrm{E}-06$ & $5.18 \mathrm{E}-06$ & $5.36 \mathrm{E}-06$ & $5.58 \mathrm{E}-06$ & $5.83 E-06$ & $6.41 E-06$ \\
\hline & $6.44 E-06$ & $6.26 \mathrm{E}-06$ & $6.44 \mathrm{E}-06$ & $6.66 \mathrm{E}-06$ & $6.91 \mathrm{E}-06$ & $7.13 \mathrm{E}-06$ & $7.34 \mathrm{E}-06$ \\
\hline & $7.56 \mathrm{E}-06$ & $7.78 \mathrm{E}-06$ & $7.99 \mathrm{E}-06$ & $8.21 \mathrm{E}-06$ & $8.46 \mathrm{E}-06$ & $8.89 \mathrm{E}-06$ & $9.68 \mathrm{E}-06$ \\
\hline & $9.76 \mathrm{E}-06$ & $9.61 \mathrm{E}-06$ & $1.00 \mathrm{E}-05$ & $1.03 E-05$ & $1.05 \mathrm{E}-05$ & $1.08 \mathrm{E}-05$ & $1.12 \mathrm{E}-05$ \\
\hline & $1.13 \mathrm{E}-05$ & $1.18 \mathrm{E}-05$ & $1.18 \mathrm{E}-05$ & $1.22 \mathrm{E}-05$ & $1.23 E-05$ & $1.28 \mathrm{E}-05$ & $1.33 \mathrm{E}-05$ \\
\hline & $1.38 \mathrm{E}-05$ & $1.44 \mathrm{E}-05$ & $1.56 \mathrm{E}-05$ & $1.58 \mathrm{E}-05$ & $1.63 \mathrm{E}-05$ & $1.59 \mathrm{E}-05$ & $1.66 \mathrm{E}-05$ \\
\hline & $1.67 \mathrm{E}-05$ & $1.77 \mathrm{E}-05$ & $1.72 \mathrm{E}-05$ & $1.81 \mathrm{E}-05$ & $1.84 \mathrm{E}-05$ & $1.91 \mathrm{E}-05$ & $2.00 \mathrm{E}-05$ \\
\hline & $2.10 \mathrm{E}-05$ & $2.03 E-05$ & $2.03 E-05$ & $2.12 \mathrm{E}-05$ & $2.13 E-05$ & $2.13 E-05$ & $2.20 E-05$ \\
\hline & $2.25 \mathrm{E}-05$ & $2.42 E-05$ & $2.38 \mathrm{E}-05$ & $2.47 E-05$ & $2.55 E-05$ & $2.60 \mathrm{E}-05$ & $2.61 \mathrm{E}-05$ \\
\hline & $2.65 E-05$ & $2.68 \mathrm{E}-05$ & $2.73 E-05$ & $2.77 \mathrm{E}-05$ & $2.74 \mathrm{E}-05$ & $2.71 E-05$ & $2.71 \mathrm{E}-05$ \\
\hline & $2.64 \mathrm{E}-05$ & & & & & & \\
\hline & & & & & & & \\
\hline & & & & & & & \\
\hline & - TALLY 12 & 25 -NEUTRC & DOSE at & ft & & & \\
\hline $\mathrm{F} 125: \mathrm{r}$ & n $\quad 125.12$ & 386.42 & $32.77 \quad 1$ & & & & \\
\hline $\begin{array}{l}C \text { AmBe } \\
\text { FM125 }\end{array}$ & e source & Strength $\mathrm{Fa}$ & actor $[\mathrm{n} / \mathrm{s}$ & & & & \\
\hline $\begin{array}{l}\text { FM125 } \\
\text { FC125 }\end{array}$ & $\begin{array}{l}2.002 \mathrm{e} 7 \\
\text { Neutron }\end{array}$ & lux-to-Dos & se Conv Fac & tors from & & ors of $\mathrm{F}$ & aments and \\
\hline & Compounds & for Neutro & n Energies & Below 30 & $\begin{array}{l}\text { "Kerma } \\
\text { MeV" }\end{array}$ & & ments and \\
\hline & -- Measure & ment at 2 & feet from & source -- & & & \\
\hline & -- Kerma & actors for & Water -- & & & & \\
\hline & -- Units & butput in & Gy/hr ( $\mathrm{rad}$ & $(/ \mathrm{hr}) \quad--$ & & & \\
\hline c Unit & ts: Energy & Bins $(\mathrm{Me}$ & & & & & \\
\hline E125 & $1.10 \mathrm{E}-05$ & $2.00 \mathrm{E}-05$ & $3.60 \mathrm{E}-05$ & $6.30 \mathrm{E}-05$ & $1.10 \mathrm{E}-04$ & $2.00 \mathrm{E}-04$ & $3.60 \mathrm{E}-04$ \\
\hline & $6.30 \mathrm{E}-04$ & $1.10 \mathrm{E}-03$ & $2.00 \mathrm{E}-03$ & $3.60 \mathrm{E}-03$ & $6.30 \mathrm{E}-03$ & $1.10 \mathrm{E}-02$ & $2.00 \mathrm{E}-02$ \\
\hline & $3.60 \mathrm{E}-02$ & $6.30 \mathrm{E}-02$ & $8.20 \mathrm{E}-02$ & $8.60 \mathrm{E}-02$ & $9.00 \mathrm{E}-02$ & $9.40 \mathrm{E}-02$ & $9.60 \mathrm{E}-02$ \\
\hline & $1.05 \mathrm{E}-01$ & $1.15 \mathrm{E}-01$ & $1.25 \mathrm{E}-01$ & $1.35 \mathrm{E}-01$ & $1.45 \mathrm{E}-01$ & $1.55 \mathrm{E}-01$ & $1.65 \mathrm{E}-01$ \\
\hline & $1.75 \mathrm{E}-01$ & $1.85 \mathrm{E}-01$ & $1.95 \mathrm{E}-01$ & $2.10 \mathrm{E}-01$ & $2.30 \mathrm{E}-01$ & $2.50 \mathrm{E}-01$ & $2.70 \mathrm{E}-01$ \\
\hline & $2.90 \mathrm{E}-01$ & $3.10 \mathrm{E}-01$ & $3.30 E-01$ & $3.50 \mathrm{E}-01$ & $3.70 \mathrm{E}-01$ & $3.90 \mathrm{E}-01$ & $4.20 \mathrm{E}-01$ \\
\hline & $4.60 \mathrm{E}-01$ & $5.00 \mathrm{E}-01$ & $5.40 \mathrm{E}-01$ & $5.80 \mathrm{E}-01$ & $6.20 \mathrm{E}-01$ & $6.60 \mathrm{E}-01$ & $7.00 \mathrm{E}-01$ \\
\hline & $7.40 \mathrm{E}-01$ & $7.80 \mathrm{E}-01$ & $8.20 \mathrm{E}-01$ & $8.60 \mathrm{E}-01$ & $9.00 \mathrm{E}-01$ & $9.40 \mathrm{E}-01$ & $9.80 \mathrm{E}-01$ \\
\hline & $1.05 \mathrm{E}+00$ & $1.15 \mathrm{E}+00$ & $1.25 \mathrm{E}+00$ & $1.35 E+00$ & $1.45 \mathrm{E}+00$ & $1.55 \mathrm{E}+00$ & $1.65 \mathrm{E}+00$ \\
\hline & $1.75 \mathrm{E}+00$ & $1.85 \mathrm{E}+00$ & $1.95 \mathrm{E}+00$ & $2.10 \mathrm{E}+00$ & $2.30 \mathrm{E}+00$ & $2.50 \mathrm{E}+00$ & $2.70 \mathrm{E}+00$ \\
\hline & $2.90 \mathrm{E}+00$ & $3.10 \mathrm{E}+00$ & $3.30 \mathrm{E}+00$ & $3.50 \mathrm{E}+00$ & $3.70 \mathrm{E}+00$ & $3.90 \mathrm{E}+00$ & $4.20 \mathrm{E}+00$ \\
\hline & $4.60 \mathrm{E}+00$ & $5.00 \mathrm{E}+00$ & $5.40 \mathrm{E}+00$ & $5.80 \mathrm{E}+00$ & $6.20 \mathrm{E}+00$ & $6.60 \mathrm{E}+00$ & $7.00 \mathrm{E}+00$ \\
\hline & $7.40 \mathrm{E}+00$ & $7.80 \mathrm{E}+00$ & $8.20 E+00$ & $8.60 \mathrm{E}+00$ & $9.00 \mathrm{E}+00$ & $9.40 \mathrm{E}+00$ & $9.80 \mathrm{E}+00$ \\
\hline & $1.05 \mathrm{E}+01$ & $1.15 \mathrm{E}+01$ & $1.25 \mathrm{E}+01$ & 1. $35 \mathrm{E}+01$ & $1.45 \mathrm{E}+01$ & $1.55 \mathrm{E}+01$ & $1.65 \mathrm{E}+01$ \\
\hline & $1.75 \mathrm{E}+01$ & $1.85 \mathrm{E}+01$ & $1.95 \mathrm{E}+01$ & $2.10 E+01$ & $2.30 \mathrm{E}+01$ & $2.50 \mathrm{E}+01$ & $2.70 \mathrm{E}+01$ \\
\hline & $2.90 \mathrm{E}+01$ & & & & & & \\
\hline c Unit & ts: Energy & Bins & & & & & \\
\hline DE125 & $1.10 \mathrm{E}-05$ & $2.00 \mathrm{E}-05$ & $3.60 \mathrm{E}-05$ & $6.30 \mathrm{E}-05$ & $1.10 \mathrm{E}-04$ & $2.00 E-04$ & $3.60 \mathrm{E}-04$ \\
\hline & $6.30 \mathrm{E}-04$ & $1.10 \mathrm{E}-03$ & $2.00 \mathrm{E}-03$ & $3.60 \mathrm{E}-03$ & $6.30 \mathrm{E}-03$ & $1.10 \mathrm{E}-02$ & $2.00 \mathrm{E}-02$ \\
\hline & $3.60 \mathrm{E}-02$ & $6.30 \mathrm{E}-02$ & $8.20 \mathrm{E}-02$ & $8.60 \mathrm{E}-02$ & $9.00 \mathrm{E}-02$ & $9.40 \mathrm{E}-02$ & $9.60 \mathrm{E}-02$ \\
\hline & $1.05 \mathrm{E}-01$ & $1.15 \mathrm{E}-01$ & $1.25 \mathrm{E}-01$ & $1.35 \mathrm{E}-01$ & $1.45 \mathrm{E}-01$ & $1.55 \mathrm{E}-01$ & $1.65 \mathrm{E}-01$ \\
\hline & $1.75 \mathrm{E}-01$ & $1.85 \mathrm{E}-01$ & $1.95 \mathrm{E}-01$ & $2.10 \mathrm{E}-01$ & $2.30 \mathrm{E}-01$ & $2.50 \mathrm{E}-01$ & $2.70 \mathrm{E}-01$ \\
\hline & $2.90 \mathrm{E}-01$ & $3.10 \mathrm{E}-01$ & $3.30 \mathrm{E}-01$ & $3.50 \mathrm{E}-01$ & $3.70 \mathrm{E}-01$ & $3.90 E-01$ & $4.20 \mathrm{E}-01$ \\
\hline & $4.60 \mathrm{E}-01$ & $5.00 \mathrm{E}-01$ & $5.40 \mathrm{E}-01$ & $5.80 \mathrm{E}-01$ & $6.20 \mathrm{E}-01$ & $6.60 \mathrm{E}-01$ & $7.00 \mathrm{E}-01$ \\
\hline & $7.40 \mathrm{E}-01$ & $7.80 \mathrm{E}-01$ & $8.20 \mathrm{E}-01$ & $8.60 \mathrm{E}-01$ & $9.00 \mathrm{E}-01$ & $9.40 \mathrm{E}-01$ & $9.80 \mathrm{E}-01$ \\
\hline & $1.05 \mathrm{E}+00$ & $1.15 \mathrm{E}+00$ & $1.25 \mathrm{E}+00$ & $1.35 \mathrm{E}+00$ & $1.45 \mathrm{E}+00$ & $1.55 \mathrm{E}+00$ & $1.65 \mathrm{E}+00$ \\
\hline & $1.75 \mathrm{E}+00$ & $1.85 \mathrm{E}+00$ & $1.95 \mathrm{E}+00$ & $2.10 \mathrm{E}+00$ & $2.30 \mathrm{E}+00$ & $2.50 \mathrm{E}+00$ & $2.70 \mathrm{E}+00$ \\
\hline & $2.90 \mathrm{E}+00$ & $3.10 \mathrm{E}+00$ & $3.30 \mathrm{E}+00$ & $3.50 \mathrm{E}+00$ & $3.70 \mathrm{E}+00$ & $3.90 \mathrm{E}+00$ & $4.20 \mathrm{E}+00$ \\
\hline & $4.60 \mathrm{E}+00$ & $5.00 \mathrm{E}+00$ & $5.40 \mathrm{E}+00$ & $5.80 \mathrm{E}+00$ & $6.20 \mathrm{E}+00$ & $6.60 \mathrm{E}+00$ & $7.00 \mathrm{E}+00$ \\
\hline & $7.40 \mathrm{E}+00$ & $7.80 \mathrm{E}+00$ & $8.20 \mathrm{E}+00$ & $8.60 \mathrm{E}+00$ & $9.00 \mathrm{E}+00$ & $9.40 \mathrm{E}+00$ & $9.80 \mathrm{E}+00$ \\
\hline & $1.05 \mathrm{E}+01$ & $1.15 \mathrm{E}+01$ & $1.25 \mathrm{E}+01$ & $1.35 \mathrm{E}+01$ & $1.45 \mathrm{E}+01$ & $1.55 \mathrm{E}+01$ & $1.65 \mathrm{E}+01$ \\
\hline & $\begin{array}{l}1.75 E+01 \\
2.90 E+01\end{array}$ & $1.85 \mathrm{E}+01$ & $1.95 \mathrm{E}+01$ & $2.10 \mathrm{E}+01$ & $2.30 E+01$ & $2.50 \mathrm{E}+01$ & $2.70 \mathrm{E}+01$ \\
\hline
\end{tabular}




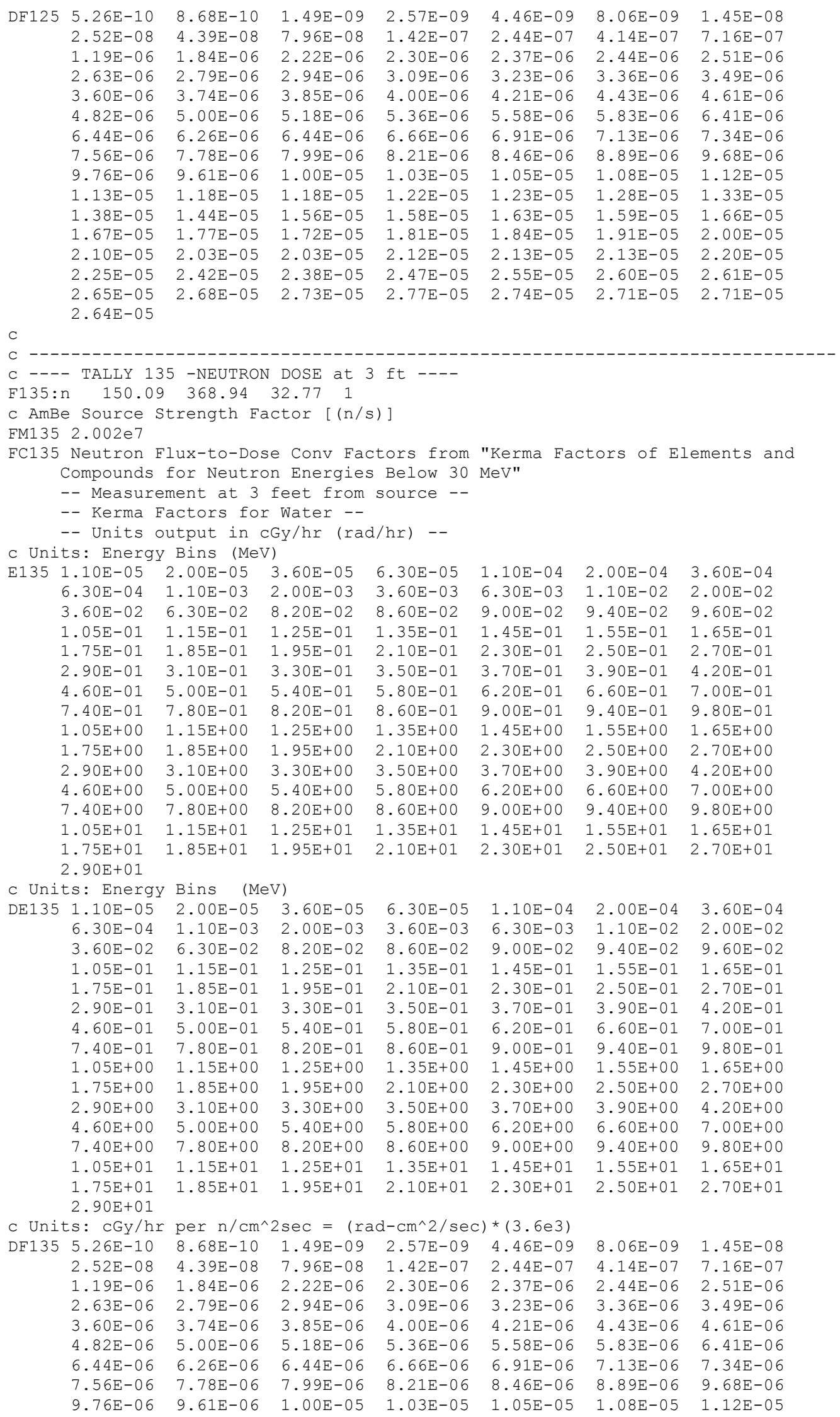




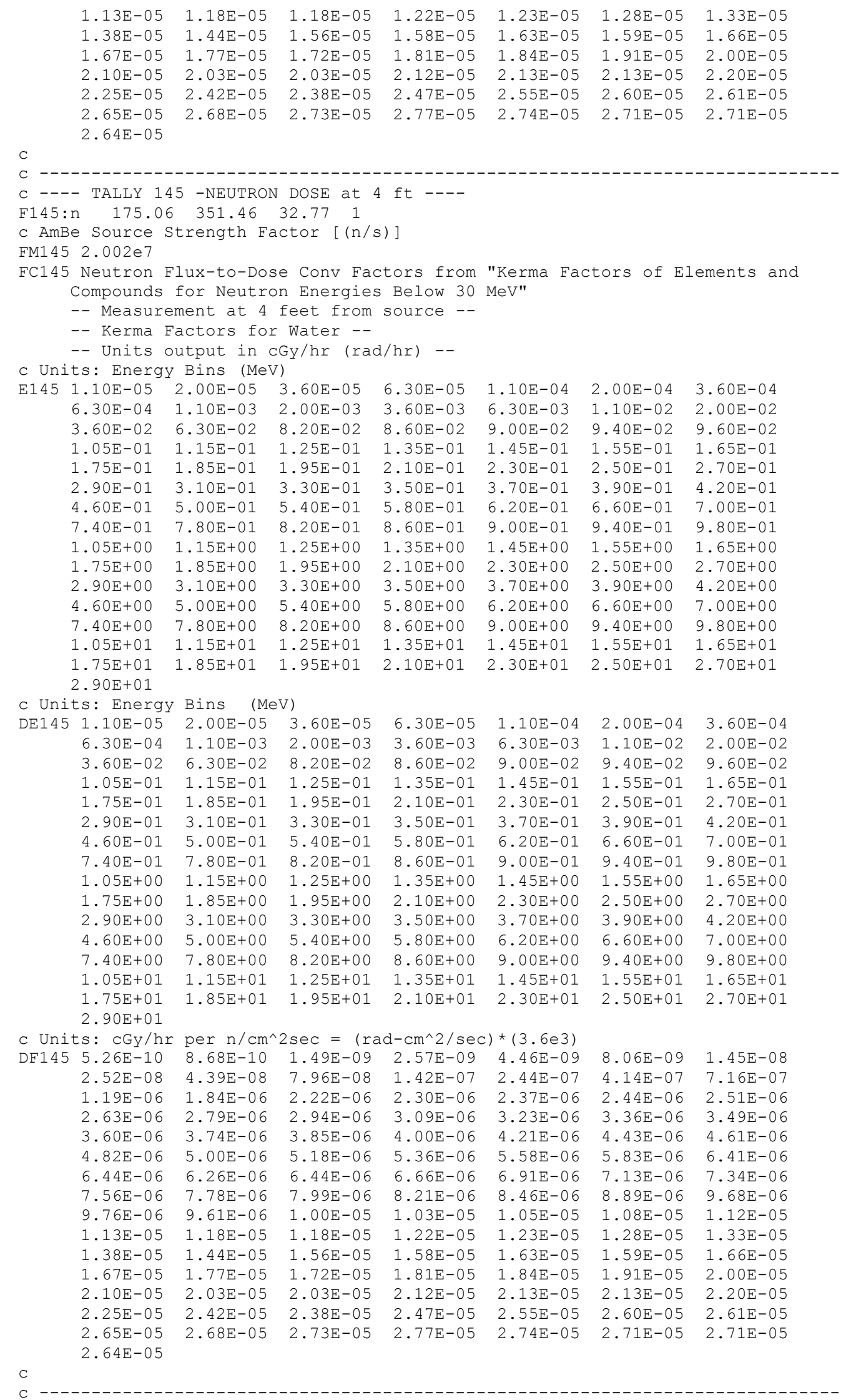




\begin{tabular}{|c|c|c|c|c|c|c|c|}
\hline \multicolumn{8}{|c|}{ C Units: Energy Bins (MeV) } \\
\hline \multirow[t]{16}{*}{ E165 } & $1.10 \mathrm{E}-05$ & $2.00 \mathrm{E}-05$ & $3.60 \mathrm{E}-05$ & $6.30 \mathrm{E}-05$ & $1.10 \mathrm{E}-04$ & $2.00 \mathrm{E}-04$ & $3.60 \mathrm{E}-04$ \\
\hline & $6.30 E-04$ & $1.10 \mathrm{E}-03$ & $2.00 \mathrm{E}-03$ & $3.60 \mathrm{E}-03$ & $6.30 \mathrm{E}-03$ & $1.10 \mathrm{E}-02$ & $2.00 \mathrm{E}-02$ \\
\hline & $3.60 \mathrm{E}-02$ & $6.30 \mathrm{E}-02$ & $8.20 \mathrm{E}-02$ & $8.60 \mathrm{E}-02$ & $9.00 \mathrm{E}-02$ & $9.40 \mathrm{E}-02$ & $9.60 \mathrm{E}-02$ \\
\hline & $1.05 \mathrm{E}-01$ & $1.15 \mathrm{E}-01$ & $1.25 \mathrm{E}-01$ & $1.35 \mathrm{E}-01$ & $1.45 \mathrm{E}-01$ & $1.55 \mathrm{E}-01$ & $1.65 \mathrm{E}-01$ \\
\hline & $1.75 \mathrm{E}-01$ & $1.85 \mathrm{E}-01$ & $1.95 \mathrm{E}-01$ & $2.10 \mathrm{E}-01$ & $2.30 \mathrm{E}-01$ & $2.50 \mathrm{E}-01$ & $2.70 \mathrm{E}-01$ \\
\hline & $2.90 \mathrm{E}-01$ & $3.10 \mathrm{E}-01$ & $3.30 \mathrm{E}-01$ & $3.50 \mathrm{E}-01$ & $3.70 \mathrm{E}-01$ & $3.90 \mathrm{E}-01$ & $4.20 \mathrm{E}-01$ \\
\hline & $4.60 \mathrm{E}-01$ & $5.00 \mathrm{E}-01$ & $5.40 \mathrm{E}-01$ & $5.80 \mathrm{E}-01$ & $6.20 \mathrm{E}-01$ & $6.60 \mathrm{E}-01$ & $7.00 \mathrm{E}-01$ \\
\hline & $7.40 \mathrm{E}-01$ & $7.80 \mathrm{E}-01$ & $8.20 \mathrm{E}-01$ & $8.60 \mathrm{E}-01$ & $9.00 \mathrm{E}-01$ & $9.40 \mathrm{E}-01$ & $9.80 \mathrm{E}-01$ \\
\hline & $1.05 \mathrm{E}+00$ & $1.15 \mathrm{E}+00$ & $1.25 \mathrm{E}+00$ & $1.35 \mathrm{E}+00$ & $1.45 \mathrm{E}+00$ & $1.55 \mathrm{E}+00$ & $1.65 \mathrm{E}+00$ \\
\hline & $1.75 \mathrm{E}+00$ & $1.85 \mathrm{E}+00$ & $1.95 \mathrm{E}+00$ & $2.10 \mathrm{E}+00$ & $2.30 \mathrm{E}+00$ & $2.50 \mathrm{E}+00$ & $2.70 \mathrm{E}+00$ \\
\hline & $2.90 \mathrm{E}+00$ & $3.10 \mathrm{E}+00$ & $3.30 \mathrm{E}+00$ & $3.50 \mathrm{E}+00$ & $3.70 \mathrm{E}+00$ & $3.90 \mathrm{E}+00$ & $4.20 \mathrm{E}+00$ \\
\hline & $4.60 \mathrm{E}+00$ & $5.00 \mathrm{E}+00$ & $5.40 \mathrm{E}+00$ & $5.80 \mathrm{E}+00$ & $6.20 \mathrm{E}+00$ & $6.60 \mathrm{E}+00$ & $7.00 \mathrm{E}+00$ \\
\hline & $7.40 \mathrm{E}+00$ & $7.80 \mathrm{E}+00$ & $8.20 \mathrm{E}+00$ & $8.60 \mathrm{E}+00$ & $9.00 \mathrm{E}+00$ & $9.40 \mathrm{E}+00$ & $9.80 \mathrm{E}+00$ \\
\hline & $1.05 \mathrm{E}+01$ & $1.15 \mathrm{E}+01$ & $1.25 \mathrm{E}+01$ & $1.35 \mathrm{E}+01$ & $1.45 \mathrm{E}+01$ & $1.55 \mathrm{E}+01$ & $1.65 \mathrm{E}+01$ \\
\hline & $1.75 \mathrm{E}+01$ & $1.85 \mathrm{E}+01$ & $1.95 \mathrm{E}+01$ & $2.10 \mathrm{E}+01$ & $2.30 \mathrm{E}+01$ & $2.50 \mathrm{E}+01$ & $2.70 \mathrm{E}+01$ \\
\hline & $2.90 \mathrm{E}+01$ & & & & & & \\
\hline \multicolumn{8}{|c|}{ its: Energy $\mathrm{B}$} \\
\hline \multirow{16}{*}{$\mathrm{DE} 165$} & $1.10 \mathrm{E}-05$ & $2.00 \mathrm{E}-05$ & $3.60 \mathrm{E}-05$ & $6.30 \mathrm{E}-05$ & $1.10 \mathrm{E}-04$ & $2.00 \mathrm{E}-04$ & $3.60 \mathrm{E}-04$ \\
\hline & $6.30 \mathrm{E}-04$ & $1.10 \mathrm{E}-03$ & $2.00 \mathrm{E}-03$ & $3.60 \mathrm{E}-03$ & $6.30 \mathrm{E}-03$ & $1.10 \mathrm{E}-02$ & $2.00 \mathrm{E}-02$ \\
\hline & $3.60 \mathrm{E}-02$ & $6.30 \mathrm{E}-02$ & $8.20 \mathrm{E}-02$ & $8.60 \mathrm{E}-02$ & $9.00 \mathrm{E}-02$ & $9.40 \mathrm{E}-02$ & $9.60 \mathrm{E}-02$ \\
\hline & $1.05 \mathrm{E}-01$ & $1.15 \mathrm{E}-01$ & $1.25 \mathrm{E}-01$ & $1.35 \mathrm{E}-01$ & $1.45 \mathrm{E}-01$ & $1.55 \mathrm{E}-01$ & $1.65 \mathrm{E}-01$ \\
\hline & $1.75 \mathrm{E}-01$ & $1.85 \mathrm{E}-01$ & $1.95 \mathrm{E}-01$ & $2.10 \mathrm{E}-01$ & $2.30 \mathrm{E}-01$ & $2.50 \mathrm{E}-01$ & $2.70 \mathrm{E}-01$ \\
\hline & $2.90 \mathrm{E}-01$ & $3.10 \mathrm{E}-01$ & $3.30 \mathrm{E}-01$ & $3.50 \mathrm{E}-01$ & $3.70 \mathrm{E}-01$ & $3.90 \mathrm{E}-01$ & $4.20 \mathrm{E}-01$ \\
\hline & $4.60 \mathrm{E}-01$ & $5.00 \mathrm{E}-01$ & $5.40 \mathrm{E}-01$ & $5.80 \mathrm{E}-01$ & $6.20 \mathrm{E}-01$ & $6.60 \mathrm{E}-01$ & $7.00 \mathrm{E}-01$ \\
\hline & $7.40 \mathrm{E}-01$ & $7.80 \mathrm{E}-01$ & $8.20 \mathrm{E}-01$ & $8.60 \mathrm{E}-01$ & $9.00 \mathrm{E}-01$ & $9.40 \mathrm{E}-01$ & $9.80 \mathrm{E}-01$ \\
\hline & $1.05 \mathrm{E}+00$ & $1.15 \mathrm{E}+00$ & $1.25 \mathrm{E}+00$ & $1.35 \mathrm{E}+00$ & $1.45 \mathrm{E}+00$ & $1.55 \mathrm{E}+00$ & $1.65 \mathrm{E}+00$ \\
\hline & $1.75 \mathrm{E}+00$ & $1.85 \mathrm{E}+00$ & $1.95 \mathrm{E}+00$ & $2.10 \mathrm{E}+00$ & $2.30 \mathrm{E}+00$ & $2.50 \mathrm{E}+00$ & $2.70 \mathrm{E}+00$ \\
\hline & $2.90 \mathrm{E}+00$ & $3.10 \mathrm{E}+00$ & $3.30 \mathrm{E}+00$ & $3.50 \mathrm{E}+00$ & $3.70 E+00$ & $3.90 \mathrm{E}+00$ & $4.20 \mathrm{E}+00$ \\
\hline & $4.60 \mathrm{E}+00$ & $5.00 \mathrm{E}+00$ & $5.40 \mathrm{E}+00$ & $5.80 \mathrm{E}+00$ & $6.20 \mathrm{E}+00$ & $6.60 \mathrm{E}+00$ & $7.00 \mathrm{E}+00$ \\
\hline & $7.40 \mathrm{E}+00$ & $7.80 \mathrm{E}+00$ & $8.20 \mathrm{E}+00$ & $8.60 \mathrm{E}+00$ & $9.00 \mathrm{E}+00$ & $9.40 \mathrm{E}+00$ & $9.80 \mathrm{E}+00$ \\
\hline & $1.05 \mathrm{E}+01$ & $1.15 \mathrm{E}+01$ & $1.25 \mathrm{E}+01$ & $1.35 \mathrm{E}+01$ & $1.45 \mathrm{E}+01$ & $1.55 \mathrm{E}+01$ & $1.65 \mathrm{E}+01$ \\
\hline & $1.75 \mathrm{E}+01$ & $1.85 \mathrm{E}+01$ & $1.95 \mathrm{E}+01$ & $2.10 \mathrm{E}+01$ & $2.30 \mathrm{E}+01$ & $2.50 \mathrm{E}+01$ & $2.70 \mathrm{E}+01$ \\
\hline & $2.90 \mathrm{E}+01$ & & & & & & \\
\hline \multicolumn{8}{|c|}{ c Units: cGy/hr } \\
\hline \multirow[t]{16}{*}{$\mathrm{DF} 165$} & $5.26 \mathrm{E}-10$ & $8.68 \mathrm{E}-10$ & $1.49 \mathrm{E}-09$ & $2.57 \mathrm{E}-09$ & $4.46 \mathrm{E}-09$ & $8.06 \mathrm{E}-09$ & $1.45 \mathrm{E}-08$ \\
\hline & $2.52 \mathrm{E}-08$ & $4.39 \mathrm{E}-08$ & $7.96 \mathrm{E}-08$ & $1.42 \mathrm{E}-07$ & $2.44 \mathrm{E}-07$ & $4.14 \mathrm{E}-07$ & $7.16 \mathrm{E}-07$ \\
\hline & $1.19 \mathrm{E}-06$ & $1.84 \mathrm{E}-06$ & $2.22 \mathrm{E}-06$ & $2.30 \mathrm{E}-06$ & $2.37 \mathrm{E}-06$ & $2.44 \mathrm{E}-06$ & $2.51 \mathrm{E}-06$ \\
\hline & $2.63 E-06$ & $2.79 \mathrm{E}-06$ & $2.94 \mathrm{E}-06$ & $3.09 \mathrm{E}-06$ & $3.23 E-06$ & $3.36 \mathrm{E}-06$ & $3.49 \mathrm{E}-06$ \\
\hline & $3.60 \mathrm{E}-06$ & $3.74 \mathrm{E}-06$ & $3.85 \mathrm{E}-06$ & $4.00 \mathrm{E}-06$ & $4.21 E-06$ & $4.43 \mathrm{E}-06$ & $4.61 \mathrm{E}-06$ \\
\hline & $4.82 \mathrm{E}-06$ & $5.00 \mathrm{E}-06$ & $5.18 \mathrm{E}-06$ & $5.36 \mathrm{E}-06$ & $5.58 \mathrm{E}-06$ & $5.83 E-06$ & $6.41 \mathrm{E}-06$ \\
\hline & $6.44 \mathrm{E}-06$ & $6.26 \mathrm{E}-06$ & $6.44 \mathrm{E}-06$ & $6.66 \mathrm{E}-06$ & $6.91 E-06$ & $7.13 \mathrm{E}-06$ & $7.34 \mathrm{E}-06$ \\
\hline & $7.56 \mathrm{E}-06$ & $7.78 \mathrm{E}-06$ & $7.99 \mathrm{E}-06$ & $8.21 \mathrm{E}-06$ & $8.46 \mathrm{E}-06$ & $8.89 \mathrm{E}-06$ & $9.68 \mathrm{E}-06$ \\
\hline & $9.76 \mathrm{E}-06$ & $9.61 \mathrm{E}-06$ & $1.00 \mathrm{E}-05$ & $1.03 \mathrm{E}-05$ & $1.05 E-05$ & $1.08 \mathrm{E}-05$ & $1.12 \mathrm{E}-05$ \\
\hline & $1.13 \mathrm{E}-05$ & $1.18 \mathrm{E}-05$ & $1.18 \mathrm{E}-05$ & $1.22 \mathrm{E}-05$ & $1.23 \mathrm{E}-05$ & $1.28 \mathrm{E}-05$ & $1.33 \mathrm{E}-05$ \\
\hline & $1.38 \mathrm{E}-05$ & $1.44 \mathrm{E}-05$ & $1.56 \mathrm{E}-05$ & $1.58 \mathrm{E}-05$ & $1.63 E-05$ & $1.59 \mathrm{E}-05$ & $1.66 \mathrm{E}-05$ \\
\hline & $1.67 \mathrm{E}-05$ & $1.77 \mathrm{E}-05$ & $1.72 \mathrm{E}-05$ & $1.81 \mathrm{E}-05$ & $1.84 \mathrm{E}-05$ & $1.91 \mathrm{E}-05$ & $2.00 \mathrm{E}-05$ \\
\hline & $2.10 \mathrm{E}-05$ & $2.03 \mathrm{E}-05$ & $2.03 E-05$ & $2.12 \mathrm{E}-05$ & $2.13 E-05$ & $2.13 \mathrm{E}-05$ & $2.20 \mathrm{E}-05$ \\
\hline & $2.25 \mathrm{E}-05$ & $2.42 \mathrm{E}-05$ & $2.38 \mathrm{E}-05$ & $2.47 \mathrm{E}-05$ & $2.55 E-05$ & $2.60 \mathrm{E}-05$ & $2.61 \mathrm{E}-05$ \\
\hline & $2.65 \mathrm{E}-05$ & $2.68 \mathrm{E}-05$ & $2.73 \mathrm{E}-05$ & $2.77 E-05$ & $2.74 E-05$ & $2.71 \mathrm{E}-05$ & $2.71 \mathrm{E}-05$ \\
\hline & $2.64 \mathrm{E}-05$ & & & & & & \\
\hline
\end{tabular}




\section{REFERENCES}

1. Garrett, W. R., Splettstosser, H. R. and Titus, D. E. Radiography in Modern Industry. [ed.] Richard A. Quinn and Claire C. Sigl. 4th, Rochester, New York, United States of America : s.n., 1980.

2. International Atomic Energy Agency. IAEA Radiation Technology Reports No. 1 Neutron Generators for Analytical Purposes. Vienna: International Atomic Energy Agnecy, 2012. ISBN 978-92-0-125110-7.

3. Bubble Technology Industries. Neutron Spectroscopy Capabilities. Chalk River, Ontario, Canada : Bubble Technology Industries, 2009.

4. Hargrove, C. K. and Geiger, K. W. A New Thermal Neutron Flux Density Standard. Ottawa, Canada : Division of Applied Physics, National Research Council, January 30, 1964.

5. National Nuclear Data Center. Chart of Nuclides. Upton, New York, United States of America : Brookhaven National Laboratory, 2014. based on ENSDF and the Nuclear Wallet Cards.

6. Analog Services, Inc. Californium-252, AmBe Substitute? Reynolds Station, Kentucky : s.n., 2010.

7. Schulte, Louis D. Actinide Beryllium Neutron Source with Reduced Dispersion Characteristics. Background Information on AmBe Source Fabrication. Los Alamos, New Mexico : s.n., 2011. LA-UR-11-01808.

8. Los Alamos National Laboratory. Special Form Capsules (SFCs). Los Alamos, New Mexico : s.n., 2011.

9. Strain, J. E. and Leddicottee, G. W. The Preparation, Properties, and Uses of Americium-241, Alpha-, Gamma-, and Neutron Sources. Analytical Chemistry Division. Oak Ridge : Oak Ridge National Laboratory, 1962.

10. High Resolution Measurements of Neutron Energy Spectra from Am-Be and Am-B Neutron Sources. Marsh, J.W., Thomas, D.J. and Burke, M. 1995, Nuclear Instruments \& Methods in Physics Research, pp. 340-348.

11. The Use of the Reaction Be-9(a,gn)C-12 to Determine the Energy Scale and the Efficiency at Low Energies of Stellar Collapse Neutrino Detectors. Baldini, A., et al., 2, 1991, Nuclear Instruments and Methods in Physics Research, Vol. 305, pp. 475-483. 
12. Pauw, H. Energy Spectra of Radioactive Neutron Sources. Institute for Nuclear Research (I.K.O.). Vienna : International Atomic Energy Agency, 1970.

13. International Organization for Standardization. ISO 8529:1989 - Neutron Reference Radiations for Calibrating Neutron-Measuring Devices Used for Radiation Protection Purposes and for Determining Their Response as a Function of Neutron Energy. 1989.

14. Marion, J. B. and Fowler, J. L. Fast Neutron Physics Part II. [ed.] R. E. Marshak. s.1. : John Wiley \& Sons, Inc., 1963. Vol. IV.

15. American Association of Physicists in Medicine. AAPM Report No. 93: Acceptance Testing and Quality Control of Photostimulable Storage Phosphor Imaging Systems. College Park : American Association of Physicists in Medicine, 2006.

16. Knoll, G. F. Radiation Detection and Measurement. 3rd. Hoboken : John Wiley \& Sons, 2000.

17. Short-Lived Radioactivity Induced in Ge(Li) Gamma-Ray Detectors by Neutrons. Buntin, R. L. and Kraushar, J. J. 2, s.l. : Elsevier, June 5, 1974, Nuclear Instruments and Methods, Vol. 118, pp. 565-572.

18. Abt, I., et al., Neutrons Interactions as Seen by A Segmented Germanium Detector. Max-Planck-Institut für Physik. Munchen : Max Planck Gesellschaft, 2007. pp. 1-17.

19. Corrections for Distortion Effects in Fast Neutron Flux Measurements with a Stilbene-Scintillator. Bormann, M., et al., 2, s.l. : Elsevier B.V., November 15, 1970, Nuclear Instruments and Methods, Vol. 88, pp. 245-249.

20. Portable Spectroscopic Neutron Probe. Ing, H., et al., Ontario : Bubble Technology Industries Inc., June 16, 2007, Radiation Protection Dosimetry, pp. 1-6.

21. A Comparison of Neutron Spectrum Unfolding Codes Used with a Miniature NE213 Detector. Koohi-Fayegh, R., Green, S. and Malcolm, S. C. 2-3, Edgbaston : Elsevier, March 2001, Nuclear Instruments and Methods in Physics Research, Vol. 460, pp. 391400.

22. Zafiropoulos, D. and Scarabottolo, G. Neutron Spectra Using a Portable Neutron Spectrometer. Radiation Protection Group. s.l. : Legnaro National Laboratories (INFN). 
23. Ipe, N. E. and Busick, D. D. BD-100: The Chalk River Nuclear Laboratories' Neutron Bubble Detector. Stanford Linear Accelerator Center, Stanford University. Stanford : Stanford Linear Accelerator Center, 1987.

24. Buckner, M. A. Improving Neutron Dosimetry Using Bubble Detector Technology. Health and Safety Research Division, Oak Ridge National Laboratory. Oak Ridge : Oak Ridge National Laboratory, 1993.

25. Williams, A. M. A Portable Neutron Spectrometer for Dosimetery in Mixed Radiation Enviroments. Department of Physics, School of Electronics and Physical Sciences. s.l. : University of Surrey, 2003.

26. Manolopoulou, M., et al., Neutron Spectrometry with He-3 Proportional Counters. School of Physics, Aristotle Universtiy of Thessaloniki. 2012.

27. Activation Foils Unfolding for Neutron Spectrometry: Comparison of Different Deconvolution Methods. Tripathy, S. P., et al., 2-3, s.l. : Elsevier, October 1, 2007, Nuclear Instruments and Methods in Physics Research, Vol. 583, pp. 421-425.

28. Blosser, T. V. and Jr., G.E. Thomas. Neutron Flux and Neutron and Gamma-Ray Spectra Measurements at the HFTR. Neutron Physics Division, Oak Ridge National Laboratory. 1968. ORNL - TM - 2221.

29. Lamarsh, John R. and Baratta, Anthony J. Introduction to Nuclear Engineering. s.l. : Prentice-Hall, Inc., 2001.

30. Williams III, R. G., Gesh, C. J. and Pagh, R. T. Compendium of Material Composition Data for Radiation Transport Modeling. US Department of Energy, Pacific Northwest National Laboratory. 2006.

31. National Institute of Standards and Technology. Tabls of X-ray Mass Attenuation Coefficients and Mass Energy-Absorption Coefficients from $1 \mathrm{keV}$ to $20 \mathrm{MeV}$ for Elements Z $=1$ to 92 and 48 Addiional Substances of Dosimetric Interest. [Online] 1996. [Cited: October 15, 2013.] http://www.nist.gov/pml/data/xraycoef/.

32. High Technology Sources LTD. Sources - Americium-241/Beryllium.

33. International Commission on Radiological Protection. ICRP Publication 74 Conversion Coefficients for use in Radiological Protection against External Radiation. s.l. : Pergamon, 1996.

34. McCoy, Richard. IMA's GE CR50P Film Scanner (with film ready to be scanned). 
35. Canberra Industries, Inc. InSpector 2000 DSP Portable Spectroscopy Work Station. 2004.

36. Ortec. Experiment 7 - High-Resolution Gamma-Ray Spectroscopy. Oak Ridge, TN : s.n.

37. Bubble Technology Industries Inc. BTI Spectroscopic Survey System Microspec-2 For High Sensitivity Radiation. s.l. : Bubble Technology Industries Inc., 2009.

38. National Council on Radiation Protection \& Measurements. NCRP Report no. 038 - Protection Against Neutron Radiation. 1971.

39. Bubble Technology Industries Inc. BTI Bubble Detector Spectrometer BDS for low Resolution Neutron Spectroscopy. s.l. : Bubble Technology Industries Inc.; 2012.

40. Los Alamos National Laboratory. PeakEasy Home Page. [Online] 2006. http://peakeasy.lanl.gov/.

41. ENDF/B-VII.1- Nuclear Data for Science and Technology: Cross Sections, Covariances, Fission Product Yields and Decay Data. Chadwick, M. B. and et al. 12, s.l. : Elsevier, December 2011, Nuclear Data Sheets, Vol. 112, pp. 2887-2996. (Endfplot). 42. Kerma Factors of Elements and Compounds for Neutron Energies Below $30 \mathrm{MeV}$. Caswell, R. S., Coyne, J. J. and Randolph, M. L. 11, Oak Ridge : s.n., 1982, International Journal of Applied Radiation and Isotopes, Vol. 33, pp. 1227-1262. 